\title{
Workplace meetings: Following the action in making organisation around the table
}

\author{
by \\ Tamika Simpson
}

\begin{abstract}
A thesis
submitted to the Victoria University of Wellington

in fulfilment of the requirements for the degree of

Doctor of Philosophy

in Sociology
\end{abstract}

Victoria University of Wellington

2006 
For all of us -

we endlessly competent workers. 


\section{Table of contents}

Abstract

Acknowledgements

1 Introduction to the thesis

1.1 Preface

1.2 Introduction

1.3 Background to the research

1.4 Structure of the thesis

1.5 Two more indications

1.6 Conclusion

Part one: Describing the empirical and theoretical material

2 What makes these meetings, these meetings? .................................... 18

2.1 Introduction

2.2 How I gained this material

2.3 A first-person walk-through of one meeting

2.4 A few observations about the meeting room

2.5 Using Becker's "Wittgenstein trick"

2.6 Conclusion

3 Overview of the theoretical material 59

3.1 Introduction

3.2 Position statement

3.3 Following the action

3.4 Conclusion

4 What makes these meetings more than these meetings? 78

4.1 Introduction

4.2 Returning with "out there" - information and power?

4.3 Proximity and membership

4.4 Processes of making: A focus on the detail

4.5 Conclusion

Part two: Following one phrase

5 The talk corpus: The phrase "out there" in the meetings 95

5.1 Introduction

5.2 Table one: Uses of the phrase "out there" by date

5.3 Table two: Uses of the phrase "out there" by topics and concerns

5.4 Questions

5.5 Conclusion 
6 An unsupported use of the phrase?

6.1 Introduction

6.2 The phrase of interest

6.3 Initial observations

6.4 Further analytic comment

6.5 Conclusion

7 Working on access to information

7.1 Introduction

7.2 Uses of the phrase "out there" in meeting six

7.3 The limits of labelling "out there" 11 and "out there" 12

7.4 Conversation analysis of "out there" 11: A problem involving "information"?

7.5 Working on access to information

7.6 Conclusion

8 Agreeing and disagreeing 166

8.1 Introduction

8.2 The interaction involving "out there" 12

8.3 The interaction involving "out there" 11 and "out there" 12

8.4 Agreeing and disagreeing

8.5 Conclusion

\section{Part three: Concluding by reflecting}

9 Reflecting on these workplace meetings

9.1 Introduction: Purposes

9.2 Authority practices

9.3 Multiple purposes and actions

9.4 Using material things

9.5 Conclusion

10 Conclusions

10.1 Reflecting on researching these workplace meetings

10.2 Conclusions from watching meeting members' practices

10.3 Conclusions from my researcher practices

10.4 So what then from this?

10.5 Epilogue

References

Appendix one: Lists of actions from meeting 5 for chapter two

Appendix two: Transcription symbols and meeting talk conventions

Appendix three: Turns of talk analyses for chapter six (OT29)

Appendix four: Turns of talk analyses for chapters seven and eight (OT11 and OT12) 


\section{Abstract}

This dissertation looks at meeting talk as organisational action, asking how meetings partly constitute "organisation". It considers how meeting members use the phrase "out there" in their work. I conducted observation research, attending the fortnightly staff meetings of an office-based organisation for six months, audio-recording, taking notes and transcribing tapes shortly afterwards. I watched conversations, and following the methodological principles of actor-network theory (ANT), tried to avoid making prior assumptions about how this action was ordered.

The phrase "out there" was used by meeting members in each of the workplace meetings attended. I have analysed what members were attending to each time the phrase was used. In three chapters, conversation analysis (CA) is used to carefully examine three uses of the phrase. I use the involvement of the phrase in the meetings to consider members' attempts to make organisational actions and realities. Is the use of the phrase part of the procedures enabling actors able to build shared worlds? I argue that "out there" refers to places and situations that exist precisely in what is made of them in these particular settings. Further, I suggest that we need to ask just where the effects of this making occur. Such effects occur not "out there" or elsewhere, but here.

More specifically, the dissertation considers how meeting members come to be allowed to undertake, and do undertake, the action in the meetings of proposing future actions, and being able to propose future actions forcefully and normatively. I suggest that first-hand experience is a valuable resource for suggesting and defending what the organisation should do next. The intention of this dissertation is to contribute to studies of talk in action and research in workplaces that attempts to understand organisational members' world-building activities. 


\section{Acknowledgements}

I owe the biggest debt to the members of the workplace meetings I attended. Thank you for ignoring me as you got on with the job. Without your permission for my presence this thesis would not be. I will also be forever grateful for the willing support of the person who introduced me to your organisation.

To my supervisors Dr Michael Lloyd and Dr Deborah Jones of Victoria University of Wellington, thank you for your advice, support and acceptance during this challenge. Mike - thanks for your encouragement and the confidence you have shown in me over the last few years. Thanks also for many discussions over coffee. Deb - thanks for agreeing to supervise me when I turned up as a stranger, and for facilitating access to a research site. Thanks also for showing me university life as many gatherings - I appreciate your creation and enjoyment of these occasions. Cheers for transporting me around the lower North Island and for your company on our trip to England.

This project got under way when I was awarded a Victoria University of Wellington Postgraduate Scholarship in 2002. A Victoria University of Wellington PhD Completion Scholarship and a number of small Faculty of Humanities and Social Sciences research grants were also a big help. Thanks are due to the Victoria Management School especially for financial and administrative support for my attendance at the Critical Management Studies Conference at Cambridge University in 2005. More generally, I am well aware that my good fortune with funding, office facilities and administrative support is not a common experience.

I will be forever grateful to my fellow researchers, whose company kept me going on the good and the bad days. Thank you in particular to the members of the group up the hill who argued for the resources we all need to complete our research projects. Out of our spatial segregation developed some invaluable friendships. My special thanks go to Sarah Anderson, Ves Guise, Shona Hill, Anna McKenzie, Moyra Pearce, Josie Roberts and Virginia Wilton. Members of the $\mathrm{PhD}$ researchers group - thank you for creating a wonderfully inclusive space in which to share our research experiences. Moving to RH was made more rewarding by your presence around the corner, and I am sad for everyone that you are no longer there. Special mention goes to Davina Stanford for her invaluable support during our last few challenging months.

Thank you to all my friends outside the university who have asked how it was going, and didn't look too bored when I answered at length. Please forgive my recent neglect. I am especially grateful to Sarah and Elisa who supported my decision to leave consultancy and go to school, and for their interest and encouragement throughout the following years of study.

Dear family - thank you for your acceptance, patience and interest during this mission of mine. I cannot express how grateful I am to have you in my life. Thank you for your care during my many visits, and especially for reviving me with food, warmth and rest when I was back at the farm late last year. Once more, I will be home soon.

Richard, being my constant companion throughout, I think you have had the hardest time. Thank you for being there day after day after day and for all the things you did. Thanks for being you and for showing me new ways to see, and be in our worlds. 


\section{Chapter one}

\section{Introduction to the thesis}

\section{TABLE OF CONTENTS}

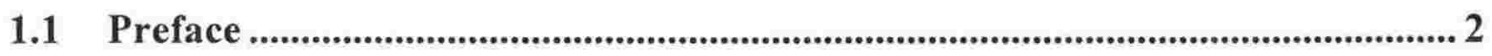

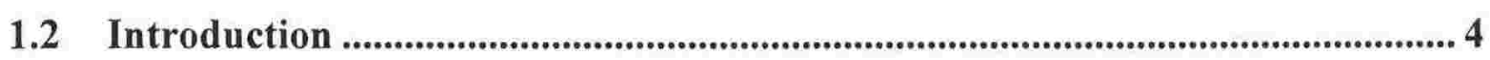

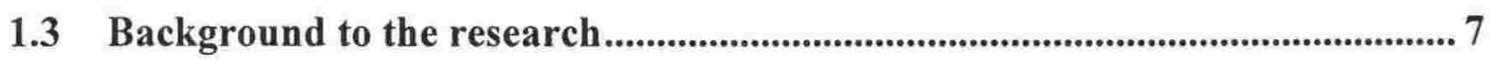

1.3.1 Why this research and this approach: One gap ......................................... 8

1.3.2 The gap between the transcripts and the minutes ....................................... 9

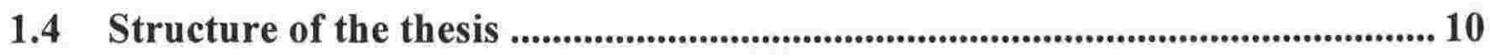

1.4.1 Part one: Describing the empirical and theoretical material ........................ 12

1.4.2 Part two: The phrase "out there" in the meetings ......................................... 13

1.4.3 Part three: Concluding by reflecting ....................................................... 14

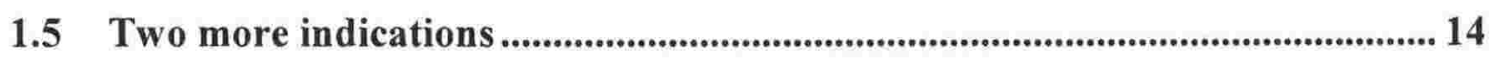

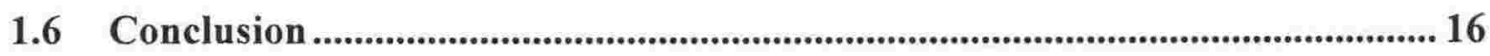




\subsection{Preface}

I will start by talking about gathered things. Some gathered things are, after all, what is before you in this material object, this thesis. Firstly, some gathered words that come mostly from the texts of academic writers. I have gathered these words and kept them safe because they are useful for my purposes. There are other important academic words in this thesis, but these are the ones I have gathered together for just here:

Enact, praxiography, participates, constitute, partial, multiple, experience, enable, momentum, extension, simultaneous.

Many of these words are doing words. Some are not. They are a collection of things precious to me for one purpose. To make an analogy, these words are like the marbles I gathered one year at primary school. Those things in their bag back then were different but alike - all used for winning other marbles. But some were not used in this way, or should I say, not often. Some were not used because they were particularly gorgeous. Some were not used because they were rare and powerful - like the giant steel ball bearings. The gorgeous and the powerful were used sparingly in those games in the dust, and this contributed to their effects. All the marble players, and all the marble player watchers, knew the additional abilities of these not-often-seen things. Bringing one of them out called the gathered people to attention; something was happening, or about to happen. Gathering is a major concern of the thesis.

My purpose in these very first paragraphs of the thesis is to show you some of my precious academic words. Words that will be known, and so will signal something important to those familiar with this particular area of research; just as we kids knew the signals of the marbles involved in our associational activity. Within the previous paragraph are a few signals to the kinds of things to be found in this thesis. They include concerns about building worlds materially and socially, association and action.

This introductory chapter is brief and provisional in that it does not answer many questions. Like the signals in the previous paragraphs, it contains indications, warnings, disclaimers and small samples of what is to follow. The broad research topic of this thesis is how people get their work done in an office workplace. The research site was in New Zealand's capital city, Wellington, in 2003. "At work" was an initial guiding phrase in that it depicts both place and activity. 
The overall structure of the thesis is that after laying out the empirical material, theoretical resources and analyses, I return at the end, in reflective mode, to the beginning. The technique of gradually building analysis is from conversation analysis (hereafter "CA"). To start with what the people are doing is a basic tenet of the ethnomethodological approach underpinning this research. This will signal to readers that the most precious words in this thesis are those of the meeting members who were generous enough to let me into one of their working spaces. Words like these, spoken in the last meeting I attended:

Sally: Ok what should be the priority here let's do this because we know that there's lots of those out there already but we need to get this right and in getting this right

Prue: yeah

Sally: it helps develop that (M14)

Without these words, this thesis would not be (how it is). 


\subsection{Introduction}

My initial research question was very broad: how do people get their work done? One of my very first moves was to undertake fieldwork, attending a series of meetings in the office of a small training organisation. This thesis is the result of a study that was guided most often by actor-network theory (hereafter "ANT"). I followed and watched the actors during the fieldwork and also by analysing selected audio recorded interactions using CA. The research sensibility I have developed has been formed by the work of Bruno Latour (especially 1996), John Law (1994), Annemarie Mol (2002), Rolland Munro (including 1996b; 1997; 1998 and 1999a) and Marilyn Strathern (1991). My approach to the analysis of talk at work has been guided largely by Paul Atkinson (1995), Deirdre Boden (1994), John Heritage (2004), Rolland Munro, and David Silverman (1997). Recognising the problems associated with labels, I have ordered these writers alphabetically, which is the solution that Jones and Munro also apply to ordering the chapters in their monograph on organisation theory (in the introduction they conclude that "disorganization is not always simply lack" (2005 p. 9)). In chapter three I explore how my researchers share techniques of watching and following the action. The concern I have taken up from their work is with "how society is held together" (Latour 2005 p. 13).

In this introduction, some background to the research is provided first. Secondly, the structure of the thesis is outlined with overviews of the chapters. Finally, two more indications about the thesis are given. Before that, however, perhaps it is worthwhile to give an initial indication of what kind of gathered thing you have before you.

After having completed the fieldwork and read, read and read some more, I tried out some possible titles. Reality, being, and building were the ideas that were strong then. The options I left contained in a computer file were: Making organisation(al) real(ity) and Round the table: Ontology in office meetings. Certainly, Mol's book was relevant, and provided "praxiography" for my collection of precious words (2002 p. 32-3). Along with other writers, she uses "enacted" and "participates" in producing a book that:

contributes to a philosophical shift in which knowledge is no longer treated as referential, as a set of statements about reality, but as a practice that interferes with other practices. It therefore participates in reality (2002 p. 152-3).

Using Bruno Latour, Mol provides a way to describe the approach I have taken in considering the meetings I attended for this research: 
The moral of [We Have Never Been Modern (Latour 1993)] is that instead of dialectically jumping between the ideas that reside in the minds of subjects and some objective reality out there, we would do better to admit that in our daily lives we are engaged in practices that are thick, fleshy, and warm as well as made out of metal, glass, and numbers - and that are persistently uncertain (2002 p. 31).

I gave $\mathrm{Mol}$ one tick for using Latour, whose work had been guiding my fieldwork practice, another for including material practice, and another for practices being uncertain. In addition, in this one sentence $\mathrm{Mol}$ uses the phrase that became the focus of my own research.

That phrase is "out there". ${ }^{2}$ From an initial wondering about what the meeting participants were doing, the phrase "out there" has become central in this research. It is used as a way of "narrowing" attention (Boden 1994 p. 120). The phrase is used to consider how in these workplace meetings "reality" is told and the effects this telling has. In the talk of these meeting members, is reality talked of as someplace elsewhere, as "out there"? Is it a reality used by meeting members as if it is independent and prior to themselves, which can be "understood as an accomplishment rather than something given in the order of things" (Law 2004b p. 37)? Are realities and worlds being made, as Law and Urry argue is the case with social inquiry and its methods (2004)?

ANT"s call to "follow the actors" is the approach taken in this research (Callon et al. 1986 p. 228). The technique of following one phrase in interaction is from Wilkinson and Kitzinger (2000). The phrase "out there" was used to gain some grip on the empirical material. It was used to choose meeting interactions on which to undertake specific and contained analyses that attempted to see "artefacts and phrasing "in use" (Munro 1999a p. 624). I have attempted to take something like Munro's approach, for example where "an emic stress on just two artefacts, the 'future' and the 'past', is traced to suggest how their presence within discourse affects processes of affiliation" (1998 p. 218). I follow the actors as they work on the things that I have chosen to focus on.

However, whilst putting selection into practice, something unsettling occurred. As I tried to reduce the material to some more manageable size, such as only using interactions involving talk of places somewhere else, rather than becoming easier to handle, the material seemed, yet again, to expand. The closer I looked, the "more detailed" things became (Strathern 1991 p. xiii):

\footnotetext{
${ }^{2}$ Throughout the thesis meeting talk quoted within sentences is indicated by double quote marks and italics eg, "out there". Concepts I have developed are indicated by italics eg, how I know (see appendix two).
} 
If one thing observed close to appears as perplexing as many things observed from afar, the perplexity itself remains. Each single element that appears to make up the plurality of elements seen from a distance on close inspection turns out to be composed of a similar plurality that demands as comprehensive a treatment (Strathern 1991 p. xv).

My concern that I had not gathered enough material, in the audio recordings of 14 meetings from one workplace, resulted partly from the recounting of time in the field in most of the ethnographies I had read, and in the holding up of long-running fieldwork as exemplary research (for example, Frankenberg in his review of Mol's The Body Multiple (2005)). This lack was replaced by a new worry, that no matter how I limited the material I would consider in this thesis, it would always expand under my yet closer gaze. The container I created to hold talk of places somewhere else became something smaller, I hoped, by limiting it to uses of the phrase "out there". But here were 31 interactions all requiring recording, listening, transcribing, describing. Strathern's (1991) dilemma of scale became another unsettling experience in the doing of this research and the concept of scale, degrees of closeness, has been used with increased awareness.

Also accepted is the utility when conducting research of holding for now, of letting uncertainty remain. The challenge was one of "finding ways of knowing the indistinct and the slippery without trying to grasp and hold them tight" (Law 2004b p. 3). This problem applies to the meetings as well as to the phrase and so I started by conducting a careful analysis of just one use of the phrase. This one, the odd one it seemed, the one that was the focus of my intense attention for a time, was the twenty-ninth appearance of the phrase in my transcripts - "out there 29". Accepting uncertainty is also asked of the readers of this thesis (Law 2004b). For example, chapter two is, somewhat unconventionally, a description of the meetings rather than a method chapter. It is also lengthy. The aim is that taking time here will be rewarded with a "feel" for the quality of the meetings I attended and an understanding of a particular way of conducting and presenting research (Jones 2005). For instance, at the time that "out there 29" was the centre of my analysis, I could not yet consider whether it was one of CA's deviant cases. I had to hold until I had other descriptions of the involvement of "out there" to compare.

Having produced further descriptive analyses of interaction, I could not tell the whole story of this phrase's involvement in these meetings, let alone of the meetings. The word "partial" is useful to produce the disclaimer that this thesis does not attempt or claim to be complete or the whole story. In this chapter I discuss how the minutes from the meetings point to a gap, a gap on which I concentrate my research gaze. The view is that 
things are only ever partial, including descriptions in research. We always choose, as Strathern discusses with regard to the way anthropologists change scale by switching perspectives when they organise their material, which

is made possible by a modelling of nature that regards the world as naturally composed of entities - a multiplicity of individuals or classes or relationships - whose characteristics are in turn regarded as only ever partially described by analytic schema. Thus one might imagine choosing two or three elements of initiation practices for theoretical consideration, knowing that for no single case had one grasped the natural character of the entire phenomenon. Other perspectives remain. (1991 p. xiv, original emphasis).

In making this representation of the meetings I do what we all do, we "report only what you need in order to do whatever you want to do" (Becker 1986a p. 125). Purpose, as I talked about in the preface. The minutes of the meetings do only what they need to do, they produce a trace (Latour 2005). Like those minutes, this thesis too is a "representation of social reality" which is "less than...the actual setting" (Becker 1986a p. 125).

\subsection{Background to the research}

In doing this research I have drawn on my experiences from fifteen years as an office-based employee in New Zealand and London, and my ongoing experiences as an office-based worker. An interest in workplaces emerged especially from a previous research project, which considered the preparation work of one organisation for a governmental inquiry into railway accidents (Simpson 2002).

To focus my current topic and fieldwork I consider the action in a workplace group. This group was made up of the staff of a single organisation, with around 10 paid employees. The meetings I attended as researcher were the organisation's fortnightly allstaff meetings. Analytic problems have emerged from the very broad question with which I began of how it is that the work gets done. The technique of starting with a broad question reflects an attempt to put the principles of ANT into practice, to be "internally consistent" (Law 2004b p. 167). Law discusses how the enterprise discourse asked him for a bottom line, and to justify the book he had written from his ethnography. Part of his reply was that "the work of ordering is never finished", but the request left him wondering:

Why do we still respond to modes of ordering that demand discrete and relatively simple conclusions that can be transported from one place to another? How might we create alternative modes of ordering, alternative ways of writing, where these demands are no longer made (Law 1994 p. 187-188).

This thesis has been guided by ANT, and especially draws on research like Law's, undertaken since the early 1990s, that focuses on work and organisation (Callon 2001). 
This is an era described as "after ANT" (Lee and Hassard 1999 p. 393). ANT has provided the broad base for this research, and CA has been used to pay close attention to specific pieces of the action. Both approaches are about watching and following the action.

Before I started I talked to various people about the intended research. Responses included "but not in my workplace". People explained that they did not want to put me in such a difficult situation, or the work was too sensitive to be exposed - the media would be interested for instance. During a break at one academic conference someone said " $m y$ workplace is a farce", a statement that went undisputed by another person who had recently left the same organisation. They then talked about recent goings on (sometimes making sure I could not hear). Yet the work still gets done and I have focused my research by looking at how, precisely. It did occur to me back then, that discussing the difficulties of their shared workplace was part of getting work done.

\subsubsection{Why this research and this approach: One gap}

The area of academic work I draw on, and hope to add to, is observation research in workplaces which considers the ongoing world-building attempts of actors, especially research using ANT and CA. There is a lack of research into workplace groups using an ANT perspective (Dugdale 1999; Jeppesen 2001). My current research adds to what we understand about how groups hold together, and especially to what we know about how this is achieved in New Zealand. Farnsworth and Austrin are currently undertaking research on meetings in a New Zealand university using ANT, and their work will add to ANT research on meetings and our understanding of that New Zealand workplace (2004).

The broad initial question, and the focus on organising in workplaces, drew me to ANT and the ongoing discussion about how to do this kind of research (see Cooper and Law 1995; Latour 1987; Latour 2005; Law 2004b; Law and Hassard 1999; Lee and Hassard 1999; Mol 2002). ANT's consideration of work as an often difficult, sometimes invisible, accomplishment resonated with my own experiences as a worker. ANT deals particularly well with the complexity, conflict and contradictions I encountered during research (on complexity see Law and Mol 2002a). ANT is an actor-centred approach, with actors being:

Any element which bends space around itself, makes other elements dependent upon itself and translates their will into a language of its own. An actor makes changes in the set of elements and concepts habitually used to describe the social and the natural worlds. By stating what belongs to the past, and of what the future consists, by defining what comes 
before and what comes after, by building up balance sheets, by drawing up chronologies, it imposes its own space and time (Callon and Latour 1981 p. 286).

ANT is particularly fruitful for the way in which it draws attention to the role of people and texts, documents and other inscriptions (see Gherardi 2000a; Law 1992; Munro $2001 \mathrm{~b}$ ). This makes the approach particularly suited to considering the ongoing processes of getting work done and the things used for this purpose, like phrases.

I have resisted "the division between human agents and the networks of the social" (Law 1994 p. 188). Further, texts, and other objects, are considered in the "circumstances in which they act" (Callon et al. 1986 p. 230) because they are "part of a practice of handling, intervening in, the world and thereby of enacting one of its versions - up to bringing it into being" (Law and Mol 2002a p. 19). Though objects are also included in this research, most of the close analysis is on recorded meeting talk. A useful justification for my close attention to work practice using CA comes from a recent special issue of Organization on "bureaucracy in the age of enterprise". The argument is that there is a "need to develop a more realistic and grounded appreciation of the inherent flexibility and durability of contemporary bureaucratic organization" (Courpasson and Reed 2004 p. 11). I consider this thesis to make a contribution here.

Though presented as an afterthought, I also claim Mumby's noticing of a gap:

In addition, organization researchers generally have eschewed the kind of micro-analyses of talk that conversation analysts in the tradition of Sacks, Schegloff and others have developed in the last thirty years or so (see Boden, 1994, for an exception) (2004 p. 248). Indeed, Boden's statement clearly illustrates my approach of following the phrase "out there" in this research:

there really is no objective environment for organizations, all of whom are dependent on the perceptions of their members and, more centrally, on the ways local perceptions actually constitute the conditions of next actions and thereby outcomes (1994 p. 38).

No "out there" other than meeting members' use of this phrase, and how they devise to make it useful to them, is considered. The concern is the there-and-then accomplished by meeting members that was their work practice. This thesis attempts to "retrieve the details of actual events" (Boden 1994 p. 200).

\subsubsection{The gap between the transcripts and the minutes}

Attending one of the meetings, or even all 14 meetings, did not seem like a huge effort, but attempting to describe some of what went on has been difficult (Latour 2005). In my previous research on a railway accident inquiry I noted the contrast between the apparent ease with which one worker told me about past events and another's struggle to 
tell me about what was currently happening in her everyday work (Simpson 2002). The difficulty of attempting to describe what happens day to day in workplaces has been partly alleviated by accepting that it is impossible to tell the whole story. While recognising this difficulty, my research focuses on the absence, or gap (Munro 1997) between the minutes and the transcripts. While some might take the minutes of these meetings as more empirical materials, I have taken them as an indication of what has been left out, or deleted (Munro 1996b). This is another way to say that my concern is on what was accomplished in these meetings. The aim is to understand something of what went on, in keeping with an ethnomethodological approach:

And, while company reports and government policy stand as 'official' records of past actions and future constraints, the gap between them and what 'really happens' (or will happen) is considerable, as we all know. One suggestion of this study is that we need to take that gap more seriously if we are to understand organizations (Boden 1994 p. 18).

Meeting members get on with things like boundary maintenance as practical matters with little fuss, and through joint effort (Boden 1994).

Boden calls on Wittgenstein to discuss how people "know how to 'go on' in social life" and "to produce specific next actions that, seen from afar, will look plausible" (1994 p. 36). These statements by Prue in the eighth and eleventh meetings I attended do not indicate falseness or pretence on her part:

yeah but we have to be seen to be identifying the issue and addressing it (M8).

nevertheless we have this significant obligation (different voice) to consult everything that moves um and we have to you know show show that we have done it (M11).

Her actions are practically relevant. Practices of showing are involved in getting work done and perhaps making work visible is increasingly important (Latimer 2000). Practices of seeing and showing are important in the thesis, including in my own research work.

\subsection{Structure of the thesis}

After this introduction, the thesis is in three parts. The concern of the first two parts is to describe something and some things of the meetings I attended, but the way description is attempted and the amount of material described is different in each. In the first part of the thesis there is a series of chapters that describe the meetings and theoretical material in a broad way. Somewhat unconventionally, description of the empirical material is undertaken in chapter two, where you might expect to find theory or method. As I said earlier, here I ask readers to accept the utility of letting uncertainty remain. Chapter two is necessarily long, given its task of asking what it is that members 
attend to that makes these meetings meetings, and makes them these particular meetings. This is not intended as a brief overview, able to be quickly skipped through on the way to the core of the thesis, to something more substantial or real in the analysis chapters. Rather, the work of showing you something of the meetings and of this research approach begins right there in chapter two because "quick accounts don't get to the heart of things at all" (Law 2004b p. 43). My decisions about how to order the chapters of this thesis are part of a conscious effort to slow things down. Law talks about "the stop", and my research is in keeping with his attempt at research that is deliberately "slow and uncertain" (2004b p. 10). Description of the literatures I have employed during this research and in writing this thesis begins in chapter three, where I describe the theoretical resources. In chapter four I argue for my approach of looking closely at the detail of action.

The second part of the thesis has a narrower focus and turns specifically to the involvement of the phrase "out there" in the meetings. Chapter five describes the 31 appearances of the phrase "out there" in the series of meetings I attended over six months. Next are three chapters (six, seven and eight) that use CA techniques especially to analyse selected interactions involving the phrase. The third part of the thesis reflects on the descriptions attempted in parts one and two. Chapter nine looks back on the descriptions attempted in chapters two to eight. In this way I am using the CA structure of initial observations and then further analytic comment within some chapters and across the thesis.

Though I ask readers to attend most closely to the large amount of empirical detail contained in this thesis, I do not want to risk being unclear about the previous academic work that has guided this research. A number of attempts are made to be explicit about where this research has emerged from, and where it may therefore fit. The Preface at the beginning of this chapter was the first. In chapter three there is a Position statement and in chapter ten the section Practical purposes: Academic uses of the phrase gathers together academic uses of "out there". These sections are somewhat repetitive in that they mostly contain the same writers and ideas. However, they are included to indicate where I hope this research makes a specific contribution. I am reluctant to apply a single label, but, as indicated by the content of these summaries, this thesis draws most often on sociological research and especially that guided by ethnomethodology. 
Chapter introductions and conclusions are deliberately short in keeping with my efforts to show what I did in the research as well as telling you about it. If I have to explain what I have described, I have failed to produce good descriptions (Latour 2005).

\subsubsection{Part one: Describing the empirical and theoretical material}

Chapter two asks: "what makes these meetings, these meetings"? It aims to show the empirical material in the mode of an ethnographic walk-through. In first-person voice, it provides a narrative of attending one of the meetings from the perspective of the taperecorder I took to all of them. This machine has been made omnipotent in order to draw together material from field notes, audio recordings and transcripts. Secondly, there is a more reflective discussion of what makes these meetings a meeting using Becker's "Wittgenstein trick" (1998) to consider what meeting members are attending to. What is it that makes this gathering of people, actions and things these meetings? What seems most often required? The final section of the chapter contains a brief discussion of how I gained the material for this thesis. Apart from Becker's methodological pointers, chapter two does not include theoretical material. This holding-back from theory has its dangers. One such danger is that my approach may not be clear enough soon enough to avoid misunderstandings. To be clear, I am describing just these meetings and make no claims that elements in this depiction are universal to other workplace meetings. The precious word "praxiography" helps here in Mol's explanation of her position:

The praxiographic 'is' is not universal, it is local. It requires a spatial specification. In this ontological genre, a sentence that tells what atherosclerosis is, is to be supplemented with another one that reveals where this is the case (2002 pg 54).

In chapter three, theoretical resources are the focus. This chapter outlines the academic material I draw on to discuss the empirical material gathered. There is a review of ANT writing, and a shorter introduction to CA work, concepts from which are expanded on as and when they are found to be useful in the analysis chapters. The guiding concern of chapter four is what makes these meetings more than meetings. How is the "in there" of the meetings mixed up with "out there"? I explore how meeting data is useful, important and mirrors some of the debates in sociology:

One of the core assumptions of ANT is that what the social sciences usually call 'society' is an ongoing achievement. ANT is an attempt to provide analytical tools for explaining the very process by which society is constantly reconfigured. What distinguishes it from other constructivist approaches is its explanation of society in the making, in which science and technology play a key part (Callon 2001 abstract). 


\subsubsection{Part two: The phrase "out there" in the meetings}

Chapter five provides a transition point for the thesis. This chapter is part description, part analysis of a selection of material. All 31 uses of the phrase "out there" in the meetings are presented in tables. Again using the CA structure, this chapter is a beginning, where I do some initial analytic observing (Heath 1981). The major question, as it is in chapter two, is what members might be attending to each time "out there" is used, and whether there any features that allow them to be grouped.

In chapters six, seven and eight $\mathrm{CA}$ is used to ask about the work the phrase does in the meetings. How is the phrase used by, and useful for, members? In particular I try to show how the phrase "out there" was used in the meetings and the effects this had (Latour 1999b). When someone says their idea is "really sort of out there so please keep it within these four walls", what are the effects, like the reactions of others, of this presentation? In these chapters I undertake "fine-grained" analyses (Atkinson 1995 p. 11; Boden 2000 p. 194), demonstrating how $\mathrm{CA}$ is a valuable way to explore how these meetings hold together. For instance the way that meeting members can be seen taking care with resources, like time, is discussed in regard to the CA concern with how turns of talk are "rationed" (Heritage 2004 p. 226).

Chapter six, the first analysis chapter, considers a potentially unsupported use of the phrase "out there 29" (hereafter, OT29). ${ }^{3}$ This chapter asks how this interaction ended up this way. In chapter six, and in other places in the thesis, you will find discussion of the way in which the meetings involve multiple things. In chapters seven and eight I analyse two uses of the phrase in meeting six (OT11 and OT12). What to do about information seemed to be the problem facing BANA ${ }^{4}$, and in these two chapters I ask how OT11 was involved in meeting members working on access to information. A mix of fine-grained analysis of transcribed talk and a broad question approach is used to ask what happens, and what else is happening, when concerns are raised about information. In chapter seven the interactions from meeting six involving the phrase are presented as a way to lead into the meeting talk which is subjected to close attention. In this chapter I use CA techniques

\footnotetext{
${ }^{3}$ In this use of the phrase "out there", "OT29" is the twenty-ninth use of the phrase in this series of meetings (referencing system is from Wilkinson and Kitzinger 2000).

4 "BANA" is the pseudonym used for the organisation.
} 
to consider Munro's question: what are the "projects conducted in the name of information" (2001a p. 199)?

Chapter eight focuses on how meeting members undertake agreeing and disagreeing. The meeting talk to which the chapter pays close attention is again presented. After analysing OT12 the interactions involving OT11 and OT12 are considered together. I discuss how members go about the tasks of the meeting. One concern is how these meetings are places for members to show they can identify, and will act on, organisational implications. In the final section of the chapter I ask whether, across the interaction, we can see meeting members working on what they might do next from the problems they have raised.

\subsubsection{Part three: Concluding by reflecting}

The final two chapters of the thesis consider how these meetings achieved forming and ask how "out there" participates in practices of making. I take a step back and broaden my focus (Strathern 1991) from the close view provided by the techniques of CA, and continue my use of Rolland Munro's work. I discuss the involvement of the phrase in attempts to make organisational actions and realities (Latour 1996; Mol 2002). I argue against divisions between these staff meetings and this organisation BANA in that "out there" refers to places and situations that exist in what are made of them in particular settings and the effects this making has.

Chapter nine reflects on meeting members' practices as seen in the analyses in chapters six to eight. I draw on my attempts to show how the phrase "out there" was used in the meetings and the effects this had (Latour 1999b). Chapter 10 is concerned with how we might reach understandings of organisation building, action, and activities. I reflect on academic research and connect further with academic writing by gathering academic uses of the phrase "out there" for my purpose of showing the focus in this research on doing things together.

\subsection{Two more indications}

Firstly this is a study of the meetings themselves. Taking my lead from Harold Garfinkel, Howard Becker and Harvey Sacks, these meetings are taken in and for themselves and not as a way of seeing past or through them to something else. As Garfinkel says, ethnomethodology: 
is not in the business of interpreting signs. It is not an interpretive enterprise. Enacted local practices are not texts which symbolize 'meanings' or events. They are in detail identical with themselves, and not representative of something else. The witness-ably recurrent details of ordinary everyday practices are constitutive of their own reality. They are studied in their unmediated details and not as signed enterprises (2002 p. 97).

Sacks" argument that the task is "to sell what I can do, and the interestingness of my findings" rather than to be concerned with theoretical underpinnings, is the motivation for my attempt to show how I have undertaken this research as well as telling you about it (Sacks 1992 b p. 3). I have employed practices of showing because you may see more than I could ever tell (Polanyi 1958). My hope in employing CA to watch conversations is that the work and skill of meeting members will be visible. This visibility may enable readers to recognise something of their workplace experiences.

The second indication is a note about personal experience and style, both of which you will find in this thesis, though not in all places. Law says the object of his organisation ethnography was to emulate Sharon Traweek in "telling a few tales" (Law 1994 p. 4). Supporting this approach, Van Maanen says the personal voice approach has remained constant, with voice in fieldwork-based sociology "perhaps increasingly, the personal voice of a situated author with a story to tell" (1998 p. xxiii). My past experience of workplaces has influenced the research I carried out in a current workplace. I have avoided using the passive voice and in this way, hiding myself as the researcher (Becker 1986b; Law 1994), opting instead for a personal style.

I use my personal experience in this research in deliberate ways (see Law $1994 \mathrm{p}$. 190 regarding context and the place of the author). I used it to choose a research site and to consider research participants who might be comfortable enough with me being in their workplace to carry on with their work. My own experiences of organisations have been used to select which researchers to draw on. As you will see, these are writers who show the skill of workplace practice. They also take workers' efforts as genuine attempts to get on with the job.

However, there are limits to the use of my own experiences. My approach is in keeping with Weick's sentiments when he argues for "disciplined reflexivity" because the "attention to self-as-theorist threatens to shift reflexivity from a means to improve theory to an end in itself" (2002). His call is to be aware of, but not preoccupied with, the researcher in moving "back and forth between perception and conception" (Weick 2002). May cites Law in arguing for "an understanding of the context and nature of interactions 
observed, along with an understanding of the relationship between observation and interpretation" (1997 p. 147). In their overview of the use of ANT in organisation and management theory Hardy, Phillips and Clegg (2001) point to Linstead's discussion of research which is "neither self nor subject oriented" (1994 p. 1327). These calls highlight how research practice involves mixes of the researcher and the researched.

These reflections are the result of doubt. I am not entirely convinced, with regard to politics and ethics, about the doing of research; in research there are always research subjects. Neither am I convinced by arguments that we can do research "with" rather than "on". Again ANT helps, being an approach that suits the current era where the expertise of the researcher is problematised (Lee and Hassard 1999). ANT enables us to be more reflexive about our research (Brown 1992). This discomfort influences other decisions, like asking how rather than why, in looking at workers' achievements, accomplishments and skills rather than for someone to blame and for solutions to problems. Moral questions such as why these meetings are this way and how they might be improved are not asked in this thesis (Becker 1986a).

\subsection{Conclusion}

This research project has an element of randomness. This was inevitable and appropriate because the study was guided most often by ANT. Research that aims to describe processes of making faces the problem that "the world in general defies any attempt at overall orderly accounting" (Law 2004b p. 6). Randomness in this thesis is the result of answering ANT's call to follow the action, especially action which attempts to make worlds more orderly and less random. Proposing a different way to construct research, Law says this kind of research will be "ad hoc, not necessarily very coherent, and ... active" (2004b p. 41). Examples of randomness from my research include the selection of the organisation whose meetings I attended. I did not especially seek out, in some kind of deliberate manner, this particular organisation or the kind of work it undertakes. Indeed "selection" is not the right word at all for describing how I came to attend meetings in this workplace. Neither is "selection" an adequate way to describe how, after I had been granted access, I came to attend the particular meetings I have used in this research. Another example is the phrase I chose to follow. I have followed the phrase "out there", but it could have been others. The first analysis I undertook using CA was that of OT29, but it could have been any of the 31 interactions involving the phrase. 
However, to say that this research has been entirely random would be to exaggerate. My research moves were not entirely random, but neither were they entirely determined; rather there was a "coincidental quality" about them (Becker 1998 p. 28). My view has also been inclusive because everything is of interest when asking how the world does its ordering (Boden 1994; Law 1994). Taking up an approach that follows the action and includes everything means randomness, coincidence, and the absence of control are unproblematic.

The work of ordering is everywhere, and so the challenge for this long-term research project it seemed, from within it, was to start by doing some watching and going from there. Like the detective in the novel I was reading about half-way through the project, my approach has been to "wander into their dialogue without a destination" (Shields 2000 p. 320). ${ }^{5}$ There is less randomness in the presentation of the research though, because "arrangement makes narrative out of random events" (Becker 1986a p. 128). For instance, one reason for analysing OT29 first was that the manager need not be the focus, despite her talk often being most obvious in meeting recordings and transcripts. Here I followed the efforts of an actor who was not a manager as part of considering workplace ordering going on. The intention was to contribute to studies of talk in action, and research in workplaces that attempts to understand organisational members' worldbuilding activities.

\footnotetext{
${ }^{5}$ Austrin and Farnsworth discuss detective work in regard to Latour's method (2002; 2005).
} 
Part one:

Describing the empirical and theoretical material 


\section{Chapter two \\ What makes these meetings, these meetings?}

\section{TABLE OF CONTENTS}

2.1 Introduction: Showing the material..............................................................19

2.2 How I gained this material .....................................................................21

2.3 A first-person walk-through of one meeting...............................................22

2.4 A few observations about the meeting room.................................................32

2.5 Using Becker's "Wittgenstein trick" ............................................................34

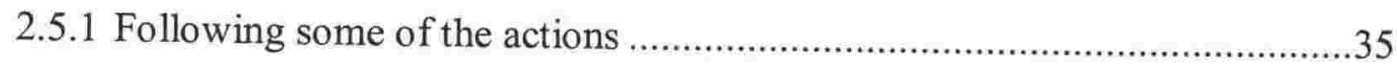

2.5.2 Bringing in material from the other meetings.......................................... 37

2.5.2.1 Following: Organising the meetings..........................................39

2.5.2.2 Re-ordering: Belonging........................................................47

2.5.2.3 Re-ordering: Attending to BANA …........................................52

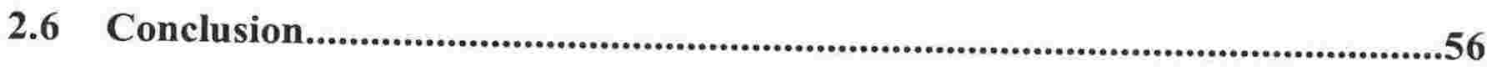




\subsection{Introduction: Showing the material}

This chapter attempts to show you the empirical material that is the source of this thesis. The concern is to ask how these gatherings are meetings, and how they are these particular meetings, different from other meetings involving these people. How do these meetings come to be and remain? The people gathered were all staff members of the organisation, but the same people attended the field advisors' and admin meetings. There were other people doing work for BANA, but they did not attend the staff meetings, nor the field advisors' or admin meetings. I will refer to these people as "non-staff". When there were visitors, the staff meetings themselves seemed to be suspended while members specifically attended to the reason for the visit, rather than to the usual topics and concerns.

The process I undertook to describe the meetings I attended as observer was to write one meeting from the point of view of the tape-recorder. Next I added a description and a number (1-56) to the sentences where I thought I could see action of some kind. I separated these sentences and their action labels to form a list (you can see it in Appendix one under A chronological set of actions from meeting five). In a second list I deleted the sentence and labelled the action according to whether meeting members could be seen working on making this meeting, this organisation, or both (presented below in section 2.5.1). Next I selected some of these actions to focus on and used them as a way to bring in, and order, material from the other meetings I had attended.

The words "following" and "re-ordering" are used in this chapter to indicate where I provide material following the chronological order, or in some re-ordering of my own devising. They also indicate an awareness of the techniques of doing research, and in this regard the chapter is guided by Howard Becker's advice about conducting research:

Since the condition [of perfect] never obtains completely, the more interesting situation is when it is met sufficiently that most people (and especially those whose opinion counts, because they are powerful and important) responded near enough to what makers intended that the result is 'acceptable' to everyone involved (1986a p. 127).

Apart from Becker, connections are not made to any literatures. Somewhat differently from the way many theses are structured, what meeting members attend to in making these meetings these meetings takes precedence in this chapter over discussing previous academic work. Because meeting members do many things, there is a lot of detail presented. This is necessary to provide a feel for the material, and how it has driven this 
thesis. Describing the meetings has taken many words but this is not seen as a problem because the thesis uses description as a way to understand meeting members' achievements. Any attempts at explanation must rest on a thorough consideration of the detail of these meetings.

In section two of the chapter I briefly explain how I gained the empirical material. Next I describe just one meeting (meeting five), as a way to show the material and be specific about this series of organisational events known as the staff meetings (Becker 1986b). In section four I provide a few observations about the meeting room. In section five I employ Becker's "Wittgenstein trick" in order to see what goes on in the meetings, to "separate what's central to our image of a phenomenon from the particular example" (1998 p. 139).

Section five is the largest section of the chapter. It is an hourglass shape, where I narrow down from the whole of meeting five to a list, and then widen out again by, at times, including material from the other meetings I attended. Chronology is left behind to gather together what members use to make these meetings. I have been selective, only following some of the items in the lists, some of what concerned members in meeting five (Becker 1986a). I have been selective in order to follow what may help us understand how meeting members get the work done. Forgetting the name to "concentrate on the kind of collective activity that is taking place", this part of the chapter asks what is it that makes this collection of people doing this rather than that, these meetings (Becker 1998 p. 144)? What seems most often required, such as an agenda and being face-to-face? Structuring the parts of this section was not easy. The necessary separations are difficult, as Becker himself notes with regard to art, but they are part of the act of describing (1982). Describing involves re-ordering.

As the chapter goes on I begin to speculate more and more about how the staff meetings might be involved in getting work done. For example, do meeting members achieve organisational momentum when they achieve the forward movement of these staff meetings? Some of these areas of meeting members' focus (information, for instance) will be picked up in chapters three and four, and the following analysis chapters. This is one way the description of meeting five shapes, and signals, the concerns of the thesis. 


\subsection{How I gained this material}

A few months after starting my $\mathrm{PhD}$ one of my supervisors took me to meet someone she knew from another of the university's workplace research projects. My supervisor had asked this person if she had any ideas about workplaces that might be interested in being involved in my research. Our research contact suggested a small Wellington office-based organisation, which she was involved in as a member of an advisory group to the governing board, and forwarded the document I had written explaining the intended research to the manager. She also arranged for me to attend their Annual General Meeting where I introduced myself briefly to the manager and collected the folder containing her card, an agenda, Annual Report July 2001-June 2002, Strategic Business Plan 2002/2003 and a brochure. The work the organisation is involved in is workplace training. They develop and assess training programmes for members (or clients) that lead to employees gaining qualifications that are recognised as part of a national framework. They have an office and fieldworkers.

Prue is the organisation's manager and the possibility of my conducting research with the organisation was raised by her at the staff meetings. In a meeting I had with Prue the staff meetings were suggested as a place to start my research. I had told her that I was interested in doing research with an ongoing group or committee, but that if people were prepared for me to be around with them in their office (a downtown Wellington high-rise) I would take that opportunity. This did not eventuate. My concern at that time was to gain access to any organisation, given that my interest was on how people get the work done. I did not seek out any particular type or size or organisation, though given my contacts and past work experience, it was fairly inevitable that it would be an office-based workplace. The main concern was to be where the action was in getting work done. I attended meetings between March and September 2003 and gathered some of the documents from the meetings. I audio recorded and transcribed the meeting talk.

These meetings were a meeting point of the organisation, a bit like a train station where you might decide to meet with others to plan, and continue, what to do next. Meeting in this particular place and time made sense for some reason. I was there at the BANA staff meetings, watching as they gathered, greeted and carried on past me. As researcher, the meetings provided a peephole into the work going on. They were all I could see, all that came into view, and so all I would use. This thesis is a view of part of the work of making organisation. I am content that the meetings were certainly enough. 


\subsection{A first-person walk-through of one meeting}

This section aims to show the material in the mode, roughly, of an ethnographic walk-through. In first-person voice, it provides a narrative of one meeting. It is slightly different however in that the narrative is from the perspective of the tape-recorder I carried to all of the meetings I attended. This machine has been made knowing to enable drawing together material from my field notes, the audio tape and transcript, in an attempt to produce an adequate description of being there.

Material has been drawn from just one meeting I attended as researcher. In the interests of giving a feel for the meetings I describe one meeting only but not because they were all the same: the meetings varied, each meeting was unique, an event in, of, and for itself. There were observable routines and structure (like going around the table), but each meeting was also different. Some things were specific to particular meetings and a few months into my regular attendance I started giving the meetings names like "Numbers, numbers, numbers" for the meeting on 22 July. The meeting described below was held on 13 May (in this thesis, referred to as meeting five). This meeting was not chosen for any particular reason, other than it was not the very first meeting I attended. Meeting five was different in that a visitor was expected to arrive before it was finished, and the members rearranged what they did in this meeting to allow for this. Writing this one is a starting point in describing something of what the meetings I attended were like.

It's a cold morning in mid-May, but there's a brilliant blue sky. The walk to the meeting, scheduled to start as always at 9am, seems busier than usual with other pedestrians getting closer than Tamika likes. This is the fifth time we've crossed town to attend the fortnightly staff meetings of BANA. We're in the lift of their building with Kim. Pat gets in behind us carrying a guitar. Someone else in the lift asks if we'd get a tune on the way up.

As usual by around 8.45 Tamika and I are inside the meeting room. Tamika sets up and tests that I'm working as expected. In her notebook she writes a few observations about the walk across town and draws a map of the room. Paula comes in and puts her filofax beside Tamika, and then leaves again. Paula is here from City A. She's the only staff member not based in Wellington, though there's usually talk in the meetings about the time May, Pat and Jo spend out of their Wellington office. Simone is getting cups from the side cabinets. May has also looked in one of the cabinets for Milo. There are two orange notes, or stickees, on the moveable whiteboard (which has printing paper sticking out of it) with the same telephone extension number written on them "ex 8437". The board is blank otherwise, no agenda items (yet). Simone comes back in and sets up a hot water dispenser, coffee plunger and about 6 matching mugs 
(a dirty cream colour with a green ring around the top) over there by the windows opposite the door, which leads to the rest of the mostly open-plan office. There's a copy of the free newspaper, Coffee News on the meeting table. There's also a cup with teaspoons near where May will eventually sit.

Pat says she has lots of papers as she sits down on the other side of Tamika. She has not been here for the last two meetings. It's hard to hear what Prue is saying as people arrive. One thing she's commenting on is that the meeting is a full house this time. May laughs, saying it's sold out. Prue asks if anyone has anything specific for the agenda. May has, and Prue asks about reminding. There's noise and chatter. People are stirring cups. Kim arrives last, and gives documents to Paula, Pat, Jo and May. In response, someone says they're impressed. And so does Pat. Kim says thank you when she's given the minutes from last time. Prue has gone out again. Jo and Kim are discussing the document, saying a graph, a table, sorry. There's some laughing about drinking as well, but I can't follow what they're saying, other than Prue also saying sorry and Susan coffee day... coffee day. Drinks seem to be a bigger feature than usual. Everyone has something to drink out of on the table, but not everyone has used the things Simone set up. Susan has a polystyrene cup, perhaps with water in it from one of those water coolers you see in most offices in Wellington. Other than hot drinks, the objects in the room are pretty much as usual: two whiteboards, a toaster, phone, the OHP and the spray used to clean its glass.

With everyone in the room, all the seats are taken. The table is designed for 10 people, exactly how many staff BANA currently has. Before the meeting started Irene and Simone were moving chairs around in the room - an extra chair was needed. Irene squeezes onto a corner between Sally and May. Tamika feels uncomfortable in her usual space at the table, especially having had to say to Sally that she needed the power point for me and with Irene in a corner spot. Simone says she'll sit there so she can see out into the reception area. The door is always left open during the meetings, I suppose because everyone is in here. I'm on the cabinet behind Tamika with my microphone stretching to sit beside her.

Like Paula, Pat has a filofax but also an A4 book. Sally has a diary, Irene a pad, May, Jo, Susan and Prue all have A4 books, Simone a green A4 pad and Kim some papers.

Prue says hi and that she has "just got a few just bits and piecey sorts of things" as pages rustle around the table. There are no other voices now. Prue does not pause, telling us that she now does monthly reporting through the management team as part of our performance agreement. There are three areas, including competency standards registration. Prue reads a list, and says that's what we've got. Cups going down on the table make a noise. Though I've recorded the words, I haven't really followed what Prue's been saying. Tamika hasn't seen what she's talking about. Pat 
asks about some others of these things. May asks whether something is going as is, or out one more time. There's a discussion between Prue, Pat and May about whether it's ready, or needs to go out again and what should be included. Sally leans back and Tamika can no longer see her. Pat and Prue are facing each other today, sitting at either end of the table. Pat, with May also saying a few things, says some more service delivery is needed and there needs to be some "gutsy discussion", and that she knows Prue disagrees with something she's saying about developing other areas. Pat says she'd "like to go out and talk to people about it instead of you know it being the way it is how it just sits". Prue is saying remember why. She says if we are going to do that, so that it won't hold up registration, it would be a separate project, with a project team. Pat says yeah because they can't advertise until some work is done so it's quite urgent that they discuss this. May says they've ended up using the generic ones. Prue says Ok, and that she'll make a note. There's a pause while she is writing. I can hear her speaking quietly and there's rustling - perhaps she's turning a page? In the 900 or so words that I've recorded to here, we've started the meeting and discussed the first topic.

Off again when Prue says Ok, something related - a new one of what they've been discussing. Prue relays what she's done and will do - getting a group together to do this work, layers of consultation, focus group, email group and if people are interested, they are to let us know. After a few sentences Pat asks who this is for. She's asking why and Prue, using her hands, is explaining, "we have a gap". Pat says Ok and right as Prue goes on with her talk about the higher-level qual being between "us and $O B D^{\prime \prime}$, and that that's how it will be because the research and work has been done. So, Prue says, the job will really be to match and get the balance right. Another pause. We can also tell she's finishing off because she tells us that's what we've got on the boil at the moment, and laughing, says Kim is relieved because she's finished with everything on her desk in this area. This is Kim's signal and she says she'll throw the desk out the window, and people laugh, quite quietly. Prue suggests Kim do it before BANA moves offices.

The office move is unsurprisingly, the next topic on Prue's agenda. Again the sound of flicking pages. Prue takes an ironic tone regarding the uncertainty about when they may be actually moving offices. Jo and Susan respond likewise - they laugh. Prue says she and Maude have prepared three options (Tamika will be worrying again that she doesn't have this document, but nobody else seems to either), for the timing of the move. Prue says she favours doing it at the same time as OBD but is not bothered when that is. Awaiting a decision from above, but in the meantime they have shortlisted two office spaces, which Prue describes in some detail. Pat asks which floor the second option is on. Prue says they are producing sketch layouts to show how BANA would fit in and she'll let us know how, where and when. There's a pause and Kim 
asks about moving in December and about leases. Prue talks about space. Kim asks another question and Prue talks a bit longer, petering out, saying she'll let us know.

Next topic from Prue - position descriptions. She's working on Pat's, but wants to accelerate them so they're all done by July. Prue talks about competency levels and what she's been doing as part of this work. She's talking about everyone being able to see how they fit and says she knows the admin team wants to work together on making sure there's a good alignment between the roles. Prue asks us to look at the QTs, which others appear to understand because they're writing. She tells them to remember they've been written for a policy shop and that people won't be, like a 2, but will be a 1 sometimes, a 3 sometimes, which she says is absolutely fine. Apart from Prue speaking, all else is quiet. She seems to have slowed - there's a pause where she takes a sip of her drink. And here's the change in topic, signaled with "kind of in line with that" and she's emphasising the word "team" as she uses it a number of times - admin team... fieldwork team. Tamika is writing, noting this talk of organising the organisation. Prue says the admin team is going to be meeting together in the same way that the field team does, with a similar set of discussions. There's a need to put it all together so it's clear. I don't understand what would be put together. Pat says a few words, but Prue is saying everything from those meetings needs to come to "this group" but not coming up through her only, and she laughs. She says it might be useful to have "a reporting back" because "that might be another way of just keeping things going".

And onwards, Prue says "in line with that as well" and struggles to describe what she's moved to. May helps out - relationship management - and Prue starts to talk about these diaries for our members. She asks us to go back 12 days to the beginning of May and record all external meetings and significant communication, and people write. She's speaking slowly, laughing a bit and changing her voice when she tells us to use judgement here about what is significant communication, otherwise we'd be "filling the damn thing in all day". The idea is that after this effort, we will all know what's happening. Prue thanks everyone, and Sally, for doing that, but I'm not sure what Sally has done. May says cool and there's more rustling of papers and a pause. We wait.

Prue says she has had feedback from two different directions about subsidies. There seems to be a problem, which Prue says could be crossed lines (so she's not blaming anyone then), but she wants to make sure everyone's clear. Pat asks which organisation said this, and Prue gives some more detail. There is a discussion. Prue says "just be aware there's an erroneous perception out there" and that we should correct it if we get a chance. Prue says it reminds her to have a clear statement on their website. The conversation has dried up and Prue seems to be reading to herself, saying "er". Pat jumps in to ask about the cap and there is discussion. Maori and 
women are mentioned, with Susan saying key groups, which creates some laughter and use of ironic tones. I get the impression that they're saying the cap isn't relevant to BANA. Yet, Prue says she saw Paul in the street and he wants to come and talk to us. As usual, I don't follow all of this as some of the others seem to when Prue says, "so a bit of I told you so there". May, laughing, says "exactly". Another um, another pause.

Prue, looking at her book, says Irene is flying out. Irene talks about her visa and dates. Prue wishes her luck and tells her to stay away from any places with SARS.

Prue announces a moderation meeting tomorrow and May jumps in to ask if the time is Ok with everyone. Prue asks May to remind us about the preparation needed and people laugh. Pat and Susan add to the discussion. Prue asks another question, which May answers. May and Prue say yep, yep. Paula and Kim are talking in the background. I can hear their voices but not what they're saying.

Prue says that's it from her. She's busy this week but next week is suspiciously clear. There's a sound of flicking pages so perhaps she has a diary of some sort in front of her. Kim says something and laughs. Prue says she is working from home next Weds am, not in a meeting but working at home, so perhaps she has a printout of her electronic diary with Wednesday morning blocked out as a meeting. Right she says, that's me, and we're into the usual round-the-table update from each person. I know about this, for one thing, because Prue says "Simone". It is also what has happened in the last four meetings l've been at.

Simone starts talking about waiting on subsidies and the special invoice Org $A$ are insisting on. Pat says that's incredible, and there is discussion of it being embarrassing for public relations. Prue will write a cover letter explaining and apologizing. She says we should then be fine. Pat continues expressing her concern, but Susan is saying the people she's spoken to seem disinterested. Paula and Simone are talking behind Kim's back while Pat and Susan are saying oh well, and doing a bit of laughing. Prue asks if she can add something, and the many voices stop. She talks about words being dropped from the "gazetted coverage statement", and Susan expresses surprise (Tamika is looking at the document in front of Kim - minutes of a field advisors meeting held yesterday). In a cackling, witchy-poo voice Prue explains that this means we potentially cover entire organisations, and someone says "good". Prue carries on with what this might mean, making a joke and people laugh. She starts to hesitate and Pat says this could work out quite well and talks about the growth stuff they looked at yesterday. Prue and Pat discuss possibilities for numbers. Prue and Susan are joking and laughing. Prue says, "sorry that was just an aside really", returning the talk to Simone.

The talk is not back with Simone for long. She says five words and then Susan asks about timing of the subsidies. Simone says something, but I can't hear her and Prue 
says they're monitoring it daily. Simone says that was the only important thing and asks about the forums she knows are coming up. Pat answers, and Prue confirms she's down to do the first one but Simone says sorry, that is something else. Pat says "Ok we need to get some clarity round this" and provides an explanation of what happened. I wonder whether perhaps Simone needs to know so she can do some of the administration tasks, but was she not part of this decision? Pat says they will bring a list to the next staff meeting but Simone says she sent them out and they discuss what's happened so far. I find this confusing; I'm unclear about who knows what. Pat talks about having more structure around the forums and seeing how it goes. Prue says the survey feedback was that people valued face to face. Simone says that's all, and everybody else is running smoothly from the sounds of things. A pause. Prue says "Kim".

The meeting is not yet half way through. Tamika wants to say something, so I will pause also.

Not yet half way. Along with the tape-recorder, I was there at this meeting, but I cannot remember proportions of time such as this. My material accomplices, like the taperecorder, have made this statement about half way possible, as they have made this narrative possible. This estimate of time is made up of an indication given by the word count of the transcript; the note I made on the day in my notebook, and in the computer document once back in my office, that the meeting lasted from 9 am until 10.20 am; and the one 90 minute tape I have in my collection. I have been listening to that tape and side $\mathrm{A}$ is about three-quarters of the way through. So, three-quarters of 45 minutes means there's about 10 minutes to go. So we're about 35 minutes into the meeting, which lasted 80 minutes. These objects tell me we're not yet half way. Already though, there are a number of areas of work, or concerns, that have been attended to more than once in this meeting. I will draw these together later in the chapter. For now, let's continue with meeting five.

Prue has announced Kim's turn, though why she needs to say her name I'm not really sure. We all know that where we're sitting at the table determines the order of our turns - we go around the table during this roundtable part of the meeting. Prue is facilitating I suppose, for one so that no one takes over too early, or leaves their start too late. Still, seems a bit unnecessary.

Kim starts by saying Prue has already said her "desk is clearing". Does this mean that she agrees with Prue's assessment then? Kim says the most outstanding work is forensic mapping, and that they've had a wonderful conversation with Bill. Who they are, and who Bill is, are unclear to me. What is clear is that something good has happened - Bill has got something "spot on", which means something can go over. Prue, Pat and May are making short comments, like good. They continue to do this as 
Kim carries on talking about her work, evaluation... compliance... by Friday. They laugh about the language Kevin has been using like "disturbing influences". She talks about an unusual message that comes up from the seamail (or perhaps it's "cmail") system Kevin uses. Prue says it's a warning to her because she's been deleting them and missing the contact Kevin has been trying to make. She tells us to be aware. Susan sums up: "so check for attachments" and Prue repeats this. Kim says "and read them" and someone laughs. Simone asks whether a message has been sent to staff about the use of seamail. There's a discussion and laughter. Kim says she doesn't think it's a problem because not many organisations are using it, which ends this part of her turn.

Kim talks about boundaries and work areas, which came up in the admin team meeting last week, and she suggests that she takes the requests for evidence guides rather than Simone and Pat. Pat is enthusiastic and Kim says, "I'm the only one that really knows". After a few turns, Simone makes a suggestion and Prue is hesitating, talking about the website, agreeing that one person would be a good idea. I can hear murmuring. Pat starts to speak about something that came up yesterday, saying, "just to give an example". She's making a suggestion but Prue is saying we will, explaining about the website. Pat is saying yeah as Prue speaks and asks a question. Prue continues to explain and Pat says "very $\mathrm{cool}^{\prime \prime}$ in a different voice. Prue carries on talking about how it will work, and she and Pat seem excited about the possibility that the website will save them time. Prue asks an ironic question and they laugh. Pat asks Kim a question about a timeframe because she is putting something together. Kim explains, Pat says "OK" and "cool, cool". Kim has a question for Pat too, about how to write them. Pat explains. Kim asks about clumping and getting moderated. Pat explains what she's been doing - cover sheets. Prue goes to the whiteboard, boinging the metal legs of the chairs on her way, and explains what Robert has been doing. As Prue speaks, Pat says yeah, oh Ok. Someone is coughing. Prue says, "which is good assessor practice" and May starts adding yep yep. May asks Pat a question and the three speakers agree it's not different from what they've been doing. Prue says "OK so" and tentatively sums up the discussion - that the requests go to Kim. May asks how far away the website is and there's laughter. Simone says she's sent a message and is hoping end of the month. Prue says it will be up, but there'll be a message saying it's not fully populated, and that Sally has done everything she can. The tape runs out and Tamika turns it over.

Referring back to Kim's discussion, Sally asks who gets the emails from the BANA email address. Prue says she thinks they go to Simone. Sally, Prue and Pat make brief statements, before the talk settles on Prue saying they're doing it this way, rather than the website giving a whole lots of addresses for different things. Susan talks about training results emails, saying what she and Irene do now and what should happen on the website. Simone says they all come to one address and are then sent 
around. Susan says she was just thinking a generic address and Pat says there will be, with them going to Simone. Susan seems unsure, asks a question and then says she'll "come back to you on that have a chat", and Prue says Ok. There's the sound of pages rustling. The discussion isn't over; we are confused, trying to sort it out. Susan is replying no to Jo. Again there are multiple voices and Susan is explaining there's a chance she'll accidentally not pick up things with emails coming to her as a person, there are so many. Prue is trying to speak but Susan carries on. Prue clarifies but there's a pause - we're still not understanding this. Sally makes a suggestion. Susan replies. Pat is concerned that she's getting missed out of the loop, a discussion is needed she says. Susan explains and Prue, speaking slowly, attempts to clear this up. Susan says yeah and Prue says this isn't a website thing. Susan says but it makes sense to. If they are now clear, I am not. Prue, laughing, asks if there's anything more from Simone from round the table. We were in Kim's turn, remember. Paula asks if Kim's finished and Prue says quite loudly "Paula".

Pages are rustling. Paula says she's visiting and hoping to have this finished by the first week of June when there's a workshop, which May will be coming to. Prue coughs. Paula says they spoke highly of the programme. Prue is saying oh yeah, right. Paula is talking about the "hard copies" that Mike is sending and that she's got to ring the managers to get some feedback. Prue says it'd be great, and asks about specific feedback. Paula says she's waiting on something but there was either a big group or spread. Pat says yeah they'd had that another time. Paula talks about something else Mike will be working on, and Prue says that reminds her, and tells Simone to transfer the subsidy. Susan seems surprised and asks for that to be said again. There is a discussion about this, but there are people speaking at once and I can't hear. Susan says it hasn't been recorded, she can tell us that. She's saying what should have happened. Confusion again. Paula says Ok got it, she wasn't aware of that. Prue is explaining further. Susan says the process is not robust enough but Prue says it was a one-off and therefore she wouldn't expect it to be robust. The talk is disjointed. Paula says what's she's done, which she says now seems to be wrong. Pat halts the discussion. Ok, she says, "this is how we need a bit better communication round this stuff'. Simone goes out to a visitor who has arrived in reception. Prue, speaking clearly, says the material sent had made it clear. Paula explains her understanding. Prue says BANA has covered costs and that is all. Susan is saying the admin didn't happen, so in future with evaluation, heaps of to-ing and fro-ing. Prue says yep Ok. Pat repeats that it's about communication and being clear when a course gets started, we need to have a meeting so we all know the story so we don't waste time. Susan says she's probably been telling people "fairy tales". Prue says she thought they had talked about how they were going to run the course, but that Paula wouldn't have been part of it. Prue reiterates, and Pat says it's a good model to set up. Paula says that's her, Prue "okey doke", and there's a pause. 
Tamika's name isn't called but she starts to speak, saying her research is going well. She's getting used to the process of coming here, taking notes, transcribing. She's coming to the end of tutoring. Prue says Phillipa is here to talk to people about travel so she'd like to go around the table fairly quickly and those who travel will stay on. She says we can always reconvene if we need to - probably not Tamika and I, as we leave the building as soon as we leave this room.

Right, Prue says. Pat starts speaking, saying her stuff is about $\operatorname{Org~} \mathrm{H}$, she's been to see them, sorted out some stuff. Robert is taking over although Pat says she needs to discuss this with Prue. Pat wants to talk to Prue because Prue's been talking to one person at Org $\mathrm{H}$ and Pat another and "so there seems to be a bit of cross communication not happening there". Prue says yeah, well, she hasn't had discussions in any detail. Pat says they've had a planning day and she talks about that. Tamika sees that Pat has a field advisors' planning day document in a clear cover with holes for a ring binder in front of her. Pat says they all understand STMs more now. She tells Susan they did a brainstorm on what they'd see in the development of the new database. Susan says oh excellent. They'll meet to talk about that. Some good material from Otago University, she'll talk about that another time. There's paperwork coming in for Irene from Org A. Prue says some have been trickling in and Susan agrees. They discuss this briefly, finishing off: yeah, OK so, and Prue says "goody, Sally".

Sally is waiting for a reply to her email to Bob, so there's nothing to say on the website. She turns a page. She's got some contracts to deal with for Susan this morning and she's got to leave early this afternoon. She'll catch up with Irene, and she's told Simone she's got space if there's anything urgent. Susan, laughing, says we're getting Org A. Sally says yeah those training agreements are coming in. Pat says there are about 80 and Susan says yep, Sally says cool. Kim laughs and says something about the timing, which I don't catch. Susan says she thought it was 60 , but Pat that there'll be a few extra, and confirms, about 80 .

I can't quite hear what is being said because the room is quiet, rather than the other problem of multiple voices making what's being said hard to hear. Irene says units and um and pauses. Susan says they're all on yep. Prue is saying something I think but it's quiet still, and unclear. It seems the transition to May has occurred. She says she hasn't got a lot at the moment. Prue says tripping around the countryside and Simone asks when her next trip is. May hesitates and says City B, but she doesn't remember which day, it's not that far away. Paula, I think, says twenty-ninth, and Simone says oh, it's one she's already got. I don't know what she means; perhaps Simone produces a schedule of trips for the office? Prue says " $\mathrm{JO}$ ".

Jo talks about modern apprentice visits and sorting the workplace assessor situation out. Prue is looking up at Jo and then back to her book. She might be noting the 
details of what he's saying, but she might not be. There's a meeting he and Pat have got this week with Org B, some stuff with Org I on the boil, and resources projects which he needs to get up and running. He hesitates and Susan asks what that is. Jo explains its resources and links to resources for the three main BANA quals. Susan says "ah" a couple of times and "sure" as Jo explains that they're customer service, business administration, and first line management. Susan asks whether that's for MAs, or ITFs and MAs. Jo says both. Prue says that's about identifying, but I don't catch the rest. Susan seems to be positive. Prue says "Susan".

Susan says Ok, there's rustling, she hesitates. Prue says, sorry, did you have something. Pat stumbles, saying yeah yeah yeah, there's something we'd heard on the grapevine that Org $\mathrm{J}$ had gone with someone else after BANA had done a lot of work with them. She's saying that's Ok, but it would have been better done at Prue's level. Prue asks questions. Kim is saying how she found out, which seems to be a funny coincidence. Susan is laughing, so are others. Jo is saying how they lost someone else and Prue is saying but they've gone for the agreement... Jo and Pat tell her no they haven't, or won't, because they don't want to be tied into a contract. Prue is disagreeing. There's a pause and Pat says hmm, we need to talk about that. Jo carries on with what options they'd given them. Prue still isn't clear and Pat and May are explaining. Pat is saying these are two huge organisations that we've done work with. Prue says yes. Pat continues, saying that when the person they had been working with left, "we kind of lost it". She and Jo had tried to do some stuff but it needed to go back to Prue for her to go down there. Pat says we need to talk about those sorts of things; it's a risk-management thing. Prue is clarifying that other organisations like BANA can't offer anything different. Pat confirms. Pat is saying there's someone who started up the qual and Prue says " $a h, O K$ " in a knowing kind of way. Jo says it's a flexibility issue that they're wanting. Prue says they could've just have had the one, and Pat confirms by repeating yeah. Prue seems resigned, oh well, Ok and there's a longer pause. Prue says "Susan".

Susan announces a database update and runs through dates and the work. She's looking at her book. She's explaining why it's sensible to give us a bit more time. The training results report has gone out and she may come back to Paula and Jo about the MA report. She's had a wee bit of feedback from someone who found the process confusing. Susan says "reading between the lines", she probably got no information and didn't know what to do. Susan is saying it might be quite useful, but Pat asks which organisation it was. Susan is hesitating. Paula suggests $\operatorname{Org} E$, perhaps a specific person that she has met with. Susan isn't sure and she's moved on, saying it would have been useful to go through a pilot process. She's been thinking, and from today's meeting it seems the quality of information people are sending is still too poor, which is an indication they don't know what the story is. She's saying rather than go off on her own, perhaps she'd work with the field advisors team to look at information 
going out and how it can be delivered, possibly website and revision of process information. Pat says fair enough, yeah. So, Susan says, she's just flagging that and is proposing when, May is saying something, but Prue is speaking also. Prue is saying the quality of the information coming to her is decreasing, and Susan repeats that Prue is not happy either. Prue is saying there are some main offenders; they're not getting the full pack. There are multiple voices with Prue's emerging, saying that hopefully these things will be sorted out once we get the website. May, and someone else, says yep. Prue is talking about the problems. Jo mentions old forms. Prue says she is "putting a lot of faith in the website having current information", but Pat objects, saying we need more than the website. Prue is saying no, not the only thing. Pat says if they don't come, we don't know about projects and we can't coach them around systems. People are agreeing and Susan says it's interesting that Pat is not getting information from these people. Prue looks at her watch and is holding her book. Pat says "oh no". Susan is asking about a central co-coordinator in that organisation and says there are indications this isn't happening either and they're not putting thought into it. Pat is saying that's not how they work and Jo adds his experience. Susan is saying it's about being new to this area and systems. Pat says they have got systems because that's what she spends her working life doing, but she says, it's about how they're used, basically. Prue is saying Ok, but the discussion continues on a bit. Pat is talking about when people leave positions and the issue she's finding with high turnover. May says, "show us a department". Kim says it's whether they're attached to individual people. Multiple voices.

Prue is announcing the people needed to meet with Phillipa. Kim asks when the field advisors are meeting. Pat says 11 o'clock, cool, thank you. Very quickly people are off. Tamika asks what's happening next, and Pat tells her it's about travel, a separate thing. Tamika starts packing up to leave. Some people are meeting with Phillipa in the room as we leave the office.

\subsection{A few observations about the meeting room}

This space, this room in a downtown Wellington high-rise, is one of the many things that made this gathering a BANA staff meeting. Apart from a pillar, windows run right along and half way down the wall opposite the door. The blinds were usually up but when it got cold in winter they were lowered. Underneath the windows were two cabinets with sides the same grey as the table top, and wooden tops that protrude slightly. Each cabinet had two metal handles and a lock. They were not quite the same height. An overhead projector always sat on the cabinet closer to the north end of the room and there were usually pens and holder and a spray for cleaning the glass, nearby or on top. During the meetings I attended, the OHP was never used. A large dangling plant appeared on the 
neighbouring cabinet in August, but by the following meeting had moved to beside the OHP. The black plastic tray which sat on one or other of the cabinets was sometimes accompanied by handitowels, serviettes, kiwifruit, a plastic container (sometimes containing mints), calculator, cups, coffee and hot water, a toy, a newspaper.

There was a gap between the cabinets and the pillar, and in July an empty cardboard box appeared there. It had gone by 2 September. Attached to the south side of the pillar on the skirting board was a small white box. Running along the wall from there was an open panel showing wires. On the panel, which leant outwards, was another white box with four (perhaps telephone line) sockets. Above the panel and also further south were two electric sockets and switches. One plug connected the toaster, which I drew in my notebook for the first time in May. I used the other plug for the tape recorder. Below was what looked like an aerial socket. Against the south wall was a display cabinet with a glass top and two lower cupboard doors. Through the glass doors I could see a couple of books and what I assumed were gifts from international visitors. I used the shelf created by the narrower glass top for the tape recorder and stretched the microphone across to the meeting table to sit beside me. A spare tape sat beside it. My backpack and recorder bag were either beside the pillar or beside the display cabinet. The rest of the south wall stood empty until May when chairs were stacked in the corner. Opposite the windows was a large whiteboard screwed to the wall. It was not often used, losing out to the printable one standing against the north wall.

These are some of the obvious things I drew before each meeting (and photographed in August and September). But my bird's-eye drawings skipped other aspects of the room. Thanks to one of the photos, I can say the ceiling was mostly white panels, with surrounding metal strips. There were also two light panels, one of which had lost its covering, and two air conditioning vents. Perhaps being less frequent made other things less obvious, like the heater plugged in that time it was cold and Paula's bag when she was down from City A, and my camera bag a couple of times and the fan on top of the display cabinet. Also missing from my silent notebook was the constant traffic noise, but it is certainly there on the audio tapes. I was usually first in the room and so I often turned on the lights.

What is very obvious though, and demands to be put first in this description, is the meeting table. It feels like the object. Perhaps this is because all else (people, objects, machines, tea cups, documents, walls) were positioned around it. Yet, it was ordinary. That 
pale office grey with metal legs, that quite frequently boing as the legs of chairs collide with them, prompting us sometimes to comment on this noise. Made up from four components (two rectangles and two with sloping sides), configured to seat 10 people, the table only just fitted in the organisation's rectangular meeting room in their downtown office. Perhaps as a result of the tight fit, I too sat at the table. This spatial inclusion prompted me early on in my attendance to ask to speak during the round-the-table turns. The table had decided with its presence, its permanence, its functional pre-eminence. It was central, including spatially, with equal spaces each side and at the ends between the table and the walls.

The tight fit held what I considered to be an advantage for me, in that I did not have to put the tape-recorder on the table. I felt just that little bit less of an intruder - a little, but not much. During the first meeting I recorded I put the tape-recorder behind me on a cabinet with the small round microphone on the table. I asked the group shortly after the meeting started if this was $\mathrm{Ok}$, even though they had all already signed the research agreement, and said I was testing to see how it would go. Prue thought the hum of the air conditioning unit (she pointed upwards and I presumed this is what it is) may be a problem and I said, yes and the traffic. The week before, when I had attended the meeting to introduce myself, they had talked about wanting their new office to be quiet. I turned the tape over once towards the "end" during the roundtable. I was aware of the hissing and was relieved that the tape did not run out while Kim was speaking. I had forgotten to bring enough tapes for the potential 120 minutes Prue had said they allowed for the meetings. Because of the microphone cord, I was sitting near a leg of the table and when I tried to move in towards the table the leg of my chair clanged (loudly I thought) against it and I said "sorry" quietly.

\subsection{Using Becker's "Wittgenstein trick"}

This section of the chapter is guided by the narrative of meeting five in section two. As with producing that first-person narrative, I am the one who has labelled what it is that meeting members might be attending to. Becker says we constantly make choices when we write (1986b). I may have missed and misunderstood aspects of the meetings, but through this collection an attempt has been made to show the kinds of things attended to by meeting members. The aim of this chapter is to follow the action, which is the research 
move advocated by ANT. ${ }^{2}$ In this section I specifically employ Becker's "Wittgenstein trick" of asking just what it is that is required in order to make these meetings these meetings (1998 p. 139). The hope is to show the multiple and mixed efforts of meeting members. There were many difficulties involved in making separations because it is not possible to say meeting members were doing solely this, or only that. Separations are a way to present the empirical material of this thesis, to represent the meetings, and this is my task here (for a discussion see Becker 1986a p. 122).

Under the heading "following", I present some of the actions that made up this BANA staff meeting in the order they occurred in the meeting. The actions in this chronological list are labelled: "this meeting", "this organisation", and both. In the list are more than 50 activities and concerns attended to by members in meeting five. This list of actions, practices and skills are the kinds of things that collectively make this meeting. I move from following the action of meeting five chronologically, to discussing it, and in so doing, undertake re-ordering. Under "re-ordering", the actions of meeting members are grouped and combined with material from other meetings. Material from the other meetings is used to show that these are the sorts of things that commonly concerned the members of these meetings.

My process of description can be followed by reading the narrative above, looking at the list in Appendix one under A chronological set of actions from meeting five, and reading the list below. The sentences used retain a link back to the full narrative above and provide a way to look back at my summarising and selecting.

\subsubsection{Following some of the actions}

The numbered list below attempts to gather, in a straightforward and succinct way, the kinds of things meeting members attended to in meeting five. It is a representation.

1. Who is here, and so, who is "staff". [This meeting and This organisation]

2. Agenda-making. [This meeting]

3. People settling in (cannot be separated from agenda-making). [This meeting]

4. Discussing documents. [This meeting and This organisation]

5. Where to sit. [This meeting]

\footnotetext{
${ }^{1}$ See Appendix two for the conventions used to indicate quoted meeting talk and concepts.

2 "Following" as a way to research is discussed in chapter three.
} 
6. Greetings and starting this meeting. [This meeting]

7. Accountability 1) to others and 2) to this group. [This organisation]

8. BANA products are in no specific place, but moving. [This organisation]

9. Clarifying understandings. [This meeting and This organisation]

10. Work timing. [This organisation]

11. Getting face to face. [This organisation]

12. Compromise. [This organisation]

13. Keeping track, being reminded (using personal things to write on). [This organisation]

14. Organising this meeting (1) (by producing a link). [This meeting]

15. Groups (finding people to do this work). [This organisation]

16. Talking as if writing (people are to let us know if they're interested). [This organisation]

17. Target market/intended recipients of BANA products. [This organisation]

18. OBD/other organisations. [This organisation]

19. Defining the next task; example of doing consultation. [This organisation]

20. Comments on other people. [This meeting]

21. Irony/showing we know. [This organisation]

22. What's not in the written report. [This organisation]

23. Waiting on the hierarchy. [This organisation]

24. Describing - the description is tailored. [This meeting]

25. Their employment. [This organisation]

26. Working together and sharing information/communication (1). [This organisation]

27. Perhaps seeking alignment (between the documents or the people)? [This organisation]

28. Comparison with other organisations (us and them). [This organisation]

29. This organisation (us). [This organisation]

30. Working together and sharing information/communication (2). [This organisation]

31. Sharing information/communication (3). [This organisation]

32. Money (1); information. [This organisation]

33. What's happening "out there" (in the field). [This organisation]

34. Communicating outside BANA. [This organisation]

35. Irony/showing we know (2). [This organisation]

36. People going away. [This organisation]

37. Other meetings (arranging) (1). [This organisation]

38. What's coming up. [This organisation] 
39. Organising this meeting (2) (roundtable). [This meeting]

40. Money (2). [This organisation]

41. Other organisations (2). [This organisation]

42. Asking permission to speak. [This meeting]

43. The future; target market/intended recipients of BANA products (2). [This organisation]

44. Apologising for speaking out of turn. [This meeting]

45. Other meetings (arranging) (2). [This organisation]

46. Working together and sharing information/communication (3). [This organisation]

47. People doing work for BANA. [This organisation]

48. This organisation (3). [This organisation]

49. Giving an example; other organisations (3); comparison/good practice. [This organisation]

50. The website. [This organisation]

51. Working together and sharing information/communication (4). [This organisation]

52. Organising this meeting (3) (roundtable). [This meeting]

53. Organising this meeting (4) (roundtable). [This meeting]

54. Being "out there" (in the field). [This organisation]

55. Problem - individuals leaving other organisations. [This organisation]

56. Visitor, and ending this meeting. [This meeting]

\subsubsection{Bringing in material from the other meetings}

Headings could be applied to divide these actions from meeting five into different stages. The stages would be something like:

- Arriving and starting the meeting (actions 1-5);

- Items of work and other concerns (actions 6-38);

- The roundtable (actions 39-55);

- Ending and leaving (action 56).

Looking at all of the meetings, members attended to arriving, who is here, taking seats, making an agenda, discussing items of work, the roundtable, and leaving. However, you will notice from the narrative of meeting five that efforts by meeting members to achieve these different parts of the meeting begin well before they occur, that is, in amongst discussing other topics and doing other things. For instance, when Prue asks meeting 
members to "go around the table fairly quickly"; she is working on ending the meeting well before the end of the meeting. Temporal divisions are difficult to make for this one meeting and all of the meetings I attended, apart from saying that at some stage, members attend to beginnings, agenda items, roundtables and endings. These meetings are temporally mixed. The members do what makes sense to them at the time. Things vary, and meeting members vary their actions accordingly. For example, in meeting five, we hear Prue ending her roundtable when she says, "I think from me that is pretty much it". When she started doing her roundtable is unclear. There was no announcement. Was it in amongst the agenda items, or was it that there were items other than May's? Rather than be concerned to see when different sections of the meetings occur, it is useful for understanding how these meetings are made to gather together the similar activities of meeting members.

I have separated some of the actions according to the labels in the numbered list, becoming more speculative as the chapter progresses. By drawing in material from other meetings it becomes clearer how these meetings are what they are and how they are unlike other meetings these people might attend in their working days. That is, the content of these meetings. In this move, I have ceased to follow the action somewhat, in that I have chosen what to discuss, and when. The first group gathers actions that make "this meeting". The second group is concerned with belonging in the meetings and to the organisation (BANA). A third grouping is where meeting members can be seen as attending to the organisation (BANA).

I have presented the sentence or sentences that are examples of what I have selected to discuss from meeting five. You will know them because they are still formatted as if they are the tape-recorder's voice. Under these examples from meeting five, I discuss similar actions and talk from all of the 14 meetings I attended. Like the narrative and the lists, presenting combinations of description and transcribed talk is another attempt at showing something of the meetings, and some of the things that made the meetings.

Meeting members achieve these actions in different ways. Three clear ones are confirmations, which have been set up a prior action or assumption, like meeting times, beginning, agendas, the room and the people present and the minutes. There are actions that are accompanied by an explanation, like when Simone said she would sit where she could see out of the door. There are also self-sufficient actions. For example during the roundtable calling a name is an instruction for that person to speak. 


\subsubsection{Following: Organising the meetings}

The actions discussed here are the small, ongoing, efforts that bring the meetings into existence. The first time I created an ideas document after attending a meeting I had the heading "Organising these meetings" where I had in mind something like organisation, or structure or routine. However I had also noticed small, but seemingly vital, practices that kept the meetings moving. An example is linking, and in June the heading was "Links or organising this meeting" (see the section Linking in the meetings below). After the meeting on 8 July I started using the heading "The work of making the meeting". This heading was used to gather actions like Prue's comments about keeping these staff meetings going. Under "carrying the load", I speculated about whether Prue had been missing Pat's input in the previous two meetings when she reassured Paula (who was on the polycom) that she did not usually do all of the talking herself in the meetings and that having few speakers was unusual.

\section{Agendas and writing objects}

Prue asks if anyone has anything specific for the agenda (action 3).

Prue was not the only one who did facilitating work in the meetings, though as in meeting five, it was usually her. This work was a responsibility that someone else took on. The one time Prue was not at the meeting at all, Simone did this work. Like Prue, Simone commented on how the meeting might be or had been:

Simone: I've only got two things on the agenda that she's asked me to bring up anybody else got anything that they want to put on the agenda (plates scraping) might be short and sweet this (unclear) (laughter)

Making an agenda was part of organising these meetings, as Simone attends to here. When I returned to my office to write about the meetings, where to place "agendas" was problematic because they are documents, objects and processes. Agendas appeared in different places and forms in the meetings. They were used to start meetings, involved in settling in, and throughout the meetings. There were meetings where the agenda and Prue's roundtable reports blurred together. There were also times when Prue announced the beginning of her roundtable turn (2 September).

Agendas were written on the whiteboard and show the involvement of writing objects in the meetings. Prue used the agenda to organise her talk in the meeting on 8 July, when she turned to look at the board and said, "um and I think that actually is everything". When Simone tried to get an agenda she said she had only two things on the agenda that 
Prue had asked her to bring up. Prue in the form of the writing on the whiteboard was in attendance. On 2 September Prue read the list from the whiteboard, achieving a call to order and showing awareness that Paula was attending via the polycom.

"Speaking to" an agenda item is a phrase commonly used, and doing something like "getting your hands on the agenda" allows you to speak. Gaining control of the agenda in these meetings was not straightforward however. On 16 September Sally moved the agenda from the permanent to the moveable whiteboard, and Simone asked whether there had been something up there. Certainly, the whiteboards gave off a strong sense of belonging. Perhaps it was something to do with their involvement or usefulness because, of the two, it was the printable whiteboard that seemed more solidly established here, in this place. The printable whiteboard was preferred. It was more frequently a use-in-the-meeting object or involved in the organising of the meetings:

(observation note: Prue wrote the agenda on the whiteboard:

1. Finalise Moderation Agreement

2. Re-cap Treaty Responsiveness

3. E-learning facilitator (18 March))

The whiteboards and agendas enabled work (in writing) to be seen by the people in the room. Writing objects helped in getting the work done. In chapters six to nine I consider the moveable whiteboard and its forwarding-on noise further.

Where to sit

Simone says she'll take her seat so she can see out into the reception area (action 5).

Prue always sat in the same place - in front of the printable whiteboard. My spot was what seemed, perhaps because of Prue's position and the door, to be down the back, which allowed me to turn and replace tapes in the recorder. Simone sat in Prue's usual seat the one time Prue was absent. Perhaps this is the facilitation seat, being so close to the preferred whiteboard. In the diagram of the table below this position is number " 1 ": 


$\begin{array}{lll} & 1 & \text { North } \\ 10 & & 2 \\ 9 & & 3 \\ 8 & & 4 \\ 7 & & 5 \\ & & \\ & 6 & \end{array}$

Position 6 (opposite Prue and beside me and the microphone) was the least popular, left empty half the time. The places almost always occupied were 7,8 and 9 , perhaps because they faced outwards to the street, as Paula commented on (19 August), so the people in them were not looking at a wall. People sometimes moved from their initial seat and I noted a variety of comments about this, including Simone's in meeting five. Here members accompany their actions of where to sit with explanations. Another example was the vocalised concern about balancing the table (16 September) once it became known how many people would be around the table that particular day.

\section{Starting the meeting}

Prue says hi to everybody and that she has "just got a few just bits and piecey sorts of things" as pages rustle around the table (action 6).

One signal that the business of the meeting was starting was someone speaking in the mode of meeting talk, as Prue did in meeting five above and here:

Prue: um I haven't got very much but I just wanted yesterday I circulated the um (flicking pages) ah... (5 August).

When Prue was not there however, meeting members still achieved a start:

Sally: I'll get my drink in a minute (unclear) shall we start (19 August).

For the meeting to be underway also requires everyone else to stop talking. Starts were achieved in other ways with other people and objects. On 22 July Prue held up the pink folder. Starting also required "just" the right people being present (see the section on who's staff below).

The regular starting time of every second Tuesday at 9am is another of the many things that make this the BANA staff meeting. Other examples of meeting times include: 


\subsection{0-10.30am 22 July 2003}

\subsection{0-10.15am 5 August 2003}

Knowing that a 9am start is usual prompts me to ask what happened on 5 August. That was the day there were visitors from the library who wanted to present their services to BANA. The event, the BANA staff meeting, was not recorded as starting until 9.20.

\section{Linking in the meetings}

Off again when Prue says there's something related - a new one of what they've been discussing (action 14).

When I presented my first writing from the research to some of the BANA staff members, they seemed interested, concerned and amused by the lack of clarity in the transcript extracts I had provided as handouts. For instance Prue, laughing, said they must speak in sentences. I had noticed how people carried on the conversations using linking words and topics:

Prue: and just carrying on from that customer service qualifications I've got them back from evaluation um it was the first time we'd used the simple template so of course we made twice as many mistakes ... (8 July).

Prue: um just on Friday by the way we've got moderators coming here I have to have Carl hasn't confirmed yet but Murray and and and Pat ... (16 September).

Sally: um and just while I'm talking about brochures ... (16 September).

Producing links could be said to be about continuing to hold the floor by not pausing. But these are actions that also keep the meetings moving along, briskly. Links were used to signal someone else to speak. For instance, I used the label "comments on other people" for meeting five:

We can also tell she's finishing off because she tells us that's what we've got on the boil at the moment, and laughing, says Kim is relieved because she's finished with everything on her desk in this area (action 20).

However, the action this utterance achieves is a signal to Kim to speak. Here, with a comment on someone else, Prue provides a link and does linking in the meeting - Kim speaks next.

\section{Going round the table}

Right she says, that's me, and we're into the usual round-the-table update from each person. I know this because Prue says "Simone" (action 39). 
Saying someone's name is a more direct way to make them speak next. In these meetings this was an action that was self-sufficient or self-explanatory. Usually after agenda items had been covered people took turns, in seating order, to tell what they had been, and would be, doing in the near future. This "future" was not necessarily only for the fortnight until the next meeting, but for some amount of time coming up. This part of the meeting was started off and described in the meeting as "going around the table" or "the roundtable":

Prue Ok let's do a roundtable and see where everybody is and what you're up to (18 March).

Though sometimes it was described in additional ways also:

Prue: so what I'm going to suggest is we go round the table and do our um general discussion and then we'll just finish off with this (2 September).

In the meeting on 2 September Prue was rearranging the order of the meeting because they were going to be discussing the layout for the new office space. This rearranging centred on Paula, who Prue suggested did not need to be part of this discussion. Paula was attending the meeting via the polycom, which sometimes sat in the middle of the meeting table. Prue did this rearranging with Paula. Once the time came for the office space discussion, Prue gave the signal. Paula had earlier said the rearrangement sounded good to her, but Prue sought Paula's confirmation here that the phone could be hung up:

Prue: Ok well I think that's all group wise

Paula: yep yep

Prue: um do you oh oh I'll get back to you it's just I'll get back to you on any items that come up in terms of the building

Paula: yep no that's fine I'm more than happy with that

Prue: but I think it's you know sitting pointing at a picture that you can't see and talking about things that are completely irrelevant to you isn't going to be much use of your time

Paula: that's cool

Prue: Ok see you Paula

Paula: Ok bye

Prue: Ok

Sally: have a good day bye (2 September).

Paula was a staff member and therefore should be at these meetings. However, like contractors (see Who's here and so, who's staff below), she was not based in Wellington and therefore did not need to discuss how to be day to day in this space with these people. 
In the minutes produced after the meetings, roundtables are called "individual reports", which brings to mind reporting, or accounting for oneself. I suggest this was what meeting members were doing, but not in a formulaic or mechanical way. Asking questions and clarifying what the speaker was saying during their turn was common. This is another example of the variation that characterised the meetings. Sometimes information was requested about particular projects during people's turns, like Prue asking Sally how the web was going on 8 July. This could be viewed as Prue checking-up, but Prue also assisted Sally accomplish her roundtable turn. It is an example of how organisation members work together. On 16 September the website was one of the first agenda items:

Prue: website

Sally: website Ok website (observation note: opens blue ring binder, which has A4 book and green stickee pad (looking thru sections (labelled) by holding up edges) um I've website is all I've done for the last two weeks I've done absolutely nothing else

Prue: excellent

Prue: and there's a lot of coming together of stuff there so would you be able to do that all of us here nearly all of us here (quietly) um we will undertake to go through that section and provide any feedback to you by Friday at the latest and if we've got that sussed then really we are ready to go up by the end of the following week possibly (moveable whiteboard: poss timeline) would that be

Sally: yep I haven't looked at the qualifications section because that's just a whole lot of linking across

Prue: right (16 September).

Prue shows high hopes that the website can help with BANA's workload (as discussed in the narrative of meeting five). It is organisationally important and Prue pays attention to its expected arrival.

\section{Speaking out of turn}

Prue asks if she can add something, and the many voices stop (action 42).

Prue says, "sorry that was just an aside really", returning the talk to Simone (action 44).

There was variety in the meetings but there were also many understandings about the usual way to do things. For example, if a question was not on the topic that the speaker had introduced during their roundtable turn, then the new speaker may seek permission to speak and then apologise. Actions 42 and 44 show an off-topic interruption during Simone's turn in meeting five. Here Prue returns the talk, and speaking space, to Simone. It was Simone's turn at talk, and Prue acknowledges that she has spoken out of turn. 
It is not that I am arguing that there are certain defined temporal spaces in the staff meetings, as I rejected at the beginning of this section. Rather I note here meeting members' understandings, and agreements. When they were doing the roundtable, whenever that may be, there were ways this part of the meeting was achieved, one of which was to acknowledge that the turn belongs to a particular person. It is not that the meeting must be returned to its core of agenda items and roundtables. What meeting members worked on achieving was this part of the meeting, and agreeing how to give everyone a turn at speaking was part of it.

\section{Meeting timing and momentum}

Awaiting a decision from above (action 23), but in the meantime they have short-listed two office spaces, which Prue describes in some detail (action 24).

Prue says Phillipa is here to talk to people about travel so she'd like to go around the table fairly quickly and those who travel will stay on (action 52).

Prue says some have been trickling in and Susan agrees. They discuss this briefly, finishing off: yeah, Ok so, and Prue says "goody, Sally" (action 53).

One way meeting members could be seen attending to meeting time and momentum was how long they spent talking on any one topic. In meeting five when Prue described the office spaces that had been short-listed it seemed that members moved on to describing particular things without announcement and without pause. This shows the concern to keep moving. Waiting for a decision from above did not slow them down. They maintained momentum, as there were other things they could get on with in the meantime. Meeting members could often be seen deciding the level of detail required here and now, and what could wait until after the meeting, or be delivered in some other form. They judged the amount of detail to give:

Prue: oh yes

Sally: that was really good learnt heaps on that

Prue: good

Sally: some of it good some of it bad (laughs)

Prue: laughs

Sally: um (unclear) Richards took that training

Prue: yes

Sally: so quite good ah won't go into detail about that um (2 September).

Meeting members showed concern to be careful with meeting time. 
Part of judging how much detail to give, and therefore how long to spend, comes from paying attention to the indications given by Prue and other meeting members. One kind of indication undertaken by Prue was predictions about the meeting. These may have been a way to indicate the length of time people should spend (for instance, in their roundtable spots). In the meeting on 2 September Sally said she wouldn't go into detail. Here is Prue's earlier statement:

Prue: (unclear) yeah um Susan will be here in just a couple of minutes um it's probably going to be a fairly short staff meeting I think

Paula: yep

Prue: today because um we're um May's not here yet um and Pat's away on holiday and Simone: (unclear)

Prue: I I only got back an hour ago so I'm still working through my emails um (2 September).

I do not label Prue's actions as sinister. For instance, Prue and I were alone in the meeting room on 29 April and she outlined, in similar fashion to 2 September, that the meeting would be short because two people were away and she was just back from the Easter break. I was now informed of what was likely to happen, though Prue cannot be seen as only attempting to direct my actions. I never took long with my roundtable turn. Here is the statement Prue made once the members were in the room for that meeting:

Prue: now I'm just expecting quite a short meeting today just to do a catch-up on everything 'cos um don't know about you guys but I haven't got very much at all I'm just getting myself (laughter and laughs) back into work and one thing and another I just want to do a quick catch up (29 April).

Is Prue directing what people should do? Can it be explained as the power she holds? If so, how can we explain Simone's prediction statement when she did the facilitating work on 19 August, that the meeting might be "short and sweet"? I suggest these actions can also be seen as understandings about how to make these meetings. Meeting members do just what is required.

\section{Ending the meeting}

There are multiple voices now. Prue is announcing the people needed to meet with Phillipa (action 56).

After the last meeting I attended (16 September), the heading I had been using about "organising this meeting" contained a question: "Organising this meeting (or is it organising in this meeting"?). In this piece of talk about ending this meeting we see Prue's work of making this series of meetings: 
Prue: great, well world record (laughter) thanks everyone and ah yeah I I think it's probably better for us to do this when people are away rather than try to postpone unless it gets to the point where there's only 2 people left (laughter)

(Someone): (unclear) you could have a good meeting

Prue: very productive (discussion (unclear) it just keeps us in the cycle so thanks everyone (unclear) (people are leaving) (laughter) (29 April).

As with a lot of what meeting members attended to in the meetings, this talk also attends to "what's next". It is an example of how, partly through Prue's effort here, the meetings come to be and remain. There are reasons for wanting them to continue on. Being a series of meetings enables ongoing discussions - about particular projects or pieces of work and positions, the thinking of members and the direction of the organisation. This is part of the carrying on of work, and part of working together. Confirmations of what happened last time and what might happen next time are frequently part of the meetings.

Like starting the meeting, various things are used along with the talk to end the meetings. For instance, the polycom helped with the ending on 8 July. I took the signal from Prue saying goodbye to Paula to turn off the tape, even though some people were staying to talk to Paula. The survey could be seen to end a discussion about whether to hold forums. Prue calls on help from what might be in the survey:

Prue: so think I just feel it would be a bit premature to say let's not do it, we're not doing this one, this month are we

Pat: no

(Simone and Sally): background tomorrow

Prue so yeah, so let's just wait and see if there's any, if there are any messages in there, if there aren't, there aren't (pause) um (pause)

Pat: (quietly) Ok (1 April).

\subsubsection{Re-ordering: Belonging}

In this section actions are presented that demonstrate how meeting members simultaneously attended to "this meeting" and "this organisation". Their actions are connected by the idea of belonging. Attending these meetings, discussing documents, and doing irony are acts of belonging to the meetings and to BANA. As I said earlier with regard to going around the table, there seems to be more to these meetings than mechanical accounting to others by showing the work they are doing, thereby how they are spending their time. In the meetings, members also expressed concerns and shared doubts, though these too could be seen as doing/showing commitment to the organisation by showing/doing concern for its well being: 
Sally: which I think people need to go in and have a look at um I haven't put all the links in there yet that you know going from one part to another um but that won't take long to do what I'm worried about 'cos Pat Pat has spent ages on this as well with me um going through the workplace assessor stuff... (16 September).

Paula: so that's cool um and we've got the first line management starting on the $22^{\text {nd }}$ and I a little anxious at the moment because we've got six people who are signed into it um but I'm hoping that a couple more from Org $\mathrm{K}$ they said that they had a couple of others and um yeah and maybe a couple from Org L so (2 September).

Showing uncertainty in the meetings is perhaps a way to do belonging. It may not be appropriate for contractors to show similar uncertainties.

Who's here, and so who's staff

One thing she's commenting on is that the meeting is a full house this time. May laughs, saying it's sold out (action 1).

What seems most often required to make these meetings, the BANA staff meetings are the people who attend. Contractors are not staff and one way this can be seen is by their absence in these meetings (I will refer to them as "non-staff"). These meetings are gatherings of the organisation and that seems to mean staff, employees, those with a physical base in BANA offices (Wellington or City A). Though it was more difficult for Paula to attend from her base in City A, Pat talked about Paula being there:

Pat: now were we going to bring Paula into this meeting (observation note: pts to middle of table) (22 July).

This work on Paula's attendance can be seen as Pat reminding everyone that Paula is staff, as well as working on her actual attendance and possibly other things, like starting the meeting.

One reason perhaps for contractors not being at these meetings was that they did not update directly. Rather, staff members working with the contractors reported what was happening with their work. It was who (ac)counts that makes up the head count it seems. For instance, Susan reported for Florry who, from the talk in the meeting, seemed to be a part-time data-entry person. In various meetings, including meeting five where I described Paula discussing the work Mike had done, Prue, Kim and Sally talked about what writers had done and would do:

Prue: um so I've said we'll do that and I've got Murray writing that right now so we will do that one and I think Hannah Mirren (8 July).

These contract workers can be seen as extensions of the meeting members who reported for them. It is not that the work they do is less real than that of the meeting members, nor 
that they were more closely managed (for instance, Prue says Murray and Pat will moderate each other's work), but contractors did not have to agree about ways of working together, like buying more milk if they had cereal in the mornings. There were no office relations with the contractors, so they would not be involved in a discussion of the disappearing milk. Contractors did not need to deal with the daily problems of working together in this space.

There were between seven and eleven people in the room during the meetings. Apart from me, Prue was most frequently at the meetings, missing only one and leaving early from another. Simone said Prue's absence in August was because she was "catching up on everything before she goes on leave" (19 August), which sounded strange then. At the time, I named this meeting "One out of the routine", perhaps because of Prue's notable absence. It was Jo's last meeting before leaving to join another organisation and he provided food from a bakery nearby. By the time I left, there were three fewer potential meeting attendees - Kim had left the organisation by July and May had gone on parental leave in August. However, many more people than these meeting members appeared to be involved in getting BANA's work done.

\section{Discussing documents}

Jo and Kim are discussing the document, saying a graph, a table, sorry (action 4).

In meeting five, Jo and Kim discussed a document as they settled in for the meeting. Certainly documents were used in this "in passing" kind of way. On 16 September Prue had a copy of a seminar brochure titled "Projects, objectives and deadlines" that she said she had gone through and held up to the members. Connecting it to their work as potentially useful perhaps, she said they were all into project management in various ways. Pieces of writing in the form of documents and the act of writing, was attended to by meeting members in many ways, like making notes to remind oneself. The meeting on 8 July showed this variation when there was mention of a form that recorded in writing what Murray would be doing. His name was put next to all the ones that he would be writing. Murray was not staff, did not attend these meetings, and could not put his own name against (or show himself as responsible) what he would do. Staff members did this, sometimes with the aid of documents.

Documents were also the subject of more extended discussions in the meetings. One kind involved in getting the work of the organisation done was the BANA products, or 
"quals". These documents are those produced by BANA and as such were not dealt with in a casual or disinterested manner. Here in the meetings, BANA's documents were produced, and their degree of completeness assessed. In the meeting conversation below, members are updating the workplace assessor manual (there is an analysis of another discussion about the manual in chapter six).

Paula: sorry

Prue: have you got a copy of the manual up there you will have won't you

Paula: um I'm not sure if it's the current one (pause)

Prue: hang on we're just going to try and turn the volume up

Paula: is this work the manual

Prue: the manual yeah

Paula: I I don't think I've got a one of the latest since the last redraft sort of

Prue: um

Paula: (unclear)

Prue: we redid it at the end of last year I think it was

Paula: yeah no no I haven't got a copy of that

Prue: Ok well

Paula: is it in the system though somewhere

Prue: ah yes it is (pleased voice) it's under

Paula: yeah I can just look at it

Prue: it's under workplace assessor manual

Simone: laughs

Prue: the latest um the latest edition

Paula: yeah

Prue: I think it might be the third edition I'm just not quite sure

Paula: yep

Prue: um we but um it's rather than you going through it and making a whole lot of changes that have probably already been changed

Paula: oh right got it

Prue: um I'm just wondering what the best way to deal with (2 September).

Here, meeting members are not sure of versions, and they work to establish who has, and has seen, which version in an attempt to avoid wasted effort. Though I have not developed it here, my description of action 8 was that BANA products are in no specific place, but moving. This constant action, this ongoing-ness is one of the major concerns of the thesis.

Along with the state of completeness, meeting members also made judgements about the worth of documents. For example, there had been talk of "an ugly unit standard" (2 
September). The concern seemed to be about improved documents, or documents not good enough to be used:

Paula: so that was pretty cool um and it was an ugly unit standard but (unclear) (laughter) with that quality management one

Prue: oh yeah

Paula: so I'm glad that's all over um tomorrow I'm going to Org $N$ to help them out with their moderation stuff (2 September).

The earlier discussion, on 8 July was also about not using something:

Paula: Ok

Prue: and I think that was the one that they were looking for but the others no we won't touch them um so so if anybody starts saying we're thinking of using the quality management standards just recommend that they hold off until the new ones come out 'cos the new standards are going to be so much better than the

(Someone): great

Prue: current ones are so awful... I don't see those as a top priority unless the original standards were absolutely awful like quality management ( $8 \mathrm{July}$ ).

Being able to judge the quality or completeness of BANA's written products holds many opportunities for showing belonging. Having been involved in the work, making judgements about documents shows your presence in this place.

\section{Irony}

Prue takes an ironic tone regarding the uncertainty about when they may be moving offices. Jo and Susan respond likewise - they laugh (action 21).

Another way belonging was shown in the meetings was members making ironic statements, and using an ironic tone of voice. Meeting members' uses of irony, in the mode of "of course this will not happen" is one way they indicated that they knew what does actually happen. Taking the opposite of what they have said shows what they think will happen:

Simone: I' $m$ hoping to get them done by the end of this week as long as I've got no meetings and nobody bothers me (laughs) (2 September).

In this way meeting members undertake showing that they know without saying so directly. In the example from meeting five above (action 21) Jo and Susan responded to Prue's use of irony. However, this was not evident when Simone made her statement. Prue used irony to achieve acceptance that when they would move offices was uncertain. Prue's use of irony was returned, the situation was understood. Simone also shows uncertainty in that whether she would get the work done also depended on the actions of others. 
Looking at the use of irony in the meetings is useful for considering how meeting members achieve multiple actions. Here I have in mind using irony to show belonging and as a way of working together. Irony carries strong connotations of being in the know, which is something they achieve together. In the following section I draw on examples from meeting five where meeting members could be seen working on ensuring they are, as an organisation, in the know.

\subsubsection{Re-ordering: Attending to BANA}

Members attend to the organisation through their work in the meetings. In this section I consider actions from meeting five that show members working on working together. The material below is structured to show increasingly explicit talk by meeting members about how to work together. In contrast to earlier sections, there is very little material from other meetings included. Meeting five contained enough material to demonstrate meeting members attending to the organisation. This indicates a key set of activities of these particular meetings.

\section{Remembering, being clear, and what to do next}

There's a sound of flicking pages so presumably she has a diary of some sort in front of her (action 37).

There were more obvious ways that meeting members were attending to working together than using irony. One of those was to make notes in order to remember the decisions they had made together, or actions they had said they would take after the meeting. Writing objects were involved. Remembering seemed to be one reason to bring these objects to the meeting room, like using diaries and books to remember to tell about what they had coming up in the near future, and the work they had done in the recent past. The whiteboards and agendas enabled work (in writing) to be seen by the people in the room, but there were also individual writing objects, like notebooks and pads. These were very often, but not always present. On 15 April, people had their A4 hard cover books. Irene had a shorthand notebook. The next time, fewer people had A4 hard cover books but this may have been because of the particular people who were not there. Irene had a shorthand notebook again, Simone had an A4 pad and Prue, Susan and May had A4 books and other documents (29 April). On 8 July, May talked about there being new books (referring I think to the red A4 hard cover books in the room), and Sally said she had grabbed one. Diaries were less frequently present than notebooks, though they seemed 
important to the work outside and beyond these meetings. Sometimes people had printed out pages from their electronic diaries. Often people would say they would make arrangements to get together after the meetings.

Another writing process, or object they attend to, are the minutes or "Staff meeting notes". These notes also helped with remembering and were involved during the meeting. On 2 September Prue spoke as if she was writing, perhaps in order that a note would be made of this action she needed to remember:

Prue: Ok well um action for Prue organise graphics design work on our letterhead (notebook: so Simone doing minutes) (2 September).

Producing these records of the meetings during the meetings, and afterwards, is not easy however. In the meeting on 19 August, Irene was trying to write the minutes (Simone was helping), which seemed to be difficult perhaps because the roundtable and discussion was not orderly. On 18 March Prue explained that she had not had a chance to do the notes yet:

Prue: And the other thing I've not yet done is got the notes out from last week's because I just haven't had time to sit down at my computer and put them in. But I will definitely do that. And I think some of the things have already started to happen anyway umm (18 March).

From Prue's statement we can take it that the notes were wanted, or expected. Perhaps the members had agreed they were needed.

Certainly, information was a concern in the meetings:

Pat is concerned that she's getting missed out of the loop; a discussion is needed (action 51).

Also in meeting five, Prue told members to record the contact they had had:

She's speaking slowly, laughing a bit and changing her voice when she tells us to use judgement here about what is significant communication, otherwise we'd be "filling the damn thing in all day". The idea is that after this effort, we will all know what's happening (action 31).

This shows a concern for making information available. Prue warns them not to spend too long on this task though (working on information is the focus in chapters seven and eight).

Once written, the meeting notes made the meeting available, in some way, to others. They may act as informant to absent members. Below are two examples of the meeting members providing other kinds of information to each other in other ways. Both show meeting members being concerned to ensure that they understand. One is the required 
preparation for the meeting they have coming up, and the other is about feedback Prue has had regarding subsidies.

Prue says she has had feedback from two different directions about subsidies. There seems to be a problem, which Prue says could be crossed lines (so she's not blaming anyone then), but she wants to make sure everyone's clear (action 32)

Prue asks May to remind us about the preparation needed and people laugh (action $36)$.

Prue's careful presentation of the feedback suggests that this may not be information only. Here is how I described the action that followed:

Pat asks which organisation said this, and Prue gives some more detail. There is a discussion. Prue says "just be aware there's an erroneous perception out there" and that we should correct it if we get a chance (action 33).

Looking at more of the action shows that while the feedback from two directions can be seen as Prue providing meeting members with information, she also uses it to call for action, asking meeting members to correct the "erroneous perception out there" (chapter five describes this interaction further). Prue also says it reminds her that the website needs a clear statement. The feedback, this information, and her use of it, reminds her to also take action. It shows working together. Prue has asked the meeting members to work on correcting a problem, that of perception, and she shows what she will do. Through her talk of being reminded, perhaps Prue also speaks other things into action like this instruction being recorded in the meeting minutes, or Sally doing something on the website. In action 16 , there was an example of what I describe as talking as if writing. Here, meeting members talk as if they are writing some form of communication, like drafting letters on the spot. Information participates in the meetings in many ways, and is often involved in talk of what meeting members should do next; attempts at putting into-action.

In meeting five there was an explicit discussion concerning what to do next, given that Pat and Prue expressed different views. That discussion, repeated below, is concluded with Prue saying she will make a note. She does being reminded, and in this action she appears to have taken on what Pat and May were saying. In this discussion, meeting members were working on clarifying and on agreeing what to do next.

Pat, with May saying a few things also, says some more service delivery is needed and there needs to be some "gutsy discussion", and that she knows Prue disagrees with something she's saying about developing other areas (action 9). Pat says she'd 
"like to go out and talk to people about it instead of you know it being the way it is how it just sits". Prue is saying remember why. She says if we are going to do that, so that it won't hold up registration (action 10), it would be a separate project, with a project team. Pat says yeah because they can't advertise until some work is done so it's quite urgent that they discuss this (action 11). May says they've ended up using (action 12) the generic ones. Prue says she'll make a note (action 13) and there's a pause while she is writing.

Above, Prue was being careful when dealing with who may have provided incorrect information about subsidies, as she works on making everyone clear. She was discussing information that had come from outside of the organisation that needed to be dealt with by correcting a perception. When Pat calls for some "gutsy discussion" within BANA, she also uses information from "out there". Information with this origin is involved in discussions of what to do next. ${ }^{3}$ Meeting members constantly attended to what to do next in the meetings.

\section{Talking about this organisation, working together and communication}

The first example in this section shows meeting members attending to how to organise this organisation. It has links with concerns with being in the know discussed above and it quickly flows into examples about sharing information. As in this example, boundaries do not hold unless something keeps them in place. Here, meeting members are discussing Kim's proposal that she take all of the requests:

She turns to a discussion about boundaries and work areas, which came up in the admin team meeting last week and she suggests that she takes the requests for evidence guides rather than Simone and Pat (action 48). Pat is enthusiastic and Kim says, "I'm the only one that really knows".

In this Kim proposes a reorganisation of work, and she backs it up with a claim to knowing. Is the implication that this would be the most efficient and effective way to order who does which tasks?

This concern with sharing the work was also talked about in meeting five with regard to the formal arranging of roles. It can be seen here how meeting members attended to adapting the objects of performance management (competency levels) to their particular

\footnotetext{
${ }^{3}$ In action 19, Prue used the research and the work already done to say what the next task should be. This time Pat accepts. Is this acceptance, for now at least, achieved by Prue's explanation that the work already done was based on consultation with "out there"?
} 
situations. Prue had been careful to say that BANA members not fitting exactly was not an issue. She talks about alignment, but it is not clear whether that is between the documents or the people.

Prue talks about competency levels and what she's been doing as part of this work. She's talking about everyone being able to see how they fit (action 26) and says she knows the admin team wants to work together on making sure there's a good alignment between the roles (action 27).

Indeed talk of teams was evident in meeting five, indicating that BANA was changing some of its ways of working:

...she's emphasising the word "team" as she uses it a number of times - admin team... fieldwork team (action 29).

She says it might be useful to have "a reporting back" because "that might be another way of just keeping things going" (action 30).

They appeared to work on these changes carefully, paying attention to people knowing what has happened in these multiple meetings involving BANA staff. Prue expressed concern that the BANA staff meetings would be split, or cease to be where the organisation in total came together. Prue's statement about the importance of keeping on going suggests the staff meetings are a valuable opportunity to move forward. As such, meeting members, Prue as manager especially, are careful when discussing the way they are organised.

\subsection{Conclusion}

One thing meeting members attended to in these meetings was how to order their organisation. This makes these meetings the BANA staff meetings. Though it was the same people attending the staff meetings as went to the field advisors and admin meetings, they worked on how to order BANA in the staff meetings. Perhaps Prue's work on the existence of the BANA staff meetings, which required the presence of staff, was part of an effort to be seen to provide members with opportunities to participate. Pat and Prue spoke about purpose specifically in a discussion of BANA's aim, in one meeting:

Pat: $\mathrm{mmm}$

Prue: politically safe I suppose (laughing)

Pat: yeah

Prue: but but the bottom line is if you turn it round the other way and say to the manager and the managers' forums our objective is to have every worker qualified to do their job how can they argue against that

(Someone): that's right 
Prue: they absolutely can't

Pat: yeah (unclear) assist you working with we can assist you

Prue: yeah

Pat: towards those qualifications well

Prue: um (22 July).

What is unique to these meetings is that this is where organisation members come together in one place. This is where discussions are held about what they might do next. As such, they are a place to provide organisation-wide instructions:

Prue: so that's performance management (observation note: looks at board) ah and and don't make a huge song and dance of it you've got quite clear outcomes just the the key areas in in each of those so so please don't spend hours and hours and hours on it um performance reviews (8 July).

There may be instructions specific to one worker or a group of workers, because this is where everyone sees Prue, but mostly what is discussed here is applicable to everyone.

The meeting members discussed ways of working together, and their concerns regarding this, and they put this into practice in the meetings. Working together was an interactional achievement. What I have in mind here can be illustrated with an example from meeting 13 where Simone raised an issue (the cost of printing certificates), Susan added some further detail, and Prue asked for clarification and outlined a course of action. Following the meetings in this chapter has indicated that there may be advantages in following the conversation in these meetings as a way to see the work, in a broad sense, being undertaken. From meeting five, an example would be to ask about Prue's response to Pat that she has not had discussions in any detail:

Pat wants to talk to Prue because Prue's been talking to one person at Org $\mathrm{H}$ and Pat another and there seems to be a bit of cross-communication not happening. Prue says yeah, well, she hasn't had discussions in any detail.

Is Pat checking on what Prue has been doing? Chapters six to eight analyse some of the meeting talk using conversation analysis to pay close and careful attention to what goes on in the meetings.

In this chapter I have presented a description of the meetings that were the source of the empirical material for this thesis. I asked how these gatherings are meetings, and how they are these particular meetings, different from other meetings involving these people. The words "following" and "re-ordering" were used to indicate where I followed the chronological order of the meetings, or used the material in some order of my own 
devising. The techniques in this chapter were guided by Howard Becker's advice about doing research. I described just one meeting, as a way to be specific (1986b), and employed Becker's "Wittgenstein trick" (1998). The separations undertaken in this chapter were noted as difficult (Becker 1982), though unavoidable in acts of describing.

This chapter became more speculative as it progressed. One suggestion was that the meetings are organisational momentum. Some of the areas that meeting members attended to will be picked up in the chapters four to nine. It is in this way that the description of meeting five shapes, and signals, the concerns of the thesis. Indeed, the thesis uses description in its attempt to understand meeting members' achievements. The large number of meeting members' words employed here are therefore valuable rather than problematic.

The meetings are the organisation at work. Some of the lasting impressions I have from having been at a few of them are: next and next and next; just; and how much detail. In the next chapter I describe the theoretical resources I have drawn on during the research and presented in this thesis. 


\title{
Chapter three
}

\section{Overview of the theoretical material}

\author{
TABLE OF CONTENTS
}

3.1 Introduction 60

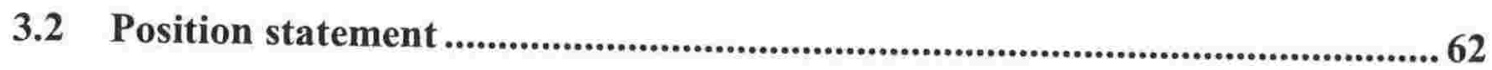

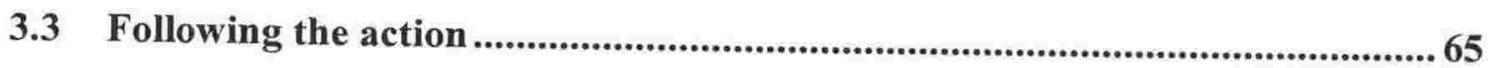

3.3.1 Actor-network theory-guided research ..............................................6 65

3.3.2 Conversation analysis and actor-network theory ................................ 71

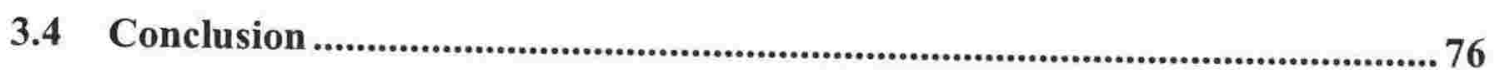




\subsection{Introduction}

In the previous chapter I outlined the empirical resources used in this thesis by asking what members attended to in making the meetings. This chapter is concerned with outlining the theoretical resources I use in the thesis. During this project actornetwork theory (hereafter "ANT") has been the overall research guide, sensibility and ethic. Conversation analysis (hereafter "CA") has been used to see the details in the transcripts of the talk I gathered from the meetings. One of the aims of this chapter is to draw out the connections between ANT and CA in considering talk as action. I will discuss how these approaches share practices of following the action and a concern to watch how we make our worlds. Partly this is a call to look carefully at these interactions, these ones just here. In the first section of this chapter a short position statement is provided. Secondly, ANT is presented. Thirdly, connections are made between CA and ANT approaches to conducting research. Rather than review CA in this chapter, in keeping with CA practice I examine just those concepts useful for doing my analysis in chapters six to eight.

Early in the project, before I decided to focus my analytic effort on recorded meeting talk gathered during fieldwork, I thought I would use a variety of sources of material to consider meetings. I ordered the depictions of meetings I might use as: my fieldwork, a documentary, a movie and a television series. Looking back, I wondered whether had I ranked them from most real to least (Latour 2002). If I ordered them differently would there be a sense that the density in an actual workplace meeting 
and dangers meetings are powerful and unpredictable? Those who speak in meetings take on a lot and it can go wrong (Urry 2003). At work we perform, and this includes during meetings (Munro 1996a).

Moaning about meetings and saying things like "I've been in meetings all day and gotten nothing done" serves many purposes (Rouncefield 2003). Yet we do charge meetings with wasting our time: "when all is said and done more was said than done" (footpath board, Wellington 2 July 2004). Notions like this perhaps "reflect the cultural privileging of action over discourse in Western culture" (Grant et al. $1998 \mathrm{p}$. 5). Viewing meetings as lacking progress, being devoid of any actual work, as "inaction", presents the danger that they are dismissed as ceremonial or irrelevant. Measuring meetings quantifiably and rigidly can make them appear to be merely "talk-fests". However, their existence suggests they are valued somehow. How do there come to be times when as organisation members, it seems better to attend than just receive the documents?

Minutes of meetings tend to be simplified versions of what went on, and are often produced by a single person. A lot of what goes on in meetings is neither possible to reproduce, nor useful to those who were not there at the time. Depictions and representations (tellings afterwards), of actual meetings may appear incoherent, even to those who were present (Latour 2002). Farnsworth and Austrin use Latour to say that how worlds are created is "routinely erased in accounts after the event" (2004 p. 5). Many of the details of the work undertaken in meetings are not useful later, and things that cannot be captured and repeated effectively like membership and belonging do not make it into post-meeting entities like minutes.

Reasons for attending meetings at work include gathering the background, "hearing it from the horse's mouth", being seen, taking part and being included. Taking a narrow view when researching these workplace interactions does not acknowledge the multiple accomplishments of meetings, and ignores those aspects that are not possible to be, and are not, captured. For instance, in a time when workers are expected to find instructions for themselves, I suggest meetings are useful for gathering what is necessary to be able to act alone, yet appropriately (Foucault's selfregulation thesis in Allen 2003; Harper in Star 1992; Munro 1997). Meetings are valuable for making future individual decisions that are in keeping and acceptable in 
some way or other for producing accounts that "fit into a circulation of accounts that is already going on" (Munro 1999b p. 436). People do not wait to be told what to do (Munro 1999b) but knowing what information means relies on putting it in the context of interactional settings (Boden 1994). Middleton says that in teamwork exchanging information is not simple, but rather "information is evoked interactionally in conversation that handles delicate problems of taking responsibility without usurping the authority or democratic rights of other members of the team" (1998 p. 245). Meetings are important in undertaking the delicate acts that are currently necessary in being a competent office-based, or "knowledge" worker (Courpasson and Reed 2004).

What is considered in this thesis is work practice, "practice" being a key word (Law 2004b p. 13). How is it that this organisation is "enacted" (Mol 2002 p. 32)? I take each of the staff meetings $I$ attended as a device for seeing this organisation being made, and so, it looks slightly different each time. Like the pedocomparator in Latour's research on the work of seeing the Amazon forest, the meeting room is a laboratory where the organisation is shrunk and confined, a slice or sample of its blurry-edge being (1999b). In the meetings "this organisation" is momentarily held, and so more able to be examined. Within these times and spaces the achievement of momentum is available for viewing. However, this reduction, this spatial and temporal holding cannot, and does not, last for long. The apparent harmony in these meetings, their momentum, requires careful and constant effort. Law, drawing on Latour and Woolgar's 1979 book Laboratory Life, argues that realities are built, but that they are difficult to build (2004b). In this research the members of the organisation work hard on the appearance of agreement and consensus. That the organisation was seen as a collective effort was important to one member at least, and this became apparent especially during my return visit to present a conference paper I had drafted (discussed in chapter four). This achievement of motion has other effects, some of which will be considered in the following chapters.

\subsection{Position statement}

In the introduction to the thesis I used the concept of gathered things as a way to quickly signal some of the concerns of this research, and some of the academic writers being drawn on in particular. This section is another attempt to be clear, briefly, especially with regard to where my research may fit with previous work. 
The most influential writers on how I went about conducting the research (my research sensibility) were Bruno Latour, John Law, Annemarie Mol and Rolland Munro. After finishing the fieldwork, when it came to how to closely analyse the talk I had recorded, Paul Atkinson, Deidre Boden, John Heritage, Harvey Sacks and David Silverman had the largest influence. I have created two groups and ordered them alphabetically, though it would be more accurate to include Munro in both. It is also difficult to label the first ANT and the second CA but those labels are useful in a rough kind of way. Also, Howard Becker and Marilyn Strathern are missing, even though I have relied on their advice also and used them explicitly at times in this thesis. Becker's techniques are in keeping with the overall reason and the way I have used the work of these writers in this research. My effort has involved following action in an attempt to describe world-building activity. My broad topic of how people get their work done comes out of specific research traditions which watch first before deciding what to look for or what is being looked at. Throughout the thesis I have labelled these ANT and CA though these labels are in many ways too blunt. It would be more correct to include only Latour, Law and Mol under ANT, as Latour does by including works by Law and Mol alongside his own (Latour 1996), as guides to "sociology of associations" or ANT (Latour 2005). However, this would leave Munro out of both groups. Brevity is not always useful.

Perhaps employing lists as a way to describe the theoretical underpinnings of research is a better technique, rather than using groups, which suggest sets and subsets, and being either in or out. Lucy Suchman is one who uses this approach. She says that the reconceptualizations of knowledge and action as produced in ongoing practices (in Law's heterogeneous engineering and Fujimura and Star's ecologies of social-material relations) are underwritten by the intellectual traditions of symbolic interactionism, ANT, cultural anthropology and ethnomethodology (Suchman 2000). Suchman's list is very like Law's, though he specifically locates his book on method within studies of science, technology and society (or STS) (Law 2004b).

From the research traditions listed by Suchman and Law I utilise techniques of observation, and one reason for selecting these particular people is that they have engaged in watching action. I use them to ask what actors can be seen (through ethnographic observation and in transcripts of conversations) to be doing. Those on 
the ANT list explicitly include non-humans when they consider how the world is made (but then so does Heath (1981), who could have been included on the CA list). They all say "hey look at this" (a story about which is provided in the thesis epilogue). They do not tend to go searching for hidden motives or speculate about intentions. When these researchers look at people and things acting, they see skilled accomplishments, rather than lack and failure that requires improvement. This is not to say that they do not see actions as attempts by actors to enlist others in their projects. They ask how things are happening in association; what we do together. These people are interested in momentum and ongoingness.

The emphasis I take from these people is on description, which is to ask about how the world is ordered. In this way the task involves questioning in a wondering, puzzled, "what do we have here then" kind of way. Having looked very carefully at what might be going on, these researchers may attempt explanations (Silverman 1999) and be explicitly critical (Latour 2003). However, I do not suggest what should happen next in the meetings I attended, nor any place else. What to do next is left to the people involved, including whether to read this thesis. They do not need my views. Rather I was the one who needed them; I needed their acceptance of my presence.

If I must apply a label, this is a work of sociology. One hope for this thesis is that it contributes something toward the effort outlined by Silverman with reference to Drew and Heritage's edited collection: "Such analysis of the creation of contexts of 'institutionality' has led to a huge corpus of CA studies which holds out every prospect of establishing a revitalised sociology of work and occupations" (Drew and Heritage 1992 in Silverman 1999 p. 407). I have used many of Heritage's techniques in his more recent article where he suggests that CA techniques "are useful in gaining access to most kinds of 'institutional' data, including the new 'workplace' studies" (2004 p. 223). With regard to ANT, I attempt to show how techniques of following can be used to explore a contemporary workplace, and I have attempted to add to Latour's call for ANT as "a deliberate attempt to terminate the use of the word 'social' in social theory and to replace it with the world 'association'" (2002 p. 117). Using Munro's work especially, I hope to persuade readers that this kind of work is valuable beyond the medical and scientific work settings where much of this research 
has been conducted to date. In recognising where my research is located, I talk about workplace as well as work and organisation. With these aims in mind, in alphabetical order, some of the recent work that my research could be included with, either in response to or alongside, includes: Cooren (2004b), Farnsworth and Austrin (2004), Fox et al. (2005), Hugill (2004) and Rouncefield (2003).

\subsection{Following the action}

\subsection{Actor-network theory-guided research}

Early on in my project I considered how ANT, and associated observation methods, had been used to consider work and workplaces. I used ANT as a guide, not a rule, in seeking studies using observation of organising processes, where the emphasis was on "the practical performances through which the work of organizing gets done" (Gherardi 2000a p. 217). I also sought approaches that use a wide definition of how the world is made, and which include non-human participants (Law 1999; Suchman 2000).

ANT is useful because it is a "relational and process-oriented sociology that treats agents, organizations, and devices as interactive effects" (Law 1992 p. 389). It is also referred to as the sociology of translation (Callon 2001). What is needed is to use translation as a verb, which implies transformation and the "possibility that one thing (for example an actor) may stand for another (for instance a network)" (Law 1992 p. 386; see also Callon and Latour 1981). Consistent with this, the emphasis in this research is on effects. As Munro says: "the important point, rather than pit the 'real' against 'test', or contest dismissal against discourse, is to recognise the effects that flow from this network of discourse and devices" (1998 p. 234). Networks are processes and achievements rather than structures, which need constant attention because there is always the possibility that they will dissolve (Akrich in Law 1996).

These achievements may also be hidden. Law says "pools of order... are the product, the outcome, or the effect, of a lot of work - work that may occasionally be more or less successfully hidden behind an appearance of ordered simplicity" (1994 p. 5). Law's development and use of modes of ordering in his ethnography of a research laboratory has been useful in my research. Along with the idea of translation, ANT 
provides many appealing concepts, such as: enrolment, obligatory passages and problematisation (Callon 1986). Simplified, it suggests "we should study how extensive and heterogeneous are the networks which support and define" whatever we are looking at (Brown 1992 p. 81). These separated concepts guide my research practice, and are viewed as potentially useful, rather than applied as a strict model for conducting research as Law discusses (1992). From ANT I have embraced the practice of following rather than relying on definitions of concepts that have been separated from their research origins (Lee and Hassard 1999 p. 392; see Callon et al. 1986 for a glossary of terms). At the same time I recognise that lists of terms help make this research possible (for instance, by providing the resources with which to argue for this approach).

Lucy Suchman's paper on bridge-building matches my research interests quite closely (2000). My research is concerned with situated action and the ways in which people use things from elsewhere, like phrases, for their local purposes (Suchman 1987). Suchman provides a link to recent workplace research with a similar approach to ANT, as demonstrated by her inclusion in the special issue of the British Journal of Sociology on workplace studies, where the contributions:

address the ways in which work is ordered and organized in the activities and interactions of the participants and examine how tools and technologies are used as practical matters in the accomplishment of the work of the setting (Heath and Button 2002).

Suchman in the US, and Heath in the UK, have shown that along with CA, the consideration of non-verbal interaction and artifacts are also useful in understanding "talk-in-interaction" (ten Have 2001 p. 10). In UK-based workplace studies Suchman is quite often recognised as important, while ANT studies use their (Law 1992; Law 1994) ideas of materially heterogeneous relations (see Suchman 2000 for a discussion).

Most of ANT's methodology is not unique, and though its consideration of nonhuman actants is unusual there are others considering the socio-technical in a similar manner. For instance, Donna Haraway is cited on the ANT website as the best-known example of the radical feminist technoscience alternative to ANT, and that the "'afterANT' studies in this resource in many cases owe as much or more to Haraway as to ANT itself" (Law 2004a accessed 9 October 2003). 
Of the two phases of ANT, I most often select work from the "after" phase (Latour 1999a p. 24). One article by Law (2000) is described on the ANT website as being an "after actor-network" piece because the focus is crucially on relations "understood in partial and incompletely centred modes" (Law 2004a). The doubt expressed in the writing of Latour and Law in the late 1990s appears now to have been part of the attempt to clarify the kind of research they were advocating. In his new ANT textbook, Latour says he is taking the opposite position from the one he took in his 1999 article "On recalling ANT" (2005 p. 9). Law has also produced a research text arguing more straightforwardly for an approach that is concerned with the relations involved in making worlds (Law 2004b).

In his sociology of work textbook Keith Grint includes ANT in contemporary theories of work organisation, saying its focus is on the practices of power and "the practices of humans in association with non-humans" (1998 p. 142-3). Research that looks at practice and organising rather than organisation is well established (for instance, see discussions of Karl Weick (1979) by Brown 1992 and Schwartzman 1993). Bate says the anthropologist's task is one of tracking, describing and explaining the process, which is a more dynamic approach to culture than some management and organisation studies writers take (1997 p. 1159). However, the focus on processes and practices is not taken-for-granted. Law and Mol quite recently discussed the shift "from articulating norms to studying the way they are practiced" (2002b p. 84). Robert Cooper, "better seen as a social theorist of modern organizing and institutionalization rather than as an academic specialist who focuses on the study of organizations" has published with Law (Chia 1998b p. 1). In their widely-cited paper, Cooper and Law argue for giving "primacy to proximal organizings rather than distal organizations" (1995 p. 271). The focus is on becoming rather than being; it emphasises processes, the continuous, the unfinished, the partial and precarious. While Cooper and Law say this approach does not totally preclude the distal because they depend on each other, in its concern for hierarchy and order a distal view is limited in that it is characterised by result, the simplified, the distilled and boundaries (1995). We need to ignore divisions like agency and structure "if we want to understand the process of ordering and patterns which result" (Cooper and Law 1995 p. 250). Law provides questions for exploring "the precarious mechanics of organization" (1992 p. 389): 
What are the kinds of heterogeneous bits and pieces created or mobilized and juxtaposed to generate organizational effects? How are they juxtaposed? How are resistances overcome? How it is (if at all) that the material durability and transportability necessary to the organizational patterning of social relations are achieved? (Law 1992 p. 390).

Looking more widely than ANT, my research could perhaps be placed in Van Maanen's category "organizational processes and informal relations" (2001 p. 240). Though I do not recognise the separation implied by "informal", I agree that there is more to getting the work done than the obvious attention to tasks. I am not proposing to discuss the opposing side of a formal/informal binary, which sets up meeting actions directly related to organisation purpose against time-out talk, and social goings-on. Rouncefield says there has been too much emphasis on this distinction, for the reasons laid out by Bittner in 1965 (2003). I have tried to describe the particulars of these meetings, as Van Maanen agrees is valuable, but I follow the ethnomethdological view that members know what they are doing and do not need our help to explain their actions (Latour 2005). I do not see my work as "allowing a degree of ethnographic charity to be granted to those whose behavior might otherwise appear as odd, alien, lazy, malicious, conformist, mendacious, uninformed, or simply inexplicable"(Van Maanen 2001 p. 243). Austrin and Farnsworth outline the variation in stances taken by ethno-investigators by contrasting research which "claims to know more than the actors it researches" with Latour's relativist sociology, which does not know "what society is made of... [but] seeks out informants who may" (2005 p. 161). While I reject some of Van Maanen's approach, he is useful for supporting the kind of research I have done; that which is "exploratory, aiming at discovery, description, and theory building" (1998 p. xii). He talks about its messiness and stresses its necessarily "emergent character", which means it is "most often designed as it is being done" (Van Maanen 1998 p. xi). Bate also notes that ethnographers are happy with a "suck it and see" approach (1997 p. 1152); and Weick argues that not taking ourselves as researchers too seriously "means we are less prone to stereotyping" (2002).

\subsubsection{Using actor-network theory}

I use ANT as a way to conduct research through practices of following. I rely most often on ANT's ethnomethodology connections:

Enacted local practices are not texts which symbolize 'meanings' or events. They are in detail identical with themselves, and not representative of something else. The witnessably recurrent details of ordinary everyday practices are constitutive of their 
own reality. They are studied in their unmediated details and not as signed enterprises (Garfinkel 2002 p. 97).

As Latour says, ANT is "another way of being faithful to the insights of ethnomethodology" (1999a p. 15). Mol uses the word "is" to discuss an emphasis on the situated "practicalities involved in enacting reality" (2002 p. 54). I will elaborate further below on the insistence that there is no gap between practice and reality, especially with regard to the work of Boden and Munro.

Using the technique of following to guide research practice involves watching "how" things are done in "what we can observe" (Salmond 1975 p. 2). Again this is not an exclusively ANT, nor new, approach (see for instance, Becker 1998; Denzin 2002). William F. Whyte (1984) used Chapple (1953) to ask "Who does what with whom, when and where?" because "you cannot observe why anyone does anything" (in Schwartzman 1993 p. 19). Latour says ANT was, for its founders, more method than theory. This excerpt provides a useful overview:

To study [projects] you have to move from classical sociology to relativist sociology, and see in the former only a particular case, an approximation, a valuable one to be sure, but only when nothing more is moving, when projects have become objects, institutions. Relativist sociology has no fixed reference frames, and consequently no metalanguage. It expects the actors to understand what they are and what it is. It does not know what society is composed of, and that is why it goes off to learn from others, from those who are constructing society. It adds its own interpretations to those of the actors whose fate it shares, often less felicitously than they. It seeks, too, to perform reality in order to keep its own version of the facts stabilized a little longer, and it confronts, fraternally, the contrary opinion of those it is studying. It has no strings to its bow but theirs, and it does not allow itself to throw 'science' onto the scale in order to unbalance the equality between itself and its brothers with whom it is conversing (Latour 1996 p. 200).

Like ethnomethodology, ANT is a way for social researchers to access sites (Latour 1999a). Latour says his sociology prefers a local history in a framework defined by the actors so what is needed is to "follow the players" (Latour 1996 p. 10).

In keeping with ethnomethodological rather than ethnographical practice I do not claim authority through length of time in the field (Gellner and Hirsch 2001 note this debate). As introduced in chapter two above, the setting of my fieldwork was a series of meetings. I visited the organisation over six months, at particular prearranged times, rather than being in and out of that workplace over a longer period of time (like, for example Law 1994). My lack of concern about the length of time in the field reflects the emphasis in this project on describing how the world is made, while recognising that description is incomplete. I have attempted to keep my claims 
relatively modest and non-reductionist (Law 1994; Law 2004b). There is no story to tell once and for all.

As much as possible, I avoided making assumptions prior to conducting the research in order to ask "how some kinds of interactions more or less succeed in stabilizing and reproducing themselves" (Law 1992 p. 380). Rather than something like "market forces or the irresistible thrust of technology" I followed "assemblies of spokespersons who bring together, during a single meeting, around a single table, different worlds" (Latour 1996 p. 42). Law connects the idea of symmetry with avoiding assumptions. However symmetry is a concept that is used in a variety of ways, even in ANT writings. It appears in many places, in new writings and in citings of older work (Mauthner et al. 2002; Woolgar 2002; and Bloor (1976) in Brown 1992). Czarniawska says because organisation researchers study people who use the same knowledge validity claims, another law needs to be added to Latour's laws of symmetrical anthropology (1997 p. 5). She says a fourth law, that of using the "same vocabulary for anthropological and nonanthropological practice" should be added to Latour's first three laws of "same language for truth and errors, humans and nonhumans, Western and non-Western" (Czarniawska 1997 p. 5). In Aramis, Latour says he did not go looking for the principle of symmetry but found it in asking "How can people be condemned for failing when those very same people are succeeding elsewhere?" (1996 p. ix).

In this, as in many other aspects of my research approach, I follow Law who contends that symmetry "is to assert that everything deserves explanation" and that everything should be approached in the same way in order not to "start any investigation by privileging anything or anyone" (1994 p. 9-10). For example, defining the laboratory he studied would breach the principle of symmetry because there were many different forms of ordering (Law 1994). He concentrated on the work of the managers, but "definitions of what the organization 'really' is do not help" because "it is, amongst other things, a network of different worlds" (Law 1994 p. 43). Critique is directed at "the means by which such organizational arrangements are achieved" (Lee and Hassard 1999 p. 403). Not insisting on attempting to see or describe the "whole" organisation is a very useful aspect of ANT. 
The idea of symmetry is also used to "treat size as a product or an effect" which allows us to ask "how it is that the macro-social got to be macro-social" (Law 1994 p. 11). A core understanding of ANT is that, because multinational corporations are no different in kind from individuals, we should study how differences in size, power or organisation are generated (Law 1992 p. 380). The aim is to follow without being influenced by the size of particular entities nor asking about the social, but being concerned with "the processes by which an actor creates lasting asymmetries" (Callon and Latour 1981 p. 286). Using one vocabulary to consider the large and the small helps in remembering that being more powerful than others is an achievement of the actors (Callon et al. 1986). So "centers of translation" enable the questioning of attempts to control diverse elements such as how their status is achieved and how they become the spokesperson (Callon et al. 1986 p. 228).

Following the action during the fieldwork and in the recorded talk was how I came to focus on the use of the phrase "out there" in the meetings. I have used a phrase from the setting and tried to frame the investigation by keeping to "the limits indicated by the interviewees themselves" (Latour 1996 p. 18-19). Transcribing the tapes I gathered from the meetings was another way I followed the action.

\subsubsection{Conversation analysis and actor-network theory}

This section outlines some of the connections between ANT and CA, discussing describing, making the meetings and organisational momentum. As discussed in the first chapter, the use of ANT and CA is a matter of differences in scale (Strathern 1991; Latour 1999a) rather than different research techniques. Combining fieldwork and CA as advocated by Silverman (1999) is not new (for example, see Moerman 1988) but is currently being explicitly debated (see Miller and Fox 2004). ANT and $\mathrm{CA}$ are broadly compatible because they share a concern with sequencing and interconnectivity; making entities like meetings is done in association and takes more than the singular actions of people and things. Rather than review CA research here, I have selected the concepts that are useful for the analysis in chapters six to eight.

The ANT emphasis on following the action guided my research practice while I attended the meetings, but continued to be employed once I was back in my office. After I had concluded my visits to the field, CA was used as a way to very closely 
follow the action once I started working with the recordings I had made. Sacks, the founder of $\mathrm{CA}$, had this emphasis on following right from the beginning of his inquiries, as Gumperz outlines with regard to a seminar series involving Garfinkel, Goffman and Sacks:

[Sacks] introduced basic theoretical notions by means of descriptive phrases such as: 'sequential ordering', 'positioning of utterances', 'the interactional job that utterances do', 'what they (i.e. speakers) need to do is exhibit understanding', 'the use of the performance rule'. In all of these expressions, verb constructions like 'ordering', 'positioning', 'understanding', and 'using (or for that matter also violating) rules' are consciously employed to suggest that reference is being made to acts that speakers perform by means of their talk and not to givens of language usage (Gumperz $1982 \mathrm{p}$. $323)$.

Thus, CA set out to follow the "acts that speakers perform", closely observing members' methods. One of the most useful aspects of ANT for me has been this emphasis on watching members' methods, which comes from the ethnomethodological roots it shares with CA. In his latest book, Latour (2005) explicitly claims Garfinkel as one of the founding fathers of ANT. The approach also shares many of the concerns of Howard Becker, whose technique of asking what was being attended to in the meetings was used in chapter two.

The concern of this study is with what members do with and through meeting talk, rather than seeing meeting talk as a reflection of other things ("social structures" for example). Schegloff says that for Sacks "talk itself was the action" (1992a p. xviii). He was able to show us things because he was prepared to examine talk "as an object in its own right, and not merely as a screen on which are projected other processes" (Schegloff in Silverman 1999 p. 417). I have used the technique of following members' use of just one phrase in the meetings (the phrase "out there"). This technique is stimulated by Wilkinson and Kitzinger (2000) who worked with the phrase "thinking positive" in cancer patients" talk. Following the action as a research practice results in examining the meetings as entities in and of themselves (Sharrock and Anderson 1986).

Of the talk-focused approaches, I chose CA because meeting members' actions are taken to be joint achievements rather than those of a single speaker, though it should be noted that forms of discourse analysis do consider the turn-by-turn organisation of talk (see Silverman,1999). Because they use CA to examine talk in workplaces I have 
drawn especially on Silverman (in particular, his study of counseling (1997)), and on Boden's book on talk in organisations (1994). As Boden puts it:

The utility of conversation analysis to theories lies in its structural and interactional emphasis on sequentially achieved social action. By directly observing the sequential context and consequences of quick verbal exchanges, analysts can track quite distinct interactional processes that are simultaneously organizational (Boden 1994 p. 206).

I draw on Boden's work on information in chapter seven. Her approach is that "units of interaction... provide a kind of revolving door through which the complexity of organizational life can be channeled, assessed, and assimilated. In particular questions and their answers provide the primary structure through which information is sought" (Boden 1994 p. 110). However, I try to avoid ranking statements such as this claim about "primary structure".

Though Boden explicitly utilises CA in her book, in many places her book exemplifies CA and ANT's shared concern with action. Boden's concern is with local action and especially "language-in-action" which provides a "direct view of human agency" (1994 p. 57). Arguing against the division of individual versus collective, Boden provides a definition of a workplace meeting whilst also advocating a way to approach workplace research. She says we need to "attend carefully to the ways in which various membership collectivities meet, merge and occasionally conflict at the level of talk" (Boden 1994 p. 51). She is also concerned with what is used for particular purposes:

...Vic goes on, in his next few phone calls, to construct a meeting with just the right mix of people 'all together in a room' ... working to avoid the intrusion of anyone who will not be 'teaching the course' (a further filtering or selective membership categorization device) (Boden 1994 p. 140).

The emphasis is on local making, where "the enacted organization is produced through the actions and inactions of its constituent members" (Boden 1994 p. 199). This approach is not new; as Silverman put it in the early 1970s, the approach does not focus on "a real world or on the way things 'really are' but on the routine production of realities" (1973 p. 66). Later in that decade, Wynn's thesis considered "the maintenance work participants continually perform on the commonality of their conceptual world" (1979 p. 18).

Attempts to make worlds involves practices of showing ourselves to each other. This is the central ethnomethodological concept of accountability, that is, of being seen to be doing this or that. Boden applies this concept specifically to organisations: 
That local logic, in turn, is built out of a kind of cooperative competence. Local actions must not only make sense to their participants but must be seen as reasonable and, in organizations, reasonably efficient and cost conscious as well as adaptive and accountable (Boden 1994 p. 22).

Munro, drawing on Garfinkel, says members' accounts involve showing that they know, that they have "communicative competence" (2001b p. 474). That meetings involve members showing themselves to each other is a point made in the often-cited meetings research by Schwartzman who argues that meetings are needed "because they are an important form of presenting the organization as an entity to its members" (1989).

Boden's work shares many similarities with the more recent work of Silvia Gherardi. Gherardi has used ANT to consider the employment of local knowledge in various sites (for example, Gherardi and Nicolini 2000), also working with the idea of communities of practice. Of this latter concept, Star says it is the same as the "interactionist concept of social worlds" (1992 p. 401). Star cites Law, Callon and Rip in outlining an intellectual movement that relied on empirical studies of work and practice and a "network-style approach" (1992 p. 395). The focus on action and practice is encompassed especially in the word "enact", which is used by Boden and more recently by Mol (2002) as I discussed in chapter one.

All this work discussed above shares an emphasis on what happens together. Recently, John Urry (2003) has used Boden's work in arguing that getting together face-to-face continues to be valued, and hence still needs the attention of sociological researchers. In keeping with Garfinkel's refusal to entertain notions of "signed enterprises" (2002 p. 97), Boden dispels notions of distancing and gaps between practice and reality:

When an organizational actor says 'we have a quorum' or 'we screwed up again' or 'they don't think like a mega-organization,' they are not marking simply their idiosyncratic or momentary understanding of some organizational practice, they are that practice" (Boden 1994 p. 204).

In this regard, Star uses Thomas and Thomas's 1928 classic theorem: "If [people] define situations as real, they are real in their consequences" (1992 p. 402). These connections running from the early 1990s show how well Boden's book fits with my existing understanding and acceptance of the ethnomethodological underpinnings of ANT and CA. 
I have used ANT and CA to produce descriptions, but also to defend producing descriptions as my research aim. These approaches advocate detailing precisely how people go about whatever they are doing, which again shows the shared background with ethnomethodology. Heritage, arguing from CA, says that context is "a project and a product of the participants' actions" (2004 p. 224). In their 1978 article on meetings, Atkinson, Cuff and Lee treated meetings as "cultural events which members make happen" and aimed to describe "some methods and machinery involved in achieving and sustaining meetings as a social setting" (1978 p. 152). Lee draws on Sacks and Garfinkel to discuss the "problem of description":

[Sacks] was thus able to dispense with the theoretical problem of description, and was able to integrate the topic of description or characterisation into the general question of conversation's organisation. His aim was to produce an exemplary sociology which uses natural data alone, and to show how that data gives access to required phenomena of the social organisation of conversation (Lee 1987 p. 31).

Indeed, Silverman contends that explanations are only possible after describing (1999). He says that non-romantic ethnographers "take from Sacks a concern with understanding the 'apparatus' through which members' descriptions are properly (i.e. locally) produced" (Silverman 1999 p. 418).

I gained reassurance from undertaking description using detailed analyses of the meeting talk (chapters six to eight). Considering meeting members' actions using $\mathrm{CA}$ was not accompanied by the feeling of unease I had when I attempted to describe the meetings (chapter two). I agree that "the aim of ethnographic accounts is to disclose the world by simply describing the unfolding of everyday phenomena", yet I found producing descriptions anything but simple (Patriotta 2003 p. 54). This is consistent with Law's argument that mess and uncertainty is unavoidable in producing descriptions (2004b p. 2). In this research CA provided the means to do something next; it has been used to deal with, and reveal, the detail involved in processes of becoming and making. An example of membership work in the meetings can be seen in chapter six where we follow Sally attempting to align herself to Pat. This is the interest in this thesis - what happens during these gatherings of organisation members. CA contributed to answering my Latourian question: "how many participants are gathered in a thing to make it exist and to maintain its existence" (Latour 2003 p. 13)? The meetings are taken to be gatherings where the organisation BANA is partly made. 
Practices of making in the meetings are considered by focusing on how the meetings achieve organisational momentum and ongoingness - where members do what's next. In chapter two I discussed how Prue attended to keeping the meetings going. Latour discusses this kind of effort with regard to who would love Aramis enough to attend to the possibility of its existence (1996). Prue can be seen to work to keep members together as the entities that are the BANA staff meetings. Prue's effort to make the website is a more obvious example: she worked on changing how BANA worked (discussed in chapters seven and eight) as those who loved Aramis worked on changing train travel in Paris. Boden attends to organisational movement (1994), saying that organisations are "locally organized and interactionally achieved contexts of decision-making and of enduring institutional momentum" (Boden 1994 p. 1). I discuss the achievement of momentum in the meetings in the analysis in chapters six to eight, showing how CA provides just the techniques for seeing how this concern with ongoingness, shared with ANT, is achieved. I argue that momentum in the meetings is at the same time organisation momentum, which is world momentum.

\subsection{Conclusion}

In this chapter I presented the theoretical resources being drawn on in this thesis. CA has taken up less space in this chapter than the discussion of ANT. This is because CA is drawn on explicitly in chapters six to eight. I have argued for an approach that accepts that there is more going on in these meetings than implied by the few bits that make it into the minutes. I have stressed that the meetings are part of the organisation and so are places.where it can be seen. In the first section of this chapter ANT was presented and some connections were made between CA and ANT approaches. Shared connections, like following the actors and description, were a major concern of this chapter.

My approach is in keeping with an associational view that inquires into what is happening in the meetings (Latour 1986; see also Allen 2003 and Lloyd 2002a). Utilising ANT and CA, I ask how organisation is created, and continued. In the thesis I attempt to bring into focus some of the "other" that may not be measurably efficient and obvious in its contribution to the organisation's "purpose", but nevertheless went on in the meetings. Urry picks this up in Schwartzman's and Boden's research where meetings also involve: 
seeing how one is heard, executing standard procedures and duties, distributing rewards, status and blame, reinforcing friendship as well as distance, judging the commitment of the organization, having an enjoyable time with colleagues and so on (2003 p. 165).

From my observation, most of what went on in the meetings was more or less concerned with getting work done. Yet the detail of these discussions, a version of which I made material in transcripts, did not make it to the meeting minutes.

So what is all the "other" stuff? What is being left behind when the members do getting back, and down, to business? I attempt to get beyond the "ordered simplicity" (Law 1994 p. 5) that the minutes present by undertaking a fine-grained analysis of meeting transcripts (Boden 2000; Maynard and Clayman 1991; Timmermans and Berg 2003). How are these meetings accomplished with talk and other things (Latour 1999a)? In the next chapter I draw on the interactions from my return visit to the meetings. In asking "so what", I argue for the relevance of meetings as interactions which are made up from what people do in association. 


\section{Chapter four}

\section{What makes these meetings more than these meetings?}

\section{TABLE OF CONTENTS}

4.1 Introduction 79

4.2 Returning with "out there" - information and power?.................................. 82

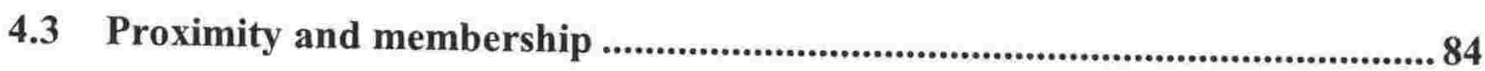

4.4 Processes of making: A focus on the detail ................................................... 88

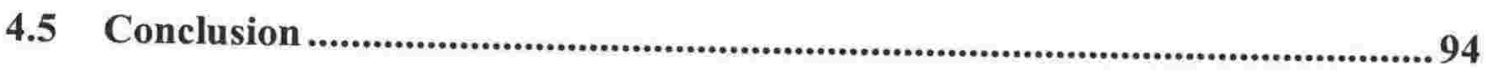




\subsection{Introduction}

In the previous chapter I outlined in an abstract kind of way the theoretical resources used in the thesis. In this chapter I continue to introduce theoretical material but also use empirical material to show some of the concerns to which this theoretical material is applied. This chapter attempts to discuss the very broad concern of the thesis - how we make our worlds. How are these meetings more than these meetings? In particular the chapter introduces the view taken of "power" in the thesis. I also discuss members' efforts, especially Pat and Prue's, to present BANA and its all-staff meetings as collective endeavours. In these ways the chapter continues in speculative mode, still holding off before I start dealing specifically with the small amount of empirical material I have selected for close examination in chapters six to eight.

The separation between empirical and theoretical resources achieved in the last chapter has been abandoned, with relief, because they make more sense together. This chapter continues the task started in chapter three of arguing for an approach to workplace research that focuses on detail, that watches interactions closely. Along with material from the series of meetings I attended, I also draw on interactions surrounding my return to the meetings, after the fieldwork period was over, to present a paper I had drafted about meeting members' use of the phrase "out there". These interactions are another effort to use the phrase "out there" to consider how in these workplace meetings the real world and the actual work are told (Mol 2002), that is, to ask about reality being made (Law and Urry 2004).

Firstly in the chapter I discuss how these meetings can be seen as more than these meetings. Secondly I use the interactions from my conference paper presentation to discuss the accounts we give of our actions and their purposes. I use my return visit as empirical material to ask about power and information, and to illustrate practices of membership. Finally I ask "so what": are workplace meetings useful and important; do they mirror the debates of sociology? In considering the local, talk and power I am concerned with exploring what people do in association; I do not take it that the actions of meeting members emerge from "external forces" that are somehow extra-interactional. 
Meetings require careful and constant effort and the achievement of motion has many effects. It became apparent during my return visit that it was important to one member at least that the meetings were viewed as a collective effort. In the conference paper I had suggested that telling stories about "out there" was a way that BANA fieldworkers were powerful in the meetings. My unsubtle point was refuted; this effort was said to be about sharing information. However, perhaps in the same collective ethos, I was not asked to change my paper, as my perspective was mine to have. One question raised by these interactions was whether "power" was only ever associational and enabling in these meetings, and whether domination, or power over, was always and entirely absent (Allen 2003 p. 5). What happened when questions were raised, in effect slowing the momentum of the meeting? In chapter six I use conversation analysis (hereafter "CA") to consider one use of the phrase "out there" (OT29) and ask whether in a "collective" organisation, power is obscured by joint efforts to make these "good meetings". Having been there, I cannot recall many instances of slowing down, which suggests that challenge is largely absent and perhaps took subtle, less visible forms. How was the momentum of these meetings, as something that could be interrupted, created to begin with?

I take the meetings to be "pools of order", which owe their continued existence to the work of their members (Law 1994 p. 5). Seeing organisations as "more or less successful ordering attempts by various actors that inhabit the organizational space" (Doolin 2003) leads to asking the question precisely how is this ordering done? I suggest that in this case the fortnightly staff meetings are involved, and important, in the existence and ongoing-ness of "this organisation". People acting and interacting (locally) create their worlds and the world. The organisation is "inside" the meetings just as much as it is "outside" them (Munro 1998).

In this chapter I turn back to the meetings I attended to consider a number of accomplishments. Mostly these are not the kinds of things made visible in the minutes (though hints appear there also). The minutes mostly contain decisions made, actions taken or predicted actions that are directly related to an explicit organisation purpose. My focus is broader. What are some of the multiple achievements of these meetings and how are they enacted (Silverman 1993)? The question is: what makes up the difference (in size, in tone?) between the minutes and the transcripts? What 
constitutes the stuff in between (time, words, bodies, table, room, me)? What is required for understanding, possibly agreeing, accepting for now, what to do next with regard to, for instance, buying milk and preparing an organisation charter?

What actions do members attempt as part of being this bounded organisation (by defining organisational purpose and tasks)? What is involved in being an organisation, which is collective rather than rule and hierarchy-driven (us and them; consensus)? How do these workers show themselves as those who take the initiative (are enterprising and entrepreneurial by trading, travelling and getting face-to-face)? These are my separations, labels, and groupings, created in the laboratory of my office for presenting this research. The work of defining this particular organisation, which is apparently collective in style and made up of workers who do not wait to be told what to do next, is part of the continual action of the meetings (Munro 1999b). My separations have stopped the action to make this effort material and visible (see a discussion of the impossibility of separating out (in Law 2004b)). The meetings continue without me - mine was a temporary visit, a standing nearby as the participants passed.

One way of viewing the manager's efforts to keep these meetings going each fortnight (discussed in chapter two) and to establish agreement in each meeting, is that the meetings partly make the organisation. Showing themselves as being a collective, information-sharing organisation is involved. The meetings are acts of working into being each meeting and the organisation. The room, the agenda, the minutes, the discussions that can be carried on or recalled afterwards, the preparation for the meetings, are all part of this organising and in turn these traces are what make up a visible, real and actual organisation. I suspected I too was at times part of this effort I too was possessed, was a property of the meetings (Latour 2002 p. 129) in that my presence as researcher also confirmed the meetings' existence.

In these meetings, members organised what they were doing in that meeting and what they could and should do next: "a shared frame of action" (Gherardi 2000b p. 1070). In this view, acting together constantly is vital because "they may lose their power the moment that they fail to act together or diminish its effect once collective, short-term goals have been won" (Allen 2003 pp. 38-9). They worked on defining their reason for being there and what the organisation did and did not do. This effort is 
visible in the meetings when members worked to create boundaries (Lee and Hassard 1999). This making of the organisation also involved aligning themselves with some external organisations but not others (Woodilla 1998). One way boundaries were envisaged was by talking about whether they, the organisation, were responsible for particular actions, like chasing the forms for people seeking registration from BANA. It seemed to be important to some of the members that they were, and were seen to be, a collective organisation. This image at least, can be seen in the meeting talk involving establishing, showing and using belonging and membership.

\subsection{Returning with "out there" - information and power?}

This section considers these meetings as places where attempts are made to define the organisation, drawing specifically on the interactions that took place when I presented some of the group with a conference paper I had drafted about talk of "out there" in the meetings. The discussion immediately after my presentation involved talk of "tension" and "conversation" as helping to keep the organisation going. Pat and Prue said their challenging each other was healthy for the organisation because it got people thinking; it was not negative.

Prue:... it's not a competition it's a tension and the tension creates a conversation and I think conversation allows us to move forward (28 October).

It was also suggested that the background of what was going on in the organisation at the time was missing from my paper. The discussions I had used were said to be about providing the people based in the office with information enabling fieldworkers to be supported, and the organisation to be more customer-focused. Hodgson says the customer is the "ultimate arbiter and sine qua non of service industry" (2004 p. 93). Bringing information back was done so a broader view could be taken of how to service BANA's clients.

Pat: ... use the resources better to give better customer service

Prue: making it easier for them... potentially 9 people a more systematic approach from their perspective... works both ways

Pat: so yeah that's a bit of the history

Prue: so this has captured some of the those/

Pat: like bringing back the examples so that people have an understanding about that communication as a bigger thing

Tamika: yeah... 
Pat: so it wasn't there as a competitive thing it was like look we're trying to get better communication for our members ... I've never seen it there as a competitive thing... a them and us I see that we all have a role in our servicing of our members and it's about how we do it ... as we've got bigger... we moved this year to look at how we can do it more efficiently... different people doing similar work (28 October).

There was no discussion after the presentation of the pseudonyms I would use in my thesis, as I had anticipated. That things did not go as I had expected was no problem because I was following the actors rather than directing them, hence their discussion became useful for my purposes. What seemed to happen was that my presentation was used as another resource for the organisation and this staff meeting, as another way to discuss the issues they were dealing with and their work on communication within BANA, another resource for being and building BANA. A major part of this discussion was about unspoken understandings between members, though Prue noted that it was an assumption that everyone in the room understood. Perhaps the assumed "shared understanding" existed only between some members. Assumptions are perhaps one way of maintaining momentum in the meetings, and keeping them moving quickly along. In chapter two I discussed Prue's predictions of how long the meeting might take - perhaps a fast pace and short time for the meetings is considered by Prue to be good because it shows unity, understanding and agreement.

The subsequent telephone conversation I had with Pat a couple of weeks later emphasised the importance, to her at least, of the appearance of a collective approach to getting their work done. This seemed to involve rejecting a power struggles view in favour of shared effort. With my paper I seemed to have made an accusation, or at least Pat appeared to be responding as if I had. This surprised me because I felt I had been careful in my paper to argue for Latour's approach of not explaining actions as driven by bad motives in the mode of "powerful agents hidden in the dark acting always consistently, continuously, relentlessly" (Latour 2004 p. 229). Calling up my non-membership of the group, Pat suggested that, because I had not understood what was going on at the time, I had mistaken information-sharing for something else. Noting Allen's summary of different types of power, perhaps I had not defined "power" carefully enough (2003). Pat seemed to suggest that the efforts in relaying stories of "out there" were in the manner of Hannah Arendt's enabling collective power, or "power to" rather than domination or "power-over" (Allen 2003 p. 118). Pat and I agreed that I would not change what I had written, because these were my 
perceptions. However, I would add in a section about the background that was missing.

The stories told by fieldworkers about "out there" that I had used in the paper were said to be part of a need for more structure, for example in forming field and admin teams and appointing a field team manager. That growth in number of people necessitates increased structure can be questioned (Hodgson 2004). I had noticed a careful handling of talk of these other meetings (see chapter seven), perhaps because despite the efforts to show collectivity, another manager indicated increased control, rather than autonomy. This was what I included in my paper from what Pat told me:

When I started attending staff meetings in March 2003 work was already underway on reviewing the structure of BANA. This was a time of rapid change. Consideration was being given to how the organisation was working and communicating given that it had grown from 3 to 10 people in the last two years. It had gotten to the stage that it was difficult to manage (Simpson 2003).

Perhaps Pat was concerned to show that she was not trying to unjustly dominate other members of the organisation, as Allen uses Sennett's work on buildings to highlight things that "represent authority not domination" (2003 p. 114). That this version rather than mine was taken up would be important if Pat was to continue to be a "guardian" whose opinion was sought (Giddens in Allen 2003 p. 58). In keeping with a collective effort, members did appear to seek each others' opinions. The understanding in these meetings appeared to be that the best recommendation was a first-hand, personal, experienced one (see chapter eight). The seemingly high status of opinion contrasts with Munro's discussion of the plant manager seeing disconnection as "reducing his view to the status of an opinion" (1997 p. S59). It is different from management "how to" texts where meetings as machines reduce emotionality and "opinions are less interesting than facts" (Alvehas 1999 p. 10). In these meetings opinions seem to be valuable.

\subsection{Proximity and membership}

Whichever way you read power, the response from Pat that my discussion of power lacked the background highlights the difficulties of attempting to provide understanding for people who were not there at the time. The fieldworkers perhaps attempted to bring a sense of "out there" into the meetings, and with my paper I attempted a portrayal of how these stories about contact were used. In both, 
understandings were put together via "partial connections", which are forever shifting and rarely complete (Strathern 1996).

The visible efforts made to keep the meetings going suggests that being together in one place was most important to the manager, but others also worked on proximity. Urry, drawing on Boden, discusses how despite new technologies, people still want to get together (2003):

It is their individual and complexly achieved collective understandings, interpretations, insights, innovations and not infrequent misreadings that drive the market... the many human agents who move the levers that move markets operate within remarkably small and routinely face-to-face conditions of proximity (Boden 2000 p. 184).

In my research, my return visit was scheduled for when Paula would be in Wellington, and there were other times that Pat worked to have Paula present (as discussed in chapter two). Whether Paula also made these kinds of efforts I do not know. She did not attend my presentation. Prue told me she and Simone could not make it but that it was not because they were not interested.

This desire for face-to-face is restricted however. As discussed in chapter two, part of making this a collective effort was that these were meetings for staff. The members were drawn from, and were, a distinct group. Even when they were not all present, absent members were involved through reference to them. This "groupness" was demonstrated very early in the research when I needed consent forms signed. There was discussion of signing one sheet with all their names on it together, perhaps to show a joint decision. Given the rules of my university's ethics process, this was not possible, though it was an opportunity to show the similarity of my situation to theirs. Unlike the interactions involving the conference paper, when insisting that the individual forms were signed I said, "You understand about bureaucratic procedures". Shared or similar experience is a resource for getting work done. Sometimes sameness was available to get my job done, but mostly it was not. Despite my proximity, I was not a member of the group because I was not involved in their joint endeavour. Unlike the others in the room my name was not called by Prue to report during the roundtable. Feeling uncomfortable about sitting at the table but being skipped over, I had asked to take my turn to speak about what had been happening with my work and what might happen next. But while this helped me feel a greater belonging, I was not involved in the same way. I was not a member of BANA. 
This is one way to explain how contractors, or non-staff, come to be absent. The meetings were carefully worked performances where understanding and agreement on a way forward was accomplished. Allen's discussion regarding collective political energies is useful for considering how this workplace group made the organisation (with a purpose). It appeared that they produced "a common platform and stance among the many wills involved" (Allen 2003 p. 125). The impression of a group was indicated in the meetings by expressing feelings like being worried or anxious (as discussed in chapter two). Are these meetings spaces where expressing feelings is appropriate, which allow or prompt the members to show uncertainty?

Acting together takes a lot of effort: "On a moment-to-moment basis, turntaking is a concerted, interactive achievement" (Maynard and Clayman 1991 p. 400). The presence of those who occasionally carry out work under the direction of "staff" is neither necessary nor appropriate. Their presence may be disruptive if they do not share the built-up knowledge, experiences, information and assumptions of the ones present in these meetings, the staff members of BANA. During my conference paper presentation Prue expressed concern that meeting members shared understandings and assumptions. Perhaps it is in this way that "they both still understand their world in the same way, and express their co-membership in the group by displaying groupspecific competence or assumptions" (Wynn 1979 p. 17)?

Prue worked on agreement in the meetings, perhaps overstating its presence at times. For instance when she proposed that one person only (Sally) fill out a particular form rather than everyone:

Prue... what does everyone think about that (unclear)

May: yep

Paula: good idea

May: that's a good idea yep (unclear)

Prue: it seems unanimous

May: yep

Prue: oh good oh good... (8 July).

There are only two people audibly agreeing here but there were five more people in the room. Yet, Prue calls this "unanimous", and in the absence of objections does "unanimous", as if everyone agrees (Boden 1994). This making, or appearance, of 
unity perhaps would be harder still with non-staff present. Though perhaps like me they could be utilised or possessed (Latour 2002).

Taking these meetings to be more than about decision-making, enables asking what else is happening. Though the fieldwork was undertaken in workplace meetings, I take a broad view in asking about meeting, organisation and world-making. I have not restricted the research to processes of decision-making regarding work tasks and the research did not start by looking for "power" (and so is different from Mehan et al. 1986 and Marra 2003). ${ }^{1}$ In one meeting Sally asked whether it was possible to have a set time for morning tea so that she could see when it was okay to interrupt other workers. There was also a discussion about access to the manager, who was busy and generally not to be disturbed when in her office. If access is restricted, meetings are important opportunities to gather what's needed for making future (solo) judgements. An example is knowing when it is okay to interrupt, discussed in chapter two (page 44) with regard to asking permission in Speaking out of turn.

These meetings involved careful balancing acts, like not wasting each other's time (discussed in chapter two (page 45) under Meeting timing and momentum). The difference in size between transcripts and minutes cannot be dismissed as repetition for its own sake, because members feel they must say something. Repetition is important in the achievements of the meetings: for instance, in checking that they (the organisation, the meeting) are still on the same wavelength. This required a group. As Wynn says, "the group continually recreates its consensual point of view in face-toface interactions" (1979 p. 16). Members can then take this to inform their daily decisions for the next fortnight. Repetition is used cautiously however, as members are careful not to take up each other's time unnecessarily or flippantly (Alvehas 1999; Patriotta 2003). A balance is sought between providing enough detail without taking too much time, so that for instance other "agenda items" are excluded. The aim is not to get "bogged in the detail" (Sally). Judging how much detail colleagues need is a skill workers practice day in, day out (Wynn 1979; Zimmerman in Silverman 1999).

\footnotetext{
${ }^{1}$ Marra argues that her research "will be the first to focus on sociolinguistic features of the discourse of corporate meetings in the New Zealand workplace" (2003 p. 5).
} 
Making sure the meeting does not get slowed down by too much detail shows how meetings are "crucial negotiative accomplishments" (Deetz 2003 p. 427).

When I presented my conference paper to the group, there was a discussion about changing levels of sharing information within BANA, perhaps indicating different, multiple, and simultaneous actions in the meetings. Sally's account of her changed level of attention to what was going on in the organisation suggests an increase in concern for the needs of other members, a concern with sharing:

Sally: I've been here a year... done several different things... participate at some level but not retain since Kim gone I've had to change my view and probably focus more indepth on what's going on ... way things have progressed ... way people converse has changed quite a bit over that time and it is about having respect for what each other does and how everybody can actually help everybody else much more information about this is what happens when I go there or

Susan: storytelling

Sally: yeah getting a lot more of that in our meetings

Pat: context of how it fits

Prue: underlying issues are the same for all of us we don't need different solutions and that's positive ... our weird conversations push us in that direction going to have to start speaking in sentences ( 28 October).

Meeting members appear to weigh-up the risks and benefits of actions (Belfiore 2004). Here, Sally supports Pat and Prue's reasons for telling a story of having been "out there" when she says it is about "respect for what each other does" and having "more information". In doing so she provides the opportunity for other meeting members to agree by producing "continuers" (Silverman 1993 p. 140). Sally's work on membership and belonging are considered further in chapter six.

\subsection{Processes of making: A focus on the detail}

As a research tool, I could imagine walls that hold the meetings I attended, and their organisation, but these walls are forever and constantly permeable (or "porous" Law 2004 b p. 41), through which "out there" flows in, and "in there" flows out. This local action reaches beyond the room it takes place in - both backwards and forwards (Munro 2004). "Out there" has to be "in there" because each is the other (Latour 2002). BANA the organisation, and its work, is done through connections to, and relations with, people and things within and beyond their "organisation":

While researchers still tend to treat them as closed spaces, contemporary organisations offer themselves as critical sites for issues that mediate between overdrawn conceptions
of society and the elusive figure of self (Munro 1998 p. 211). 
These interactions appear stable but this apparent stability has to be constantly worked into being.

Members gather materials and things for the meeting, gather together and are gathering for their interactions with worlds "out there". Differently, and perhaps less directly than the money dealers in Boden's research, these meeting members "need a delicate balance of trust, temporal framing, interactional co-ordination and constant monitoring just to get through the day" as they "come together in tight social worlds to use each other and their shared understanding of 'what's happening' to reach out and move those levers that move the world" (2000 p. 194). Plan all you like, but people decide what to do next locally, together and often face-to-face (Suchman 1987):

Some sociologists shy away from theorizing society, including institutions and organizations... but organizations, as social relationships, are affected by and constituent of these vast changes in modernity (Casey 2002 p. 1).

In this final section of the chapter I argue for the value of considering local action and the detail of interaction seen in my research as the stuff in between the transcripts and the minutes. My transcripts record some of "the how", whereas minutes list some of "the what". In my research, I consider what might go on in the gap between the minutes and the transcripts I created from the meetings I attended, rather than how this action came to be left behind as "other". Munro says it is useful to consider "gaps, breaks and absences" (Munro 1997 abstract). Latour talks about "in-between" (1999a p. 18-19) and Law, "part" (2004b p. 2). Drawing on Cooper and Law's widely cited paper (1995) Clegg, Kornberger and Rhodes also describe an emphasis on the action as "divisions, gaps, difference and in-between" (Clegg et al. 2005 p. 153). The focus is on that which is left out of the meeting minutes.

Using the gap made obvious by the absence of the detail of these everyday meetings, I argue that there is no gap between these meetings and the world. To build one is to build the other. It is by considering the detail of this "how" and ignoring any "micro/macro distinction" that we can come to understand something of how the meetings are generated (Latour 2002 p. 117-8). Latour uses Gabriel Tarde's reaction to Durkheim:

[My conception] in brief, is almost the reverse of that of Mr Durkheim. Instead of explaining everything by the so-called imposition of a law of evolution which would constrain larger phenomenon to reproduce, to repeat themselves in some certain 
identical order, instead of explaining the small by the large, the detail by the big, I explain the overall similarities by the accumulation of elementary actions, the large by the small, the big by the detail (Latour 2002 p. 125 my emphasis).

Latour, like Zimmerman and Boden (1991), rejects disconnections between members' methods and society. Star argues that "when people join local truths they create a robust, emergent negotiated order" (1992 p. 403).

The transcripts I created are representations of the original meetings (ten Have 2002). However, that there is such a difference between the number of words attests to the minutes not "capturing the detailed work that is necessary to perform competently the tasks that each setting poses" (Maynard and Clayman 1991 p. 405; also see Atkinson 1982 for a discussion). In the gap between the minutes and the transcripts we can see something of "the practical details that make it possible for these entities [hierarchies, professions, institutions, organizations] to last for more than a minute" (Latour 1986 p. 277). In the talk occupying the gap can be found a way of understanding how these face-to-face meetings come to endure, by looking at traces (Latour 2002). Though the meeting members use information and opinions from outside "experts", they put it to use for them, locally (Boden 2000; Star 1992). However, in the example below, the name "professional" is what is used rather than the content of their expert advice (Munro 1996a; and also Munro 2001a). The designers of BANA's new office space were called on as "professionals" to help stop a questioning:

Susan: oh

Prue: but I've said that our role 50 percent is actually data entry and we need

Susan: but again would they know what that actually kind of meant

Prue: well I

Susan: are they going to talk to Irene

Prue: I don't know

Susan: are there any

Prue: I don't know at this stage what where they go to from here I'm sure they're they're professionals (unclear)

Simone: I think that's first on the list at the moment

Prue: getting that done

Susan: I I think we do need to consult with

Prue: yeah

Susan: just in regard 'cos again unless they're doing data entry work I'm not sure (unclear) (2 September).

Du Gay warns that under-description risks not seeing "the job each [public institution] is doing, that each has its own history and distribution and has fashioned its own 
ethos, and is directed by its own techniques to its own ends" (2004 p. 54). In Boden's view, exposing the "membrane that supports, connects, and binds social actors" is to be doing sociology at its best (1994 p. 2).

Even though there was a large quantity of words spoken in these meetings, members also know more than they can say. In arguing for his interest in "seeing the good sense of what people are doing or understanding their skills in local contexts" Silverman points out that "we are all cleverer than we can say in so many words" (1997 p. 24). In outlining implications for practice, Patriotta calls on Polanyi's maxim that "we know more than we can tell" (2003 p. 209). Patriotta says commonsensical knowledge is tacit and if it was "made explicit it would be transformed into procedural knowledge and probably lose its effectiveness" (2003 p. 165). That the skills of workers in making judgements can be made solid is questionable, as Maynard and Clayman point out:

the most elaborately codified rules and procedures cannot exhaustively enumerate the range of situations to which they should apply; they inevitably require judgmental work which cannot itself be specified by rule, for it is the foundational process through which rules of all sorts are implemented (1991 p. 405).

If we take it that practices of judgement are complex, then they cannot be pinned down because to pin them down would be to lose them (Law and Mol 2002a). The meeting talk above perhaps alludes to the abstract ideas and ideals of management knowledge can be stored and so individuals are interchangeable. Yet, in the meetings, judgements were constantly practised, and the group accepted and undertook rule bending in reaching "broader concerns" (Maynard and Clayman 1991 p. 405).

The difficulties involved in talking about what we just do and in the ways people tackle this problem are useful for understanding how work gets done. Taking tacit knowledge to be a challenge for these meeting members, in chapters six to eight I take up ten Have's suggestion that "conversation analysis is a strategy or method for dealing with the "invisibility of commonsense"" (in Maynard and Clayman $1991 \mathrm{p}$. 397). In showing this problem, which she would like to deal with, during my return visit the manager expressed a concern to share what she knows:

Prue: and sharing it around putting it in the right place be that a physical place or an electronic place or just with other people (28 October).

Perhaps Prue's statement is about demonstrating the willingness, if only it were possible, to distribute her knowledge and experience rather than hoard or hold it. The 
lack of challenge from meeting members perhaps indicates that they assume it is possible to share "knowledge", which suggests they assume it can be captured and held, that it is possible to distribute Prue's accumulated resources. This may be because sharing knowledge is a shadowy idea and that makes it useful in this setting. The assumption that knowledge can be shared is useful in this meeting because like an "idiom", it is "vague and general" (Wilkinson and Kitzinger 2000 p. 802). Perhaps the idea of sharing knowledge acts as a "boundary object" in that it is "plastic" enough for the local needs of the people employing it, and at the same time "robust enough to maintain a common identity across sites" (Star 1992 p. 406). In his novel Powers says "words are safe exactly because they're so fuzzy. Deniable near-misses" (2000 p. 307, original emphasis). That something is ambiguous (Greatbatch and Clark 2005), and so can be reformulated if something goes wrong, adds to its utility. To be able to deny that was what you meant will be discussed in chapters six to nine with regard to a "misunderstanding machinery" (Sacks 1987 p. 66).

Shared understandings and assumptions, like the possibility that knowledge can be held, were important in getting the job done because work could proceed, and more quickly, if not everything had to be articulated each time. Reading Allen's book on power, it is hard to see how power is different from the action I observed in the meetings and saw in the subsequent transcripts (2003). Can power and action be used as interchangeable terms if we take Arendt's view that "power is not generated 'from above' by a mobilizing leadership, but solely through association. It is rooted in mutual action" (Allen 2003 p. 53)? Latour can help here:

This shift from principle to practice allows us to treat the vague notion of power not as a cause of people's behaviour but as the consequence of an intense activity of enrolling, convincing and enlisting. When the second framework is chosen instead of the first the practical resources necessary to perform society appear clearly. We have to study them if we wish to do away with the notion of power (1986 p. 273).

The point is that power is created here and now rather than stored, and so again, we must follow and watch the action:

Since, in the translation model, power is composed here and now by enrolling many actors in a given political and social scheme, and is not something that can be stored up and given to the powerful by a pre-existing 'society", it follows that debates about the origins of society, the nature of its components, and their relationships become crucial data for the sociologist (Latour 1986 abstract).

When I returned to present my paper I became one of the many actors in the "political and social scheme" that was that meeting. My research on BANA attested to BANA's 
existence. This conception of power is that it is a locally produced effect (Munro 1997). Maynard and Clayman argue that the accomplishment of making utterances intelligible "implies a social organization that is local and for itself, rather than, say, operating on behalf of some externally based social structure, such as class, gender, or ethnicity" (1991 p. 399).

Rouncefield argues against what he sees as the misconception that ethnomethodology does not consider power:

data is examined to see how and in what ways 'power' might be an appropriate description of various interactional accomplishments and what such a description turns on. To anticipate: of particular interest is what might be seen as the 'breaching moments' of refusal and rejection within meetings, the management of incumbent roles and the display of and orientation to hierarchy (2003 p. 158).

When I considered pulling an example from the meetings I attended where the momentum of the meeting was slowed by someone attempting to say no, I recalled a discussion about the new office. This part of the discussion is about where the reception desk in BANA's new office would be placed:

Irene: I'm just ah yeah I am cut-off from the other staff

Prue: um yeah that's unavoidable I'm afraid

Irene: with all my old job like office assistant I'm becoming more receptionist (laughs) yeah and not assistant office assistant

Prue: it's

Irene: here in reception

Prue: yeah

Susan: down there

Irene: (unclear)

Prue: that I'm afraid is actually unavoidable the the the original our original thinking was to have us over here and have it there and there but it actually just doesn't fit Irene: hm (2 September).

It seemed that while deciding how to get tasks done was worked on co-operatively in the meetings, when the smooth momentum of the meetings was threatened, the boss stepped in. It could be said that she held power. However, Latour's point would be that rather than pointing to power as waiting in the wings, a more explanatory alternative would be to consider how it is that Prue comes to be able to say "that's unavoidable", through her "intense activity" (Latour 1986 p. 273). 


\subsection{Conclusion}

Looking closely, we saw the ideal of sharing knowledge being spoken into being and we also saw other things. This is the move I make in this research. I attempt "to discover the things that persons in particular situations do, the methods they use, to create the patterned orderliness of social life" (Warfield Rawls 2002 p. 6). I use the trick of assuming that the meetings have "not causes, but a history, a story, a narrative" (Becker 1998 p. 61). I started in chapter two with what I could see (Salmond 1975).

In this chapter I argued for an approach that accepts that there is more going on in these meetings than implied by the few bits that make it into the minutes. I have stressed that the meetings are the organisation and so are one place where the organisation(al) action is and where the organisation in action can be seen. The view I have tried to share is that the meetings are where the organisation is made. I discussed the interactions from my conference paper presentation to meeting members. In asking "so what", I argued for the relevance of meetings as detailed interactions which are made in association.

This chapter completes the first section of the thesis, which aimed to broadly describe the meetings I attended as researcher and the theoretical materials I am drawing on. It also announces the move into the second part of the thesis, where I undertake close analyses of turns of talk using CA to ask how talk of, and from outside, these meetings is made relevant (Atkinson et al. 1978). This analysis is achieved by using the involvement of the phrase "out there" in the meetings. For instance, when Prue says her idea is "really sort of out there so please keep it within these four walls" (OT9), what are the effects and what is revealed by this presentation and the reactions of others? How is it that the new website is referred to as "up there", yet a new idea is "out there"?

In the next chapter I introduce the material, or the talk corpus, which will be used in the following chapters to consider what "out there" is doing "in here". Chapter five describes all of the interactions involving the phrase "out there" in the meetings. The aim is to explore what members might be attending to each time "out there" is used, and whether there any features that allow them to be grouped. 
Part two:

Following one phrase 


\section{Chapter five}

\section{The talk corpus: The phrase "out there" in the meetings}

\section{TABLE OF CONTENTS}

\subsection{Introduction}

5.2 Table one: Uses of the phrase "out there" by date .........................................98

1.2.1 Table one: Uses of the phrase "out there" by date ................................... 99

1.2.2 How often was "out there" used in the meetings? .................................. 104

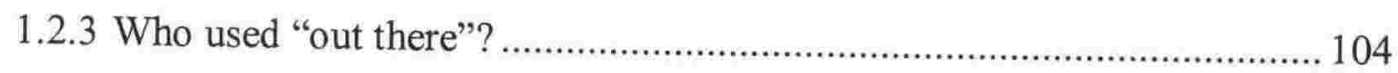

1.2.4 When was "out there" used and what was the topic being discussed?...... 104

1.2.5 What was referred to with the phrase? ............................................... 105

5.3 Table two: Uses of the phrase "out there" by topics and concerns................107

1.3.1 Table two: Uses of the phrase "out there" by topics and concerns ........... 108

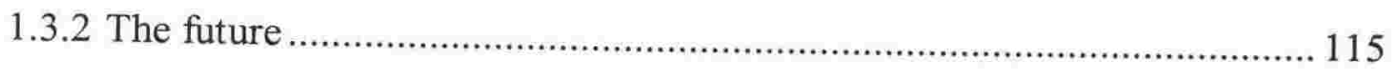

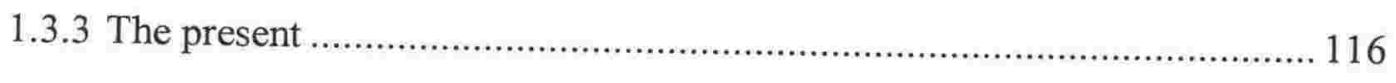

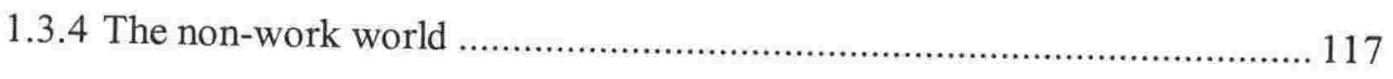

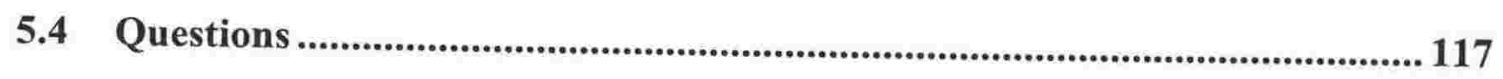

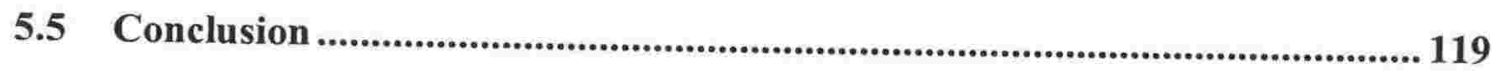




\subsection{Introduction}

This is the first chapter of the second part of the thesis, where I turn my attention specifically to the involvement of the phrase "out there" in the meetings. ${ }^{1}$ This chapter considers how meeting members employ the phrase in relation to how organisation is accomplished. I want to understand something of what "out there" accomplishes "in here". In this chapter I present the 31 uses of the phrase and speculate about what members might attend to with it. The chapter could have been included in the first section of the thesis because it relies on my descriptions from the meeting audiotapes and transcripts to introduce the material that will be the focus of the following analysis chapters of the thesis. At the same time this chapter also generates questions to guide which interactions to follow. As such this chapter provides something of a transition point where description flows in from the first part of the thesis and analysis flows out into the second. It has been produced to be permeable in this kind of way.

The decision to focus the thesis around the use of a particular phrase was influenced by Wilkinson and Kitzinger's research on the phrase "thinking positively" in cancer patients' talk (2000). This is a successful piece because it combines "how questions", or member techniques, with analysis of a phrase in prominent use. Strathern has also been influential in selecting just one phrase to follow in the thesis:

Thus one might imagine choosing two or three elements of initiation practices for theoretical consideration, knowing that for no single case had one grasped the natural character of the entire phenomenon. Other perspectives remain (Strathern 1991 p. xiv,
my emphasis).

The disclaimer produced in the introduction about partiality is put into practice in this second part. In keeping with the structure of the thesis, this chapter contains some "initial noticings" (ten Have 1999 p. 152 and following Heath 1981). One of the elements that members attend to in the meetings are places, times, and situations beyond the meeting room. One way they do this is by employing the phrase "out there". This chapter begins to ask how the phrase is involved in the meetings.

Does talk of "out there" contribute to making "in here" a meeting? How is it made a part of the business of the meeting (Atkinson et al. 1978)? Can we use the phrase to see how "institutional imperatives originating from outside the interaction are

\footnotetext{
${ }^{1}$ See Appendix two for the conventions used to indicate quoted meeting talk and concepts.
} 
evidenced and made real and enforceable" in the meetings? (Heritage 2004 p. 224). Are there multiple ways that members use the phrase "out there"? Do they use it to refer to the focus of their (operational) work, or their version of "the market"? Is "out there" involved in the marking of boundaries, and does this work show how the use of the phrase relates to making the organisation? Is the phrase included in producing accounts and doing identity work by showing actions and work undertaken (Munro 1999b)? Are meeting members referring to something, work perhaps, in a place other than this meeting, or "clients", where the action is, a particular kind of action, in the future, or in the past?

The phrase "out there" was used at least once in thirteen of the series of fourteen workplace meetings I attended. Though I transcribed all of the audio tapes, the 31 appearances of the phrase make up the recorded talk "corpus" (ten Have 1999 p. 134) for the entire thesis. From this material, only selected interactions will be analysed in the following chapters. Employing the conversation analysis (hereafter "CA") structure in this chapter I do some initial analytic observing (Heath 1981). The major question, as it was in chapter two, is what members might be attending to in the meetings, but this chapter is especially concerned with what members attend to with "out there", and whether there are any "generic features" that allow them to be grouped (Becker $1998 \mathrm{p}$. 141)?

As a way to start inquiring into what members are attending to with their use of the phrase, a number of initial questions are asked. The way the answers are presented is by using the technique, more usual in quantitative studies, of producing tables and then briefly writing up some of what the tables contain. Like the previous chapters, the attempt is to show something of how I came to follow particular uses of the phrase in chapters six to eight. Therefore the tables contain all uses of the phrase "out there" in the meetings, along with speculative labels, question marks and highlighted words, only some of which are discussed in this chapter and in the following analyses. Table one provides a chronological summary of the uses of the phrase across the series of meetings. This table contains a lot of the relatively straightforward detail, which aims to provide a descriptive "feel" for the material, from which analysis then proceeds. This you will find in table two, which considers the topics and concerns meeting members attend to with the phrase. Table one could then be used to check back on the detail of any uses of particular interest. 
Table one asks who uses the phrase, and when? Table two, in section three, asks about the topics being discussed, and attempts some groupings. Keeping the interrelated questions separate is a deliberate first move in this analysis, taken in the hope that a gradual inclusion of more detail will provide understanding of how the phrase "out there" is involved in this series of meetings. In the final section I outline the questions raised, some of which will be taken up in following chapters where actornetwork theory (hereafter "ANT"), Rolland Munro's work and CA are used to analyse some of the interactions involving the phrase.

\subsection{Table one: Uses of the phrase "out there" by date}

Table one provides an overview of all uses of the phrase in the chronological order of the series of 13 meetings. Along with the turn of talk, the table attempts to answer the following questions:

- Was the phrase "out there" used in the meetings?

- Who used "out there"?

- At what point in the meeting was "out there" used - during an agenda item or someone's roundtable turn?

- What was the topic under discussion?

- What was referred to with the phrase? 
2
0
0
0
2

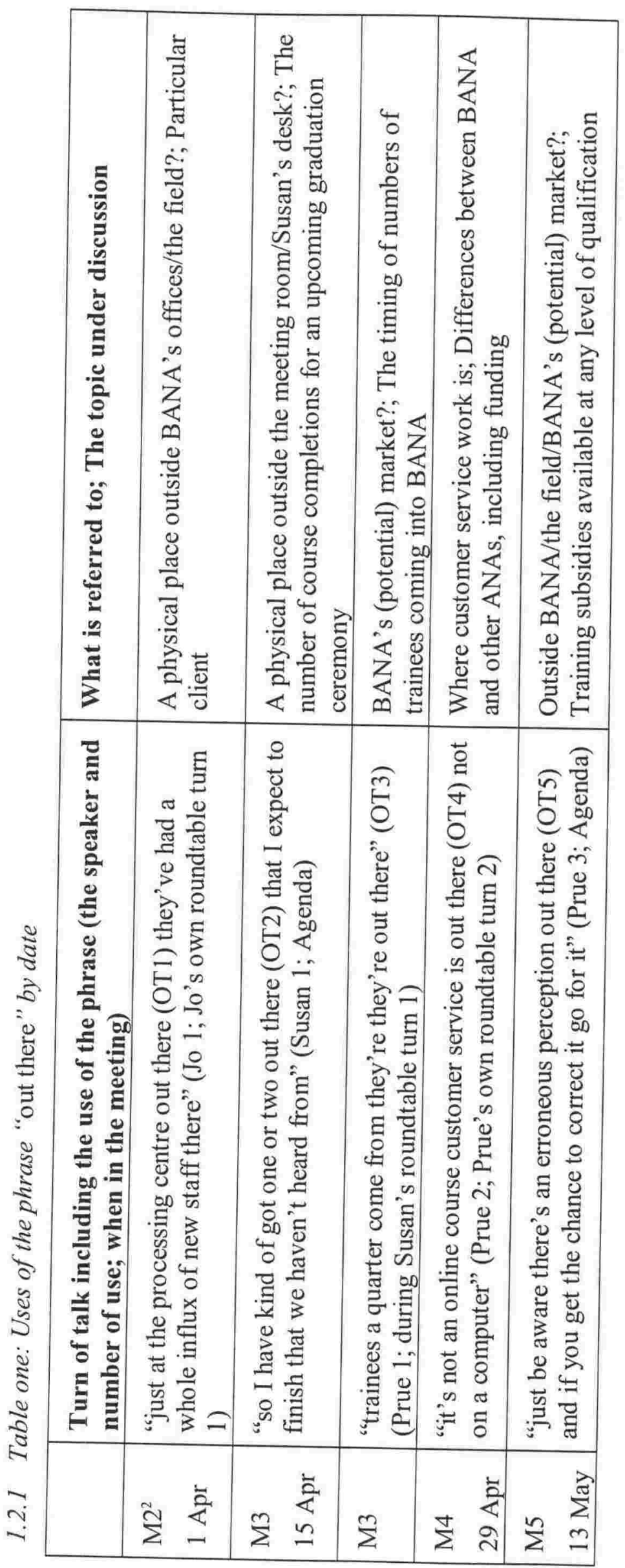

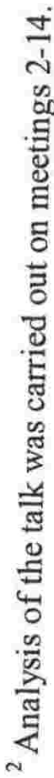


8
8
0
0
0
0

\begin{tabular}{|c|c|c|c|c|c|c|c|}
\hline 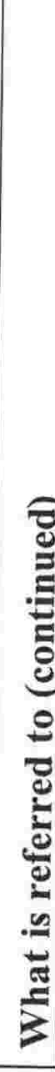 & 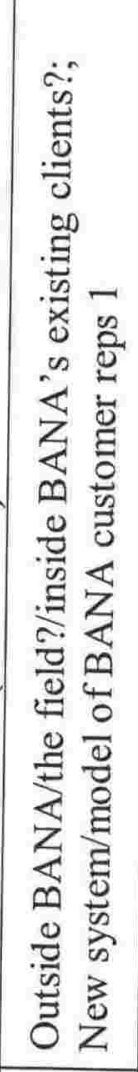 & 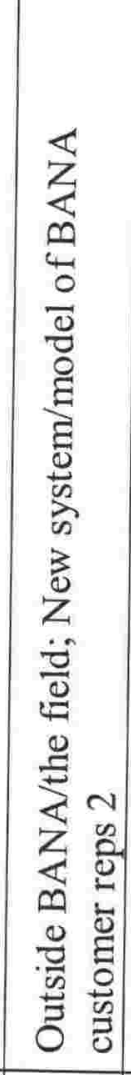 & 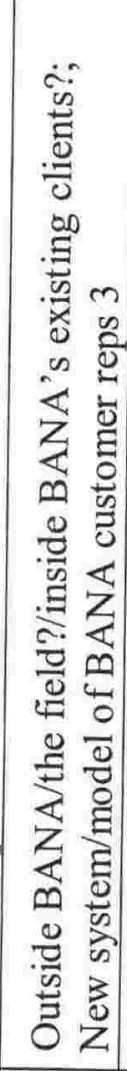 & 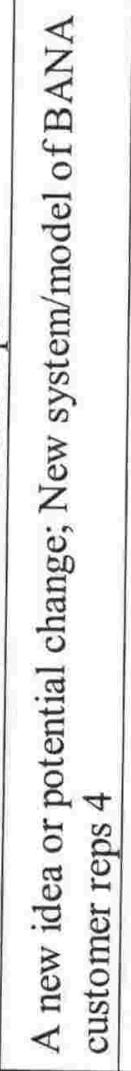 & 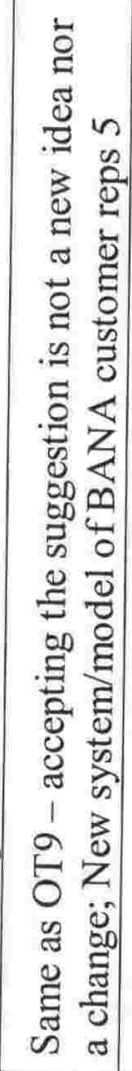 & 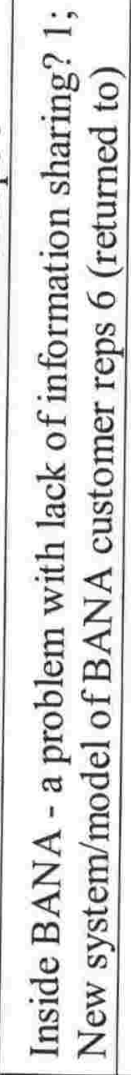 & 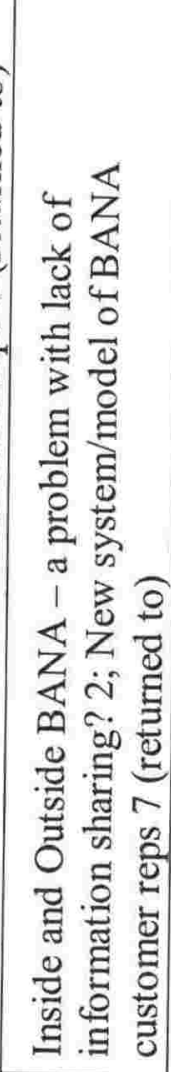 \\
\hline 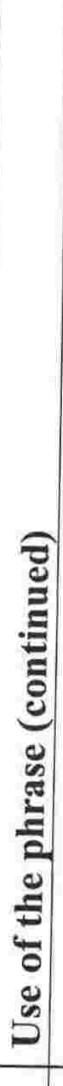 & 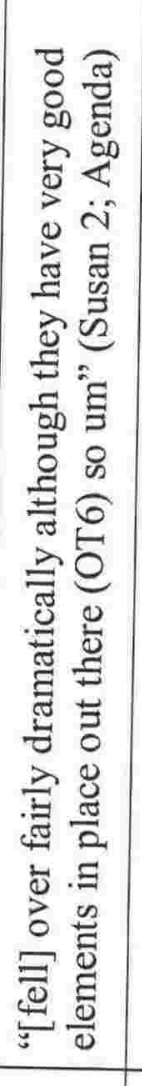 & 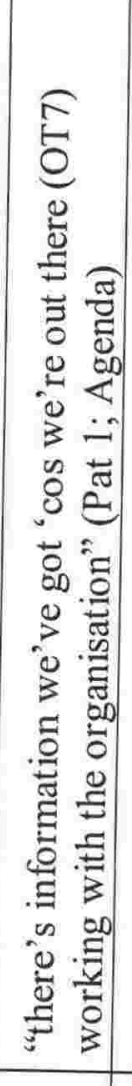 & 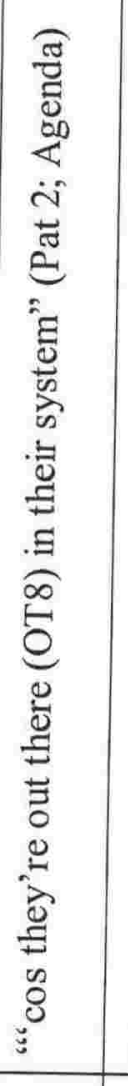 & 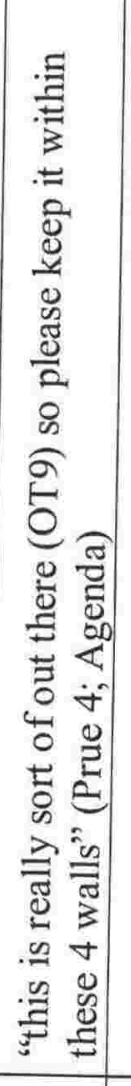 & 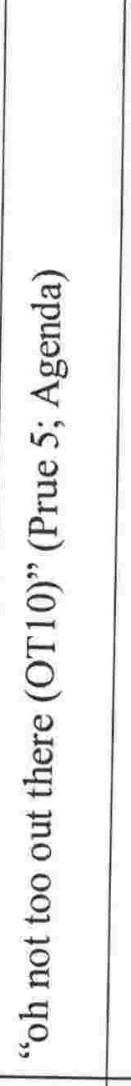 & 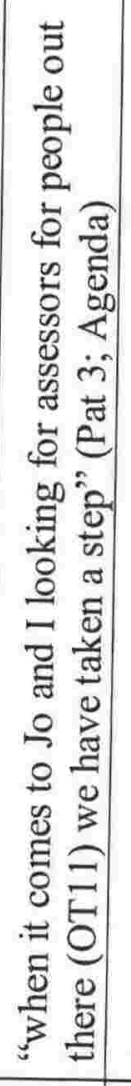 & 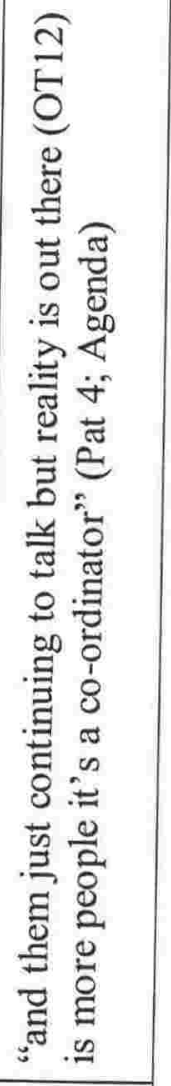 \\
\hline & $\begin{array}{ll}\Sigma & \vdots \\
\Sigma & \sim\end{array}$ & $\sum^{\circ}$ & $\Sigma$ & $\sum$ & $\Sigma$ & $\Sigma$ & $\Sigma$ \\
\hline
\end{tabular}




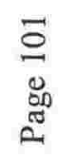

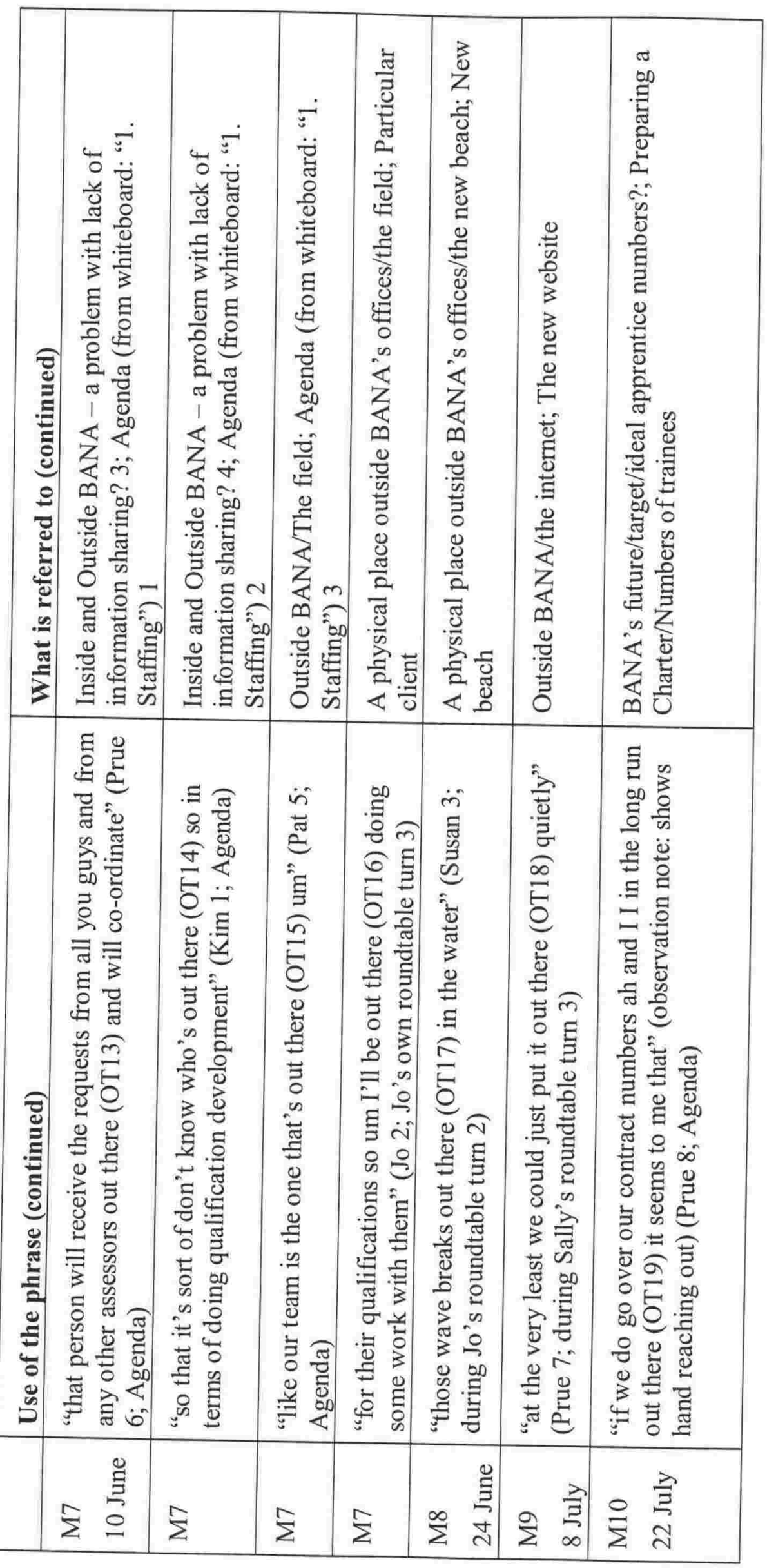




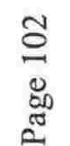

\begin{tabular}{|c|c|c|c|c|c|c|}
\hline 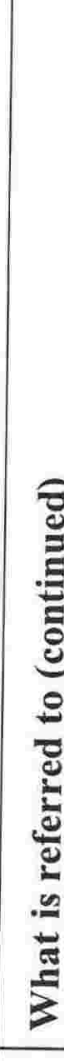 & 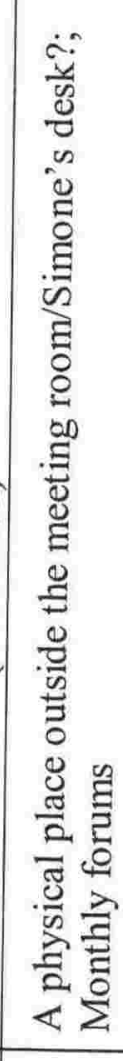 & 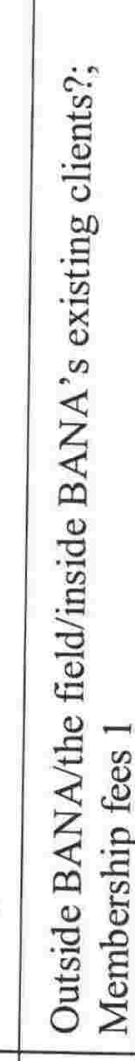 & 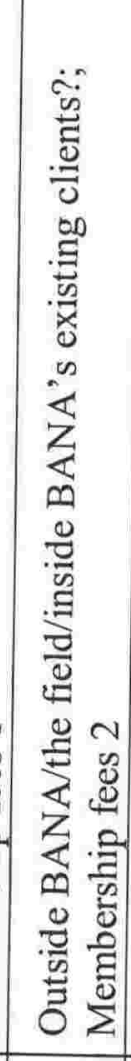 & 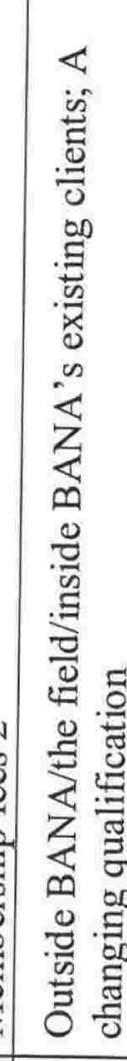 & 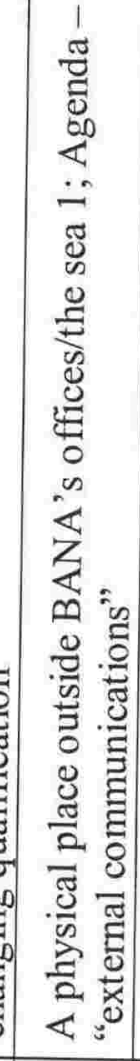 & 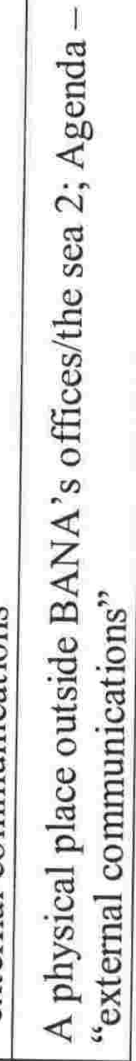 \\
\hline 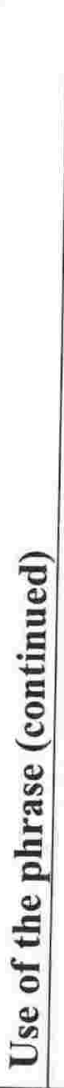 & 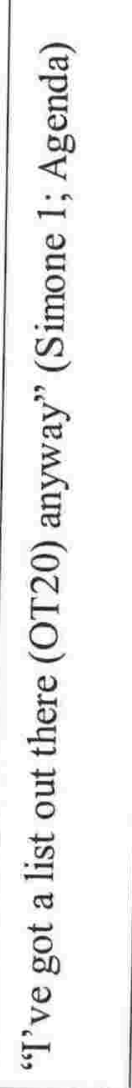 & 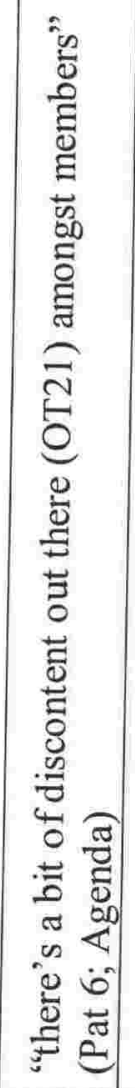 & 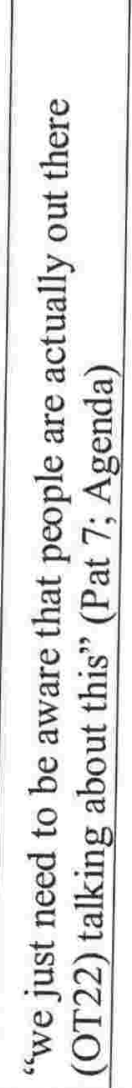 & 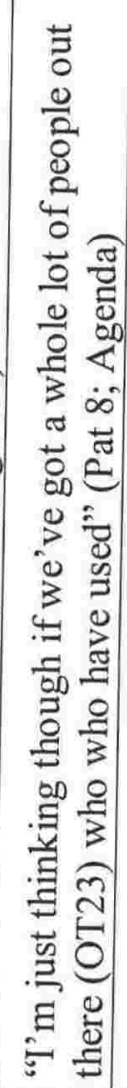 & 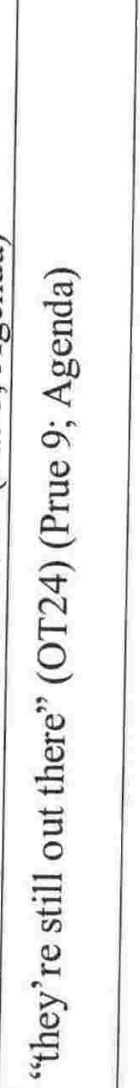 & 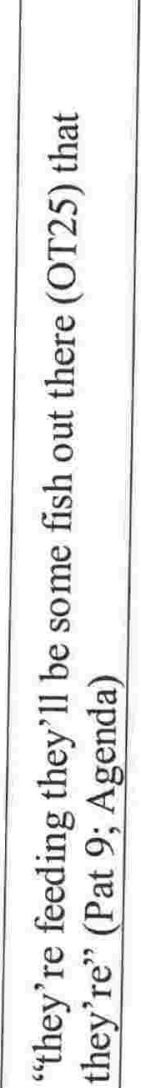 \\
\hline & $\begin{array}{ll}\bar{\Sigma} & \vec{\tau} \\
\text { in }\end{array}$ & & & $\Sigma$ & & \\
\hline
\end{tabular}




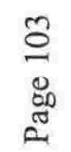

\begin{tabular}{|c|c|c|c|c|c|c|}
\hline 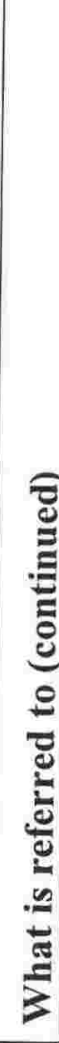 & 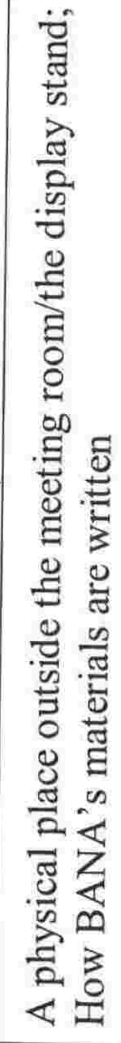 & 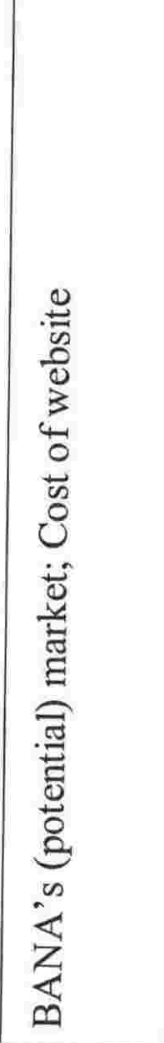 & 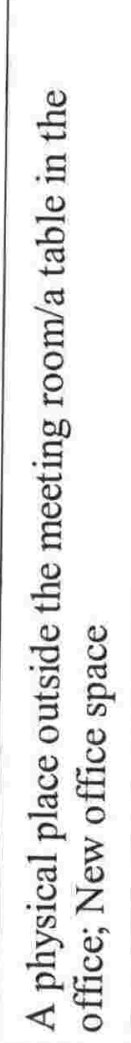 & 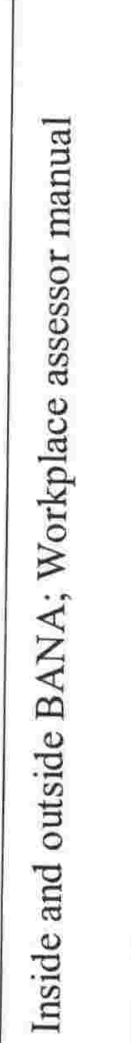 & 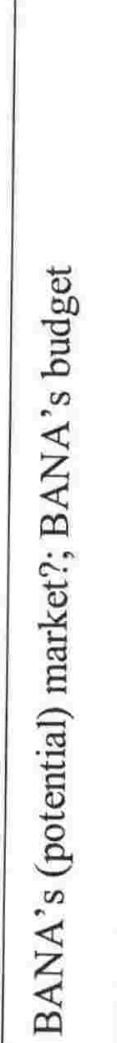 & 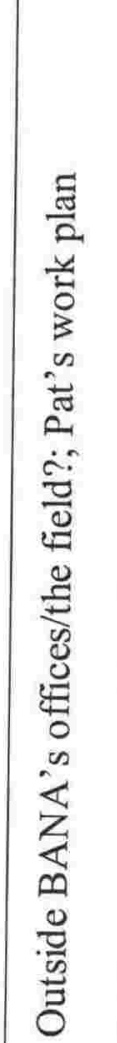 \\
\hline 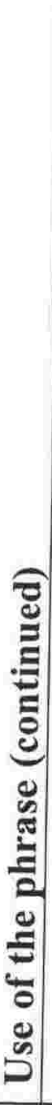 & 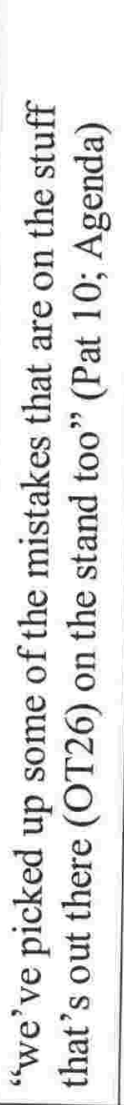 & 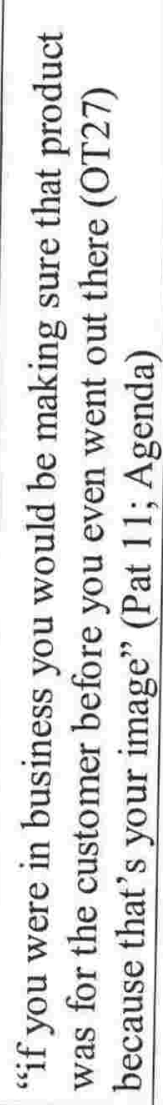 & 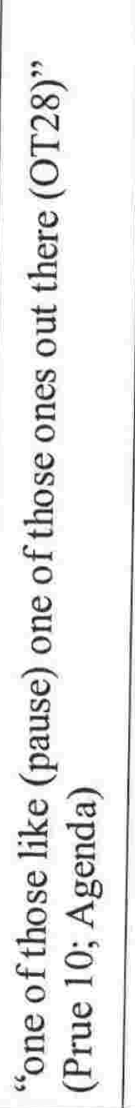 & 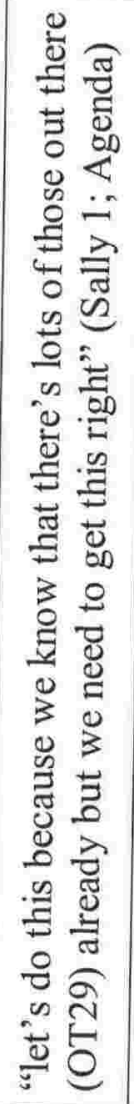 & 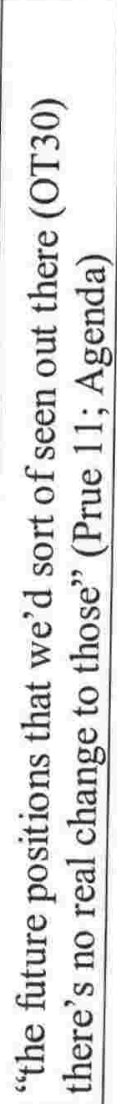 & 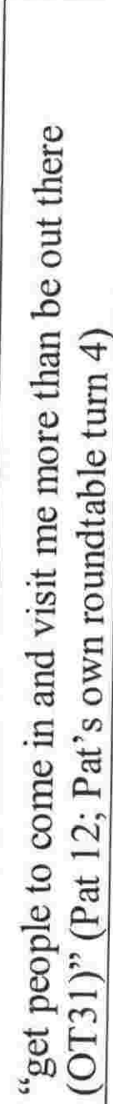 \\
\hline & $\begin{array}{ll}N & z \\
\Xi & a \\
\end{array}$ & $\frac{N}{\Sigma}$ & 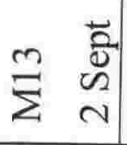 & $\begin{array}{c}\overrightarrow{0} \\
\dot{D} \\
\Sigma \\
\Sigma \\
0\end{array}$ & $\stackrel{ \pm}{\Sigma}$ & $\stackrel{J}{\Sigma}$ \\
\hline
\end{tabular}




\subsubsection{How often was "out there" used in the meetings?}

The phrase "out there" was used in all of the 13 meetings analysed. During a single meeting it most often appeared once (in seven meetings) or twice (in two meetings). Of the total 31 appearances, three meetings (M6, M7 and M11) account for more than half (17) of the uses.

\subsubsection{Who used "out there"?}

Seven of the ten meeting, and therefore organisation, members used the phrase. By location of work (field or office), two fieldworkers (May and Paula), and one office-based worker (Irene) did not use the phrase. The organisation's two long-serving members account for more than two-thirds of total uses. Pat, the "potential field manager", used the phrase most often - a total of 12 uses and Prue, the organisation's manager, 11. All other meeting members used the phrase far less frequently (between one and three times each).

Pat's disproportionately high usage is not explained by frequent meeting attendance. The spread of use across different meetings is wider for Prue, who used the phrase in 10 of the 12 meetings she attended, than for Pat, who used it in five of the eight meetings she attended. Most (eight of 10) members attended between eight and 13 of the meetings. Sally attended all 13 meetings but used the phrase only once. Paula attended six (four in person and two via the polycom) and Kim attended four meetings, resigning before meeting eight. Pat used the phrase most in two meetings (four times in M6 and three in M11), suggesting that her use was connected to particular topics.

\subsubsection{When was "out there" used and what was the topic being discussed?}

Separating the timing of uses of the phrase into agenda items and roundtable turns, seven uses of the phrase occurred during roundtables. Three of the four during the speaker's own roundtable turn were about specific physical places (of work) in the near future, suggesting the reporting and proposing of possible next actions.

The rest (24) appeared during agenda topics. During the first five uses of the phrase, which were spread over four meetings, the topics were:

- Particular client 1

- Number of course completions for upcoming graduation ceremony 
- The timing of numbers of trainees coming into BANA

- Differences between BANA and other ANAs, including funding

- Training subsidies being available at any level of qualification

In meeting six however, discussion of a new system or model of BANA customer representatives accounts for the next seven uses - five initially and a further two when this topic was returned to later in the meeting.

In the following meeting (M7), three uses were during the agenda item on staffing and for the second time in the series of meetings, the phrase was used when discussing a particular client.

In each of the next three meetings the phrase was used once: during discussions of the beach being built across town from BANA's office (OT17), the new website and numbers of trainees for preparing a charter. Meeting 11 had a number of uses, but in contrast to meeting six different topics were being discussed when the phrase was used:

- Monthly forums

- Membership fees (twice)

- A changing qualification

- Agenda - external communications (twice)

In meeting 12 , the only meeting that Prue did not attend, the phrase was used during a discussion of how BANA's materials were written and the cost of the website. Meeting 13 had only one use, during discussion of the new office space. In meeting 14, the phrase was used three times during discussions of:

- The workplace assessor manual

- BANA's budget

- Pat's work plan

\subsubsection{What was referred to with the phrase?}

Four of the first five uses, in meetings two to five, referred to places outside BANA's offices and the other to a place outside the meeting room. Only two were 
specific places, the others being something like BANA's external work sphere or "the field" (for example, OT4). Two involved the future, or potentials.

There were multiple uses in meeting six. Firstly referring to outside BANA or the field and existing clients (a problem and information); then discussion of a new idea or potential change (future solution); and turning to inside BANA and "a problem with lack of information sharing". This "problem" was still evident when the phrase was involved in talking about inside and outside BANA in meeting seven. The final use in meeting seven was a reference to a physical place outside BANA's offices.

The next two uses in meetings eight and nine referred again to places outside BANA - the new beach (OT17) and the internet. However the use in meeting 10 was more difficult to label, perhaps referring to BANA's future, target, or ideal apprentice numbers?

Only four of the six uses in meeting 11 were work-related. Two involved a discussion of fish in the harbour. The first work-related use of the phrase referred to a list outside the meeting room. The remaining three uses referred to what may have been happening with BANA's existing clients.

The six uses of the phrase in meetings 12,13 and 14 show the wide range of uses of the phrase: specific physical things outside BANA and the meeting room; what to do next; what is happening with members; and possible next actions. 


\subsection{Table two: Uses of the phrase "out there" by topics and concerns}

Table two attempts to present the uses of the phrase in groups and list some of the similarities between uses, like when the phrase is used, by whom and what is referred to. The reason for creating this table is to consider the topics or concerns, like "information", which may be attended to with the phrase. Time, space and the material world are used as initial groupings of members' uses of the phrase. Again question marks are used to indicate my uncertainties and hesitations in undertaking this work. The 31 uses of the phrase have been gathered into eight groups:

1. Future.

2. Proposed future ways of working and work tasks.

3. Proposed future ways of working and work tasks.

4. Near future.

5. Current situation?

6. Current practice?

7. Current.

8. Current. 
$\infty$
$\stackrel{0}{0}$
$\stackrel{8}{\infty}$
జ

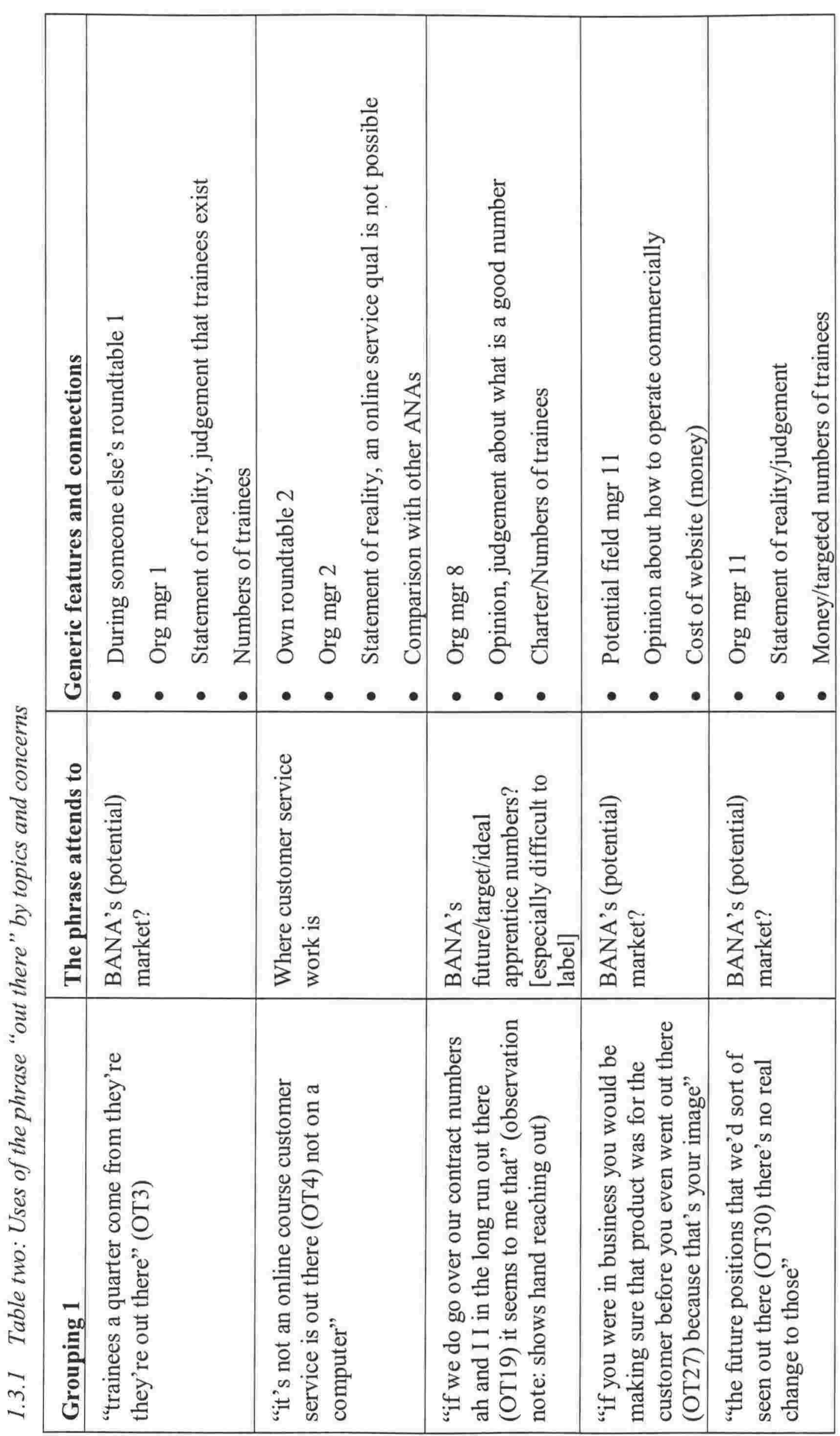


8
0
0
0
0

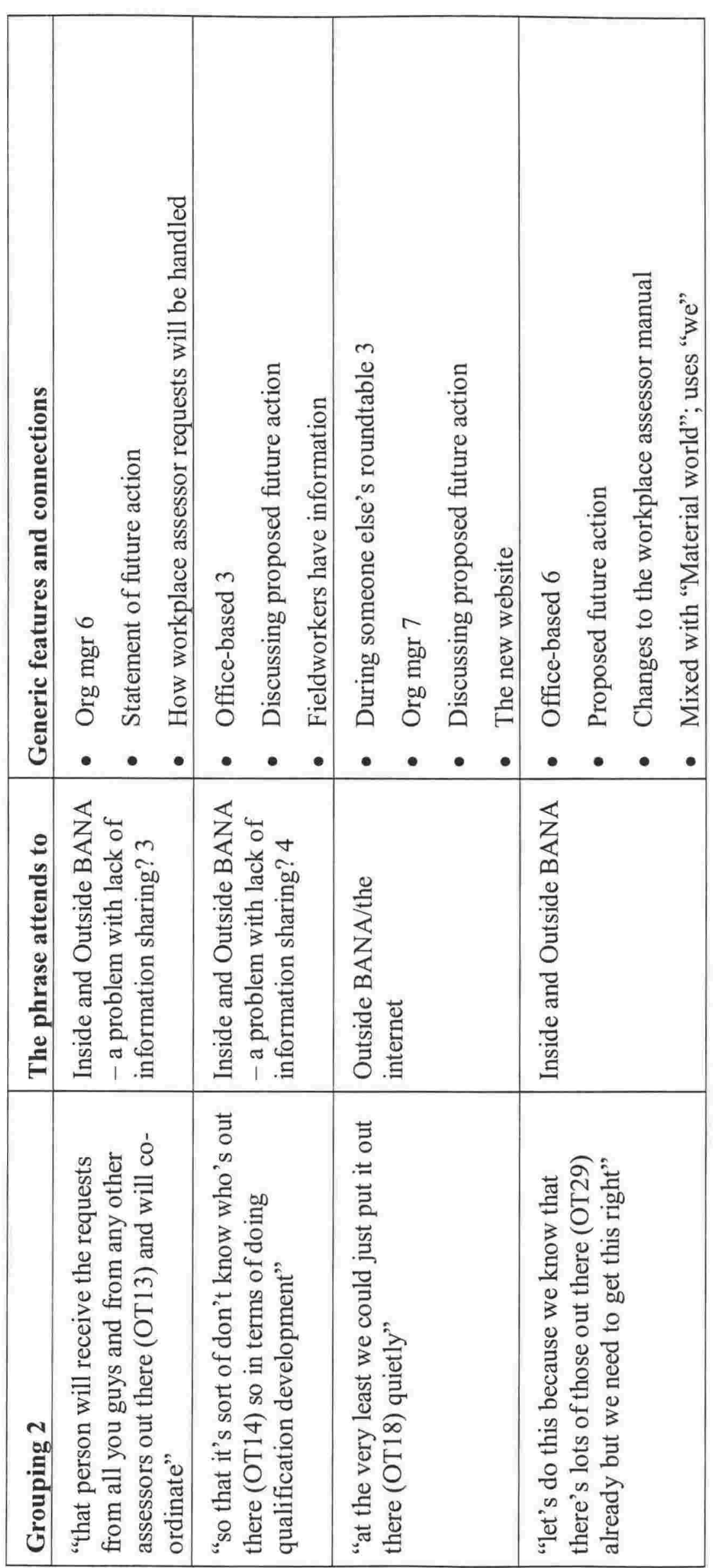


$\stackrel{ }{\Xi}$
品
。

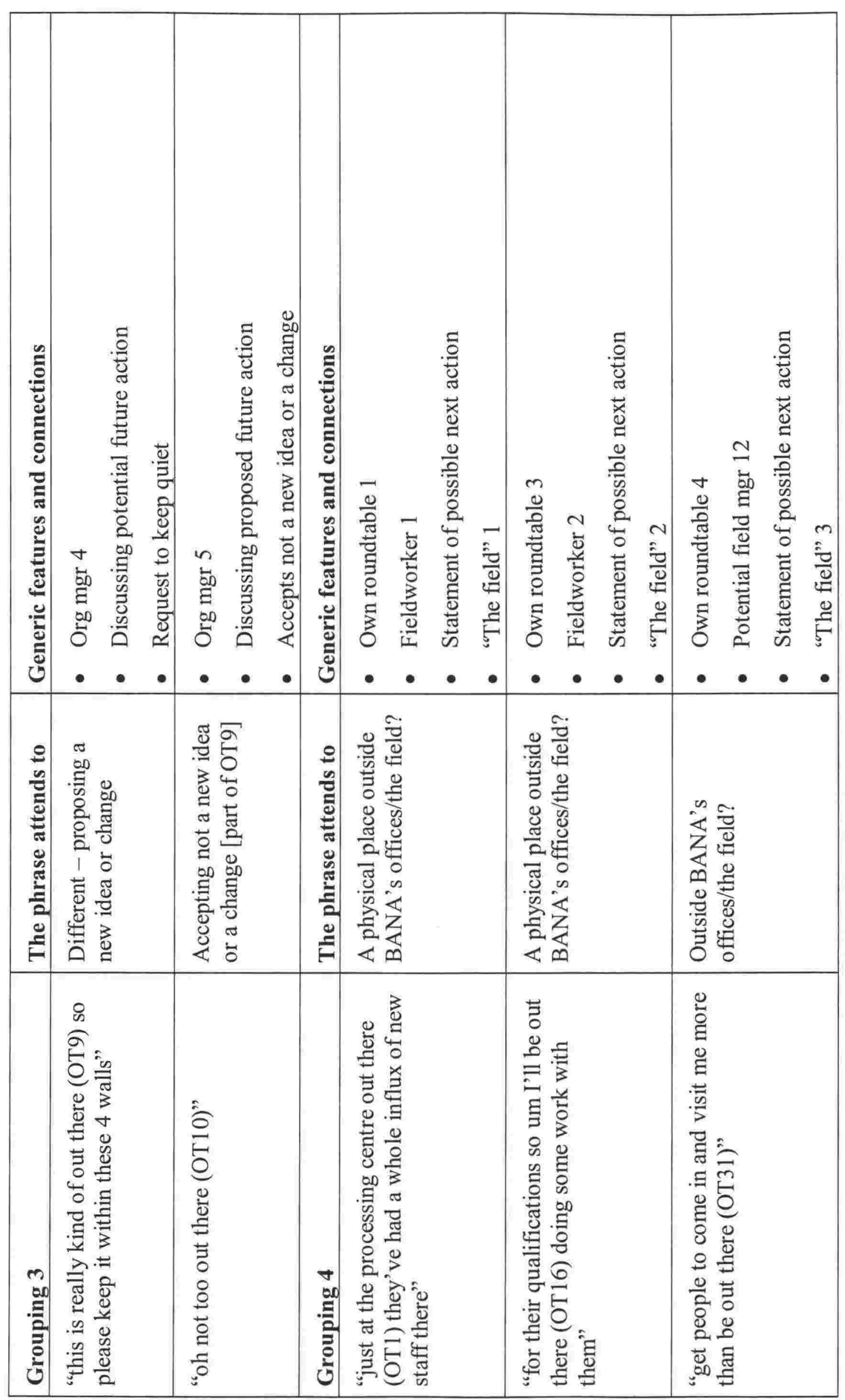


$\Xi$
$\Xi$
$\approx$
$\approx$

\begin{tabular}{|c|c|c|c|c|c|}
\hline 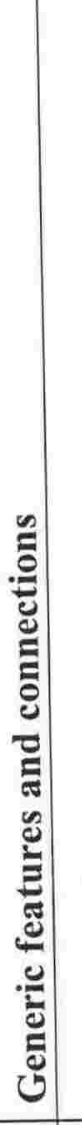 & 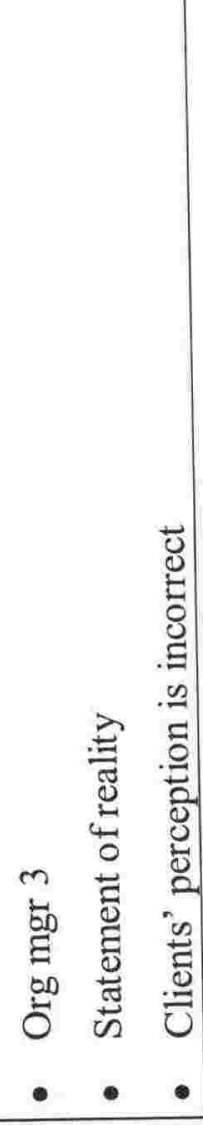 & 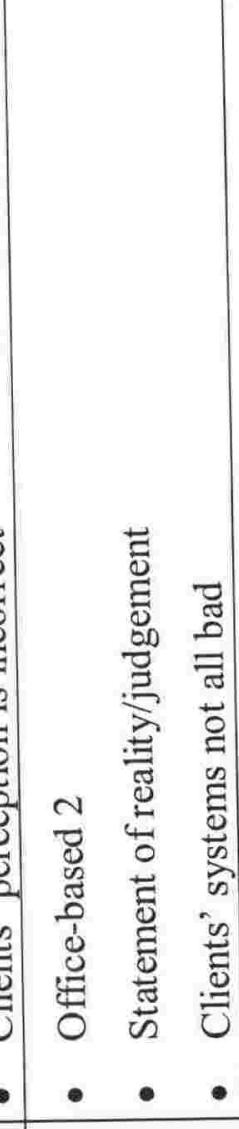 & 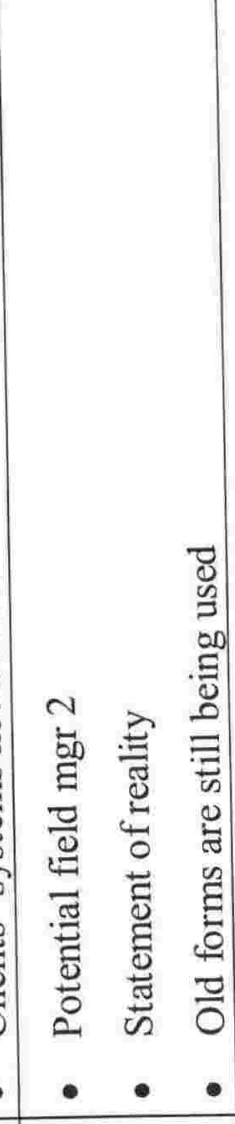 & 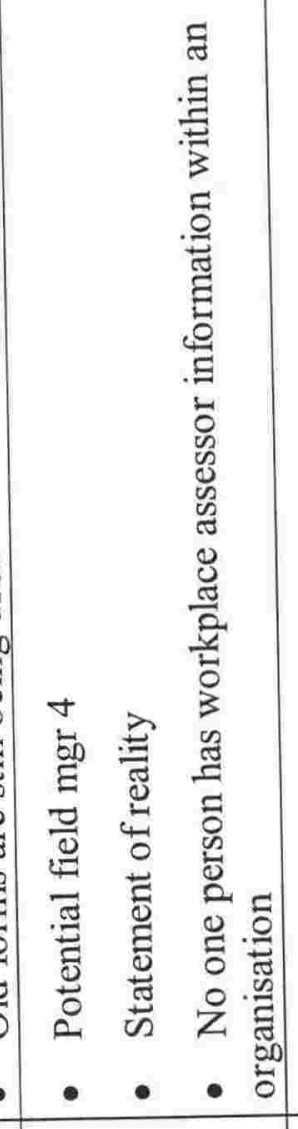 & 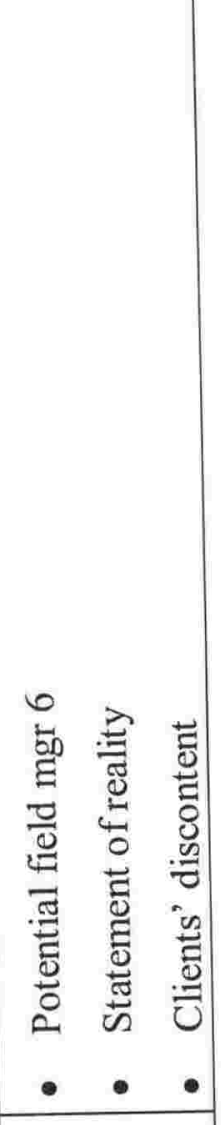 \\
\hline 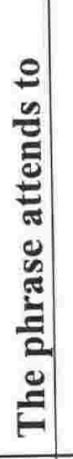 & 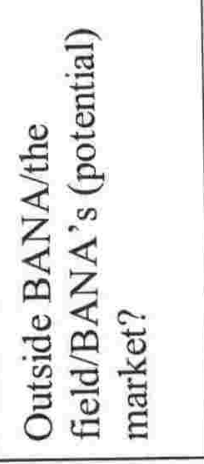 & 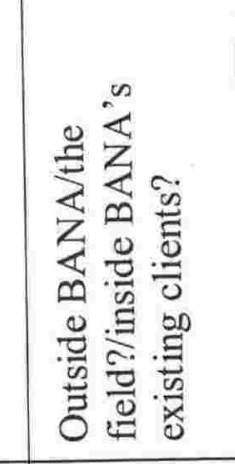 & 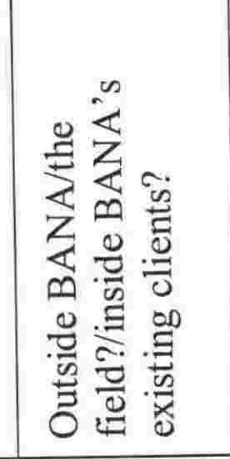 & 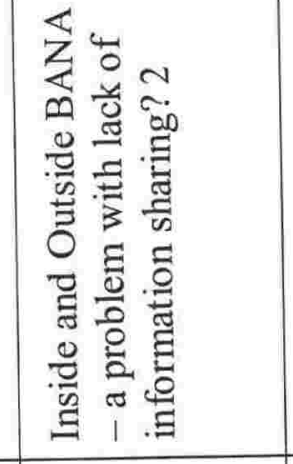 & 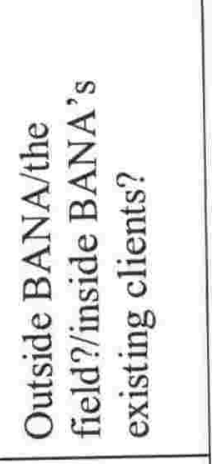 \\
\hline 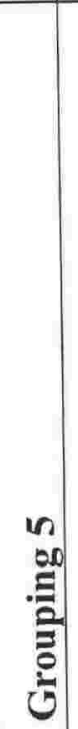 & 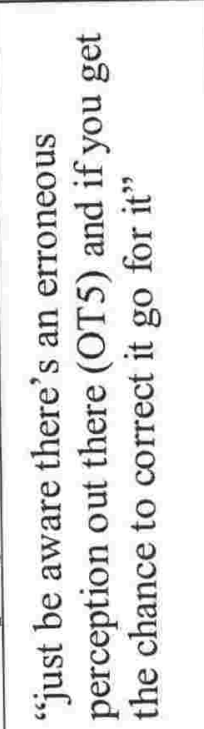 & 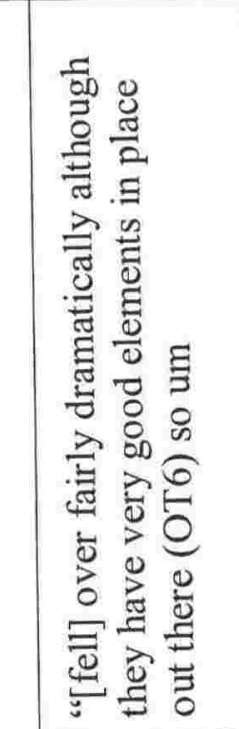 & 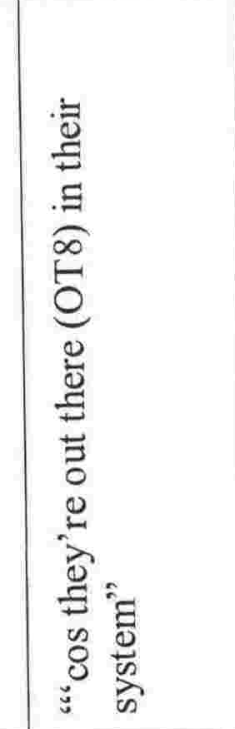 & 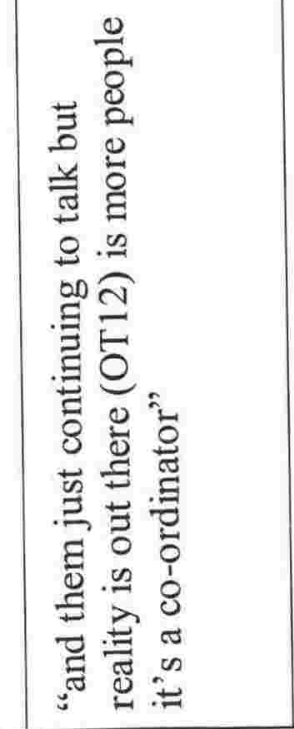 & 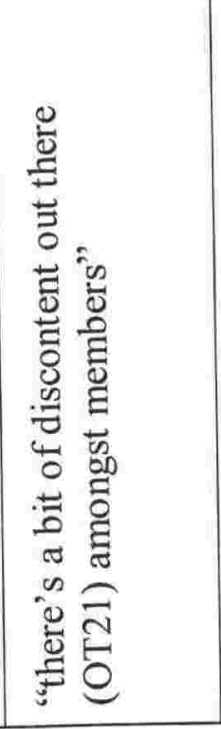 \\
\hline
\end{tabular}




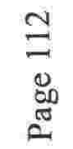

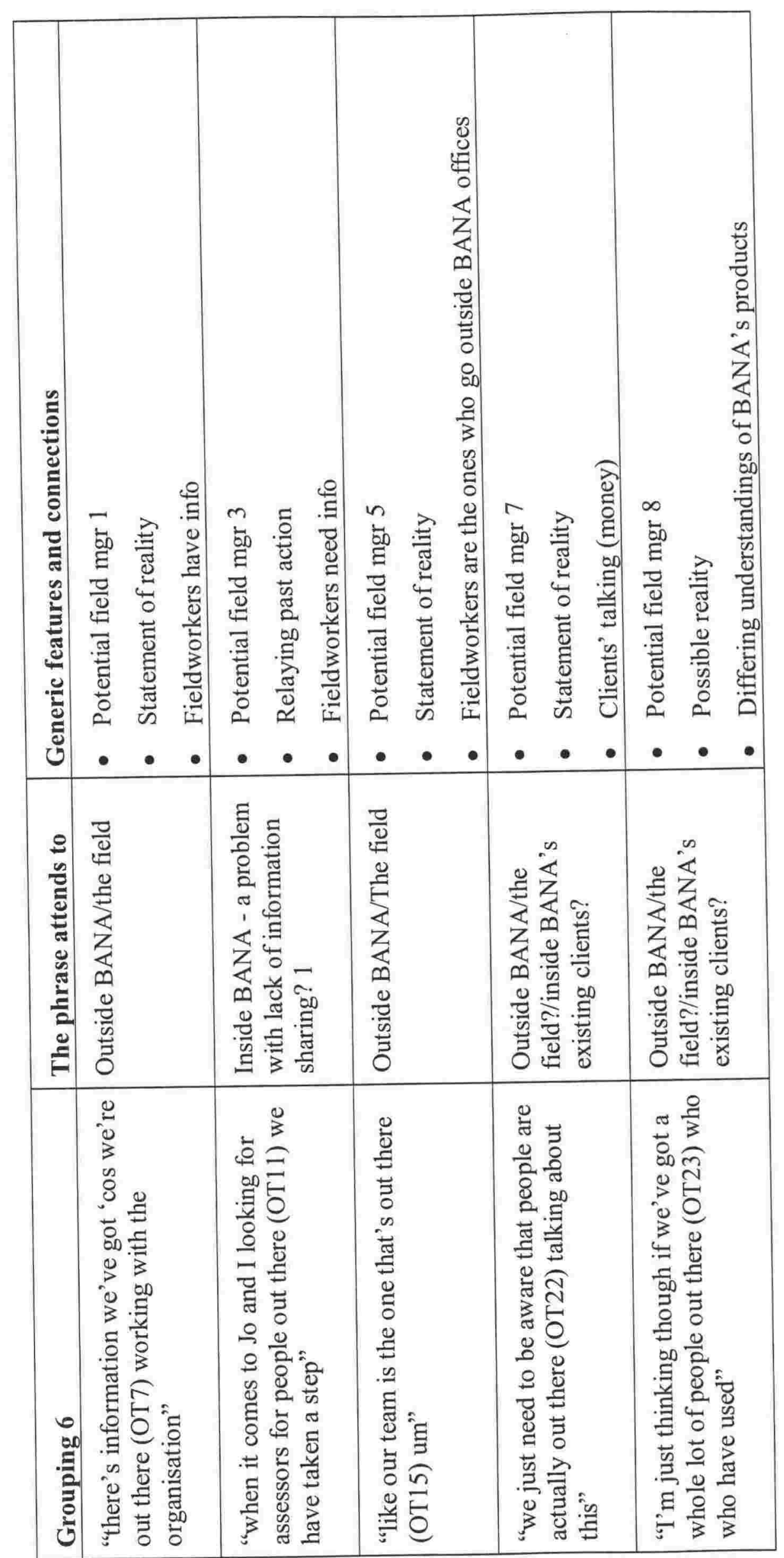


$\cong$
$\Xi$
$\infty$
$\approx$
$\approx$

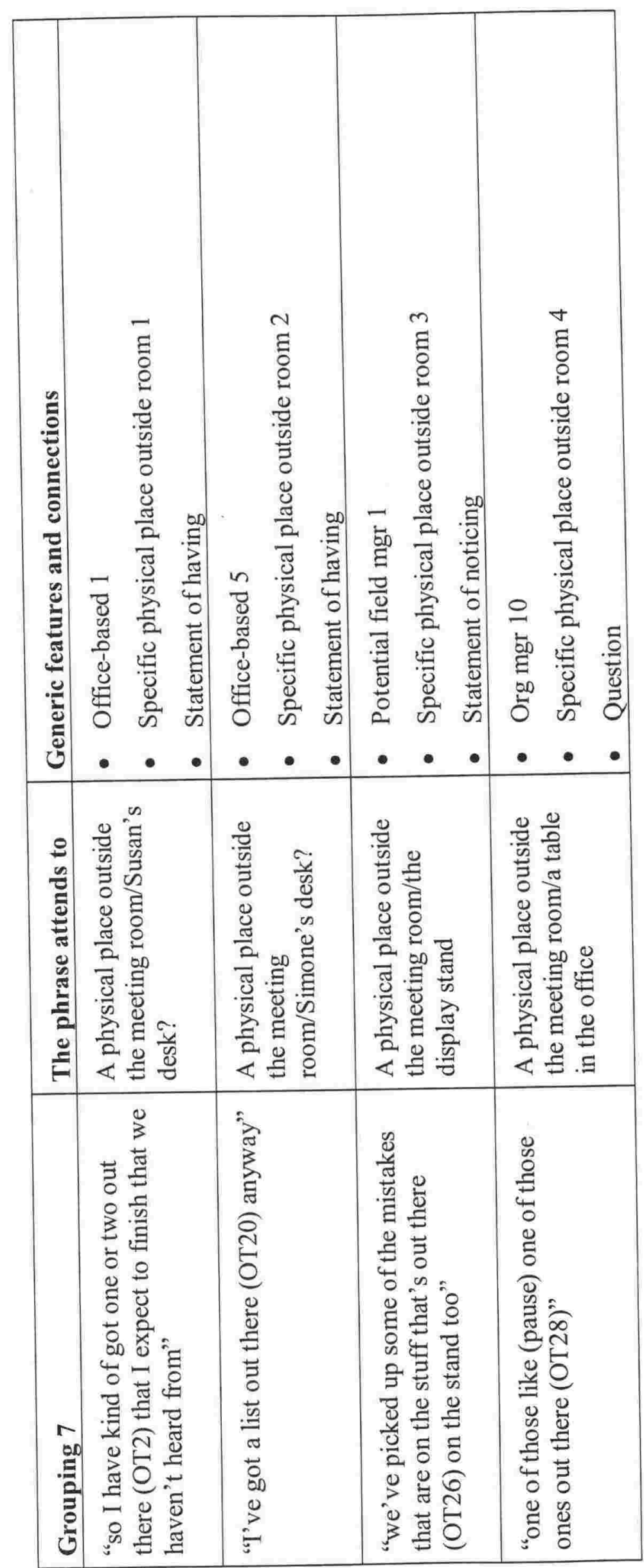




\subsubsection{The future}

The phrase "out there" was involved in discussions attending to the future 14 times. Of these, three were near-future (the time between this meeting and the next) discussions over three meetings about the possible next actions two members might take. They took place during their own roundtables and with reference to the physical places of the field (OT1, OT16, and OT31). Of the other 11, five are grouped under "BANA's potential and/or new members; BANA's market" as they seemed to concern the organisation's future generally. The discussions (over five meetings) concerned the connected topics of money and numbers of trainees. As you can see in the table the topics are:

- Numbers of trainees (OT3)

- Comparison with other ANAs, including funding (OT4)

- Charter/Numbers of trainees (OT19)

- Cost of website (money) (OT27)

- Money/targeted numbers of trainees (OT30)

The manager made most of these statements, opinions, and judgements but one was made by the potential field manager. Perhaps use of the phrase "out there" to discuss numbers, targets and budgets indicates a concern for comparison and judging how the organisation was doing?

The next grouping of four uses of the phrase, over three meetings, concerns future ways of working and work tasks. Grouped under the category "space", are discussions about work within BANA with reference to "the field". The topics discussed were:

- How workplace assessor requests will be handled (OT13)

- Fieldworkers having information (OT14)

- The new website (OT18)

- Changes to the workplace assessors' manual (OT29)

There are three speakers. Again this included the manager, but also the singular uses of the phrase by office-based workers, Kim and Sally. 
The final future grouping contains two uses by the manager with regard to future ways of working (OT9, OT10). These have been separated because having BANA representatives was presented as a new idea or potential change rather than existing in any current place or practice.

\subsubsection{The present}

Slightly more uses of the phrase were about current situations and practices (17 of 31). However, taking out the three "non-work" uses of the phrase shows a balance between the future (14) and the present (14) uses of the phrase. Under "discussion of current situations", Prue, Susan and Pat used the phrase five times over three meetings with regard to BANA's clients or members. Using "they", "their" and "there", the statements appeared to be about what was happening currently, based on judgements from first-hand contact with clients. The specific topics were:

- Clients' perception (OT5)

- Clients' systems not all bad (OT6)

- Old forms are still "out there" (OT8)

- No one person has workplace assessor information within an organisation (OT12)

\section{- Clients' discontent (OT21)}

The next grouping involves BANA's current practice and statements about what should be done because of what was happening outside BANA (with reference to the field). Pat used the phrase five times over three meetings with "we" and "our team" (OT7, OT11, OT15, OT22, OT23). Two of the statements were that fieldworkers had information; another that fieldworkers were the ones who go outside BANA offices. Pat also stated that clients' were talking (about money). The final use in this group was a discussion involving differing understandings of BANA's products.

The final group in the category "present" involves direct reference to physical places outside the meeting room but within BANA's offices. The statements (OT2, OT20, OT26, OT28) by four people over four meetings were about having or noticing material things. Pat and Prue were again users of the phrase in this way. This group included Simone's single use. 


\subsubsection{The non-work world}

Meeting 11 is also in the group of three uses of the phrase where BANA's work was not referred to directly. In meeting 11, Prue and Pat again used the phrase to talk about the world (OT24, OT25). Both were during the agenda item on external communications. Prue and Pat's use of the phrase was not about work, but the phrase was put to work for them, in some way. What is it about meeting 11 that results in multiple uses of the phrase? The other "non-work world" use was by Susan during Jo's roundtable in meeting eight (OT17).

\subsection{Questions}

Thinking back to the ethnographic description of the meetings in chapter two, do the uses of the phrase show the range of topics usually discussed in the meetings? Who attends to what kinds of spaces and times? For instance, does only Prue, or only Prue and Pat attend to the future and BANA's potential? Consider this description of OT5 in meeting five in that earlier chapter (in the format that indicates the taperecorder's voice):

Pat asks which organisation said this, and Prue gives some more detail. There is a discussion. Prue says "just be aware there's an erroneous perception out there" and that we should correct it if we get a chance (from chapter two).

Talk of the future involves planning and reassuring and was, obviously perhaps, done here by Prue, the organisation's long-serving member and manager. Current (and near future) talk can be described as reporting and explaining, and this kind of talk was undertaken by a broader range of meeting members. Warnings about current BANA practice however, seem to be undertaken by Pat (the other long-serving fieldworker who at the time of these meetings was a candidate for the newly created fieldworkers' manager position) using first-hand experience of "out there". The questions arising include:

- Did Pat use the phrase "out there" to warn?

- What can be said about warnings? For instance, how do they compare to Prue's uses of the phrase? In contrast to Prue's "instruction-giving", were Pat's uses presented as making aware, and so more like persuasion? 
- Is "out there" a normative and "future" phrase, used by members as part of showing leadership in demonstrating commitment and responsibility (for instance, Pat showing that she can be the new manager)?

Dividing by present and future, the multiple uses of the phrase in meetings six and 11 occur mostly during discussions of current situations and practices. This perhaps indicates that the phrase is used to attend to problems. Questions include:

- What connects meetings six, seven and 11 apart from multiple uses of the phrase (M6 and M11 were the meetings in which Pat used the phrase a number of times)? Do the non-work uses of the phrase in M11 indicate tension in the meeting?

- Were meetings six, seven and 11 connected by concerns about customer service and how to structure and staff BANA?

- Considering uses of the phrase in meetings six, seven and 11 in discussions of the new system (of organisation structure and staffing), what are the ways in which meeting members discuss an issue facing the organisation?

There do not seem to be differences with regard to time in use of the phrase by the main location of work of the user (field or office-based). Under the category "future", two of the 11 uses of the phrase (OT14 and OT29) are by office-based workers. Though proportionately this is not out of place, I consider the interactions involving OT29 in the next chapter, OT11 in chapter six and OT12 in chapter seven to inquire into:

- Whether field accounts were able to stand alone in these meetings (perhaps indicating that accounts from having been in the field were useful).

- How assertions of what the organisation should do next were defended.

- Whether Sally's use of the phrase (OT29) with regard to what should happen next can be seen as rejected or moderated by Prue. If so, what can be said about this? For example, it was not defended with a legitimately used field account, which indicates an organisational hierarchy where Sally is only an office-based worker.

At first glance, uses of the phrase "out there" appear to be about the current situation based on judgements from first-hand contact with clients and other nonBANA people. 


\subsection{Conclusion}

This chapter began the work of considering whether particular kinds of entities, notions and realities were being worked on in the meetings, and how this was done. Firstly, with regard to making this bounded organisation and attending to its purpose, meeting members talked about not having time to chase other organisations and also compared themselves to other organisations. Secondly, part of showing themselves as a group who works together collectively, members demonstrated a concern with sharing information (using "we"). Thirdly, being an enterprising organisation made up of enterprising workers, was indicated, for example, when getting "out there" was taken to be a good action. I have these kinds of meeting member attempts in mind when I look closely at the meeting action in the following chapters. For instance I will consider whether field accounts are powerful in that members can do things with them. What are the effects of this? For instance, if a meeting member does not have access to the resource "field account", are they excluded from making statements about what should happen next in the meetings?

The way I have inquired into these kinds of questions about organisational action is by examining uses of the phrase "out there". As outlined in this chapter, this is the action of particular interest. The concern is with making - this organisation; the world; these meetings. The aim is to see how this is accomplished, which is attempted through observing actual talk (Silverman 1993). I want to understand something of what "out there" does "in here". What does the phrase interactionally accomplish?

The aim of this chapter was to present the 31 uses of the phrase and speculate about what members use it for. One example is that of "comparison" between organisations; talk of standard and best practice in contemporary workplace practice. In chapter two "comparison" appeared twice in the list of actions from meeting 5 (action numbers 28 and 49). One involved talk of good assessor practice, perhaps to confirm that BANA was doing things right. The fourth use of the phrase "out there" also involved comparison (OT4). Is this an example of Boden's contention that: "as actors also look 'sideways' and adjust their actions to those of others across the organizational landscape, they are acutely, if incompletely, aware of their coordination" (1994 p. 207)? Can we see that organisational practice involves constant comparison and co-ordination? 
The remaining chapters draw on the techniques of $\mathrm{CA}$ and $\mathrm{ANT}$ as a way to see what work the phrase does in the meetings. Using CA is one way to alleviate the concern that separating uses of the phrase into my categories and groups like "talk of the future", ignores interactions and the sense that "this one meeting" is an event for itself. For instance, how is it that meeting six involved the highest number of uses of the phrase "out there"? How was talk about "information" involved? In this chapter some specific questions were raised that could be explored in the analysis chapters. The hope in the remaining chapters is that considering the involvement of the phrase "out there" in some of these workplace interactions will provide some understanding of the meeting members' multiple attempts and achievements.

As a way to start closely and carefully examining the material, in the next chapter (chapter six) I look at Sally's sole use of the phrase while I was attending the meetings. One concern of theses analyses is how statements of what BANA should do (next) are defended and I have chosen OT29 because of the hunch that it was a failed attempt to propose organisational action. I have CA's deviant case technique (Heath 1981 ) in mind. If OT29 is not like some of the others, does this reveal anything about the others? What may be gained by examining different, non-dominant uses of "out there"? Is OT29 a departure from some kind of turn-taking organisation in these meetings? 


\section{Chapter six}

\section{An unsupported use of the phrase?}

\section{TABLE OF CONTENTS}

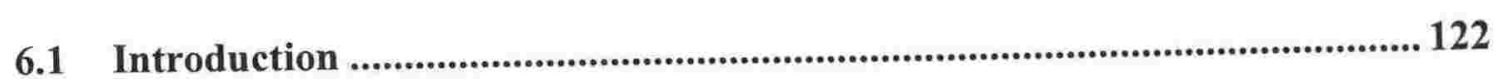

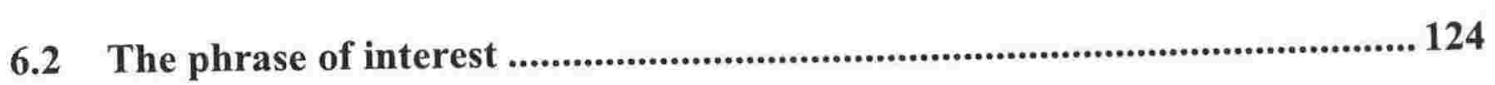

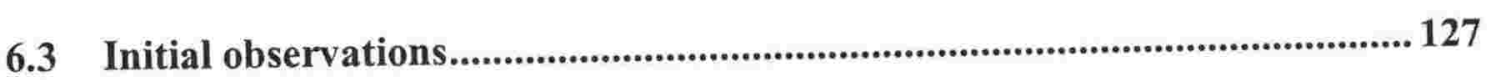

6.3.1 Section 1 of the interaction: Producing this update ............................. 128

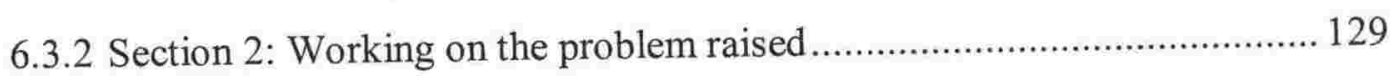

6.3.3 Section 3: Solving the problem raised ............................................ 130

6.3.4 Section 4: Attempting an exit and emphasising the problem ................... 130

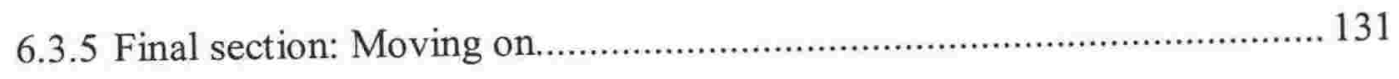

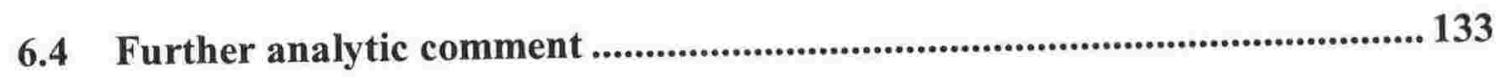

6.4.1 The organisation of the talk: The object within the sequence .................... 133

6.4.2 Multiple actions: Working on alignment and showing commitment ........ 135

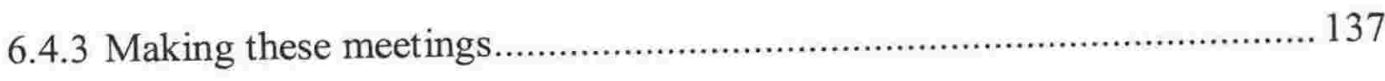

6.4.4 Further questions: Expected contributions ....................................... 139

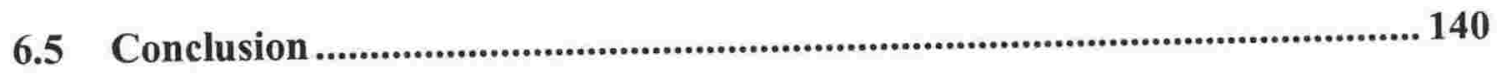




\subsection{Introduction}

Sally: Ok what should be the priority here let's do this because we know that there's lots of those out there already but we need to get this right and in getting this right

Prue: yeah

Sally: it helps develop that (M14)

In the previous chapter OT29 was described as one of the two uses of the phrase "out there" by office-based workers to talk about the future. The questions raised in that chapter after all 31 uses of the phrase in this series of meetings had been compared, included how assertions of what the organisation should do next are defended. Speculatively, I asked whether field accounts could be seen as standing unchallenged in these meetings, and how statements about what BANA should do next, and the future of the organisation, were defended with accounts from having been "out there" in the field. Further, I want to ask, if a member does not have access to field accounts are they excluded from making "should" statements in the meetings?

As I outlined in chapter three I am attempting to follow the action. I am doing this by using the phrase "out there" and asking how some of the uses of the phrase are involved in the meetings. This has led to considering how field accounts were used in these meetings, how they were or were not useful. For instance, were they used in attempts to have some other place ("out there") influence what happened here? In this chapter and in chapters seven and eight the work of John Heritage, Rolland Munro and Harvey Sacks is drawn on to consider how the phrase is used as a "resource" (Heritage 2004 p. 239; Munro 1998 p. 208; Sacks 1987 p. 56). By following the involvement of one phrase across a series of meetings, but choosing only a few interactions to consider closely, I am mixing Munro's "circulation of discourse" approach and conversation analysis (hereafter "CA") (1998 p. 211). The involvement of the phrase is watched to see the ordering of these meetings, the partial making of this organisation, and the accomplishment of the work.

As a way to consider these broader concerns, this chapter is a careful and close exploration of the involvement of the phrase in this meeting. How is "out there" "deployed" and for what purposes (Munro 1998 p. 217)? How are uses of the phrase involved as "part of some larger sequence (like giving instructions)" (Moerman $1988 \mathrm{p}$. $42)$ ? In this chapter OT29 is considered alone. Sally's work here is in particular focus 
because "out there" appeared in one of her turns, but it is the interactional actions of all members that are the subject of close scrutiny. The numeric label OT29 holds for now, but the hope for this analysis is that some kind of description conveying how the phrase "participated" will be possible (Mol 2002 p. 152-3). The overall structure for the chapter is to start with initial observations and build towards a fuller account (following Heath 1981, and Silverman 1999). At the same time, it is recognised that this description is "partial" (Strathern 1991 p. xiv). The concern is to see some of "the practical resources necessary to perform society" (Latour 1986 p. 273).

Firstly, the entire interaction of just over 90 turns of talk is presented. During the analysis, the interaction was divided into five sections and this structure is used to make some initial observations in the second part of the chapter. In the third section, further analytic comment is made about the structure of the talk using concepts from CA, including a discussion of Sacks' "misunderstanding machinery" (1987 p. 66). In the final section the interaction involving OT29 is discussed as an example of workplace "action, context management, and intersubjectivity" (Heritage 2004 p. 224). Munro's work is also drawn on to ask about how some things like power, hierarchy, or rank may be seen in this one interaction, a concern expanded on in following chapters.

Apart from OT29 standing out as one of only two uses of the phrase by office-based workers to talk about the future, which marks it as unusual, what is it about this interaction that warrants this singular consideration? Prior to closely considering the interaction using $\mathrm{CA}$, the decision to follow this use of the phrase was based on a hunch that it was a failure of some sort regarding what should happen next. In keeping with the CA technique of identifying a deviant case or departure from some kind of organisation, this interaction was singled out as one where something possibly was wrong.

I noted the conventions used to mark meeting talk and concepts in a footnote in chapter one and also in appendix two, but in this chapter, where I frequently use meeting talk and my own concepts within sentences, a reminder is useful. Where excerpts of talk from the meetings are used within my text they are indicated by double quote marks and italics (this convention is used by Middleton 1998 p. 250). For example:

Though Prue has the last word, it is not a concrete action, it is less emphatic than her initial suggestion that they "go back to the individual departments and projects" (150). 
Where I have developed concepts, these are italicized. For example: One focus of the research has become attempts at telling how I know in these meetings.

The full transcript of the interaction being considered is presented below. With regard to transcription symbols, following Atkinson's (1995) advice about readability, CA's technical marks have been kept to a minimum. Conversation analysis transcription marks follow Paul Atkinson (1995 p. 152) and David Silverman (2001 p. 303). A complete list of transcription symbols used can be seen in Appendix two. In this chapter in particular: "=" indicates no silences between lines of talk; "[" overlapping talk; capitals increased loudness; empty brackets or "(unclear)" indicates uncertainty, or failure to transcribe.

\subsection{The phrase of interest}

The interaction surrounding this use of the phrase is about 2.40 minutes long, which is a tiny piece of the hours of the total transcribed talk. One advantage of concentrating on this small fragment is that it made it possible to create a file that could be listened to using software that is part of the standard accessories on personal computers, rather than relying on the tape surviving multiple playings. This computer file allowed repeated listening, resulting in a more precise transcript of the interaction. For example, Prue makes a " $t u t$ " sound during Sally's talk about what she had seen while working on the manual. Listening again and again suggested that this " $t u t$ " may have been influential in this interaction. For instance, it may be something Pat picks up and uses for her proposal during the interaction, and one indication Sally takes that she can speak strongly and say what should be done next.

This is Sally's only use of the phrase "out there" in the 13 meetings from which material was analysed for this thesis. It is from the final meeting I attended. At the beginning of the interaction Prue introduced a new topic, which she said had been discussed in the previous meeting. She asked about the completion of the review of a manual by BANA people. The interaction is presented as five sections as a way to see the different actions attempted and accomplished across the interaction.

\section{Section 1}

1. Prue: ah just we talked about the the workplace assessor manual is that has that been reviewed now

2. Sally: no 
3. Prue: Ok [

4. Sally: [(unclear)

5. Prue: so that's still in progress

6. Sally: yep yep and I mean just the other day I it might have been yesterday I picked it up and I was reading through a particular section to find out some information and there was a be instead of by and a though instead of through

7. Prue: tut

8. Sally: and so it's that sort of detail that you actually have to go through

9. (unclear): $=($ unclear $)=$

10. Pat: =oh yeah and that's why I'm wondering about sending it to an editor=

11. Prue: =yep well we've got to get our side of it done first=

12. Pat: =done first but and 'cos there's a couple of pages that are in there twice $=$

13. Sally: =twice

14. (Prue): [is there (unclear)

15. Pat: [and we can't figure out oh god we only spent a few minutes on it aye= 16. Sally: =yeah (unclear)=

17. Pat: =trying to figure out what the hell happened here and then we thought no let's not worry we just said [oh it's there you know (unclear) spend hours

18. Prue: [nup nup (unclear) mark it on the $=$

19. Sally: =we took the website as the priority=

20. Prue: =yes=

21. Pat: =yeah=

22. Sally: =too many little things in the manual

End of section 1

Section 2

23. Prue: well what's um because we're running out of manuals to send out to workplace assessors

24. Pat: yeah

25. Susan: >photocopy ' $\mathrm{em}<$ (speaking quickly)

26. Prue: so we $=$

27. Pat: =yeah I'd just photocopy

28. Prue: $\mathrm{Ok}=$

29. Pat: =til we til we got this done

30. Prue: Ok

31. Pat: is that $\mathrm{Ok}=$

End of section 2

Section 3

32. Prue:

33. Pat:

=Ok so [we'1l do another how many are we going to need 30 or 40 [yeah

34. Susan: oh (unclear) will it take that long

35. (Simone): how many manuals do you need

36. Sally: well it depends [(unclear voices) 
37. Irene: (unclear) [depends

38. Simone: how many workplace assessors have we got that are new

39. Prue: they're coming through quite thick and fast at the moment it seems to

me

40. Irene: one for you told me one oh no you told me that one can go to Org $M=$

41. Pat: =you only need one manual [(unclear voices) and you know some things like that and there's another group that's going to come in and register as assessors and they only need one manual for their business too and (unclear) $=$

42. Irene: =(unclear) co-ordinator only it's [(unclear)

43. Prue:

at the moment about 10

[yeah so so how many have we got left

44. Irene: no no=

45. Sally: =two two I saw two over there (laughing)

46. Irene: was five a week ago so

47. Prue: Ok so you know I think 20 at least

48. Sally: at least 20

49. Pat: yeah=

50. Sally: =at least 20

51. Prue: so get 20 more done and then if we need to get another 20 after that fine

52. Pat: [yeah

53. Prue: 'cos I think it's going to take a little bit more time to do it ourselves

54. Sally: yep

55. Prue: ah because if we've got if we're taking the forms out putting them on the web there's references right through so $=$

56. Sally: =exactly

57. Prue: appendix a or whatever it is

58. Pat: yeah

59. Prue: ain't going to exist anymore

60. Pat: ah yeah (laughing voice)

End of section 3

\section{Section 4}

61. Prue:

62. Sally:

63. Pat:

um and also (unclear) take time [(unclear)

[the resource material

[it's a much bigger job than we thought

aye we just thought the manual oh yeah

64. (unclear): oh yeah

65. Pat: but then when we started working on it and we realised wooh

66. (Sally): yeah yeah (unclear) and I mean=

67. Pat: =(unclear) might as well do it at the same time (unclear)

68. Sally: yeah the resource stuff needs to be which Pat and I are going to look at today needs to be updated in the manual as well 'cos we've got

69. (Susan): oh yeah=

70. Sally: = THREE PAGES OF STUFF NOW that we're going to check see if it actually does exist $=$

71. Pat: =yeah have we got copies of this still and you know is it current 


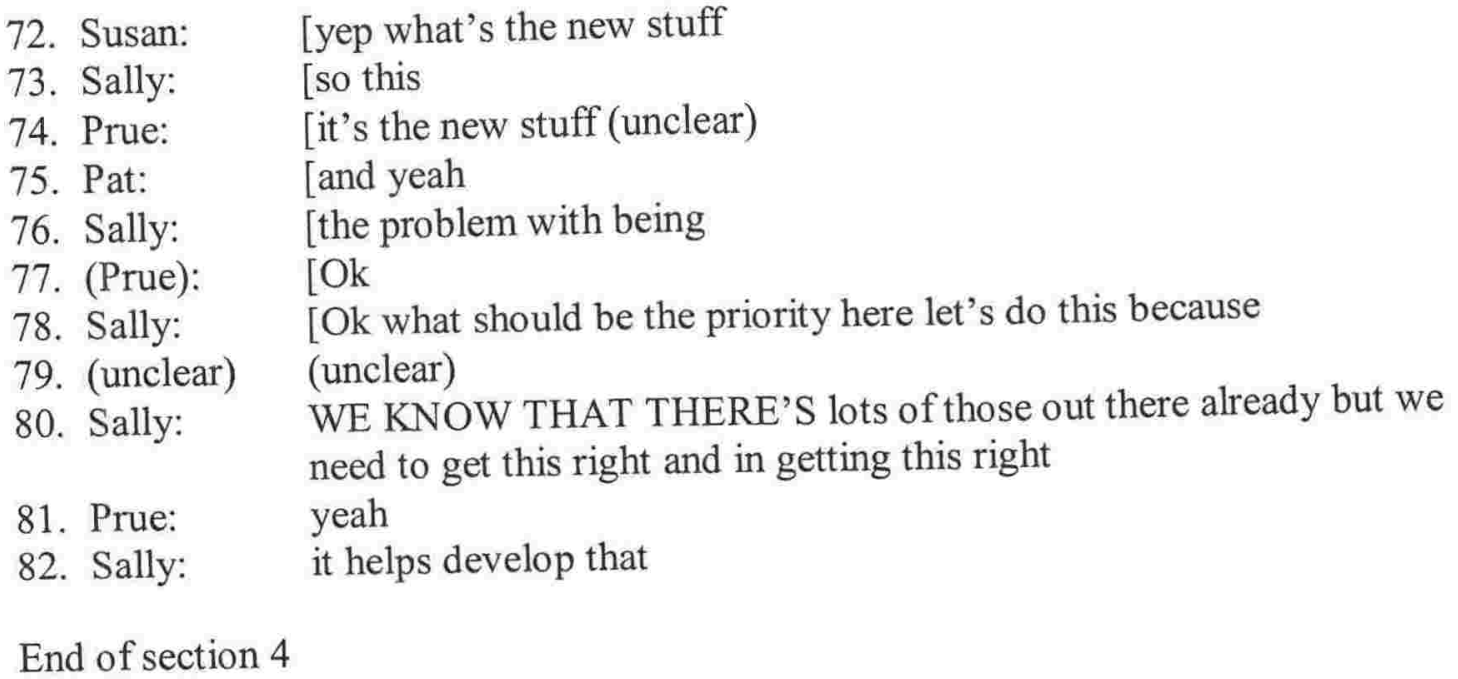

Final section

83. Prue: and I don't think I mean I don't think the core value of the manual is compromised $=$

84. Sally: =oh no no not at all

85. Prue: by this it's all there and it's useful

86. Pat: yeah

87. Sally: yeah

88. Prue: so let's not get

89. Sally: yeah

90. Prue: our knickers too much (smiling voice) in a twist about that

91. Sally: yep that's cool (flicking pages) just time to do that's all (flicking pages) (pause)

92. Prue: Ok um (whiteboard noise) (Observation note: Prue: looks back at whiteboard and forwards it on) (long pause)

End of final section

\subsection{Initial observations}

With regard to proposing future action, can this use by Sally be seen as rejected, or moderated by Prue? What can be said about this? Is Sally brought back into line with some kind of organisational order where she is expected to speak about what she has been involved with directly? Can we say that Prue places Sally, an office-based worker, back in the details? With her quick retreat does Sally at the same time act to keep these meetings on track and therefore showed herself as being a good organisational member, an aid to Prue as meeting facilitator and organisation leader? Perhaps the sense that this use of the phrase failed originated in the way the interaction closed. Can we say that Prue rules Sally "out of order" (Heritage 2004 p. 226; see also Atkinson 1982)? Is this one action Prue achieved when she said "let's not get our knickers too much in a twist" especially taking 
into account that Sally's response was to retreat: “yep that's cool just time to do that's all'?

How did this interaction end up this way? Was it that Sally's use was not warranted because there was no accompanying first-hand story supporting her contention that this piece of work was important as an organisational priority (Atkinson 1995)? In her use of "we know", did Sally make a mistake in using "out there" without the necessary resource of first-hand experience to support her claim? Was "out there" an artefact not available for Sally to use as a resource (Munro 1998)? Did Sally also misjudge the timing of her use of the phrase in this meeting and in this interaction? Was she not attentive enough to what was happening in the meeting to notice that Prue was attempting to close this interaction, and so her strong statement ended up being last (as discussed in chapter two (page 45) under Meeting timing and momentum). Sally's turn of talk failed to be picked up and carried on in the momentum Sally, Pat and Prue had all created during the interaction. It was picked up, but rather than being carried on, Prue put an end to it.

An analysis was undertaken by considering each turn of talk (this initial work can be seen in full in Appendix three: Turns of talk analyses for chapter six (OT29). What follows is a summary of the turns of talk by sections. Concepts from CA are introduced briefly to help highlight meeting members' interactional accomplishments.

\subsubsection{Section 1 of the interaction: Producing this update}

The first section or "cluster of activity" of the interaction (taking about 50 seconds) involves producing an update (Heritage 2004 p. 228). Prue is the person who introduced the query. Boden's argument for there being differences between questions and queries is accepted in this description but I am using "query" to indicate where the topic is broadly introduced as a way to allow many potential speakers rather than to achieve "shifts in topic [and] changes in ways of treating the same topic" (1994 p. 122). Sally and Pat are the meeting members who talk about the work done so far. This is in keeping with "the occasioned assembly of information so that it 'tells a story': a story that serves to represent the work done and in progress" (Hughes et al. 2002 p. 23). These three speakers jointly produce an account of the situation by continuing each other's turns (Silverman 1993 p. 140), including the use of repeats (Schegloff 1987). There are differences though, between Prue and those who have been directly involved in the work. Generally, Prue queries and states what needs to happen and when. Sally and Pat talk about the actions 
they have taken so far and make judgements based on what they saw during their work. This involves engaging in "“accounting' - "the giving and taking of reasons" (Munro 1998 p. 225). For example Sally accounts to Prue for the manual not having been done when she says "we took the website as the priority" (turn 19).

\section{A "gross" (Sacks 1987) summary of the turns is:}

- Prue queries the progress on a piece of work already identified.

- Sally (as a person involved in the task) tells of the action she has taken and provides a judgement of what to do next.

- Pat (as a person involved in the task) tells of the action she has taken and provides a judgement of what to do next.

- Prue continues these turns by agreeing, disagreeing and moderating Sally and Pat's turns.

Already in this summary there are indications of other efforts Sally is undertaking, in addition to the reporting of the work she has done so far on the manual. A concern of the chapter is Sally's aligning work (Munro 1996a), where she shows that she is concerned with the organisation more generally. This will be taken up specifically in the next section but for now, note in this first section of the interaction Sally's use of "we", "priority" and "little things".

\subsubsection{Section 2: Working on the problem raised}

The second section of the interaction involves searching for a solution for a situation made visible and verbal by the update produced, that the manual has not been reviewed. Again Prue frames a query by stating the problem this poses, which seems to open up the potential, but also perhaps the requirement, or "situational and organizational obligation", for input from other meeting members (Boden 1994 p. 113). It is Susan who suggests they photocopy manuals, but Pat speaks mostly in proposing and checking potential next steps with Prue, who has difficulty regaining the turn.

In summary:

- Prue produces a query by stating the problem arising from the update (piece of work not being completed).

- Susan suggests solution.

- Pat speaks mostly, proposing actions and checking. 


\subsubsection{Section 3: Solving the problem raised}

In the third section, Prue confirms they will photocopy and produces a query by taking a guess at how many should be copied (30 or 40 ). Again the meeting members are working on a solution. This time however, Susan reacts to Prue's guess in that it suggests the manual review will take some time. A number of people (especially office-based members) speak. It may be that they are "obligated to engage in a search for help" (Maynard 1991 p. 178). Perhaps Susan's show of uncertainty seems to prompt meeting members to work to restore harmony, or prevent disharmony. With regard to this, Sacks' "misunderstanding machinery" and preference for agreement will be discussed below (1987 p. 66). After a bit more talk, Prue revises her guess to 20, which Pat and Sally support. However, Prue defends the possibility of copying another 20, and in doing so, perhaps makes something else also permissible in the independent decisions and organisational action that may occur after the meeting. This brings the number of manuals to be copied back to Prue's original guess of up to 40. Prue, Pat and Sally then discuss the review for a few more turns.

In summary:

- Prue confirms they will photocopy and produces a query by taking a guess at how many they should photocopy (30 or 40 ).

- Susan queries (the answer alerts her to a lot of time before the review is completed).

- Meeting members, especially office-based members, add information and ask questions.

- Prue revises her guess to 20 .

- Pat and Sally support.

- Prue defends, or makes room for, the possibility of copying another 20 .

- Prue, Pat and Sally discuss further how long the review might take and what is involved.

\subsubsection{Section 4: Attempting an exit and emphasising the problem}

Overlapping talk indicates another change in the interaction, and so a fourth section was developed during the analysis. Here Prue seems to find it hard to retain the turn and appears to give up. Susan does not gain the turn. With regard to keeping the meeting going as a meeting, perhaps Prue was trying to close this topic (see Heritage's discussion of Schegloff and Sacks on "managing a coordinated exit" (2004 p. 228)). At the same 
time, Pat and Sally can be seen as working to keep the topic open. Perhaps Prue was trying to return the meeting to order and avoid the way "in multiparty situations, the conversational turn-taking system exhibits a bias toward a 'breakdown' into two-party talk" (Zimmerman and Boden 1991 p. 14). Prue's apparent giving up suggests something like the CA conception where speakers "repair "more than one at a time"" (Sacks et al. 1978 p. 39; also Atkinson 1982). With Prue's action of ceasing to speak, Sally and Pat have the floor, making further points about the extent of work involved in reviewing the manual. Prue's casual presentation late in section 3 ("ain't going to exist anymore") may have indicated that Sally and Pat could also relax their "shared attentiveness" (Atkinson 1982 p. 97). This section then could be seen as attempting an exit and emphasising the problem. In showing that there are different actions being attempted, these labels only go so far.

It is towards the end of this section that Sally uses the phrase "out there" to forcefully make the case for "getting this stuff right". Note her use in this section of the terms "the problem", "the priority", "let's do this" and "get this right". These are strong calls to organisational belonging and action, and as such, may be more expected to come from Pat and Prue as the long-serving and senior members of the organisation. However, Sally is in a process of becoming. During the presentation of the conference paper to the meeting members around six weeks after this meeting (discussed in chapter four), Sally said that she had been with BANA for a year, but since Kim had gone (three months earlier), she had had to change her view and focus more in-depth on what was going on. This statement too can be seen as an act of showing increased, or increasing, commitment. 
with the use of increased loudness). However, in closing this section of the meeting on the topic of reviewing the manual, Prue can be seen as putting an end to Sally and Pat's jointly-produced talk about the review of the manual. Notice that Prue's re-entry into the talk is not combative. Starting with "and", it appears that Prue will continue Sally's strong statement about what needs to be done, and go on to agree with Sally. Prue also sounds like she is smiling as she says "knickers". What begins looking like agreement however ends as a sanction of sorts. It is a disagreement and as such is "pushed rather deep in to the turn that it occupies" (Sacks 1987 p. 58).

In return, Sally appears to retreat from what has been throughout the interaction a confident and active stance, culminating in a forceful presentation of what should be an organisational priority. Sally's reply to Prue can be seen as a "repair" to a misunderstanding (Schegloff 1992b p. 1301). Sally's agreement with Prue's statement about the manual ("I don't think the core value of the manual is compromised") is no ("oh no no not at all'), which Schegloff calls turn-initial particles in third-position-repair turns (1992b p. 1305).

In summary:

- Prue pulls Sally and Pat up, and in doing this perhaps attempts to reduce the problem they have produced.

- Sally accepts Prue's "summing up".

- Sally and Pat continue Prue's talk by agreeing.

- Sally accepts and tries to clarify (Prue has misinterpreted).

- Prue moves the meeting on to the next topic.

Does this interaction show the "preference for agreement" in the conversations of meetings (Sacks 1987)? Is keeping the meeting moving whilst also disagreeing part of it? The organisation perhaps needs a visible amount of agreement to continue to work. Does the continual movement explain how, at first glance, these meetings appear to be smoothflowing? This smooth momentum is created by doing harmony, of a sort, in the meetings. Sally's use of "just" is very like Sacks' example when he discusses the "misunderstanding machinery" (1987 p. 66):
A: $\quad$ You got an answer for everything so shuddup
B: I don't want to
$\rightarrow \mathbf{A}$ : I didn't ask you to, I was just kidding
B: $\quad$ Oh, OK (Sacks 1987 p. 69) 
Prue: $\quad$ so let's not get

Sally: yeah

Prue: our knickers too much in a twist about that

$\rightarrow$ Sally: yep that's cool (flicking pages) just time to do that's all (flicking pages) (pause)

Prue: Ok um (whiteboard noise) (long pause)

The appearance of harmony does not come from an absence of disagreement, but rather from a constant moving on of the talk in its many forms (Schegloff 1992b).

\subsection{Further analytic comment}

In this section I firstly ask what the organisation of the talk in this interaction might be. Secondly the multiple actions of the meeting members are considered, especially concerning attempts at alignment and showing commitment. An argument is made for not turning away from CA for this kind of analysis. Thirdly I make some points about the making of these meetings. Finally, some of the questions this analysis poses are briefly outlined.

\subsubsection{The organisation of the talk: The object within the sequence}

From the initial consideration of the sections of talk above, OT29 does seem to be an unsupported or unsuccessful use of the phrase. The question of whether this is because its use is a "departure" from some kind of turn-taking organisation (Heritage 2004 p. 226; see also Silverman 2001 p. 168) will be considered over this and the following three chapters as I examine three uses of the phrase "out there". For now, the question is what the organisation of the talk in this one interaction involving OT29 might be. To start quite broadly, it is something like:

- Meeting facilitator produces a query about a previously known task.

- People who have been involved jointly produce an update using "we".

- Another meeting member raises an objection with regard to what the answer to the query means (its organisational implication).

- A larger number of meeting members work on finding a solution by adding what they know and asking questions about what needs to be known.

- People who have been involved in the task continue discussion of what may be involved in completing the work.

- Member makes a claim for organisational importance or priority.

- Facilitator stops the discussion, reducing the problem built up by those involved, with an " $P$ " judgement. 
- Previous speaker accepts judgement.

- Facilitator produces a pause and moves the meeting on to the next topic.

The organisation is that Prue raised the topic and those with information, an opinion or questions (contributions of various sorts) added these in, until Prue summed up what has just been discussed and moved on to the next topic. Reduced down, the organisation or sequence is:

- Facilitator produces a query.

- Meeting members contribute information, opinions, ask questions and produce queries.

- Meeting member attempts a claim about priority.

- Facilitator attempts a judgement.

- Meeting member accepts judgement.

- Facilitator moves on to next topic.

In searching for these kinds of sequences (Sacks 1987) (query-contributions-claimjudgement-acceptance), would there be a large number found that do not include a claim about priority (query-contributions-judgement)? The form would be single speakermultiple speakers-single speaker, like a diamond or egg-shape, which bulges in the middle. This is one reason OT29 was singled out for analysis as somehow different. For this sequence in this one interaction, it is useful to consider an object (Sacks 1992a p. 31) within it. This object creates an additional end piece on the diamond shape. That of:

- Sanction/retreat.

The sanction used here by Prue is that meeting members should not "get our knickers in a twist" (turns 88-90). Using this analysis, questions can be asked about the appearance of these kinds of query-contributions-judgement sequences and especially about sanction/retreat objects in this series of meetings. The hearing of the object sanction/retreat was perhaps what created my hunch that this use of the phrase "out there" was a failure of some sort by Sally. Who has summing up, or final judgement "rights" (Munro 1998 p. 237)? Who is allowed in the meetings to have "the last word" and how is this achieved (Atkinson 1995 p. 2)? Is part of this keeping the meeting on track in the mode of "no time for moaning, we're all busy"? Is this then part of Prue's more general work of keeping the organisation moving along? 


\subsubsection{Multiple actions: Working on alignment and showing commitment}

More can be gained however from analysing this interaction in answering the thesis question of how these people "get things done" (Munro 1996a p. 6). With regard to organising this one interaction, OT29 may stand out because the interaction is winding down, and Sally's keeping it alive is jarring to the smooth momentum of the meeting, but I wish to explore how the actions of the meeting members in this interaction also show efforts towards alignment and showing commitment. Sally's effort at alignment (Munro 1996 a p. 8) or "conversational collusion" (Boden 1994 p. 155) with Pat especially, is perhaps one way to see the organisation and hierarchies of office-based and advice (or knowledge) work.

In keeping with the familiar arguments that $\mathrm{CA}$ does not provide explanations and ethnomethodology cannot consider power because they stay close to the interaction (as recently discussed in Oswick and Richards (2004)), it may appear that a move beyond CA has become necessary at this point in this analysis. I make no such move, in keeping with Rouncefield's thorough reply to this charge (Rouncefield 2003; see also Fox et al. 2005). Rather I follow CA's three-pronged concern to consider what else members are attending to in this interaction; what else Sally attempted in her use of the phrase "out there":

CA analyses are ... simultaneously analyses of action, context management, and intersubjectivity because all three of these features are simultaneously, but not always consciously, the objects of the participants' actions (Heritage 2004 p. 224).

This CA approach highlights the multiplicity involved in workplace practice that is of central interest in my research and its guiding approach, ANT. There is no gap implied when Munro, talking about ethnomethodology, says that "in helping explain social order, there is of course an implicit story of power" (1997 p. S46). The idea of multiplicity can be seen in the work of Howard Becker, whose work (Becker 1960) is credited with inspiring a great deal of subsequent inquiry:

$\mathrm{He}$ argued that we construct the commitments of our world in joint practice, and that at any one time we are participants in a number of activities. We therefore run multiple 'side-bets' all the time, and the structure of our commitments is determined by their fate in the multiple communities of which we are all a part (Star 1992 p. 402).

Whilst the members of the meeting talk about the review of the manual, they are also working towards its completion (the action). Secondly, this is a meeting of the organisation, where organisation-wide problems are discussed. Meeting members' turntaking makes it such an entity, which shows context management where, for example, 
Susan raises an organisational concern about how long the review might take. With "we" Sally shows her membership of the organisation. Sally also uses "we" to align herself with Pat, and in doing so may be attempting to move herself toward what is perhaps the privileged side of this organisation's lay-professional divide (see Maynard 1991 p. 178), and to show commitment to the organisation in that she has become a more permanent member. Pat shows an orientation to the future and so makes herself management material. In meeting four, it was announced that a field manager position was being created and Prue said that Pat had been the team leader by default.

In the mode of keeping the organisation moving, is Sally's use of the phrase "out there" a non-productive delay, which is not warranted? With regard to Prue's responsibilities as manager, it perhaps falls to her especially to do something, like telling Sally and Pat not to "get their knickers in a twist". This responsibility work includes "display" (Munro 1999a p. 620) and by their presence, all organisation members are made aware of Prue's stance on this issue. It is a matter of making the meeting, and it is also organisation making. Sally's attempt to set organisational priorities is perhaps refuted by using size or importance. Sally may be permitted to talk about details, but when she attempts to be involved in deciding organisational priorities (the big picture domain of more senior organisation members perhaps), Prue steps in. Sally's attempt at "extension" (Munro 1996b) of herself beyond the details is blocked by Prue.

Sally's call to priority may have failed because she attempted to employ a resource without having the right to. Heritage discusses the rights of access to knowledge (2004), which in this interaction I suggest is the right to use experiences from "out there". In business settings one frequently tells of direct experiences (Pomerantz 1984), but in this instance Sally was telling of a direct experience of the manual, rather than of the field "out there". By stating that the manual is fundamentally solid (there has been no meltdown here), Prue excludes Sally from judgements about the value of this presumably expert-written material, possibly written by Prue herself. Is there something telling in the difference between Prue's use of " $P$ ", perhaps as one who not only knows, but has the "rights to know" about cores in this organisation and Sally's use of "we" (Heritage 2004 p. 239)? Prue does not need to make a collective claim, as her knowledge is rightfully hers, whereas Sally perhaps has to do the extra work of aligning herself with Pat. This strategy by Sally appears to fail. Prue has placed Sally back in the realm of administration 
work, of details like spelling mistakes. Looking across the interaction, amongst the details was a place Sally seemed to have been working to remove herself from when she said there were "too many little things in the manual".

While the analysts' temptation may be to separate out actions, CA's approach shows that this is not possible nor useful (Munro also argues against separations (1996a)). Replacing "or" with "and" makes irrelevant any confusion about whether Prue is working simply to keep the meeting on track. We can see that she is doing this, but she is also working to keep Sally's attempts to align herself with Pat organisationally appropriate. Prue uses her accountability for meeting efficiency and time keeping as a resource to achieve other things, simultaneously. Meeting members often achieve multiple actions.

\subsubsection{Making these meetings}

In the series of meetings I attended as researcher, there was one (M12) where Prue was not present and Simone did the facilitating work. Rather than focus on any power that Prue may hold, is it the shared goal of being careful in using meeting time that has the effect of meeting members seeking "permission" to tell a story or signal an extended turn of talk (Schegloff in Silverman 1997 p. 43)? The "shared attentiveness" (Atkinson 1982 p. 97) to meeting time may partly explain saying things in the meetings like "I don't want to go into it too much" (Pat, M11), and "won't go into detail about that" (Sally, M13).

Mostly, all meeting members paid attention to being to the point, rather than roughly on topic. This perhaps helps explain Sally's quick retreat from Prue's sanction. As member, she heeds the call to attend to time in the meetings.

With regard to the influence of different facilitators, there is an interesting point to be made about skill and opportunity involving artefacts that help achieve control. During this research I have been wondering about the things of the meetings. This is not easy to capture as a researcher, hence the focus on the meeting talk gathered by the tape-recorder. Yet, being there in the room and later listening to the tapes I could see and hear the importance of objects, like the table and the whiteboards, to this organisational action. While the focus on talk has made everything else "other", the contribution of material objects cannot be excluded from the accomplishments of these meetings. Here is a brief example from the closing of this interaction:

93. Prue: our knickers too much (smiling voice) in a twist about that 
94. Sally: yep that's cool (flicking pages) just time to do that's all (flicking pages)

From my observation note you can see that the meeting is held (silent) with the whiteboard. Perhaps this is one reason why this moving, printing whiteboard was preferred by meeting members above the static one screwed to the wall (as discussed in chapter two). With its forwarding-on noise, the whiteboard "appropriates" the hearing space of the meeting (Munro 1996b p. 248). With it Prue produced a pause. However, this pause was not provided as an opportunity for someone else to start speaking (Heritage 2004). Control, without the need to confront with voice or hand, is made possible. Prue is "merely" keeping the meeting on track by working through the agenda, which members have had the opportunity to contribute to, on the whiteboard. The whiteboard "augments" Prue as meeting facilitator and she "augments" it as a useful artefact (Munro 1996b p. 266). That Prue always occupied the seat directly in front of this whiteboard in the meetings would be another way to ask about facilitator influence in the one meeting where Prue was not present. The whiteboard's involvement in the meetings will be seen again in following chapters.

Returning our focus to the talk involving OT29, in both ways, lacking the resource to back up her statement, and in her timing in the interaction, Sally can be seen as having misjudged. Prue's statement produces a sense of jarring, a call to pay attention (Atkinson 1982 p. 97). Looking at the whole interaction however, it can be seen that Sally had many indications in the talk of Prue and Pat that she could make such a strong statement. So perhaps the sense of jarring comes from Prue and Pat's sudden abandonment of Sally's talk. They have moved on without her, and without notice. In this lack of care I suggest we see power - it does not have to be careful.

In doing the constant "momentum" (Boden 1994 p. 1-2) of the meeting, Prue shows herself as the boss in seeing that turns of talk in the meeting are "rationed" (Heritage 2004 p. 226) by stopping Pat and Sally going "on and on" (ibid p. 230). In chapter two I discussed the work Prue does to make these meetings, like making predictions of how long the meeting may take and assessments of how they had done during meeting closings. In addition, here Prue has worked to avoid new tasks being created when she asserts that the manual is okay as it is. Prue is moderating claims about how bad the 
situation might be, and in so doing, is being watchful of resources. However, Prue has not put an end once and for all to Pat's suggestion of using an external editor. These differing views on how to achieve the review of the manual remain. But, as Boden says,

Deferring disagreement or debate is not a casual or random matter; it is central to the smooth and practical enactments of the organization and to the recurrent patterns of interaction and activities that constitute and perpetuate that work organization. Discussion, debate and the process of position-taking and decision-making are necessarily fragmentary and incremental by virtue of these recursive practices. This again reflects the fragmentary work styles observed by Mintzberg, but reveals them to be effective strategies for getting through the workday (Boden 1994 p. 155).

Here is intersubjectivity. These different positions are not overly threatening however. Listening to the conversation, this exchange does not appear to cause alarm, is not heard as out of the ordinary. All of this is part of getting "through the day" for these organisational actors (the phrase is Molotch's, cited in Boden 2000 p. 196).

\subsubsection{Further questions: Expected contributions}

Prue's rejection of Sally's forceful presentation is suggestive, though, of some form of departure from "the types of contributions individuals are expected to make" (Heritage 2004 p. 226). Some possibilities for these kinds of organisations in the meetings that will be explored further in following chapters include:

- Being allowed to undertake the action in the meetings of proposing future actions.

- Being able to propose future actions forcefully and normatively (using "should").

- Supporting future actions by stories of first-hand experience.

The use of first-hand experience (Sacks 1992c) is considered further in the next two chapters with regard to "telling how I know" (Pomerantz 1984).

One focus of the thesis is how members work on what the organisation should do next. Who is allowed by meeting members to make calls to organisational priority? As boss, is it Prue who can tell people what to do, or Pat with the support of first-hand field knowledge? This will be explored with regard to ordering speakership by rank (Heritage 2004 p. 226). Does OT29 fail to gain support as a proposed future action not despite the use of "we know" and "we need" but because of them? Did Sally speak out of turn in this organisational setting in that she did not have just the right resources to back up her claim (Munro 1997)? Is the necessary resource direct experience from having been "out there" in the field, or could it also be "out there" on my desk or the "in there" of the database 
(for instance)? Perhaps Sally was not careful enough to specify how she had come by the knowledge she was using to make her statement that "WE KNOW THAT THERE'S lots of those out there". In regard to Schegloff's (2000) concept of granularity Sally may have implied that she had direct experience from having been "out there" in the field. Though Prue initially produced continuers for Sally's account of "still in progress" like "tut", in the end she closed down Sally's call to priority. Prue watched the time in the meetings. As organisation leader, she was getting her job done. In their "action, context management, and intersubjectivity" so were all the meeting members (Heritage 2004 p. 224). What was going on in this one interaction was multiple.

\subsection{Conclusion}

This chapter was concerned with showing how the phrase OT29 was involved in this meeting. This was achieved by using concepts from CA to closely examine the interaction of which OT29 was a part. The interaction was divided into five sections to make some initial observations. Further analytic comment was made about the structure of the talk. It was suggested that the meeting members produce fortnightly staff meetings as one way they make the organisation. This is what "these local exchanges of information, opinion, options and objections" are (Boden 1994 p. 129). One question in this chapter was whether something like rights to use "out there" could be seen in this one interaction, and this will be returned to in following analyses.

This chapter contributed to the overall concern of the thesis to consider how these meeting are opportunities for attendees to use, and at the same time, gather materials, resources and things as they get their work done. The interaction involving OT29 was taken to be an example of workplace "action, context management, and intersubjectivity" (Heritage 2004 p. 224). Taking an approach like CA, that concentrates on the details and asks "how", makes it possible to ask questions about organisation building. If suggesting that something like rank or "asymmetrical relations" are involved in this workplace interaction appears an obvious point to make after such a close examination of this meeting talk, the concern being that I have stated what everybody knows already, this analysis provides an example of how, precisely (Munro 1998 p. 229). I have embraced Sacks' argument that obviously observable things should not be ignored because they are obvious (1987). This obvious observability may be of interest for seeing entrepreneurial 
character and conduct (du Gay 2004) in action and showing how something like rank was involved in this contemporary workplace. Watching:

practice allows us to treat the vague notion of power ... as the consequence of an intense activity of enrolling, convincing and enlisting [and in so doing] the practical resources necessary to perform society appear clearly (Latour 1986 p. 273).

As discussed in chapter four, the view of "power" is that it is generated in associations and as such it is mixed up with "action". As Munro discusses with regard to new managerialism, if managers believe or are unsure about whether others know more "the power effect of bolstering hierarchy will be the same" (1998 p. 229).

When it is made explicit that watching this interaction is to be at the same time considering "social order" (Boden 1994 p. 7), the question that follows in some research approaches is "why" is it this way and what can be done about it (Becker 1986a p. 130; Boden 1994 p. 31 and p. 44). For instance, what does Sacks' thesis about preferring agreement do for being able to speak up and defend one's view in workplace meetings? What are the disempowering effects of starting by agreeing before going on to disagree? What should be done is left to analysts who have their own questions. Following CA, the concern of this chapter was to see how members were doing things in this workplace interaction. The question then becomes something more like, what are the (many) effects of using "out there" in these meetings? This chapter, and this thesis, belongs to the first move advocated by Silverman when he says there is nothing wrong with explanation, as long as we "have first closely described how the phenomenon at hand is locally produced" (1999 p. 410). 


\section{Chapter seven}

\section{Working on access to information}

\section{TABLE OF CONTENTS}

7.1 Introduction

7.2 Uses of the phrase "out there" in meeting six ................................................. 144

7.2.1 OT6: Clients' systems not all bad ................................................... 144

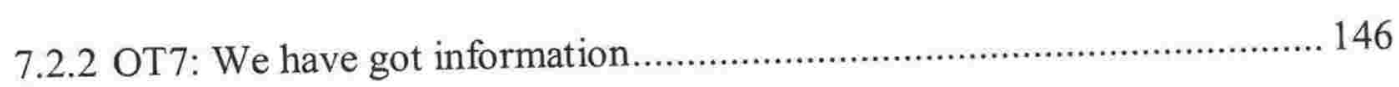

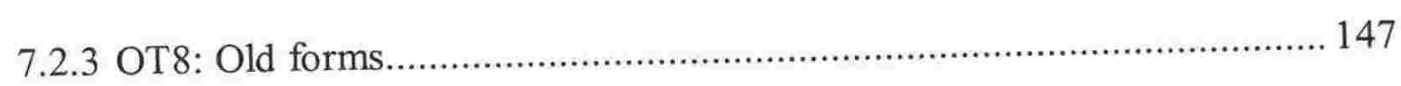

7.2.4 OT9 and OT10: A new idea or potential change and Accepting............... 149

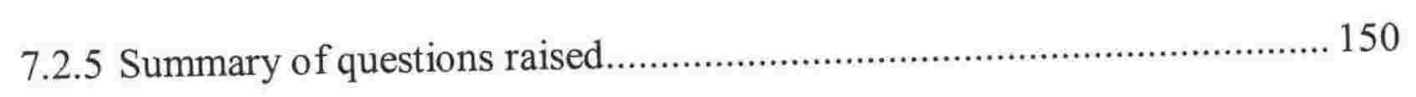

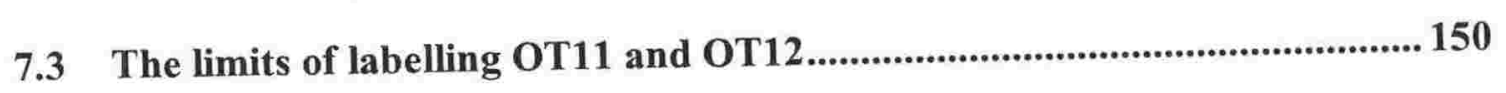

7.4 Conversation analysis of OT11: A problem involving "information"? ....... 152

7.4.1 This use of the phrase of interest (turns 147-212) ............................... 153

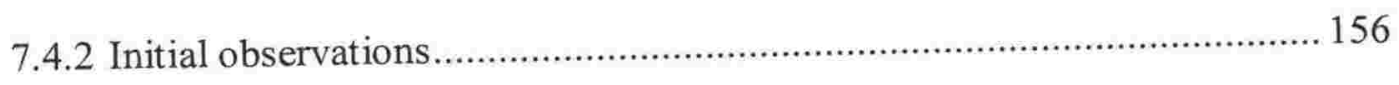

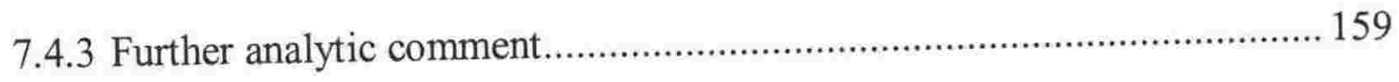

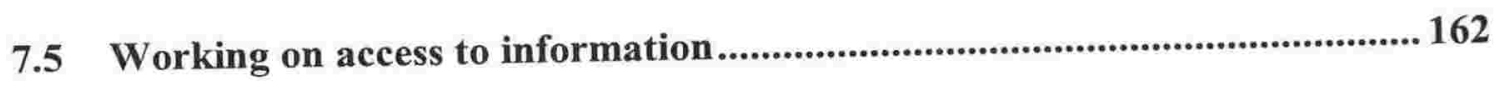

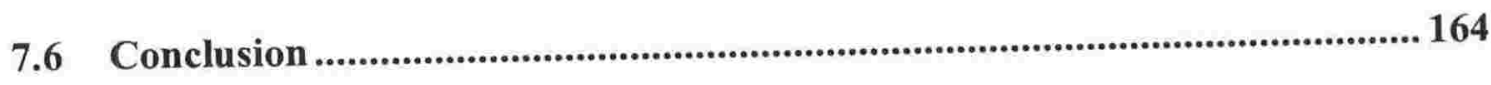




\subsection{Introduction}

Pat: but but there is a point there about the overview and about us being able to source stuff in a different way because the reason why I wanted to get back into that loop is that like when it comes to Jo and I looking for assessors for people out there (pause) we had taken a step (pause) and Paula a step back (by) not knowing who was registering it meant that we didn't know well look there's this group of people from this organisation in um City A (flicking pages) that we could use as private contractors for assessors so so (M6)

Like the previous chapter, this one also carefully examines meeting talk. Again the mode of questioning is one of asking what is going on here. However, there is more meeting talk presented in this chapter than just that which is closely attended to using conversation analysis (hereafter "CA"). The presentation of more of the empirical material from meeting six is undertaken in an attempt to show how some of the concerns of the thesis have emerged and because the talk focused on in this chapter and the next is from that meeting. The interaction closely analysed in this chapter continues into the next chapter, and these two chapters should be considered a pair. During the analysis of the turns of talk it became clear that one chapter could not contain the detail revealed by this close examination. Rather than reduce the level of detail, chapter boundaries were shifted. Therefore the questions in this chapter and the phrases I have highlighted as of interest are driven not only by the talk analysed using CA but from the fieldwork and the very broad research question of how meeting members get the work done.

This chapter is concerned with information, as discussed in chapter two (page 52) under the heading Remembering, being clear, and what to do next. In the narrative of meeting five in that chapter Pat's word "loop" was retained in the description:

Pat is concerned that she's getting missed out of the loop; a discussion is needed (action 51).

This chapter examines the next meeting I attended (meeting six) and Pat's use of the word "loop" is again in focus. As in previous chapters I continue to distinguish meeting member talk with italics and quote marks, and analytic concepts with italics. ${ }^{1}$ The uses of the phrase I labelled in chapter five as involving information occurred in

${ }^{1}$ See Appendix two for the conventions used to indicate quoted meeting talk and concepts and transcription symbols. 
meetings six and seven (OT7, OT11, OT12, OT13, and OT14). In this chapter and the next I analyse two of these uses of the phrase (OT11 and OT12). To lead into the meeting talk I firstly present the interactions from meeting six involving the phrase in the order they appeared in the meeting. I use CA techniques to consider Munro's question: what are the "projects conducted in the name of information" (2001a p. 199)? What to do about information seems to be a problem facing BANA. A mix of fine-grained analysis of transcribed talk and a broad question approach is used to ask what happens and what else is happening when concerns are raised about information.

\subsection{Uses of the phrase "out there" in meeting six}

There were multiple uses of the phrase "out there" in meeting six (OT6-OT12). This section presents some of the talk surrounding the first five of these. In this way something of that meeting is described before using CA to carefully consider the final two uses of the phrase in the next section and the following chapter. Apart from the meeting talk being presented as turns of talk, mostly the transcription conventions of CA are not used in this section. Rather, the aim is to start to describe that meeting and generate some potential guiding questions to use when analysing OT11 and OT12.

While I was transcribing the tape over the few days following meeting six I included notes in amongst the talk. Some of these have been left in the talk presented below because these "at the time" observations and wonderings have influenced the topics I have chosen to follow. I have also highlighted some of the words that are more significant in this analysis.

\subsubsection{OT6: Clients' systems not all bad}

The first time the phrase "out there" was used in meeting six was by Susan during an agenda item. Prue had introduced the item ("next one quality of training agreements and workplace assessor applications"). Susan had moved to stand at the permanent whiteboard, commenting that she had not been "quick enough aye":

Susan: my thoughts on possibly one way of addressing it (observation note: she is drawing on the permanent whiteboard; Pat and Jo have moved their chairs back) 5 stages ... now presumably at some stage um the client will actually be appointed with a a specific BANA um customer representative or a point of contact so it's still high level... actually happened... and then (pause) $3 \ldots$ it's at this stage here where the paperwork I get usually arrives and these will be the actual training contracts themselves... my experience... is that quite commonly the people I'm contacts aren't 
aware of the big picture... don't know about their internal processes... why enquiries being generated ${ }^{2}$

Pat: and one of the things Susan and I discovered... never been in contact with me

\section{Susan: yep...}

Pat: so some how people are moving straight to there and I haven't got a clue what the project is or what

Susan: they're going here to here

Pat: they could... but still we have no knowledge of who Susan and I have no

knowledge of who the key contact is... what model they're using we haven't seen anything

Susan: it seems to me there a lot of people who haven't established this yet they haven't gone through and put in the work and as soon as somebody moves on everything like in the case of Org $\mathrm{C}$ it all fell over fairly dramatically um although they have very good elements in place out there (OT6) so um... when this is not happening it's an indication that this isn't happening either and I've seen evidence of that as well... indicates that the whole training programme has really been abandoned an ideal time to send people a survey and say how how has your pilot and I think pilot's the right way... to send people who are... how did it actually go for you ... really looking at new people

Jo: Susan one of the issues we face is that no matter how much hard work Pat does at that stage or information that I give them when you've got agencies like Org I they have a very transient type workforce

\section{Susan: yep turnover}

Jo: we do all this work we have a great person there and suddenly they leave and then it gets chucked to the next person and this is this is the problem we've got with some of the large agencies

Susan uses the phrase "out there" as part of her talk of the difficulties caused by lack of paperwork and knowledge of trainees when people leave organisations. The phrase is used to say there is a problem, but that it is not all bad - there are "very good elements in place out there" and for Susan to continue her turn to suggest a possible next action. At first it seems that Jo will dispute this, but he reiterates that despite his and Pat's effort, people moving on is a problem. The questions raised include:

- In the discussion about BANA "customer representative or a point of contact", are there suggestions, concerns and hopes that things should or could be singular? Are there relations between this and responsibility?

- What is Pat referring to when she says she has "no knowledge" and what is the connection with not having seen; how is it that things "moving straight" result in Pat not having "a clue"; how is seeing involved in knowing?

- How are the two whiteboards involved?

\footnotetext{
2 “..." indicates omission of part of the transcript.
} 
- How are examples and direct experiences used to talk about something as a problem?

\subsubsection{OT7: We have got information}

The second time "out there" is used by Pat later in the same discussion:

Prue: you know I'm sorry I can't talk to you because you're Org A and I'm no so we've actually got to work out... I think a key relationship person is going to be the way to go I think it will become realistic at the end of this year when we've got 2 more field staff on (unclear) because then it becomes manageable um and it's not that that person is the only... has the overview of that department so if someone rings me up from Org $G$ and starts talking to me I just check the list and say ah right um Paula's the key contact for Org G better talk to Paula and let her know what's happening so yeah because the thing is this is going to get too big

Pat: yeah

Prue: for all of us to be doing everything

Pat: yeah that's that's what we're quite aware of that

Prue: very quickly

Pat: yeah

Susan: you might find...

Prue: that's the pure model

Susan: (unclear)

Prue: and we'll rarely see the pure model ...

Pat: and quite often people contact Prue and leave us out of the loop field advisors out of the loop and there's information we've got 'cos we're out there (OT7) working with the organisation

Prue: yeah

Pat: that Prue hasn't got

Prue: and I don't know

Pat: yeah .... and I kind of think why don't they come and talk to me I'm the person that's working with the organisation it's sort of

Susan: (unclear)

Pat: yeah for people but the other thing in talking to Org A it's for what we need to send to organisations, what they would like what all the co-ordinators would like is a list of all the people who work for BANA and their role ... they're saying that as well... who do they contact around money that's Simone who do they contact around... Pat spoke for "field advisors" who had "information" because they had been "out there". Perhaps she was referring to where BANA's members were and so where BANA's efforts should also be? The phrase seemed to be used to discuss how the organisation should arrange itself. Prue had had a long turn talking about the need for structure in the form of a "key relationship person" because the organisation was getting bigger. Prue agreed that Pat had information from being "out there" that she 
has not got herself, which allowed Pat to carry on her concern about people not talking to her. The questions raised are:

- How is the idea of "a key relationship person" becoming "realistic" and "manageable" put in relation to BANA getting bigger?

- Is OT7 a claim to know through direct contact, which indicates realness and indisputable evidence? Is there a sense of action as good in the mode of "we're 'out there' doing it, not stuck in here talking or reading about it"?

- What are the effects when meeting members say this is what they do already?

\subsubsection{OT8: Old forms}

The third use of the phrase is still part of the discussion on this agenda item. This time Pat used it to say that old forms are still "out there". The large amount of talk has been included here to show discussion of technical systems and access to information, which are discussed again later in the chapter:

Prue: does this replace the IDMS diary file

Susan: oh yeah yeah streets ahead... and of course Paula will be having access to the database

Prue: a much improved base well information base from which to manage a communication system

Susan: get appointed an ANA person

Prue: what do we do with this

Susan: we go wop so tell us about your training

Prue: on the batch header ... and if that's blank there's a little alarm bell

Susan: how about if I bring that form along to a field team meeting and we look actually what information

Pat: we're having real hassles that the forms... old forms

Prue: no no no we won't be needing to do that at all it will go on the website \{faith in website $\}^{3} \ldots$ and when there's a change of form we say on the website

Pat: but organisations need to know Prue that there's been a change on the form...

flicked out through the people \{Pat's preferred - the people?\} (observation note: Pat and Prue leaning forward?)

Prue: no I don't think it does 'cos if you flick it out

Pat: needs to be a message to say forms have been changed 'cos what happens \{actually, out there, in reality\} people put the forms in a file

Prue: have they only been doing that because it hasn't been accessible on the web ...

Kim: procedural manual

3 " \{\}$"$ indicate observations made during transcription of the audio tapes. 
Sally: you go to a hard copy and copy it that's what you do

Prue: the changes to the forms are not that regular

Pat: 'cos they're out there (OT8) in their system

Prue...

Pat: you can understand in large organisations with hundreds and hundreds... how a form goes round the organisation... they had forms from somewhere...

\section{Prue: we can't deal with their problems}

Pat: yeah that's right what I'm saying Prue you're talking about organisations with hundreds so you can understand and you see when I was talking to them ... all these different systems for all the different people so you can understand how it ends up breaking down you know

Susan: the only thing is to keep working at it

May: yeah

Prue: when we put all the forms and things on the web we do increase the risk of people just coming in at stage 3

Susan: that's where I got the idea from actually what's going to go on the web ...got me thinking about (unclear) a picture

Pat: so going back to the one about... that's why we need formalised contracts because because if we had a had contract with... boundaries set around what that was... that sort of stuff documented so we all know what's going on really

Prue: I don't know whether you remember we were going to have contracts memorandum of understanding we were calling it and they basically didn't want to go there so we're going to have be careful about what we call it how we present it and what's in it

Sally: you might be better to look at them as joint projects joint training projects (unclear) (discussion) type of name rather than

Pat: our forms have been to the legal department within Org A they get around if we let them out?\}

Prue: Ok well \{summing up after having left time/space for more discussion - don't seem rushed today?\} I think if you leave can you leave that on the board

Susan: it would people like me to draw up a diagram and attach it to perhaps the minutes \{minutes from this meeting or field team?\}

Pat used "out there" to continue the discussion and seemed to take the clients' point of view. Prue rejected this, saying "we can't deal with their problems". Pat appeared to agree but reiterated her face-to-face experience and said again "you can understand", perhaps suggesting that fault should not rest there. Susan seemed to try to end this talk with May's support, but Prue raised another issue. The questions raised are:

- When meeting members say "“cos what happens", are they using their direct experiences in a general way?

- Does Prue suggest that things like "the website"can help, while Pat works to have problems verbally acknowledged now? 
- Are members working on (including showing) the value of technical systems and direct contact (or field experience)? Can Pat be seen to argue for information gained through direct contact, and Prue and Susan information being held in technical systems?

\subsubsection{OT9 and OT10: A new idea or potential change and Accepting}

Though I have separated the fourth and fifth uses of "out there", the talk continued directly on. Here the phrase was used by Prue after confirming that people leaving organisations was a risk, but that she was not sure what they could do:

Prue: in association with a whole lot of other things... what can we do to manage these risks and I think one of the risks all the way through is key staff member in organisation leaves... that's all the way through (laughing) and I'm not sure what we do about that

Pat: and also BANA staff leaving as well

Susan: mind you developing key relationships means that someone from BANA... yeah 'cos often you get

Prue: this is really kind of out there (OT9) so please keep it within these 4 walls is that um... what I've been thinking about for the next stage of growth and it is just an idea...talking with the biggees... someone who has a loyalty responsibility in both who manages those the biggees if they've got enough to warrant it just a way of blending (observation note: uses 2 index fingers together) their co-ordination with our co-ordination

Jo: I think Org A has already considered that idea

Pat: a whole lot of planning and papers going up at the moment

Prue: oh not too out there (OT10)... might assist in terms of the seamlessness the the transitions and having someone who's actually got a voice in both organisations

Pat: so Kim does that follow on to our thing on the board

Kim: yes it does really (pause) (observation note: Prue forwards board on)

Prue seemed to make use of the phrase to highlight her idea, suggesting that it was different from current practice. Perhaps the phrase was used to gain people's attention again after a long period of talk on one topic. In this turn Prue used many words and phrases that may have had the ability to call meeting members to attention, including "please"; "I've been thinking"; "growth"; and "the biggees". Jo and Pat responded that Prue's idea was already being considered. Prue acknowledged this and wrapped up by putting her idea more tentatively.

The additional questions raised are:

- Does the phrase help Prue accomplish placing responsibility for the field, which includes knowing about it, with others?

- Again, what can be said about the involvement of the whiteboard? 


\subsubsection{Summary of questions raised}

The questions raised by the interactions involving five uses of the phrase "out there" are gathered here into three groups. Firstly, with regard to responsibility and organising BANA in the discussion about BANA "customer representative or a point of contact", is there a concern with making things singular and is this connected to responsibility? How is the idea of "a key relationship person", becoming "realistic" and "manageable" related to BANA getting bigger?

Secondly, how is talk of direct experience, witnessing, seeing, and knowing involved? For instance, what is being referred to when Pat talks about having "no knowledge" and how is it related to not having seen? How is it that things "moving straight" result in Pat not having "a clue"? How is seeing involved in knowing what is happening - is it to witness? Is this the way in which OT7 can be seen as a claim to know? Are examples and direct experiences used to talk about something as a problem? When meeting members say "cos what happens", are they using their direct experiences in a general way? What is involved when meeting members say this is what they do already - does Prue use the phrase to show others know more and does this have the effect of placing responsibility for the field elsewhere?

Thirdly, there is the involvement of material things. For instance, how is the whiteboard involved? Does Prue propose solutions, like saying "the website" will help, while Pat works to have the problems acknowledged here and now? Are members working to create the value of technical systems and direct contact (or field experience)? Can Pat be seen to argue for direct contact, whereas Prue and Susan argue for information being held in technical systems?

\subsection{The limits of labelling OT11 and OT12}

In chapter five OT11 and OT12 were labelled after I had listened again to the recorded talk and before I had analysed it using CA. Some comment is made here about those labels in considering what can be gained from closely examining turns of talk. I have avoided the temptation to change the labels contained in those original tables. While the analysis done then may now appear hasty or sloppy (indeed I hope that is the case in justifying my more careful examination here), I made an honest attempt then, and it stands as is.

In Table 1 in chapter five OT11 looked like this: 
- Who: Pat 3

- Agenda or roundtable: Agenda

- What is directly referred to: Inside BANA - a problem with lack of information sharing? 1

- Topic under discussion: New system/model of BANA customer reps 6 (returned to)

And OT12 this:

- Who: Pat 4

- Agenda or roundtable: Agenda

- What is directly referred to: Inside and Outside BANA - a problem with lack of information sharing? 2

- Topic under discussion: New system/model of BANA customer reps 7 (returned to)

You can see that the labels applied to each use of the phrase were the same. I considered these to be the sixth and seventh times that the topic of BANA customer representatives had been discussed using the phrase "out there". This is not surprising given that this was a major concern of meeting six, and these labels were applied to the talk in its chronological order. However, it is interesting to note that OT11 and OT12 are both labelled "(returned to)". Perhaps one reason these uses of the phrase were chosen for particular attention was because Pat would not let the topic of BANA customer representatives drop in meeting six. The question mark after the label "a problem with a lack of information sharing" shows my uncertainty. However, I went ahead, knowing I would say more than this in Table 2, and especially if I came to focus on OT11 and OT12 using CA. Those labels were sufficient for my purposes just then.

When I created the second table, which moved away from descriptive questions and chronological order to ask about topics and concerns, OT11 and OT12 were no longer so alike.

OT12:

- Time - Current situation? Space - Non-specific places; The field; BANA's existing members

- Generic features (what are the connections?): Potential field manager 4; Statement of reality; No one person has workplace assessor information within an org 
OT11:

- Time - Current practice? Space - Work within BANA with reference to the field?

- Generic features (what are the connections?): Potential field mgr 3; Relaying past action; Fieldworkers need info

OT11 and OT12 had become separated. Table 2 was ordered by groups using time and space, and when reading through, OT12 appeared before OT11. Though they have the same time category (current), I labeled one "practice" and the other "situation", applying a question mark to each. With regard to the category "space", you can see that OT12 contains a list, which indicates uncertainty on my part, and while the statement about space for OT11 appears confident, I have again used a question mark. "The field" is included in each, perhaps suggesting that OT11 and OT12 should have been together in table 2 rather than in separate groups, two pages apart.

Looking at generic features however, suggests that this split was appropriate then. As I said above, I knew when I was creating those categories and separations that they would be unlikely to hold in this thesis. For those uses of the phrase "out there" not analysed beyond these tables, my further analysis of OT29, OT11 and OT12 casts doubt on those labels. Were a reader to use chapter five and its tables in isolation, as a way to understand the use of the phrase in the meetings I attended, there would be limited value from material arrived at by such short-cuts. Rather, those tables were useful as some kind of start in considering the meetings. You may feel that I have taken an unnecessary risk here, that a thesis chapter should stand alone, that this is the expectation of those who read theses. As with not being able to contain the analysis of OT11 and OT12 within one chapter, expectations and hopes of containing, do not always last once and for all. We are always moving on and the closer we look, the more there is to say (Strathern 1991). Through the close analysis of the talk in the next section I hope to show, using CA, that there is more going on than these kinds of labels can convey. Again there is a lot of meeting talk presented.

\subsection{Conversation analysis of OT11: A problem involving "information"?}

As seen in the labels above, the fifth and sixth appearances of "out there" in meeting six are close in some ways. They are part of the same piece of conversation, occurring around six minutes apart. Having listened carefully to the talk, some of the 
labels have become unsatisfying and no longer seem adequate. For instance, how was it that meeting members were working on a "New system/model of BANA customer reps"? That label does not convey the many things going on. Turning to CA allows an opening up, a stepping back to ask the broader question of how the phrase "out there" is involved.

In the lead up to this piece of conversation, Kim has said that one of the issues from the stakeholder survey was sparse communication from BANA; who people from outside the organisation could or should talk to. Somewhere other than the staff meeting some of members of BANA had looked at where the first point of contact occurred between BANA and clients. They had thought that as BANA had grown things had become more difficult, and that a structure was needed around each project. Already in this discussion there had been talk about resources and membership fees and value for BANA members. The risk associated with people within BANA not having an overview of what was happening in different member organisations was raised. Pat has said that updating with regard to this at the staff meetings was a good idea.

\subsubsection{This use of the phrase of interest (turns 147-212)}

Only the turns of talk analysed using CA are presented below (147-212). You can see the initial labelling of all of the turns of talk (1-302) in Appendix four: Turns of talk analyses for chapters seven and eight (OT11 and OT12). The focus of the work just prior to where the turns of talk analysis starts below was the development of a list of key BANA contacts. Prue was standing at the whiteboard, writing. Pat introduced the topic, briefly saying what they had done perhaps to update those members not directly involved in this work (turns 1-41). Next they worked to clarify the task. This appeared to involve developing the list and highlighting a problem as Pat saw it (4267). The discussion included who was the key contact for workplace assessors, and meeting members seemed to agree it was Pat (68-117).

There appeared to be a problem (118-146), during which Sally said "no one person" three times ("so there's no one person responsible" (turn 132), "but no one person has an overview" (turn 140), "nobody does there's no one person so" (turn 146)). Taking over quickly from Pat (“...it's stopped happening” (turn 135)) and Sally, Prue explained that there was "a process now which has different people 
involved at different stages" (137). After Sally repeats "no one person" Prue takes over the talk and starts defending the change.

\section{Analysis section 1}

147. Prue:

148. ( )

149. Sally:

150. Prue:

151. ()

152. Prue:

153. ()

154. Prue:

155. Jo:

156. Pat:

157. Prue:

158. Pat:

159. Prue:

160. Susan

161. Pat:

162. Susan:

163. Prue:

164. Sally:

165. Prue:

166. Pat:

167. Prue:

168. Pat:

169. Sally:

170. Prue:

171. Sally:

172. Prue:

173. Pat:

174. Prue:

175. Pat: and can there be how many have we got 350 ? (pause) um ()

(300)

380 ()

is it not really something that we go back to the individual departments and projects

(mm)

and say what's happening in here

()

because let's be realistic how can you possibly retain an overview of what 350 different people are doing in 30 different agencies yeah try doing it in Org D (laughter) but but there is a point there about the overview and about us being able to source stuff in a different way because the reason why I wanted to get back into that loop is that like when it comes to Jo and I looking for assessors for people out there (pause) we had taken a step (pause) and Paula a step back (by) not knowing who was registering it meant that we didn't know well look there's this group of people from this organisation in um City A (flicking pages) that we could use as private contractors for assessors so $\mathrm{so}=$ =well the private contractors one that that information is going to go on the web

$\mathrm{mm}$

we've go that information that will go on the web so that will that but the thing is there's so many coming through Pat I I

(unclear) important

$\mathrm{hm}$

to be honest

I'm I'm evaluating every single one of these

mm

every year

$\mathrm{mm}$

and I've I've got no idea

$\mathrm{mm}$

yeah

there's too many I I I it's just it's just there's too many so so in a way I think the registration process is almost independent of (pause) maintaining who you know who=

$\Rightarrow$ the quality $<$

the information in a different way (that) knowing who've we've got where because it's too much=

$=\mathrm{I}$ don't $\mathrm{I}$ don't see it as independent Prue=

$=$ (but) $=$

=because I to me it's all part of that communication key contacts

link in that if yeah now you see by me seeing the first I've only seen

one group of files and in that group of files I discovered that there 
176. Prue:

177. Pat:

178. Prue:

was a whole lot of people from Org $\mathrm{C}$ registering as assessors for health and safety so that gave me the information (pause) around a whole lot of other links [that I need = [=oh no I'm I'm not saying that that's not an important part of it but I'm what I'm actually saying is that it I mean yeah I I I've got no argument there I agree with you it's useful but basically there's so many it's it's there's so much of it it's not going to be information from that source you're going to be able to hold in your head there's too much of it I've got no 'cos I've tried and I've lost the plot with it there's too many

\section{$\mathrm{mm}$}

there's too much so we've got to have other ways of holding that information=

End of section 1

Analysis section 2

179. Pat: $\quad=$ yeah like in the database that there is so many people that are ah um

180. (Prue) yeah yeah

181. Pat: (unclear) New Zealand

182. Prue: and and the person who's responsible for Org B

183. (May) (unclear)

184. Prue: knows how many assessors is is checking in the database to see how many assessors=

185. Susan: =or even better still the database sends them a little report saying= 186. Prue: =yeah so $\mathrm{so}=$

187. Pat:

188. Prue:

189. Susan:

190. Prue: $=$ or the database sends us a report to say how many people there are in there

191. Pat:

192. Prue:

193. May: and and see

if in fact you're the you're the ANA [rep for that agency you get an automatic report saying in the last month (unclear) new people have [that that um report

$\mathrm{mm}$

that report that Susan put out about the number of training agreements we've got and the different qualifications in in each agency

$\mathrm{mm} \mathrm{mm}$

195. Pat: $\quad \mathrm{mm}$

196. May: it was

197. Prue: now we can match that with the sort of information about workplace assessors

198. (Sally) workplace assessors

199. Pat: $\quad \mathrm{mm} \mathrm{mm}$

200. Susan: (exactly) that one so you're getting reports based by agency or by

201. Prue: yeah

202. Susan: domain 
203. Prue: $\quad$ so you know we've got twenty new there's twenty assessors of which ten have been registered in the last six months or something like that

204. Susan: or by agen- like which kind of agencies yeah

205. Simone: (unclear) workplace assessors

206. Prue:

207. ( ) yeah I just just think that will be a better

208. Susan:

209. Prue:

(unclear)

Org C did (laughs)

210. Susan:

211. (Pat)

212. Susan:

better way of of um of holding the information in the long term $\mathrm{mm}$ like getting reports and analysis

$\mathrm{mm}$ (pause)

End of section 2

\subsubsection{Initial observations}

The section (or "cluster of activity" (Heritage 2004 p. 228)) that we pick up on first involves Prue taking over the discussion from Sally who had been repeating that within BANA there was "no one person" (turns 132; 140; 146) responsible and who had an overview $(134 ; 140)$. Pat had suggested that her being out of the "the loop" was a problem in that she was not seeing all of the paperwork as it came through the office (turns 78 and 91). The "loop" that Pat seemed to be seeking was where she would be bodily, physically, materially involved, viewing documents as they moved through the BANA office. This would enable her to know (turn 95).

\subsubsection{Section 1: One head cannot hold that amount (147-178)}

When Prue took over from Sally, she questioned the possibility of "one person" within BANA being able to hold that amount of information in their head. Pat, the other main speaker in this section, still wanted to get back in "the loop" and she employed the phrase "out there" (OT11). Pat used the phrase to show that the field advisors not having some of the information others in the organisation had was a problem, including a resulting loss of opportunities. Prue responded that thanks to "the website", information to help with the specific example Pat had used would be available in the future. More generally Prue argued that there were too many forms coming in for one person to maintain an overview, arguing that, because of the amount of information, Pat would not know by seeing the papers. Rather, Prue suggested that member organisations should know. 
A gross (Sacks 1987) summary of the turns is:

- Using the number " 350 " Prue disputed the possibility of having "one person". She suggests what should "really" be done is to go back to members; retaining an overview of that number is not being "realistic". Used "we" in inclusive mode.

- Sally and Jo produced continuers for Prue's turn (147-155).

- Pat took turn with "but but" and produced an extended turn. She repeated wanting "to get back into that loop" and gave an example using "out there" (OT11), signaled by "well look". She called up Jo and Paula, indicating the fieldworkers. Pat suggested that not knowing was the reason, had meant that, and had resulted in, BANA going backwards. This lack had caused that (missed opportunity). Used "different way". (156)

- Prue said Pat's particular example would be fixed by the website ("going to go on the web").

- Susan said "important" and "honest" in the background.

- Prue continued her point using her experience, saying she has tried but failed. Used " $P$ " in authoritative mode.

- Pat and Sally produced continuers.

- Prue continued with the point that there were too many, talked about separation and used "different way". (172)

- Pat attempted to stop. She disagreed, repeating Prue's word "independent" and retaining the turn (from Prue), explaining and giving an example in an extended turn, of a missed opportunity. Again used ' $P$ ".

- Prue took an extended turn (176) with an overlap. She suggested that Pat misunderstood and repeated her point about there being too much "information from that source" to hold in one's head. Used " $T$ ", perhaps indicating authority.

- Pat produced continuer.

- Prue said there must be "other ways of holding that information" (178). Used "we" perhaps appealing to the group.

In this piece of conversation the general concern seemed to be with ways of having access to information. Pat and Prue both talked about a "different way" (156; 172). While Prue told Pat that in "the website", specific information would be available (157-159), Pat appeared to be seeking to be included in a material chain of events. These points will be picked up later in the chapter.

In Susan's use of "secondary" (55) we can perhaps see, like Sally's use of "no one person" (turns 132; 140; 146), work on simplifying, control and singularity. In the meeting talk, can we see the members of BANA wrestling with multiplicity and 
plurality as a problem? How is it possible to do collective organisation and also place responsibility?

With regard to the organization of this talk, one question raised is whether knowing a number allows Prue to take the turn. Silverman talks about various ways of obtaining "the right to speak" (1998 p. 115), and perhaps in these meetings, using numbers was one such mechanism. Comparing Prue's use of numbers in OT29, suggests numbers are involved in acts of doing $I$ know, which allow members to gain the floor (Silverman 1998). In the third section of the analysis of OT29, Prue produced a query by taking a guess at how many should be copied (30 or 40). In that analysis I suggested, drawing on Boden's work, that in these meetings queries allowed for opening up the discussion (1994). In this use Prue (147) is not opening up the topic, but providing a platform for what should "really" be done. The next chapter asks more specifically about who has the right to make suggestions in these meetings (by telling how I know and how it is).

\subsubsection{Section 2: The future? (179-212)}

In the second section we see Pat quickly take over from Prue's point about needing to hold information. Despite the speed of action, a new analysis section has been created here for a number of reasons. Pat had stopped arguing for getting "back into that loop"; there were more speakers than Prue and Pat; and there was a strong sense of the future. Was Pat now supporting "the database"? With this turn did Pat indicate that the danger had passed (179)? It may not be that Prue sees "the database" as the answer to the problem Pat had raised, but it was a reply to Pat for just then. It was an effective reply in that Pat would find it problematic perhaps to disassociate from, or not associate herself with, "the future" as it appeared here in the form of "forward looking information systems" (Munro 1998 p. 222). There is a sense in this section of talk that all is $O k$. Members seem to be agreeing as they talked about future possibilities and the meeting continued on. Looking closely at the turns of talk shows how this was made possible by possible through Prue stopping Pat. The general feeling that nothing is amiss here, and Prue's stopping of Pat, may have allowed Susan to come back in and talk about how good "the database" would be.

A gross summary:

- Pat talked about "the database". 
- Prue took over with an abstract example of what a person might do, how that person might use "the database" - they would check with it.

- Susan said how "the database" could be even better used - it would send them a report.

- Prue attempted a turn but Pat achieved it in supporting Susan's turn of talk.

- Prue tried again but Susan continued.

- Prue overlapped, gaining the turn with a specific example (using what we "all" know).

- May produced continuers and with her and Pat's support, Prue suggested what they could do now.

- Susan added more about a potential report.

- Prue produced continuers for Susan.

- Simone mentioned workplace assessors.

- Prue repeated her point with what would be better (attempted to resolve a problem).

- Susan produced continuers for Prue, giving an example and laughing.

- Prue repeated her point about a better way; used "holding" again.

- Susan took turn, with Pat producing continuer, saying that concise information is better.

The end of this section was indicated by a lack of urgency, a trailing off.

Initially there seemed to have been agreement in this piece of conversation that "the database" would help. There appeared to be no split of Pat's argument for contact with the paperwork against Prue and Susan's talk about technology (for example turn 187). However, looking closely we can see that except for her mention of "the database", Pat said relatively little here. It appeared to be more as though Prue and Susan were attempting to convince Pat. With her turn did Pat provide an opportunity for Prue and Susan to convince her of what would be better in the future? To consider this further I will ask whether one of the concerns of this talk is with different kinds of access to things like information. Because of the concern with access, more time is spent commenting further on section 1 .

\subsubsection{Further analytic comment}

Starting quite broadly, the overall structural organisation of the talk in section one (turns 147-178) is something like:

- Meeting facilitator disputed a suggested possibility (reducing a problem?) and suggested something different (not our responsibility). (we) 
- Other members produce continuers.

- Potential field manager defended, giving an example of a missed opportunity. (we)

- Meeting facilitator dismissed - that example would be fixed by "the website" (future). Meeting facilitator said she has failed to achieve suggested possibility (it was impossible); something different was required (future). (I)

- Another member spoke in background.

- Potential field manager defended, giving an example of a missed opportunity. (I)

- Meeting facilitator does you misunderstand - the suggested possibility would not achieve the aim of knowing, "other ways" were required (future). (I)

- Potential field manager produced continuer.

- Meeting facilitator repeated "other ways" were required (future). (using we) Prue disputed Pat's suggestion of what to do next (using we), Pat defended with an example (also using we), Prue stated what would fix that particular example and showed how Pat's suggestion was impossible (using I), Pat defended with another example (using I), Prue does Pat misunderstands, and repeated "other ways" are required (178). Reduced down, the organisation or sequence (Sacks 1987) is:

- Facilitator disputes suggestion and provides alternative suggestion.

- Potential field manager defends with an example.

- Facilitator dismisses that example. Facilitator disputes with her experience that the suggestion is impossible, other ways are required.

- Potential field manager defends with another example.

- Facilitator does misunderstanding, repeats other ways are required.

Though Prue has the last word, it is not a concrete action, and is less emphatic than her initial suggestion that they "go back to the individual departments and projects" (150). Pat's defending can therefore be seen to have softened Prue's suggestion of what they should do next. Like a wedge, Pat's defending made space for other possibilities; the topic was opened up, for now, from an initial narrowness. With the words "well look" Pat created her own opportunity to be convincing. Looking at it this way suggests that the analysis section break is premature, but I will continue for now.

In this sequence we saw:

- - disputing and providing an alternative

- defending

- disputing and stating "other ways" are required

- defending

- repeating "other ways" are required (OT11 and OT12 (1)). 
Comparing this sequence to the one seen in chapter six, perhaps it is the doing of misunderstanding that signalled to me to place a halt in the talk? In that chapter we saw the sequence:

- Query-contributions-claim-judgement-acceptance (OT29).

In each, misunderstanding was involved near the end of the sequence. In this sequence Prue says "but I'm what I'm actually saying" (176), and in the previous one Sally said: "yep that's cool just time to do that's all". There are differences between these, and I will talk about Sacks" "misunderstanding machinery" further in chapter nine (1987 p. 66).

What can be said about the organisation of the talk in section 2 (turns 179-212)? Here is the already reduced sequence:

- Potential field manager asks about "the database" (seeks information; provides an opportunity for others to convince her?)

- Meeting facilitator provides an example of how it might work (someone would check in "the database").

- Technical person provides a different example ("the database" could send a report).

- Potential field manager supports different example ("the database" could send a report).

- Meeting facilitator gains turn by reminding about previous report Susan had put out, seeks confirmation of value (192-196).

- Fieldworkers agree it was valuable.

- Meeting facilitator gives unspecific suggestion: they could match that (is it a report or waiting in "the database"?).

- Technical person and Meeting facilitator talk about the unspecific suggestion.

- Office-based person asks.

- Meeting facilitator says a better way (206-209).

- Technical person confirms. 
While Prue and Susan appear to continue each other's talk about what could be done using "the database", this close examination reveals that there are differences. Prue starts off with an example where someone who was responsible would check in "the database". In contrast, Susan suggested "the database" could send a report, and it is this option that Pat appeared to support. Can we see here that Pat is still working to have an object (paper or electronic) delivered to her, rather than have it available for her to seek out? What Prue does next (192) is hard to pin down however. She talks about a specific report and gains confirmation of its value from May and Pat. It may appear that in talking about reports, Prue accepted Susan and Pat's idea of sending reports. However, she did not talk about reports, rather she was unspecific, using "match" (197), and "holding" (209) and ended with the need for a better way. The sense is that there was not agreement yet, and it was unclear what Prue was now proposing. In the next chapter I suggest that we see Sally doing being unclear and it is her question in the next turn where chapter eight picks up the talk.

The sequence for this piece of conversation is:

- Query-provides example-provides different example-supports different example-seeks confirmation-unspecific suggestion-says a better way (OT11 and OT12 (2)).

\subsection{Working on access to information}

The concern taken up here involves how Pat and Prue worked on kinds of access to information. This work appears to be more than just about seeing because Pat would see "the database" or "the website" as she would see paper. Rather what seems to be important here is how the opportunity to see would arrive. Whatever eventuated after the meeting, Pat and Prue can be seen to put a lot of effort and care into the discussion of these matters. There are many ways to gain access to information but the alternatives seen in the work of Pat and Prue in meeting six can be summarized as something like:

1. Bodily (seeing paper, holding information in heads), as being materially involved in a process. See for example: "the reason why I wanted to get back into that loop" (Pat, 156). 
2. Technically (available, held in system), waiting to be retrieved. See for example: "that information is going to go on the web" (Prue, 157).

Having considered this by looking closely at turns of talk, it is useful to go back to my initial noticing during the fieldwork. I wondered then about Pat talking about keeping personal contact, and Prue and Susan suggesting technology and machines for handling information. Back then I noted Prue saying that she was "putting a lot of faith in the website having current information" (see section 7.2.3 (OT8) and the narrative of meeting five in chapter two). Now I wonder how Prue used the future to stop Pat.

I did not do much with that observation as it stood then. From ANT and Munro's work I accepted that things were multiple, collective, associational. It has been the case that CA has provided a way to follow an insistence on relations. Here, I suggest that Pat's arguing to "get back into that loop" is not solely a concern for being in the know, nor is Prue's reply that "other ways of holding information" (178) are needed, purely a managerial concern for efficiency (Munro 1998 p. 233). As in the previous chapter (OT29) I have followed CA's lead that "action, context management, and intersubjectivity" are being worked on simultaneously (Heritage 2004 p. 224). Following Heritage (2004) and Munro (1998) I am arguing that there is more going on than (just) that. Looking closely I saw a contrast between Pat's calls to "get back into" and Prue's replies using "will go on" between existing practice (the past) and what may happen next (the future).

Having said in a previous chapter that I would avoid using parts of the work of others as a launch pad, I wish to separate out a statement from Boden for my purposes here. Taking a multiple view means that though I appreciate Boden's work, I have not sought examples from these meetings to confirm her statement that "In particular questions and their answers provide the primary structure through which information is sought" (1994 p. 110). Rather, I have asked Munro's broader question: what are the "projects conducted in the name of information" (2001a p. 199)? This enables going beyond the name "information" to ask how it is involved in enacting organisation like making information available (waiting) rather than delivering it (being in a “loop"). Using Munro's question and CA, I have been able to step back to ask whether this is a way that control and responsibility are worked on. I have been able to explore what else could be said about Prue's contention that bodily being in the 
loop would not meet Pat's need for information, that it was impossible to hold that amount in a head.

It is too simplistic to say that what is being worked on here is a hierarchy of technical systems (the new database; the new website) over fieldworker contact with, and sighting of, paperwork. Too easy, though at first glance understandable, to say that we can see a battle of Susan and Prue versus Pat. What can be said without moving directly to a power struggle argument, because it may involve that as well, at times? For instance, what can we make of Pat's reply to Prue that "yeah like in the database" (179), which suggests she is not opposed to the help of systems? The particular focus here is on whether this turn of talk suggests that we can see how meeting members work on what to do about information, including ways to gain access to it. I suggest we can see how members worked on what to do next in getting the work of BANA done. One way was providing platforms for others to make proposals and convince each other of what to do next. Meeting members can be seen as sometimes involved in activities of "enrolling, convincing and enlisting" (Latour 1986 p. 273). This is not to say that there are no differences. It is not to suggest that there are no disagreements. What I said in the previous chapter about disagreements being useful for members holds here also. For one it may be possible to say that Prue works on keeping the momentum of the meeting going, while Pat works to remind and show the members of the meeting (including Prue), the complexity of the field (see turn 52) and to say that things are often not that simple in practice.

\subsection{Conclusion}

This chapter carefully examined meeting talk. While the mode of questioning was again one of asking what is going on here, more meeting talk was presented than in the previous chapter and some was not presented according to CA conventions. In this way the chapter used a mix of techniques in an attempt to see something of what went on. All of the uses of the phrase "out there" were presented from meeting six in the order they appeared in that meeting. It was the eleventh use of the phrase that was analysed using CA. Meeting members appeared to be concerned with information, so I asked how information was involved in the meeting. Singled out for attention was Pat and Prue's talk about information, and I asked what else was happening when 
different proposals were made regarding access to information. As in the previous chapter, the technique of misunderstanding seemed to be used by meeting members.

The analysis in this chapter was partly driven by my wondering about my interaction with Pat after I had presented a draft conference paper (as discussed in chapter four). Pat's account for my interpretation that telling stories about "out there" was a way that fieldworkers were powerful in the meetings, included saying that the background was missing from my paper. She said her concern was about sharing information. In this chapter can we say we saw Pat working on seeing all of the information about the field (contact outside BANA)? Was seeing put in relation to knowing, and was knowing in some kind of relation to being allowed to make suggestions about what should happen next? I argued that it is too simplistic to label the actions in this meeting as attempts to maintain control, yet control was also involved.

How suggestions that information could be better held in "the database" are acted upon, including as some kind of challenge to knowing, continue to be explored in the next chapter, especially with regard to external contact and responsibility. One focus of the thesis has become attempts at telling how I know, and telling how it is in these meetings. I noted the changing uses of "we" and " $P$ " by Pat and Prue above. Are these uses of " $P$ " (for instance, Prue 176) an attempt to do I know about this? Ways of telling how I know, and telling how it is, are again in focus in chapter eight. 


\section{Chapter eight}

\section{Agreeing and disagreeing}

\section{TABLE OF CONTENTS}

8.1 Introduction

8.2 The interaction involving OT12 (turns 213-302)........................................ 168

8.2.1 Example of use of the phrase of interest ............................................ 168

8.2.2 Initial observations

8.2.3 Further analytic comment.............................................................. 176

8.3 The interaction involving OT11 and OT12 (turns 147-302) ....................... 181

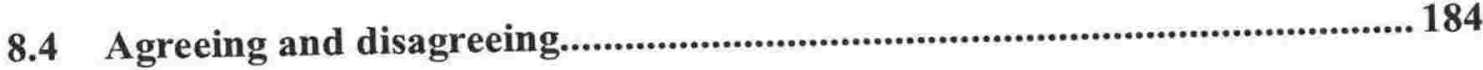

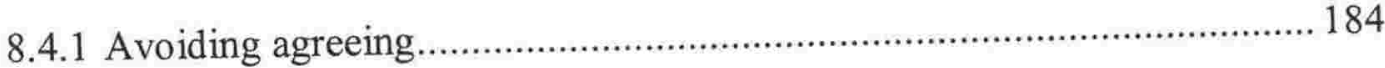

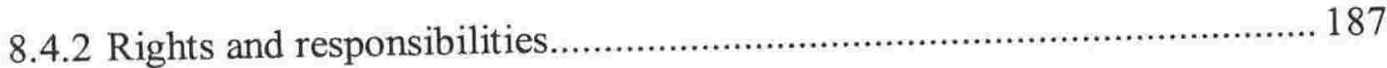

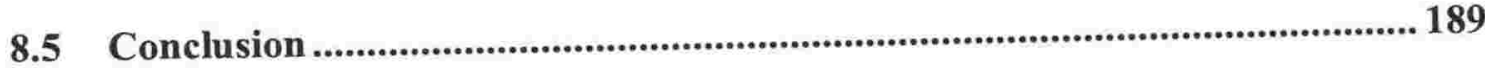




\subsection{Introduction}

Pat: but but there is a point there about the overview and about us being able to source stuff in a different way because the reason why I wanted to get back into that loop is that like when it comes to Jo and I looking for assessors for people out there (pause) we had taken a step (pause) and Paula a step back (by) not knowing who was registering it meant that we didn't know well look there's this group of people from this organisation in um City A (flicking pages) that we could use as private contractors for assessors so so (M6)

Pat: and it's and we have lots of different situations Prue like we've got you know training and development staff like Org B that we're working with and Jo has done a lot of work with Org B and I've done some stuff and met with Jackie

Prue: $\quad \mathrm{Mm}$

Pat: and then I've got a manager within Org B who just wants to bypass those people "cos they're sit sick of waiting round and nothing happen and them just continuing to talk and they've got a training budget and they want to use it in business administration you see so then um what I'm saying this thing about having a co-ordinator in (every) organisation I think is a very great idea but reality is out there it's more people it's a co-ordinator of a project as opposed to a co-ordinator of an organisation it's a bit like May with the diploma you know um (M14)

This is the third and final chapter with the aim of carefully examining meeting talk using conversation analysis (hereafter "CA"). This chapter is the second part of the analysis of the interaction containing two uses of the phrase "out there" from meeting six (OT11 and OT12). This split became necessary because of the detail involved in closely examining talk. I use CA as a way to see the action in the meetings, and ask how these uses of the phrase are involved in attempts to defend suggestions of what should happen next.

I firstly present the meeting talk analysed in this chapter. What to do about information seems to be the problem facing BANA. Initial observations are made about the actions the meeting members are attempting. This is done by summarising the turns of talk in the four sections into which this talk was split during analysis. Next I make further comment about this interaction by looking at the organisation of the talk and drawing on previous CA research. In this section I discuss further how members go about the tasks of the meeting. One concern is how these meetings are places for members to show they can identify and act on organisational implications. I will consider how members show that they are acting on implications using the word "so". 
In the final section I consider together the talk analysed in this chapter and the previous one. I ask whether, across the interaction, we can see meeting members working on what to do next from problems raised. I firstly consider the overall structural organisation of the interaction and secondly how meeting members undertake agreeing and disagreeing. As in previous chapters I continue to distinguish meeting member talk with italics and quote marks, and analytic concepts with italics. ${ }^{1}$

\subsection{The interaction involving OT12 (turns 213-302)}

The transcribed talk presented in the last chapter finished at turn 212 and we pick up directly here at turn 213.

\subsubsection{Example of use of the phrase of interest}

\section{Section 3}

213. Sally:

so that comes out in your existing database

214. Susan:

215. Pat: it can't do it in existing (unclear)=

216. Susan:

217. Pat: $=$ no it can't do it and see that's the thing it can't do it yeah and it's it's just gotten to be a bit of a huge mess really because because it can't be done it's like um Org A say to me so how many workplace assessors have we got registered with you (pause) and you know like we have an expectation from here this is this is the point BANA has an expectation that they will know themselves

218. Prue: yep

219. Pat:

220. (Prue)

221. Pat:

222. Prue:

223. Susan:

224. (May)

225. Susan:

226. Pat: and because it's such a huge organisation they don't it's like you know I think we have to be realistic

227. Simone: [so are you actually doing

228. Susan: [absolutely

229. Simone: like the workplace assessor and the quals that they (offered)

230. Prue: [no no

231. Susan [we don't we don't we can't record quals

232. Prue: no no no

233. Pat: no see like

\footnotetext{
${ }^{1}$ See Appendix two for the conventions used to indicate quoted meeting talk and concepts.
} 
234. (Susan) [this is why (really)

235. Pat:

[I have to have a look at paper files to do that

236. ()

yeah

237. Pat:

I mean that's why it's=

End of section 3

Section 4

238. Simone: =is the new system going to be able to do that I mean that's ()

239. Prue: [yep ah

240. Susan: [I'm very much hoping so and that's why I'm quite keen to move it into a soon as possible because our current system doesn't do reports

241. Simone: ah

242. Pat: ()

243. Sally: [and its sort of all the a lot of the information that the new database can provide

244. Pat: [( )

245. Sally: is the sort of information that you need in order to get to where you want to be

246. Pat: yeah that's right (exactly)

247. Sally: in terms of your communication

248. Jo: it's basic isn't it it's just basic isn't it=

$\begin{array}{ll}\text { 249. Susan } & =[(\text { ) } \\ \text { 250. Pat: } & {[\text { it is it's basic information that people like the field advisors need }}\end{array}$

251. Susan: [absolutely yep

252. () yep

253. Pat: $\quad$ you know

254. Jo: when we have someone ring up on the phone who's a bit cross and we can't (pause)

255. Pat: yeah

256. Sally: yep

257. () Ok

258. Susan: um so we are actually awaiting on the on the the current vendor to actually finish the the database and then roll it out to the existing clients so we get a look in after them basically um but I am pushing them quite hard that we get it sooner rather than later

259. () $\mathrm{mm}$

260. Susan: so yeah

261. Prue now um

End of section 4

Section 5

262. Pat:

so at this stage paper is the only way that we get information about workplace assessors (pause)

263. Prue

264. (May) hm (long pause) 
265. Prue:

266. Pat:

267. Prue:

268. Pat:

269. Prue:

270. Pat:

271. Prue:

272. ( )

273. Pat:

274. ()

275. Prue:

276. Pat:

277. Prue:

278. Pat:

279. Prue:

280. ( )

281. Prue:

282. Pat:

283. Prue:

284. Susan:

285. Pat: but I think one of the things we'll need to do is is actually be more proactive in in sourcing the main contact of with with the with the project in a particular agency who who is going to be the person that's going to be we will communicate with

$\mathrm{mm}$

so we've got a [single (point)

[and it's and we have lots of different situations Prue

like we've got you know training and development staff like Org B that we're working with and Jo has done a lot of work with Org B and I've done some stuff and met with Jackie

$\mathrm{mm}$

try and sort stuff out over there and it's a bit of a mess and then I've got a manager within Org B who just wants to bypass those people 'cos they're sit sick of waiting round and nothing happen and them just continuing to talk and they've got a training budget and they want to use it in business administration you see so then um what I'm saying this thing about having a co-ordinator in (every) organization I think is a very great idea but reality is out there it's more people it's a co-ordinator of a project as opposed to a coordinator of an organisation it's a bit like May with the diploma you know um

oh yeah but um

(isn't it)

yeah

()

I'm I I would assume that if there were projects happening that they would each have they would have a co-ordinator but for us it's a single point of contact where a bit a bit like what Org E have now given us

$\mathrm{mm}$

to through Toni yeah there's all sorts of things happening but $>$ just make sure she's always in the loop as well $<$ so a again it's part of the the $<$ keeping the people who are going to be authorising the paying of the bills $>$

$\mathrm{mm}$ informed that we're doing this that and the other all round the place it's um an early warning alarm bell which for instance with the um with ah Org D if we had had that in place for that Org F (development) maybe it wouldn't have (altered) to the degree it did (pause)

( )

well (laughs) yeah get halted the way the way it did so um so it's um and and that person will change and we'll have to sort of keep tracking them down (flicking pages)

286. Susan:

$\mathrm{mm}$

all those sorts of things but it doesn't mean we shouldn't try

(flicking pages)

keep on asking the question

$\mathrm{mm}$

who is the key co-ordinator 
287. Prue: we've got we've got someone like Jennifer in in Org A and she's pretty much been

288. Susan: (there's) two of them

End of section 5

Final section

289. Prue:

290. Pat:

291. (May)

292. Pat:

293. Prue:

294. Pat:

295. (Prue)

most (of) Ok (pause) gone as far as we can on this one for the moment?

hm I think yeah

(yes)

but we need we just need to um what we want

just capture it

from today is that this is going to happen (whiteboard forwarding noise) um (pause) and that we can have time at staff meeting to do that

296. Pat:

297. Prue:

298. Pat:

yeah=

299. Prue:

300. Pat:

301. (May)

$=\mathrm{Ok}$ (pause)

well maybe the first thing is for for the next meeting (board

forwarding and paper tearing noises) is everyone everyone to bring to this table the projects that they're working on externally with different departments

302. Prue:

$\mathrm{mm}$ (pause) (board forwarding noise)

um

because we probably just get one done a staff meeting I should imagine

mm (pause)

what I (pause) (laughs) (board forwarding noise) in a way this is part of the same thing it's about communications and projects and how we decide on them and what I (pause) (flicking pages) what I've started to do and I've just just put it in extremely quickly and there may may need will need adding to and and and confirming I was looking at you know we're we're asked by all sort of people to develop all sorts of qualifications ah usually we have been um demand um driven um increasingly we're starting to be proactive in in in qualification development um I think proactive is going to be the way to go although we're still going to get the odd ques- the you know the the specialists are probably always going to be demand driven it was to actually have some agreed principles on which we base the decision to go ahead with an agreed project um and see how how it fitted in so I just threw all this stuff up with very little form

End of final section

\subsubsection{Initial observations}

An analysis was undertaken by considering each turn of talk and this initial work can be seen in Appendix four: Turns of talk analyses for chapters seven and 
eight (OT11 and OT12). What follows is a summary of the turns of talk by sections concerned with showing the actions the meeting members can be seen attempting.

\subsubsection{Section 3: What the existing database cannot do (213-237)}

The sense that the talk is trailing off called for a new section here. We are however still on the topic of information. Perhaps Prue or Pat would be the ones to bring this discussion to a close, but what happens next is that Sally asks about the existing database.

In summary:

- Following on from Susan's turn, Sally asks about the existing database. Uses "so".

- Susan answers "it can' $t$ ".

- Pat takes the turn quickly, repeating Susan's statement but adding "no" ("no it can't..."). She says this is a problem ("mess") because she cannot answer a member question and that BANA ("from here") expects members to know themselves. This extended turn is signalled with "this is the point".

- Prue agrees, produces continuer.

- Pat says because of the size of that organisation they do not know and "we have to be realistic" (219). Prue said "let's be realistic" earlier (see chapter seven, turn 154).

- Prue talks in the background.

- Prue, Pat and Susan overlap each other's talk. Susan gains the turn: "pull them out" (how many workplace assessors). (225)

- Simone asks. Uses "so".

- Susan, Prue and Pat provide answers - "no no"; "we don't we can 't..."; "no see...". $(230 ; 231 ; 233)$

- Pat overlaps and takes turn explaining what she has to do because the database "can' $t$ " - she looks at paper files. (233-237)

Apart from the extended turn (217) where Pat said there had "gotten to be a huge mess" and outlined a resulting problem, the turns of talk in this section were short. There is a lot of overlapping talk between the main speakers, Prue, Susan and Pat. Most of the talk involved what the existing database could and could not do (for instance $214 ; 215 ; 231)$. Pat concluded that she had to look at paper files. This is not a comfortable section of talk. It seems to involve an existing organisation limitation. Note Simone and Sally's turns, especially their use of "so". 


\subsubsection{Section 4: Agreeing the new database is worthwhile effort (238-261)}

Though Simone started taking turns in the last section (from 227), a new section has been created here because Simone takes over quickly from Pat. Simone is not usually heavily involved in the meeting talk, and you will see that she soon ceases to talk here also. Looking back to the beginning of the previous section (turn 213) we see Sally and Simone doing the work of asking questions.

This section involves asking about the new database and producing an account. After Simone's question, Susan updated on the development of the new database. Many speakers contributed to these achievements. Supporting Pat's concerns was also undertaken, yet the precise concern was not clear. Pat expressed a concern perhaps about gaining what was essential for her to do her job. This is perhaps one way to see the discussion of the "sort of" and "basic" information needed (Sally 243; Jo 248; Pat 250).

In summary:

- Simone asks, as Sally did, about the new database (future).

- Prue answers "yep" but qualifies " $a h$ ".

- Susan overlaps and takes turn with her hopes and explains that is why she is keen to get it moving.

- Pat attempts turn.

- Sally takes turn - talks about the information the new database can provide and what that enables ("where you want to be" - future again).

- Pat produces continuers. (243-246)

- Pat and Jo agree.

- Pat takes up the turn from Jo, repeating "basic". (250)

- Susan and someone else agree.

- Pat, Jo and Sally produce joint talk. Jo gives an abstract example of the current problem, which is one of his few turns. (254)

- Someone says, "Ok" - perhaps it is Prue attempting to stop the talk.

- In an extended turn Susan talks further about her work on the new database. (258-260) Using "um so" and "so yeah"

- Prue attempts a stop and sum up with "now um".

In this section Susan talked about what she was waiting for on the new database and what she was doing (she was "pushing them quite hard"). Sally, Pat and Jo can be seen as having called for this account. 


\subsubsection{Section 5: What we can do (262-288)}

In this section there is a change to mostly two speakers. Such changes in the number of speakers indicated where breaks could be inserted in the analysis. In this case, there had been a reduction of many speakers to two; a restriction of some sort in the conversation. I suggested in chapter six that seeking "permission" to tell a story, indicated that members attended to being careful with meeting time (Schegloff in Silverman 1997 p. 43). The reduction in the number of speakers here also involved the use of meeting space. Pat has repeated her concern and Prue and Pat were largely the speakers here, continuing each other's turns despite opposing positions. Susan came back in towards the end of the section.

In summary:

- Pat confirms currently "paper is the only way". Uses "so".

- Prue takes turn. Agrees, pauses as she writes on the whiteboard, and qualifies.

- Prue continues extended turn, talks about what BANA members can do. Is she suggesting the fieldworkers can do more? Pat produces continuer.

- Prue continues turn - explaining that this would achieve " $a$ single point". Uses "so".

- Pat overlaps saying there are "lots of different situations" and gives an actual example, showing the work she and Jo have done. Prue produces continuer.

- Pat continues extended turn using example. She suggests Prue's point isn't easy: "great idea but reality is out there".

- Prue agrees initially then replies. Uses "but um".

- Unclear turns. (272-274)

- In an extended turn Prue repeats BANA's need for a "single point" and gives an example. Uses "but". Pat produces continuer.

- Prue continues, agrees things will vary and uses specific example to say keep those paying "in the loop", a phrase Pat used earlier. Speed of talk varies. Pat produces continuer.

- Prue continues saying something is a warning and gives an example of a situation (a shared experience?) that might not have happened the way it did if they had done this.

- Prue seems to pick up an inaudible point (280), laughs, saying again that things will vary.

- Susan and Pat produce continuers as Prue gives examples.

- Susan supports Prue, with what they can do - they can keep on trying.

- Prue gives an actual example. (287) 
- Susan adds to this example, though by saying " $t w o$ ", has she disputed Prue's point about a "single point"?

Using "so", we can see Pat refusing Prue's attempt to sum up with "now um". Pat does not let Prue's directive settle here. In this section we see Pat continuing the discussion, keeping the issue alive and present in the meeting. Pat used "so" in her repeat that paper is the only way (262). Can we also see her calling Prue (and Susan) to account? Can Prue's talk about what BANA can do to achieve single contact people in member organisations be seen as a response to the collective agreement in section 3 and Pat's turn (262)? Can we see Prue in her turn (265) and across this section "produce an agreement in the first instance and then modify it away" (Sacks 1987 p. 63)? Can we see Prue pushing back against this in suggesting what BANA can do in aiming for a single contact person? Is the concern of the two speakers to have responsibility rest somewhere: Pat says BANA, Prue says members? Can we also say that Pat's statement of paper being the only way (turn 262) is intended to be heard by all organisation members, as I asked about Prue saying "let's not get our knickers too much in a twist' in chapter six?

8.2.2.4 Final section: What will happen immediately next (289-302)

The final analysis section is signalled by Prue's attempt to finish the talk on this topic. In this section of talk we see closing, agreeing what to do next, and Prue moving on, but these are not achieved smoothly. Prue brings the wide discussion to a close and Pat states what they want, which Prue appears to support when she tells everyone to "bring" their external projects "to this table". In summary:

- Prue starts, pauses and asks if they've "gone as far" as they can (future).

- Pat and May agree.

- Pat stops the talk with "but". There is the sound of the whiteboard forwarding on (Prue has pressed the button).

- Prue says something I do not understand.

- Pat continues, stating what "we" want from today. Who is Pat referring to? What are the "this" and the "that"? Is it a request that BANA members who have had external contact will tell fieldworkers what they have done (294)? How are the staff meetings used?

- Prue agrees (is it a reply or continuer?).

- Pat takes it as a reply and says "OK" quickly.

- Prue makes suggestion of what to do next. Pat produces continuer. 
- Pat takes turn with how many. May produces continuer.

- Prue does link and move to next topic.

\subsubsection{Further analytic comment}

In the talk presented we have seen Simone and Sally use techniques of asking, and Susan produce an account in the meeting. Pat and Prue it seems, have had the last words, as I discussed in chapter six (Atkinson 1995 p. 2). As in the previous chapters, I am following many of Heritage's ways of analysing material and here I look at meeting members' "task orientation" with regard to information (2004 p. 227). In this section one particular concern is whether these meetings are places for members to show they can identify, and will act on (for instance by speaking in the meetings), organisational implications. Meeting members seem concerned to show that they know that "if this happens then I, or we, can do that". In addition, by spotting implications, members produce warnings (if this then that will or will not happen) which again attempts to achieve I know how it is. The involvement of "so", "well", versions of "real" and the phrase "out there" are paid particular attention in this analysis. Positions in the organisation are used rather than names, to see whether there are differences in actions.

\subsubsection{The organisation of the talk involving OT12: Section 3}

Under initial observations (section 8.2.2.1) I labelled this section of talk "what the existing database cannot do". How was this topic achieved in the talk of the meeting? To start quite broadly, the organisation of the talk is something like:

- Using "so", and following on from previous speaker an office-based member asks (sums up, clarifies current situation).

- Previous speaker (Information Systems member) confirms "it can't do it".

- Potential field manager gives an example of the problem this causes for hershe cannot answer a question (states the problem caused). She says "we have to be realistic" (statement of the implication of this for the organisation). Has Pat been waiting for an opportunity? Does Sally provide it? (217-219)

- Manager, potential field manager and Information Systems person overlap each other regarding what the current situation is. 
- Using "so", another office-based person asks (sums up, clarifies current situation).

- Manager, potential field manager and Information Systems person answer no; "can't".

- Potential field manager says what she has to do because of this. (233-237)

The organisation of the talk is that Sally asks, in the mode of summing-up or clarifying. Susan replies that this cannot be done at present. Pat uses an example to state the problem this causes her and what this means for the organisation (indicated with "we"). Prue, Susan and Pat overlap each other. Simone asks, perhaps summingup or clarifying, to which Prue, Susan and Pat reply that it cannot be done at present, and Pat says what she does instead. Reduced down, the organisation or sequence is:

- Office-based member asks, summing up ("so").

- Manager, potential field manager and Information Systems person make contributions about what this means (the implications).

- Office-based member asks, summing up ("so").

- Manager, potential field manager and Information Systems person make contributions about what this means (the implications).

Here we have the sequence:

- Summing up-contributions-summing up-contributions (OT11 and OT12 (3)).

This is similar in some ways to the sequence seen in chapter six: query-contributionsclaim-judgement-acceptance (OT29), though rather than a "summing up", I called the beginning of that interaction "a query". It was a query produced by Prue. The interaction involving OT29 perhaps quite predictably began with a query produced by Prue as meeting facilitator. However, in this section of talk we see that others also do this kind of (facilitation) work in the meetings, and they use "so" to do it. This comparison also highlights that the turns of talk examined here are a part of an interaction, and that I may have prematurely introduced a section break, but I will hold this separation for now. 


\subsubsection{The organisation of the talk involving OT12: Section 4}

Simone started taking turns in the previous section. Here she takes over quickly from Pat, though her involvement is fleeting. After Simone's question, Susan provides an update on the development of the new database. The organisation of the talk in this section is:

- Office-based member asks (perhaps as a way to seek clarification) about the new database. She does not continue previous talk but rather asks about the future.

- Information Systems member responds that she hopes so, that this is the reason for her effort.

- Another office-based person talks about what the new database will enable (the future).

- Office-based member, potential field manager, fieldworker (and with fewer turns, Information Systems member) agree about the basic information fieldworkers need.

- Information Systems member talks about her work on the new database.

- Manager attempts to take the turn, perhaps to stop the talk.

In this section Simone asks about the new database, the future, and what might happen next. Sally, Pat and Jo agree that certain information is needed by fieldworkers. Susan agrees and talks about the work she is doing. Reduced down:

- Office-based member asks about the future.

- Information Systems person confirms that is the reason for her effort.

- Office-based member, potential field manager, and Fieldworker confirm this effort is needed.

- Information Systems member gives more details.

- Manager attempts to take turn.

The sequence is:

- Asks about the future-confirms-confirm-more details-attempts turn (OT11 and OT12(4)). 
I have been suggesting that Sally, Pat and Jo call for an account from Susan. However, looking closely we can also see Sally, Pat and Jo supporting Susan's hopes and so confirming where she put her effort. In response, Susan provides more details. Susan is still accounting to meeting members, but the sense is that she is responding to something like you are on the right track rather than explain what you have been doing. Prue has been largely absent from this talk, apart from being overlapped near the beginning, and attempting to come in at the end. Others have the floor.

\subsubsection{The organisation of the talk involving OT12: Section 5}

At the beginning of this section Prue may have been ready to move on from this topic, but Pat continues, keeping the issue present. Again we see the use of "so".

- Using "so", potential field manager confirms that "paper is the only way" following on from previous speaker (sums up current situation).

- Manager suggests future action and using "so" explains what this would achieve.

- Potential field manager overlaps, uses example to say situations vary and manager's suggestion is not easy to achieve (perhaps deflecting the directive; does not let responsibility, priority and what should happen next be placed).

- Manager repeats need for suggested future action and gives an example.

- Manager agrees things will vary and uses specific examples to suggest they should try.

- Information Systems member and potential field manager produce continuers as manager gives examples.

In this section Prue has stayed firm on the need for single contact people within member organisations. She has achieved this by taking over from Pat in giving examples of how this suggested action will help. At the beginning of the section Pat was the speaker taking extended turns, but in the second half of the section (from 273) Pat has only 5 one-word turns ("yeah" once, and " $m m$ " four times). These are continuers for Prue, who has the floor. Reduced down the turns in this section are:

- Potential field manager sums up current situation.

- Manager suggests action.

- Potential field manager questions suggested action with example showing that things vary.

- Manager defends suggested action based on need, with an example. 
- Manager does not disagree that things will vary, defends trying to achieve suggested action with specific examples.

Pat's questioning did not result in Prue abandoning her suggestion. Indeed we can see Prue doing what Pat had been doing in using examples to defend her suggestion of what should happen next. The sequence here is:

- Sums up situation-Suggests action-Questions suggested action-Defends suggested action-Defends trying to achieve suggested action (OT11 and OT12 (5)).

In this talk, Prue says it may not be easy to achieve because things vary $(277 ; 281$; 283). However the attempted directive (if it is such a thing) remains that members continually try to achieve, or know, single contact people within member organisations.

\subsubsection{The organisation of the talk involving OT12: Final section}

I suggested that perhaps Prue had attempted to end the talk on this topic at turn 261 with "now um". What we saw instead was Pat keeping it going, using "so". By taking over from Pat, Prue ultimately did finish the discussion on this topic. In this final section of the interaction Prue asks whether they have "gone as far" as they can "for the moment". Prue's explicit closing of this topic is careful, as if she is treading cautiously here, making a tentative suggestion. Despite the appearance of something like a query opening the way for all to contribute, it is questionable whether this is an opportunity for more talk, by more members. Prue's talk in the previous section, and the examples Prue was able to call on would perhaps make it hard for members to respond. The organisation of the talk at the end of this interaction, which has already been reduced down, is something like:

- Manager attempts close with query.

- Potential field manager (and fieldworker) replies.

- Potential field manager makes request.

- Manager produces continuers.

- Potential field manager does request accepted.

- Manager makes suggestion of what to do next.

- Potential field manager predicts how many.

- Manager moves to next topic. 
In this section of talk we see closing, agreeing what to do next about this topic, and Prue moving on. Prue and Pat are the speakers in this section, and possibly May, though she is hard to hear. There is little sense however of the two main speakers producing the talk together by picking up or continuing each other's turns. They each seem to make more out of the turns of the other than seems warranted. The organisation of turns of talk shown above seems to have gaps in it, and so I have left the position labels in for this closing sequence of the interaction:

- Manager attempts close-potential field manager makes request-potential field manager does request accepted-Manager makes suggestion-potential field manager predicts-Manager moves to next topic (OT11 and OT12(final)).

Though Prue clearly stated what meeting members should do next (297), she also indicated that this was not finished. She closed it only "for the moment", showing that she knows the problem was not solved, but that the topic is finished with for now. In the tentative beginning to her turn ("well maybe the first thing") Prue does "something less than an agreement" (Sacks 1987 p. 59). Pat hears Prue's instruction that BANA members who have had external contact tell what they have done in these meetings, but it does not appear emphatic. Can we see Prue and Pat closing the topic for now and so moving on in the meeting, yet without there being agreement? In this section can we say that Prue uses the whiteboard to bring the topic to a close, and Pat works hard to make her request appear accepted? Can we see them each attempting to have the last word on this topic, for now (Atkinson 1995 p. 2)? For instance, does Prue include Pat with her repetition of and emphasis on "everyone" (297)?

\subsection{The interaction involving OT11 and OT12 (turns 147-302)}

To consider the action further it is useful to bring all of the sequences for this interaction together. The aim is to see the acts of meeting members in the talk analysed in this chapter and the last, as Gumperz tells of the presentation by Sacks in 1972:

[Sacks] introduced basic theoretical notions by means of descriptive phrases such as: 'sequential ordering', 'positioning of utterances', 'the interactional job that utterances do', 'what they (i.e. speakers) need to do is exhibit understanding', 'the use of the performance rule'. In all of these expressions, verb constructions like 'ordering', 'positioning', 'understanding', and 'using (or for that matter also violating) rules' are consciously employed to suggest that reference is being made to acts that speakers perform by means of their talk and not to givens of language usage (Gumperz 1982 p. 323 , my emphasis). 
I employ the verb "using" especially, but also "positioning" and "placing".

Looking at the initial headings I used for the sections of talk we can see that across the interaction what to do next is being worked on (perhaps led by Prue), which involves problems and organisational implications (perhaps led by Pat):

- One head cannot hold that amount (turns 147-178) (OT11 and OT12 (1)).

- The future (turns 179-212) (OT11 and OT12 (2)).

- What the existing database cannot do (turns 213-237) (OT11 and OT12 (3)).

- Agreeing the new database is a worthwhile effort (turns 238-261) (OT11 and OT12 (4)).

- What we can do (turns 262-288) (OT11 and OT12 (5)).

- What will happen immediately next (turns 289-302) (OT11 and OT12 (final)).

Gathering the turns of talk from the interaction together, the six sequences show how what to do next was achieved in the meeting. Looking closely at what meeting members are attending to, asking how, shows that in the final section Prue's talk of what will happen immediately next is a request, which may not hold:

- Disputing and providing an alternative-defending-disputing and stating "other ways" are required-defending-repeating "other ways" are required (OT11 and OT12 (1)).

- Query-provides example-provides different example-supports different exampleseeks confirmation-unspecific suggestion-says a better way (OT11 and OT12 (2)).

- Summing up-contributions-summing up-contributions (OT11 and OT12 (3)).

- Asks about the future-confirms-confirm-more details-attempts turn (OT11 and OT12(4)).

- Summing up-suggests action-questions suggested action-defends suggested action-defends trying to achieve suggested action (OT11 and OT12 (5)).

- Manager attempts close-potential field manager makes request-potential field manager does request accepted-Manager makes suggestion-potential field manager predicts-Manager moves to next topic (OT11 and OT12 (final)) 
After considering the sections of talk, we can see that many of the sections involve Prue and Pat defending their suggestions. This is particularly clear in section 5 where Pat repeats that paper is currently the only way to get information, which is in keeping with her saying she needs to get materially back into "that loop". Over many extended turns, Prue works to suggest that they should try to have single contact people within member organisations. In summary, we see Pat and Prue defending different options for where responsibility for knowing about workplace assessors is placed.

With a view to considering the interaction further I have put meeting members' names and the topics they were discussing back in here. It is again useful to reduce the interaction down:

- Prue defends her alternative suggestion of what will help with Pat's problem $(147-178)(1)$.

- Prue and Susan defend the value of the Information Systems being developed $(179-212)(2)$.

- Pat defends her suggestion by showing what the existing database (information system) cannot do (213-237) (3).

- Many members agree the new database is necessary, without disagreeing that there is a problem for Pat (238-261) (4).

- Pat defends her suggestion of seeing paper and Prue defends seeking single contact people in member organisations (262-288) (5).

- Prue attempts to close, Pat makes a request, Prue agrees (289-302) (final). In the remaining two sections the particular interest is in how we can see members of this meeting do defending. How Prue and Pat defend their different positions using examples of their direct experiences is explored. The concern is with experience as useful resource, as Middleton says: "Accounts of past practice in the present become a resource in defining future practice" (1998 p. 248). Looking closely shows that achieving defending involves more than just the two meeting members who speak most in this interaction. 


\subsection{Agreeing and disagreeing}

In this interaction Pat and Prue disagreed, or did disagreement. Prue's suggestion in the final section of what should happen immediately next shows that her stance has perhaps been softened by Pat's actions in the interaction. Prue's "retreat" (176, repeated below) indicates that Pat may have achieved disagreeing in her turn. In the previous chapter I described Pat's work as creating a wedge in the interaction where Pat's defending could be seen as having made space for other possibilities. Perhaps we see this when Prue says "we've got to have other ways" (178). Despite this softening, it is not altogether certain that Pat successfully defended her contention that she be put physically back into "that loop". By saying there will be time in staff meetings to talk about external contact, Prue has only partly or partially accepted Pat's argument for being materially involved. Organisation members were told by Prue to "bring to this table the projects that they're working on externally with different departments" (297). This means that, depending on members' actions, some "information" may be physically delivered to Pat and she will not need to go searching for it in technical systems.

Pat achieved this instruction, at least, from Prue and showed all meeting members what her preference was. Pat may have also indicated that responsibility for knowing is not solely hers, given that others have contact with members, contact she is not always aware of. As Boden says: "through their exchanges, organizational members legitimate the day-to-day work plans" and "realize the 'boundaries' of the organization as practical matters, designating the 'edges' of responsibility, redefining realms of influence, and substantially guiding resource access and allocation" (1994 p. 132). Pat has perhaps attempted to spread responsibility at the same time as she works to avoid it being placed.

\subsubsection{Avoiding agreeing}

This section considers two ways disagreeing was done in this interaction. I consider how interactants could be seen as "minimizing or de-emphasizing the stated difference between oneself and co-interactants" by "forming a disagreement as a partial agreement" and by presenting evidence as a way to tell "how I know" (Pomerantz 1984 p. 620). Meeting members using examples to defend suggestions of what BANA should do next is perhaps one way they used how I know and how it is. 
As such the staff meetings were opportunities to show authority by knowing. One effect of this appearance to know may be that other meeting members give them the floor in the meetings in the form of an opportunity to convince and be convincing. I especially consider what meeting members attempt to do using "so", "real" and "out there".

We can see that in the interaction Pat and Prue defend their different views whilst also agreeing with each other, or without disagreeing directly with each other. Take for instance, this turn:

$=o$ no I'm I'm not saying that that's not an important part of it but I'm what I'm actually saying is that it I mean yeah I I I've got no argument there I agree with you it's useful but basically there's so many it's it's there's so much of it it's not going to be information from that source you're going to be able to hold in your head there's too much of it I've got no 'cos I've tried and I've lost the plot with it there's too many (Prue, 176)

In chapter six, I showed disagreement being "pushed rather deep in to the turn that it occupies" (Sacks 1987 p. 58). Sacks discussed how disagreement is made weak and "held off" in the turn of talk, as people "find a way to do it which does not involve them actually saying 'no"' (1987 p. 69). Prue's turn here is another, more obvious example of this.

Sacks considered the use of "real" by interactants (1987 p. 57). In this interaction the most similar use to Sacks' example is the use of "really" (Prue 150) and "realistic" (Prue 154). In those turns Prue gained agreement from Jo (155), but not from Pat, who produced an extended turn (156). Sacks found that preferred answers, like Jo's, are short whereas dispreferred answers, like Pat's, add an account (Silverman 1998). Pat used the phrase "out there" in that dispreferred answer to Prue, and we can see that her other use of the phrase in this interaction (268-270) is also a dispreferred answer to Prue. Though Prue does not use "real" (263-267), she is again calling for member organisations to know about workplace assessors, and can be seen as attempting to place responsibility for knowing.

Pat puts "really" (Pat 214; Pat 217), "realistic" (Pat 219) and "reality is out there" (Pat 270) to use in avoiding agreeing with Prue. Further, the phrase "out there" can be seen as involved in an attempt by Pat to gain rights to make opposing suggestions to Prue with regard to what BANA should do next. In this interaction we can see Pat taking it as her responsibility to relate the expectations of BANA to "notions of the market, as the 'outside world', as 'business', as 'reality" (Munro 
1998 p. 227). Pat uses the phrase "out there" (268-70) to call up her direct experience (Sacks 1992c). By using Prue's name, Pat nominates her as the next speaker (Silverman 1998). In response to Prue saying "be more proactive in sourcing the main contact", Pat replies that things are not that simple in practice; BANA has "lots of different situations" (268). We can say that Pat is disagreeing, and that the effects of this are multiple. Silverman's analysis of "resisting advice" is useful for highlighting how Pat can be seen to deflect responsibility. She does not let Prue place responsibility with member organisations, which would perhaps place the responsibility for "trying" with fieldworkers (1997).

Sacks' work on agreement and disagreement is particularly applicable in the last two sections ( 5 and final) of talk in this analysis. In section 5 we can see Pat's use of "so" (262) and Prue's use (267) as designed to be answered "yes", as Silverman discusses using Sacks' work:

questioners can create preferred answers - for instance, by asking a question like 'so you're quite happy now?' which embeds an expectation that the answer will probably be 'yes' (1998 p. 123).

Heritage has also explored practices which show the "dispreferred status of an action" (Heritage 1984 cited in Silverman 1997 p. 135). In this interaction, neither Prue nor Pat is successful in gaining "yes". Prue and Pat both avoid answering, or achieve not answering this way.

One non-verbal practice that could be seen to help Prue show a dispreferred answer and avoid answering yes to Pat was the use of the whiteboard (263). Pat eventually overlapped Prue and talked about her direct experience (268-270) (she presents "evidence" (Pomerantz 1984 p. 620)). Is there a connection between Pat's efforts to keep it real and her telling of direct experiences? In the second half of section 5 (273-285) Pat has just 5 one-word turns ("yeah" once, and " $m m$ " four times). Sacks calls these response tokens, which "can signal that someone is saying 'the story is not yet over. I know that"' (in Silverman 1998 p. 119). Heritage, referencing Schegloff (1982), says the use of "mm hm" is a "prototypically noncommittal continuer" (2004 p. 236).

In the final section Prue and Pat also seek "yes" answers from each other (Prue 289; Pat 294), but still they do not receive them. Again we see Prue and Pat using just what they have to hand for their purpose (one of the major concerns of ethnomethodology (Hester and Eglin 1997)) of not saying yes. Here we see something 
like compromise, or what Pomerantz describes as "forming a disagreement as a partial agreement" (1984 p. 620). Looking closely at the talk shows how Prue and Pat do this topic as not being closed, or knowing more will be said on this at some other time (for an example, see Schegloff (1982)). Again Prue used the whiteboard, and with her timing of pressing the whiteboard button she can be seen to take Pat's reply (" $\mathrm{hm} \mathrm{I}$ think yeah", 290) as a definite yes. Prue used the whiteboard (noise and writing) to avoid saying no and to quickly achieve yes (I will pick up the involvement of the whiteboard in the concluding chapter). As a result, Pat's continuation of her turn is interrupted by the forwarding-on noise of the whiteboard (294). With her quick "OK", we can see Pat acting as if her request (in turns 292-294) had been accepted by Prue, though Prue had also used "yeah" (295).

\subsubsection{Rights and responsibilities}

It can be seen in section 4 of this interaction that not disagreeing is an achievement of many more speakers than Pat and Prue, and that it occurs across many turns. In the turns 243-246, Sally and Pat discussed what having information could enable. With Jo and Susan's support, at turn 250 the talk was again concerned with what Pat needed; lack of access to information resulted in Pat not being able to answer members' questions. Pat made a call to get back into "that loop", which was not disputed by the meeting members. With her use of "so" beginning the last section (213) we could perhaps see Sally provide a platform or opportunity to talk about this concern raised by Pat. Again I suggest we can see the subtle and careful ways these members go about actions in the meetings.

In chapter six I suggested that Sally could be seen as attempting to align herself with Pat. By considering Simone's contribution here, we can see Simone and Sally providing speaking space, giving the "speaking right" to Pat (Silverman 1998 p. 115). In section 4 of this interaction Sally can be seen as supporting the development of the new database, and so Susan's work, but again it is in the mode of what fieldworkers need. In this section, many meeting members can be seen as agreeing by continuing Susan's turns of talk. We can see how Sacks' contention, that in conversation people prefer to agree, is useful here for avoiding moving straight and quickly to explaining Sally's actions as driven by roles and power relations (Sacks 1987). I suggest that Sally is using the meeting to gather resources to do her job and working on 
membership and belonging, and that includes being concerned with what fieldworkers need. As Silverman says, explanations require careful description of the local production first, that is, after "elegant analyses which make a lot out of a little" (1999 p. 415).

Simone and Sally provide speaking space by using "so". Looking closely at the talk in section 3, can we also say that Sally and Simone call Prue, Pat and Susan to account? There appears to be a connection between the use of "so" and the word "actually" in the mode of summing up or trying to clarify what is happening (see also Susan, 258). Is "so" not only a way to take a turn, but a way to make others? Are Sally and Simone also seeking responses here? There is a sense in this talk of wanting others to state what the situation is currently (for instance in Simone's use of "so" (227)). Perhaps we can see that Sally and Simone prompt those who have (are given) rights to the speaking space of the meetings, to use it.

The use of "so" by Simone and Sally seems to be similar to the way meeting members in Hugill's research on a construction project meeting moved the talk on "through a question that sought an assessment" (2004 p. 183). He showed how a meeting member used "and so" to identify a consequence and produce a link (Hugill 2004 p. 172). Hugill discusses how negotiating in the episode was accomplished, not through the obvious display of power but partly as an "opportunity for parties to elaborate upon their position" (2004 p. 187). However, somewhat differently, I have tried to emphasise how actions are achieved by many meeting members and not necessarily according to obvious "seniority". Hugill implies that some members are passive when he says that "senior members have certain significant party responsibilities and the less senior members await a clear indication from them as to the nature of the 'position' the party is taking" (2004 p. 177). In my research members other than those with seniority were involved in keeping each other to their responsibilities. Less senior members also called for indications.

Hugill's focus was on commercial negotiation and that meeting involved people from different organisations, whereas the meeting members in my research were part of a single organisation. This comparison perhaps illustrates Munro's point, drawing on Garfinkel's early research on jury work, that "people do not wait to be instructed over what to do - except under some peculiar and very particular conditions" (1999b p. 436). Middleton says that in teamwork exchanging information is not simple, but 
rather "information is evoked interactionally in conversation that handles delicate problems of taking responsibility without usurping the authority or democratic rights of other members of the team" (1998 p. 245).

\subsection{Conclusion}

This chapter firstly considered the second half of an interaction from meeting six where the phrase "out there" was used twice. CA was used to see the action in the meeting and ask how the phrase was involved in attempts to defend suggestions of what should happen next. I presented the meeting talk and made some initial observations about the actions the meeting members could be seen attempting. Next I made further analytic comment about this interaction by looking at the organisation of the talk and drawing especially on Harvey Sacks' work. One concern was whether these meetings were places for members to show they could identify, and would act on, organisational implications. In the second part of the chapter I considered the talk analysed in the previous chapter and this one together. I asked whether what could be seen across the interaction was meeting members working on what to do next from problems raised. In this section I considered the overall structural organisation of the interaction and how meeting members did agreeing and disagreeing.

In the next chapter I will compare the action analysed in this chapter and chapter seven with that seen in chapter six. One question is how Pat successfully defended her suggestion of what should happen next (information about workplace assessors being delivered to her), in comparison with how Sally did not (reviewing the manual as a priority). I will compare how defences of what should happen next are attempted and inquire into hierarchy in these meetings with regard to:

a voice that inscribes personal knowledge as the property of the teller... It conveys the personal advice of the clinician, and is frequently addressed directly to his or her junior colleagues, in that it formulates what 'you' ought to do (Atkinson 1995 p. 140).

Are there different ways meeting members use "so" according to organisational rank? Do Simone and Sally use it to ask questions (to continue or open the discussion, provide platforms and demand to know), while Prue and Pat (and perhaps Susan) use it to end or close topics and say what should happen? Is this a way some meeting (and so organisation) members make more "highly" ranked members accountable for telling them how the organisation is going, and so provide resources for deciding what 
to do next? Some of the uses of "so" do seem to be involved in providing platforms and opportunities for some members to be convincing about what the organisation should do next. 


\section{Part three:}

Concluding by reflecting 


\section{Chapter nine}

\section{Reflecting on these workplace meetings}

\section{TABLE OF CONTENTS}

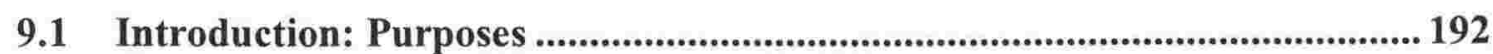

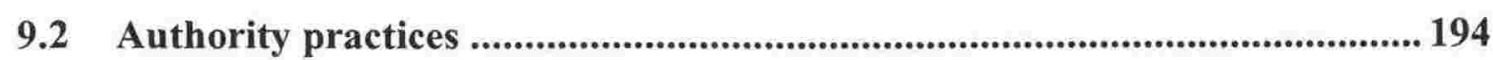

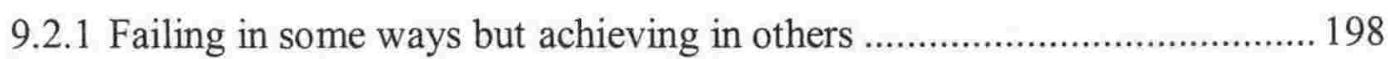

9.3 Multiple purposes and actions.............................................................................. 200

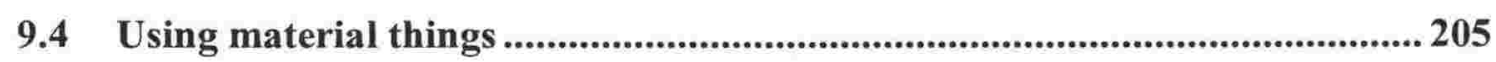

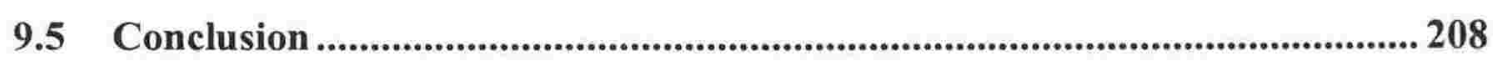




\subsection{Introduction: Purposes}

As I said in the preface and the previous chapter, doing words, and especially the verb "using" are privileged in this research. I have focused the research around the phrase "out there", showing how it is useful for the practical purposes of meeting members and myself in this research project. Explicit attention is paid to the way the world is verb-like by both actor-network theory (hereafter "ANT") and conversation analysis (hereafter "CA"). In 1972 Sacks presented "verb constructions like 'ordering', 'positioning', 'understanding', and 'using (or for that matter also violating) rules"' to show the actions of speakers (Gumperz 1982 p. 323). In the late 1980s, speaking for ethnographers and conversation analysts, Moerman argued that " "the world out there' is a verb, not a noun; a social activity, not a pre-formed thing" (1988 p. 102). ANT's main protagonists, Latour, Law and Mol, have all used "verb" to explain their concern with worlds being made. Law said his ethnography was "a sociology of contingent ordering, a sociology of verbs rather than nouns" (1994 p. 103). More recently, Mol used the verb "enact" to argue that "in practice, objects are enacted" (2002 p. 41). Latour argued that the associational, rather than social, concern of ANT has a forefather in Gabriel Tarde, who "in one of the most important sentences of his work" regrets the focus on the "verb to be" rather than the "verb to have" (2002 p. 129).

This chapter considers how the meetings achieve forming. In chapters six, seven and eight we have seen the making of the meetings themselves in the practices of members. In particular I tried to show how the phrase "out there" was used in the meetings and the effects this had (Latour 1999b). I asked how "out there" participated in making realities (Mol 2002). I tried to make this series of staff meetings visible in this kind of way, and argued against a priori divisions between these staff meetings and this organisation BANA. The concerns in the thesis have especially been with useful things, practical purposes and seeing. In this chapter I reflect on meeting members' practices. The structure is again that of starting with what could be seen in the previous three chapters. In the next chapter I reflect on doing this workplace research, opening with a discussion of practical purposes. I also connect further with academic writing and gather academic uses of the phrase "out there" for my purpose of showing the focus in this research on doing things together. 
My broad answer to the research question of how these people get their work done is that meeting members carefully used and placed rights and responsibilities as they undertook the divisions of labour for their organisation. Members working together on the organisational problem of who might do which tasks, tacitly recognising and using "prestige and power hierarchies", and making their work in this place visible as meetings, is in keeping with Atkinson, Cuff and Lee's research (1978 p. 140). As I suggested in the introduction, practices of showing are perhaps increasingly important in workplace conduct (Latimer 2000).

Taking practices of showing and visibility further, I suggest that placing (individual) responsibilities was undertaken carefully perhaps out of a concern to achieve appearances of collectiveness. My research is consistent with Latimer's discussion of the operation of persuasion and permission, in her analysis that power relations are (re)accomplished at the same time as everyone is provided with space to speak (2004). I argued in chapter six (OT29) that Prue attempted to place Sally back in the realm of details, and in chapter seven (OT11) I suggested that Prue attempted to push responsibility for knowing back outside BANA. To see aspects of these meeting as processes of placing is a way to consider power, and I suggest that it is analytically productive to consider the actions of meeting members as attempts at placing (and “moving” (Latimer 2004 p. 760)).

Taking an approach like CA, that concentrates on the details, and asks "how", makes it possible to ask questions about the making of organisation. Part of this is who will do what; dividing the available labour. Throughout this research project my view has remained that work is "associational... a coordinated, organised, collective and meaningful human activity... characterised by divisions of labour - the delineation and distribution of roles - which shape the concrete management of tasks" (Lloyd 2002a p. 13). Saying that forms of hierarchy are involved in workplace interactions is to make an obvious point about something that everybody knows. However, this analysis, based on a close examination of the meetings, provides an example of precisely how "asymmetrical relations" (Munro 1998) are involved in dividing labour. Sacks" "obvious observability" was useful for asking how holding together was achieved (1987 p. 56).

The CA concern with turn-taking was used in the previous three chapters to see what meeting members were attempting and accomplishing with regard to 
organisation-making (Sacks et al. 1978). In particular I was concerned with how the phrase "out there" was used in attempts at actions and what it helped accomplish. Where Silverman concluded that "Interview and Information Delivery" were "the stable and persistent formats in counselling sessions" I asked about the formats used to make BANA (1997 p. 45).

I expected to find turn-taking organisations in the meeting talk because the time available was "rationed" (Heritage 2004 p. 226). Below are examples which show this concern with how time was spent in two meetings. Prue had said during a discussion about whether I would be allowed to attend the meetings as researcher that two hours were allocated for each meeting, yet while opening and closing these meetings she included statements about time:

now I'm just expecting quite a short meeting today just to do a catch-up on everything 'cos um don't know about you guys but I haven't got very much at all I'm just getting myself (laughter and laughs) back into work and one thing and another I just want to do a quick catch-up on um... (Prue, M4)

it's probably going to be a fairly short staff meeting I think... today because um we're um May's not here yet um and Pat's away on holiday (Prue, M13)

Talking about the meetings to come, Prue not only started meetings four and thirteen but provided indications of how much time they might take. What these statements achieve however depends on the actions of others. With her closing of meeting thirteen we can see that perhaps meeting members took it as an indication or instruction of how much time they should spend:

great, well world record (laughter) thanks everyone and ah yeah I I think it's probably better for for us to do this when people are away rather than try to postpone unless it gets to the point where there's only 2 people left (laughter) (Prue, M4).

In this statement we can not see whether meeting members paid heed to making "quite a short meeting" and having "a quick catch-up", but we can perhaps see Prue taking it as if they have. Prue's attempt, contained within her opening of meeting four, indicated the authority of her position as organisation manager and meeting facilitator, but others ultimately decide on her success.

\subsection{Authority practices}

I suggest that in the previous three chapters we have seen turn-taking organisations that "order speakership" by some kind of "rank, or other criteria of seniority" (Heritage 2004 p. 226). There was an example of authority in action in chapter eight where Pat created an opportunity for herself to speak and made space for 
other possibilities, indicated by Prue saying "we've got to have other ways" (turn of talk 178). Despite this softening, it was not clear that Pat successfully achieved her contention that she be put physically back into "that loop". However, Prue was observably more careful in her response to Pat's suggestion of what should happen next (that information about workplace assessors be delivered to her), than she was in her response to Sally, who suggested that reviewing the manual was a priority (chapter six). The question arising then was how Pat and Sally had made their suggestions of what should happen next and what they had used to defend them. The phrase "out there" was involved in what can perhaps be considered "the manufacture of truth claims" (Munro 1997 p. S59), but only some uses of the phrase were part of "statements that carry authority" (Law 2004b p. 27). One focus of the thesis became practices of how I know, and how it is.

One way authority was worked into being in the meetings involved seeing directly, or witnessing (Pomerantz 1984). In chapter seven I noted the changing uses of " $w e$ " and " $P$ " by Pat and Prue. These uses of " $T$ " seemed to indicate members doing I know about this. Witnessing, from having been there, from seeing, was one way authority was attempted in the meetings. Some researchers who undertake fieldwork also attempt to claim authority through "intimate knowledge" (Becker 1986b p. 35), and users of CA claim to have witnessed when they talk about what they can see in turns of talk. My interest was with how authority was worked into being in the meetings, as knowing, from the resource "direct experiences". Meeting members seemed to pay heed to and value first-hand experience in reports from having been "out there". I suggested that Sally's use of the phrase failed because she did not have rights to use the resource "out there" in the way Pat did. In his research on medical work, Paul Atkinson argued that the expression of attitudes towards knowledge and its sources as having differing value "[inscribed] aspects of the moral and technical division of labour" (1995 p. 127). I too asked about the divvying-up of work in these meetings through the creation of authority. I considered how seniority was related to "rights to tell such stories" (Atkinson 1995 p. 147).

Many stories of external contact from outside BANA were mostly what Pat had to bring to these gatherings of the organisation. Pat had "out there" stories with which she could do things, including showing herself as knowledgeable (Munro 1999b). It was with these stories that Pat showed meeting members that she was in a position to 
be able to judge. With regard to the visibility of authority in the meetings, Pat's statement that paper was the only way (chapter eight) also appeared to be designed for all organisation members. Perhaps it was the variety of resources Prue had at her disposal for her purposes that contributed to her authority (Simpson 2003). Prue was also able to call on stories from having been "out there", and she had other resources, like control of the whiteboard. In being able to draw on many resources when it suited her purpose, Prue had "ambiguity on her side" (Munro 1998 p. 236).

Prue's response to Sally's suggestion of what to do next was that she thought the manual was fine as it was, and that meeting members should not "get our knickers in a twist". Comparing that to Prue's response to Pat: "because let's be realistic how can you possibly retain an overview of what 350 different people are doing in 30 different agencies" shows how, in a more persuasive mode, Prue supports her alternative proposal (Latimer 2004). Prue and Pat were able to do "extension" (beyond the room) (Munro 1999b) when they replied to each other's objections with things like numbers and examples from "out there" (chapter seven). When they used these experiences, they not only "examine each other's 'competence" but they show their competence to all members of the meetings (Munro 2001b p. 475). Though Prue did respond to Pat, and so did not let her have "the last word" (Atkinson 1995 p. 2), she seemed to take more care in her response to Pat than she did with Sally (chapter six). In this we can see that perhaps Pat had one resource that Prue did not in that Pat was able to disagree more openly than Prue in the meetings.

"Misunderstanding" as a way to avoid disagreement was involved in each of the interactions I closely examined, which indicated that practices of misunderstanding perhaps make visible authority, or seniority. One way to argue that OT29 was a failure to achieve what should happen next is that Prue did not hide her disagreement with Sally. Perhaps she was not required to because Sally had made an unsupported claim. Though the beginning of Prue's response looked like agreement (Sacks 1987), it ended in a sanction and Prue was ultimately not careful enough in rejecting Sally's proposal. After Sally had suggested what should happen next, Prue told the meeting not to "get our knickers too much in a twist" and Sally retreated: "yep that's cool just time to do that's all'. In replying to Pat, Prue was cautious (turn 176):

$=$ oh no I'm I'm not saying that that's not an important part of it but I'm what I'm actually saying is that it I mean yeah I I I've got no argument there I agree with you it's useful but basically there's so many it's it's there's so much of it it's not going to be 
information from that source you're going to be able to hold in your head there's too much of it I've got no 'cos I've tried and I've lost the plot with it there's too many

Here what Sacks calls the "misunderstanding machinery" was used by Prue to avoid disagreement (1987 p. 66). In not using misunderstanding, Prue can be seen as being less careful in her disagreeing response to Sally. Rather it was Sally who used misunderstanding, perhaps called to do so by Prue. Both of Prue's responses involved disagreeing, but the degree to which disagreement was "held off" in the turn of talk, as people "find a way to do it which does not involve them actually saying "no"" varied (Sacks 1987 p. 69). Misunderstanding was used to back down to varying degrees. Doing misunderstanding enabled members to do disagreement yet stay together in the room. However, Prue was more and less careful when disagreeing. Practices of misunderstanding and disagreement were intertwined in the meetings.

Apart from providing evidence, another way to consider authority in the meetings is to ask about strong statements. A good example involves the phrase "knickers too much in a twist". Another example was seen in chapter two when Prue told meeting members to only include "significant communication" because otherwise they would be "filling the damn thing in all day" (meeting 5). Prue used something like an "extreme case formulation" (Pomerantz 1986). These kinds of replies are perhaps made possible by vulnerable attempts to suggest what should happen next like Sally's use of OT29. Lack of support for a claim provides the opportunity, and perhaps the expectation of rejection. Prue is perhaps the only member who had the authority to use unsupported statements in the meetings but she too also backed up her claims with examples at times (chapter eight).

In chapter eight we saw meeting members using "so", perhaps according to organisational authority practices. Simone and Sally employed it to continue or open the discussion, provide platforms and demand to know, while Prue and Pat (and perhaps Susan) employed it to end or close topics and say what should happen. Comparing Sally's effort with Simone's (OT12 in chapter eight), shows how Simone and Sally worked to provide speaking space to Pat. Providing speaking space was done for particular reasons rather than through authority in some kind of "justbecause-I-can" way. I suggest that members provided each other with opportunities (Heritage 2004; Hugill 2004)). I could see members provide what looked like "platforms" from which to speak, but these can be seen as opportunities and demands 
for others to convince that their proposal for what to do next was a good one. This was done by Pat who had made a counter proposal in the form of a debate (turn of talk 179, chapter seven) and also by Simone and Sally (perhaps on Pat's behalf) with their use of "so" (chapter eight). "So" could be seen dong the work of providing speaking opportunities. Providing opportunities to be convincing seemed to be a way members worked together on what to do next. Acting next is how we make our worlds.

\subsubsection{Failing in some ways but achieving in others}

In chapter six I suggested that Sally failed to gain support for a proposed future action because it was unsupported, despite her use of "we know" and "we need". In these meetings, there were observed conventions, like the permission and apology Prue performed when she speaks out of turn during Simone's roundtable in meeting 5 (see that section in chapter two, page 44). Chapter six showed Sally speaking out of turn (see Atkinson 1982) in this organisational setting in that she did not have the information and knowledge to back up her claim (Munro 1997). Sally's use of the phrase "out there" can be seen as a failed attempt to make a strong statement and defend a proposal. This failure indicates that members need to have particular resources, including forms of competence with which to make their calls to organisational priority and what the organisation should do next. First-hand experience was another resource, but in this case it includes knowing who had rights to use first-hand experience. Prue and Pat could tell people what to do with the support of first-hand field experiences. Not being witness meant that Sally was not the one who "owns rights to tell this story" (Sacks 1992c p. 243) of "out there". She did not have the "discursive rights and resources" (Atkinson 1995 p. 147). Furthermore, she did not show that she knew she did not have these rights.

However, Sally did achieve showing that she was working on her membership. As Munro puts it:

Garfinkel's definition retains a notion of 'show'... His stress is on persons making themselves 'visible' as members: accounts given as a display of membership are identical to the everyday practices of members.... Be they dancers in the dark, or employees in an organization, accounts require a knowledgeability, or communicative competence among members: a competence that includes knowing when to remain offhand, detached, silent (Munro 2001b p. 474).

In chapter six I suggested that Sally could be seen aligning herself with Pat. In the interaction in chapter eight Sally supported the development of the new database, and thereby also Susan's work, and again the concern seemed to be with what 
fieldworkers needed. I suggested that Sacks' (1987) contention that people have a preference for agreement was useful for avoiding moving too quickly to explanations of actions in terms of roles and power relations. Sally could be seen to use the meetings to gather resources to do her job, for her purposes, and that included showing a concern for what fieldworkers need. Sally shows her good membership through attempting to provide accounts which "fit into a circulation of accounts that is already going on" (Munro 1999b p. 436).

It is useful for understanding how these members get their work done to consider the actions of meeting members as self-governing in accordance with the enterprise discourse (Law 1994). For instance, Sally can be seen to align herself not only with people (Pat as "management material") but also through "processes of affiliation" with "the future" (Munro 1998 p. 219). These workers are oriented towards gathering in these meetings what they need for working out for themselves what is expected between this meeting and the next in keeping with "enterprising "organizational selves"” (Courpasson and Reed 2004 p. 7). For one thing, the meetings were opportunities to show their "affiliation" with people and things (Munro $1998 \mathrm{p}$. 233; Wilkinson and Kitzinger 2000 p. 803). How OT29 is not like OT11 and OT12 shows something of authority in the meetings. Prue had summing up, or final judgement, rights, and often had "the last word" (Atkinson 1995 p. 2). Pat was at least able to attempt to have the last word (see OT12 in chapter eight).

Prue's "moves" (Latimer 2004) can be seen as related to the rationing (Heritage 2004) of time in the meetings in that care with meeting time is a resource. She kept the meetings on track using the sanction no time for moaning, we're all busy. As Law says, "managers do not whinge", complaining is unproductive (1994 p. 63). It is part of Prue's work of keeping the organisation moving along, and meeting members could be seen being careful to help (see Sally's retreat above and in chapter six), or at least not hinder others getting their job done. Prue's acts that show her taking care with meeting time also encompass calls to be careful with meeting time, and have the effect of limiting the speaking space of the meetings (Latimer 2004). Though Prue initially produced continuers for Sally's account of still in progress like "tut", in the end she closed down Sally's call to organisational priority. 


\subsection{Multiple purposes and actions}

I have tried to stress throughout the thesis the multiple things going on in the interactions I have considered. Though I have selected only some aspects to concentrate on, I accept that meeting members simultaneously achieved "action, context management, and intersubjectivity" (Heritage 2004 p. 224). I have tried to use "and" rather than "or" in the thesis. For instance, I could have looked at the differences in degree of care in Prue's responses according to the importance of the task being discussed. Prue's response to Sally perhaps also showed this to be a small matter concerning what to do immediately next about one project (the manual), and the work of one or two people, and so was a discussion that could be ended then and there. Prue's careful response to Pat showed that this involved the much bigger concern of how to order the organisation. These matters would continue to be discussed elsewhere, and perhaps always, because it involved placing names against tasks, on a list, assigning responsibility and dividing the available labour.

In Susan's use of "secondary" we saw, like Sally's use of "no one person" (chapter seven), work on simplifying and control. In the meeting talk, members

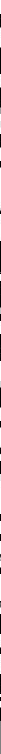


responsibility for knowing about "out there" with fieldworkers. When she retracted her statement, she positioned herself as no longer the one with information. In showing that others knew more, Prue positioned them as responsible for spotting and acting on the organisational implications of what was said in these meetings. The care Prue took when she disagreed with Pat can also be seen as taking care not to dislodge Pat's position of knowing the field in front of the members of BANA. With OT9 Prue created an opportunity which meeting members could use, a platform onto which they could climb. Stepping up, Pat showed she did know the field better, which may have had the effect of placing responsibility with her. Responsibility for knowing the field being placed with others may help Prue move away from fieldwork. I suggest we can see here how "non-identity is also an accomplishment" (Munro 1996b p. 264). Pat's gain through being positioned as knowing the field better is not subtracted from Prue however. Because there is "no 'core' self' Prue suffers no "loss of self' (Munro 1996 b p. 264) when others are magnified through being shown to know the field better.

We can perhaps see Pat take up Prue's opportunity and call to responsibility when Pat makes the move to the next meeting topic. This is done in a particular way, which involves "show" and "display" of responsibility (and seniority) (Munro 1999a p. 620). When Pat said "so Kim does that follow on to our thing on the board" Pat achieved Kim speaking next and Prue forwarding the whiteboard on. Though Prue maintained direct contact, Pat gained some control of the whiteboard. As I discussed in chapter two, and we saw in Susan's comment in chapter seven, the moving whiteboard appeared to be an especially valued object in the meetings. The interaction involving OT9 and OT10 shows how "artefacts are more than instrumental, they are also expressive. Persons do not act alone; they draw on available materials to 'show' where they stand" (Munro 1999a p. 624). Prue and Pat created "multiple readings of self' when they positioned themselves and each other in different relations to the whiteboard (Munro 1999a p. 624). From "one moment" to the next members can be seen to "accomplish extension through artefacts" (Munro 1996b p. 264). When Prue forwarded the whiteboard on she showed Pat as knowing more, which had responsibility effects. In the meetings the whiteboards were used to indicate the positions members were taking up. Pat showed she was responsible rather than saying it directly. The moves were much more subtle than that and they also involved 
material things. I argued in chapter six that Prue used the forwarding-on noise of the moveable whiteboard to achieve control at the same time as "merely" keeping the meeting on track by working through the agenda.

In chapter seven I discussed how Pat did not make a verbal demand for control of information. I suggested we could see Pat attempt to maintain control over contact with the field "in the name of" (Munro 2001a p. 199) sharing "information". I argued that Pat could be seen to attempt to attain a position in which papers regarding workplace assessors would be physically delivered to her. Having materials delivered to her as if she was the one with "the expertise" (Munro 1995 p. 140) would in turn position her as the one who did indeed have it. It is therefore useful to consider meeting members' work on how to organise information with regard to the "artefact of access" (Munro 1999a p. 628). In the talk involving OT11 and OT12 Pat seemed to suggest that in order for her to achieve responsibility, and to accept responsibility, she needed access to information. This was a particular kind of access where Pat would be provided with information. This is reminiscent of ordering access to information as a "cascade" (Munro 1998 p. 228) in that Pat would see every workplace assessor registration as they came through the office. However, it is more than information, in that through this delivery Pat would know who had had contact external to BANA. In contrast Prue's proposal perhaps involved providing access to information as an opportunity open to all members of BANA.

Pat's concern to know what was going on with BANA clients (or members) is of interest with regard to her identity and responsibility as a fieldworker. How does Pat come to need to "get back into that loop"? As manager, we see Prue acting to keep the organisation going more generally. Her use of "wasn't that valuable" (194), with regard to a report that Susan had produced, appears to be an attempt to have all meeting members show agreement (especially Pat perhaps) on the value of holding information in "the database" rather than in heads. Looking at the meeting talk as ways of making the organisation shows that it is not contradictory for Prue to have argued that no one person can hold that amount of information in their head, and later in that meeting to argue for having a single person. These examples show how sometimes having "one person" is useful but sometimes it is not - it depends on the purpose at hand. While singularity was considered useful when BANA needed to know who in client organisations was responsible for paying the bills, Prue did not see 
it as valuable for holding information within BANA. Here Prue is being entirely consistent in making BANA rather than using singularity inconsistently.

Whether it was the case or not, Prue appeared to add ready availability to the "scale", as Latour discusses with regard to science (1996 p. 200), in favour of systemheld information. In this way she attempted to use for her case the impossibility of holding that much in one head. The visibility of ready availability as a resource is clearer if we consider Pat and Prue as representing different groups in the organisation where members "representing their party, have a right to correct" (Hugill 2004 p. 171 and Atkinson et al. 1978). In this way Pat takes responsibility for representing the fieldworkers (her "we") and claiming the right to, so she argues for knowing all about external contact, whereas Prue shows responsibility for the whole organisation (her "we") and argues for providing access to information for all BANA members.

The value of seeing first-hand (Sacks 1992c) was not restricted to witnessing events and things outside BANA's offices. Direct observation seemed to be more generally useful. Witnessing documents seemed to be prized, and may for instance be one reason Pat argued for seeing the forms as they passed through the office. Seeing was valued not only from having been "out there" of the field, but also in other places. Under Pat's proposal of seeing all workplace assessor registrations she would be the person through which external contact with BANA members (the field or BANA's market) passes. In this way she can perhaps be seen as working on being what Latour calls an "obligatory passage" for contact with the field (cited in Munro 1998 p. 223). In contrast, under Prue's proposal of workplace assessor registrations being held in a technical system, Pat would go and find out what had been happening with regard to them. In this way Pat would be in the same position as any of the members of BANA. This may be problematic for Pat because the effect of such an act would be to place the technical system in the position of (to show it as) knowing about the field. This has been the particular position of field workers as Pat said, "there's information we've got 'cos we're out there working with the organisation". Hierarchy is involved in members' work on placing responsibility for acting next, for instance, when I suggested that Pat worked to avoid having information ordered so that she would be positioned to go and seek it out, rather than have it delivered to her.

Pat seemed to make a case for accepting responsibility for knowing about the field by relating it to the provision of all of the information regarding contact with it - 
she claims to need to be "central to information flows" (Munro 1995 p. 140). This is one response to the observation that there seemed to be some kind of relation between meeting members' concern with making things singular, and responsibility (chapter seven). This is not in the manner of attempts to control for nothing other than control's sake. This is not power struggles as a self-explanatory part of workplaces. The point I am making is that Pat's attempts to gain or retain "control" over contact with the field is of interest with regard to how she gets her work done. This involves what she shows to be her purposes and this includes her positioning work in regard to information. My argument is that Pat does not seek control or power for its own sake, as some kind of hollow thing, but rather she works on control for particular purposes, which are related to her responsibility for getting her work done.

Yet there are control effects of having all workplace assessor registrations going through Pat. Access to information in the way Pat seems to argue for would put her in the position of knowing all about the contact organisation members have had with the field. Munro's ideas are useful for considering how Pat comes to work on getting "back into that loop":

First, instructions are no longer something to be passed top-down. Rather managers are positioned to go and find their instructions. In that it has now become their responsibility to work out strategy, this is where they enter initially into a process of strategy-making that will end, continuously, in their own extrusion from the process of strategy-owning (Munro 1997 p. S52).

Perhaps Pat resists losing control of BANA's contact with the field. Before BANA grew larger, the "out there" of the field was her "domain" (Latimer 2004 p. 771).

As I suggested in chapter four, perhaps action and power are somewhat interchangeable in mutual action. Seeing aspects of these meeting interactions as attempts at placing, accepting and holding off, is a way to ask about making organisation, and how relations of power are involved. Furthermore, I suggest that it is useful to consider power and action as interchangeable terms where "power is not generated 'from above' by a mobilizing leadership, but solely through association" (drawing on Arendt, Allen 2003 p. 53). This is Latour's call for a "shift from principle to practice" in order to see "the practical resources necessary to perform society" (Latour 1986 p. 273).

Any action can have power effects, but these effects depend on the responses of others. For instance I could describe Prue and Susan's responses to Pat (turns 179-212 
in chapter seven) as reassurances in line with the view expressed by one of the managers in Munro's study that "all they were after in seeking information was "comfort" because "as a manager at Bestsafe, you are expected to know what you are doing" (1999a p. 628). Prue and Susan can be seen as responding to Pat as if she was seeking reassurance rather than control. I suggest that also involved here are Prue and Susan taking the opportunity created by Pat to be convincing that working on the database is still what the growing BANA (chapter four) should do next with regard to information. This may involve convincing Pat that she does not need to see papers as they pass through the office; that it will be alright if she no longer controls contact with the field "out there" and ceases to know in this way. At the same time Prue and Susan can be seen as reassuring Pat and other meeting members in showing they know what they are doing.

To see aspects of these meeting interactions as attempts at placing and positioning is a way to consider how power and control are used and agreed to. Taking it that the actions of meeting members have effects is a way to open up the terms "power" and "control" in order to see how in practice they are made in, and out of, associations. I have tried to show how this is a mutual making in that it takes more than one person - I have tried to avoid showing only "one side of performance" (Munro 1999a p. 622). The important point here is that when members act as if things are real, they are real in their effects as Munro says: "as long as each manager believes it to be true, or at least is unsure about how much more or less the senior knows, the power effect of bolstering hierarchy will be the same" (1998 p. 229). So it will be the members of BANA who show in their next actions whether Pat is seeking control unjustly and unjustifiably. They will do this for just the purposes of their associational activity.

\subsection{Using material things}

From undertaking the CA analyses I could clearly hear the involvement of more than words in these interactions. In this section I continue to explore how the meetings and the organisation are made in association with material things:

'Power' is now transferred to the many resources used to strengthen the bonds. The power of the manager may now be obtained by a long series of telephone calls, recordkeeping, walls, clothes and machines. The list is open ended... the so-called social elements are simply items among many others in a much longer list (Latour $1986 \mathrm{p}$. 276). 
In chapter seven and above I explored how meeting members' proposals for what to do next, what to do about the problem of access to information, involved material things. For instance, I suggested that the involvement of things could be seen in Pat working to avoid information being contained in technical systems. I talked in chapter seven about Pat working on the value of personal contact, and Prue (and Susan) having "faith" in technology and machines for holding information. Prue's statement ("because let's be realistic how can you possibly retain an overview of what 350 different people are doing in 30 different agencies") can be seen as an attempt to make the technical holding of information appear more rational than people holding it in their heads (Munro 2001b p. 477). As we saw, Pat retained information sharing as a face-to-face practice by achieving agreement, for now, that people report on their contact with members in these meetings.

In order for her to be responsible, achieve and accept responsibility, Pat argued that she be provided with information that people in the office have. One ordering means information is made available (it waits for Pat to seek it out) and the other that information is delivered (Pat is in "that loop"). As I said, Munro's concept of extrusion is applicable (1997 p. S52). With regard to access to information, Pat questioned it being held by websites and databases rather than being delivered to her. Perhaps Pat was aware of the "'hailing' effects of artefacts" which would result in her being compelled to seek out information if it were made available (Munro 2001b p. 476). We can perhaps see Pat working to avoid a situation, an ordering, where she would be subject to the "hailing effects" which "do not come from other people, but arrive through processes like budgeting" (Munro 2001b p. 476; see "granting" in Lloyd 2002 b p. 115 with regard to academic publishing). If information were available in technical systems, Pat could be seen as responsible for acting next instead of those who see the forms coming through the office. Pat resists suggestions of ordering information, and the organisation, this way. Pat was aware perhaps of the responsibility effects of this ordering.

The whiteboard was a resource that Prue had to hand and is another example of the involvement of material things in ordering the organisation, and avoiding explicit use of authority. The whiteboard was another way to non-verbally achieve stopping in the meetings. In chapter six we saw the whiteboard hold the meeting silent. At turn 263, while Prue interacted with the whiteboard, other meeting members waited. As 
Munro outlines with regard to the consumption thesis, "the value of goods lies in their use by 'members' to make judgements on each other visible to each other" (1996b p. 256). Munro discusses how the "readiness-to-hand" of consumer goods makes them "supple to identity work" (1998 p. 218). More recently, Latimer discussed how chairs can magnify the boss (2004). This is perhaps one way the printing whiteboard comes to be preferred by meeting members above the static one screwed to the wall. With its forwarding-on noise, the whiteboard "appropriates" (Munro 1996b p. 248) the hearing space of the meeting. Control, without the need to confront with voice or hand, is made possible. Prue is "merely" keeping the meeting on track by working through the agenda. The whiteboard "augments" Prue as collaborative meeting facilitator and manager, and she augments it as a useful artefact (Munro 1996b p. 266). Prue always occupied the seat directly in front of this whiteboard and so it was possible for her to use the whiteboard to show cooperation and achieve control simultaneously.

In showing how the whiteboard was used to do "no" without trampling on other meeting members, and so disturbing appearances of collaboration, I am not suggesting that Prue was manipulatively hiding her position of power but that she used what she had to hand to get her job done, which included keeping the meetings and the organisation going along together. With regard to making this organisation, which seemed to involve being concerned to appear to, and to, act collectively (chapter four), members were careful when they stopped, refused, and when they placed responsibility for acting next with other members. One way they did this was by doing "no" non-verbally. Meeting members used material things to disagree without saying "no". When Prue moved to the next topic in the meeting, she did facilitation carefully with the aid of the moveable whiteboard. The whiteboard noise called meeting members to attention. Perhaps one reason the moveable whiteboard was preferred by meeting members to the static one screwed to the wall was that the moveable whiteboard provided authority and control. Mute objects have power, but ones that speak have even more, that is in Latour's sense, that they can "make you do things", like making you silent (2004 p. 243).

The involvement of the whiteboard in the meetings was also evident in the final section of talk involving OT11 and OT12. Prue and Pat could be seen seeking "yes" answers from each other, but not receiving them. Here we saw Prue and Pat using just what they had to hand for their purpose of not saying yes. For one, Prue used the 
whiteboard, and with her timing of pressing the whiteboard button she took Pat's reply (" $h m$ I think yeah") as a definite yes. Prue used the whiteboard (noise and writing) to avoid saying no (Sacks 1987) and to quickly achieve yes. As a result, Pat's continuation of her turn was interrupted by the forwarding-on noise of the whiteboard. This can be expressed as Prue using the whiteboard to stop the meeting and show a "dispreferred turn" without saying stop. The whiteboard holds - it makes people do things, like being silent.

\subsection{Conclusion}

In chapter two I said some of my lasting impressions from having been at a few BANA staff meetings were next and next and next; just; and how much detail. After considering the analyses in chapters six, seven and eight I need to add taking care, making opportunities, and persuasion. These are some more of the things that seemed to be used and useful to meeting members in their associational activity. In the concluding chapter I reflect on doing this workplace research, connecting further with academic writing, and gather academic uses of the phrase "out there" for my purpose of showing the focus in this research on doing things together. 


\section{Chapter ten}

\section{Conclusions}

\section{TABLE OF CONTENTS}

10.1 Reflecting on researching these workplace meetings................................210

10.1.1 Practical purposes: Academic uses of the phrase ............................. 212

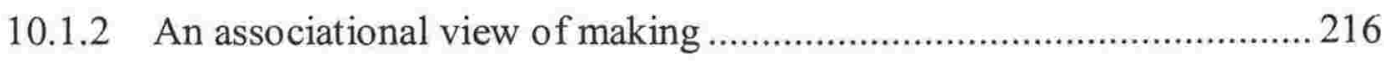

10.2 Conclusions from watching meeting members' practices ............................219

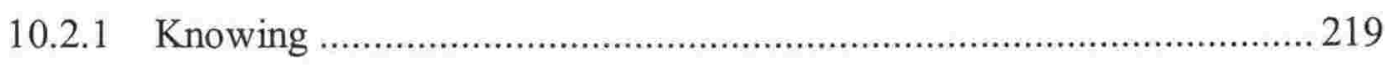

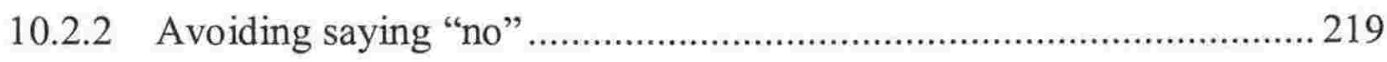

10.2.3 Avoiding confrontation and taking care ...................................... 220

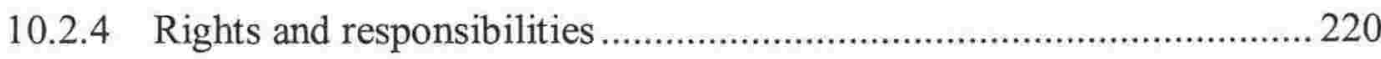

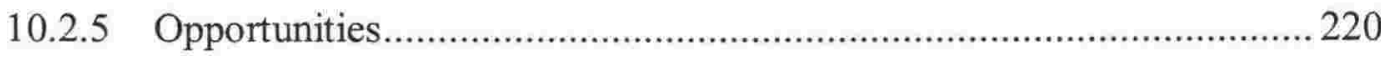

10.3 Conclusions from my researcher practices .................................................. 221

10.3.1 Knowing from witnessing the details ........................................... 221

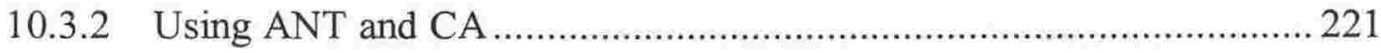

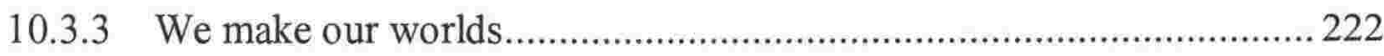

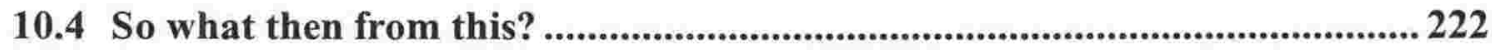

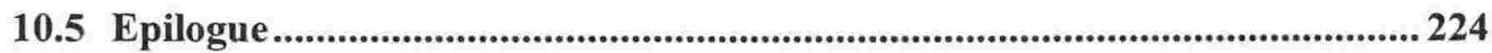




\subsection{Reflecting on researching these workplace meetings}

This thesis belongs to the first move advocated by Silverman when he says that before we attempt explanations we must first describe how the phenomenon was locally produced (1999). With regard to describing local action, Latour's recently repeated suggestion to follow action is clear:

Using a slogan from ANT, you have 'to follow the actors themselves', that is try to catch up with their often wild innovations in order to learn from them what the collective existence has become in their hands, which methods they have elaborated to make it fit together (2005 p. 12).

I have combined Latour's approach with Silverman's call for "elegant analyses which make a lot out of a little" (1999 p. 415). My research practice involved:

Being aware of the effects of the order in which research is conducted. I have timed my research moves by asking broad questions first and holding off providing answers for as long as possible;

Following the action and trusting that I would see worlds being made if I took the time to look;

Being concerned with the details;

Being unconcerned about being concerned with the details. Strathern's concept of scale helped - the closer I looked, the more I saw (1991);

Taking a broad view by including everything in the cube of the meeting room and maintaining a multiple view by considering talk as action, that objects were involved, and things occurred simultaneously; Including everything but using just one phrase to follow and to select interactions to analyse closely;

Attempting to maintain connectedness by writing plurally;

Not being afraid of randomness and accepting lack of control at times; Being wary of offering explanations, which meant going slowly, treading carefully, being modest and limiting claims.

I elaborate further on some of these practices below. Also in this final chapter I connect further with academic writing and gather academic uses of the phrase "out there" for my purpose of showing the focus in this research on doing things together. 
Chapter four argued that these meetings were a way to see practices of making, and that focusing on the detail they contained was a valuable way to conduct research in a workplace. My concern in this section is again with how meeting material is useful, important and mirrors debates in sociology. In that earlier chapter I talked about forever and constantly permeable walls and the way this local action reached beyond (Munro 1998; Munro 2004), that "out there" is "in here" (Latour 2002). The concern has been with the never-ending connections and relations which make the gatherings that are BANA the organisation, as seen in the stuff in between the transcripts and the minutes.

My concern has been with the skill of meeting members in working together on what to do next, and using what they have to hand to do it. I have tried not to limit what might be involved and to present the multiplicity of the meetings, though I am aware that by pinning it down I may have lost the complexity involved (Law and Mol 2002a). Looking closely I saw meeting members working as if it was possible to share information, watched them struggle with capturing just what they know and what they just do in getting the work done (Silverman 1997). I started with, and tried to stay close to, that which was observable. My research involved practices of watching during fieldwork and analysis of recorded talk.

One effort has been to say that power is created here and now rather than stored, and we must therefore watch the action as, "debates about the origins of society, the nature of its components, and their relationships become crucial data for the sociologist" (Latour 1986 abstract). In chapter four I gave an example of how carefulness and the show of co-operation in the meetings were sometimes abandoned. However, rather than pointing to power as waiting in the wings, we should consider how Prue comes to be able to say "that's unavoidable". One example seen in chapter eight was the way Prue worked authority into being through providing multiple examples which showed that she knew about that topic. Having done this, Prue had something that could be put to use for her practical purposes. Munro's broad question: "So who is doing this ordering work?" can be employed to avoid moving directly and quickly to the replies of hidden motives and power that just exists (2001b p. 476). Power may still be the research concern, but it is useful to hold this label off for as long as possible in order to see the control effects of actions. Unlike a lot of the research undertaken using CA (see Heritage 2004 for a recent summary), mine was 
not institutional in the sense of professional-lay divides, where there is a difference in particular resources and competences and so power, for example between doctors and patients. However, I could argue that a professional-lay kind of divide was evident in the meetings as it is in the everyday conversations of knowers and others (Pomerantz 1984), and that the phrase "out there" was involved in this divide.

\subsubsection{Practical purposes: Academic uses of the phrase}

In chapter two I talked about Who's staff and some of the practical reasons for only including certain people at the staff meetings, of having "just" the people necessary (Boden 1994 p. 140). The idea of "just what is needed" appeared in an early CA piece on meetings, which argued that just those who belong were included in the meetings for these local purposes (Atkinson et al. 1978). At around the same time, Latour and Woolgar were also concerned with practical purposes:

Nevertheless, we know that observers regularly produce such ordered versions for consumption by others. His production of order must therefore be done 'for practical purposes,' which means that he proceeds by evading or ignoring difficulties of principle (Latour and Woolgar 1979 p. 35-6).

My discussion of belonging, cores and the material world reflects on the phrase "out there" as useful for practical purposes.

As the phrase "out there" guides this thesis, Munro's conception of membership as being "in" or "out" is useful (1997). The idea that "institutions can be thought to create interior spaces - an 'inside' where people experience feelings of belonging" (Munro 1998 p. 208) is one way to frame Sally's efforts discussed in chapters six and eight. As has been stressed, this is not a fixed belonging, and Munro's conception of shifting is accepted: "an interpretive sociology can acknowledge the possibility of meaning - feelings of belonging - without insisting on an epistemological reduction, or translation, of this into specific meanings" (1998 p.238). What this thesis takes from Munro's work on extension is the focus on a lack of fixedness (1996b) because it is in keeping with the varying efforts seen in the meetings where members sometimes worked on one thing, sometimes another. Sometimes they defended, sometimes not. Latour's idea of enrolling as deliberate or insistent was not always evident.

The impression from being there as researcher was of a lack of certainty or stability; yet the meeting members all the while achieved making the meetings and the organisation, BANA. As Munro discusses with regard to there being no fixed 
identities, I suggest that there is no core to these meetings. They are just what they need to be, as members deem necessary at the time. Law uses a lack of fixedness with regard to how managers are made up by a collection of things (Law 1994; see also Farnsworth and Austrin 2004). This is a concept related to gatherings:

what makes the sovereign formidable and the contract solemn are the palace from which he speaks, the well-equipped armies that surround him, the scribes and the recording equipment that serve him (Callon and Latour 1981 p. 284).

An example is the facilitator's chair and its proximity to the preferred whiteboard. As discussed in chapters six, seven and eight, and the last section of this chapter, the printing whiteboard made the meetings, in that "one might turn to more solid and less variable materials in order to act in a more durable way upon the bodies of our colleagues, parents and friends" (Callon and Latour 1981 p. 283-4).

The idea of things in association links ANT and CA. In CA, it is the connectedness of turns of talk. There is no returning to the core of this or these meetings. They do not return to themselves because these meetings are the meeting and the organisation at once. The word "the" is sometimes too singular for members' purposes in the meetings and for mine here. I did come to see the meetings as single events - connected but not able to be merged during description. Each meeting was not the organisation in total, forever (Munro 1997). Rather, they were the ongoingness that is, and makes, BANA (Mol 2002).

One way the phrase "out there" has been useful for me was in asking how academic workers attempt to put it to use for their purposes. I have used it to present some of the work of some academic writers rather than list academic definitions and depictions of meetings and organisations (Cuff and Sharrock 1985). By drawing together academic uses of "out there" the phrase helps me narrow the material I cover. In this way the phrase is useful for my purpose of clarifying the concerns of this thesis and placing my research.

Having decided to use the phrase "out there" as a way to analyse the empirical material I had gathered, seeing Law use it in his recent book on method felt fortuitous:

I am not saying that since the world defies any overall attempt to describe and understand it, we can therefore realistically believe anything about it we like... everything I argue assumes that there is a world out there and that knowledge and our other activities need to respond to its 'out-thereness' (Law 2004b p. 7).

Fortuitous, but not really a surprise, nor entirely random (Becker 1986a). Law's work has been influential on this research and his glossary listing encapsulates some of the 
concerns of the thesis: "Out-thereness: the apprehension, common in Euro-American and many other cosmologies, that there is a reality outside or beyond ourselves" (2004b p. 162). He discusses how distinctions are involved in assuming "that there is a world out there already in place" (Law 2004b p. 25) but that "it is not a matter of words representing things. Words and worlds go together" (Law 2004b p. 33). These academic uses of the words of others are concerned with how worlds are made. At the same time, these words make worlds. I have used Law to start this selection of academic uses of the phrase partly because citing recent work is a way to produce an account to (and at the same time account for) the place in which I have situated my research $(2004 b)$.

Bruno Latour's use of the phrase runs a very close second however. Very close, partly because this thesis asked how the phrase was involved in "the procedures which render actors able to negotiate their ways through one another's world-building activity" (Latour 1999a p. 21). In this use of the phrase Latour argues for a future for ANT without separations and binaries:

Instead there is only one single predicament which, no matter how entangled, has to be tackled at once. To sum it up in one simple formula: 'out there' nature, 'in there' psychology, 'down there' politics, 'up there' theology. It is this whole package that by happenstance ANT called into question at once (Latour 1999a p. 22).

Latour should perhaps come first because, like Law, many writers draw on Latour and Woolgar's conception:

We do not wish to say that facts do not exist nor that there is no such thing as reality. In this simple sense our position is not relativist. Our point is that 'out-there-ness' is the consequence of scientific work rather than its cause (Latour and Woolgar 1979).

Latour's use links us to Mol, whose interpretation of Latour was used in the thesis introduction:

instead of dialectically jumping between the ideas that reside in the minds of subjects and some objective reality out there, we would do better to admit that in our daily lives we are engaged in practices that are thick, fleshy, and warm as well as made out of metal, glass, and numbers - and that are persistently uncertain (Mol 2002 p. 31).

In Mol's conception of reality enacted, "out there" exists because the meeting members use it in their practice (Mol 2002 p. 44). In this research what exists includes material things like the printing whiteboard, those talked into being through the phrase "out there", and the phrase itself.

In her research on medical practice, Mol reports one worker's use of the phrase:

At such moments doubt is smothered and certainty is being manufactured. 'But surely we are all fighting the same disease? We share a goal, don't we?...' 'But listen, people 
die, people suffer. There is a real disease out there.' As if the certainty of death and misery necessarily brought with it the singularity of the real. So in the hospital there are, at least, these two repertoires (Mol 2002 p. 163-4).

As in Mol's research, Munro's use of the phrase comes from a worker talking about what is to be done, as being, or coming from, someplace other than where the phrase is used:

An expertise over quality facilitates a further translation, one of turning the demands of the customer into a production schedule: 'It comes about mainly because we have a customer out there who wants a product. Then their demand is translated back into a schedule, so that's the thing that tends to drive us.' (production director) (Munro 1997 p. S59).

Here is a similarity, some kind of connection. Including mine, there are three uses of the phrase by workers reported by academic researchers. These researchers are reporting that using the phrase "out there" is something utilised by the workers involved in their research. In this act, researchers are showing their own having been "out there". In another article, Munro takes the position that "far from being somewhere 'out there', context is that which is always being created and reproduced through accounts" (1996a p. 3).

The mode of this worker talk seems to be something like a standing back, a reflecting, or perhaps an explanation. As these uses show, and you saw in chapter five, describing uses of the phrase in the meetings I attended, sometimes the phrase is used to indicate what is driving the speaker's actions, something like "demand" in economic terminology. In Law and Mol's use of the phrase, they talk about the pressures on the manager of the laboratory. Again there is a sense of someplace else driving what happens here:

And this knowledge, these inscriptions, are an integral part of the process of managing the Laboratory, of making sure that things don't go wrong, of making sure that the science gets done, that the Laboratory has a good reputation out there where it matters in the scientific community, that it will build up the confidence among the grant-givers and obtain future funding (Law and Mol 1998 p. 26).

Workers' uses of the phrase "out there" are taken by these academic researchers to be involved in making because we can no longer "retain conceptions of language as a merely neutral medium for the transmission of information, values and beliefs about a world 'out there'. Instead we can examine language use as a form of social action" (Wooffitt 2001 p. 326).

If it is accepted that the use of the phrase was sometimes involved in defending a proposal of what should happen next in the meetings, then the phrase can be seen as 
especially participating in (face-to-face and written) gatherings where placing responsibility (that is, dividing labour) is accomplished. Latour has more recently repeated his arguments about the impossibility of separations: "A thing is, in one sense, an object out there and, in another sense, an issue very much in there, at any rate, a gathering" (Latour 2004 p. 233). What is useful for my purpose is the sense that the world is made, or built (Latour 1999a p. 20) by gathering many things, including the phrase "out there".

What I take from these uses of the phrase in the sorts of academic writing useful for my purpose, is confirmation that looking closely at members' methods shows something of the world being made:

Social structure, on this view, is not something 'out there' independent of members' activities, nor are the structures of social action located at the unobservable level of Durkheim's collective. Rather, they are the practical accomplishment of members of society (Zimmerman and Boden 1991 p. 19).

Chia uses the phrase to advocate for the inclusion of the human senses (specifically the visual) in contemporary organisation studies. That is, as a way to achieve a "wider and deeper understanding of the 'world-making' capacities of modern organizing", instead of pursuing " the perfect representation of a world that is already "out there" (Chia 1998a p. 9). This is the world on the move, constantly in the making and being made, not one already made and one able to be made differently.

\subsubsection{An associational view of making}

I have considered meeting talk, analysing the phrase "out there" with its surrounding interaction to ask how it was used by meeting members. It is the ability of the phrase "to act in a durable way" that is useful for this research (Callon and Latour 1981 p. 284). In the meetings "out there" is real because meeting members do things with it - it is real in its effects in the meetings and the organisation (Mol 2002). The phrase however, is only one thing on a long list of "new and non-human resources" useful for the purposes of meeting members (Latour 1986 p. 276). With regard to the material world, the question is "how are materials engaged in the enactment of reality" (Mo1 2002 p. 49)?

One way the material world was involved was when meeting members verbally pointed to places and objects outside the room. Meeting members spoke as if the objects they used were flesh, and about making things flesh: "going to be fleshed out" (M6). The impression was one of calling corporeality into being: to visualise and give 
substance to what the meeting members were discussing. This seemed to be a way of making it real and making it a reality (see Mol 2002 p. 31 and 44 and Star 1992 p. 403). This involvement in material objects in sharing has been noted by Atkinson who uses Schutz's work on practical phenomenology, in saying that people "may assume, for all practical purposes, that they inhabit a world of shared objects" (1995 p. 79). Also from CA, Boden draws on Pollner (1987) using Merleau-Ponty's idea of "retrospective illusion" to discuss objects made by people being used by them in acting together (1994).

The importance of acknowledging the involvement of the material world, like the whiteboards in these meetings, has been a major contention of ANT for nearly 25 years:

The ethnomethodologists forget to include in their analyses the fact that ambiguity of context in human societies is partially removed by a whole gamut of tools, regulations, walls and objects of which they analyse only a part. We must now gather up what their analyses leaves out and examine with the same method the strategies which enlist bodies, materials, discourses, techniques, feelings, laws, organizations (Callon and Latour 1981 p. 284).

In this research the meeting room was viewed as something like a box or a cube, all the contents of which were necessary to make the meetings (Farnsworth and Austrin 2004; Star 1992). I have attempted "to mingle our humanity with not-so-mute, active, performative objects... [in] this co-performance of sociality/materiality" (Pels et al. 2002). The meetings are taken to be "a 'doing' which involves people, technologies and textual and symbolic forms assembled within a system of material relations" (Gherardi and Nicolini 2000 p. 333).

I could have undertaken this research by asking solely about how material things were involved in the meetings. However, this would hardly have reduced the meeting interactions to be included in the thesis, because documents, diaries, machines, buildings, software were nearly always there in the conversations. I accept that these things are the "co-constituents of social order" (Preda 2000 p. 270). Following Callon and Latour I have attempted to explore practices of making with the understanding that "things, facts and artifacts, are major components" (1992 p. 348). Blackler and Engestrom's more recent calls for a focus on objects provide a summary when they say "organizations are built and maintained around partially shared, partially fragmented and disputed objects. This means that the study of organizations 
should increasingly also be a study of objects and their organizational potentials" (Blackler and Engestrom 2002 p. 358; Engestrom and Blackler 2005).

This associational view brings the external, material world into focus, at the same time that the concept of an internal, singular, self-sufficient mind is rejected:

The notion of a world 'out there' to which a mind-in-a-vat tries to get access by establishing some safe correspondence between words and states of affairs should now be seen for what it is: a very unrealistic position for science, so forced, so cramped that it can only be explained by powerful political motives (Latour 1999b p. 113)

With a similar concern to Latour's, to consider something more or different than one (the singularity of individual), more than internal (the inside of mind), Star discusses "distributed" and "collective cognition" (1992 p. 396 and p. 404). One effect of viewing the world as made in association is being uncomfortable using words like "intelligence" and "mind" in research. The risk is that readers may be mistaken about the approach. For example, while many of Cooren's ideas follow Latour, and draw on Hutchins as Star does, his idea of "collective mind" is not clear enough about things being externally associational (2004a). Another way to read Pat's concern to be in a physical process (OT11 and OT12) is that she is working to have material things remind her (Star 1992). This is not mind (internal, singular), not motives and intentions, which imply inside mind, but associational practice for practical purposes. As I discussed in chapter eight, there are many things going on when Pat says she needs to get back into "that loop", but her attempts are only achieved in association.

Using the detail of empirical materials, CA has shown how direct witnessing of events was influential in these meetings. I hope I have also shown that fieldwork is valuable in this research, despite not having spent large amounts of time continuously in the field. I have used observation methods to show something of what went on in a particular place at a particular time, but do not claim the name "ethnography" because I did not spend the usual length of time in the field such a label suggests (I cannot produce a sufficient ethnographic ac(count)). This means I do not say it "is" ANT but that I have used some of the techniques of ANT for my purposes (see Austrin and Farnsworth for a discussion of fieldwork practice issues (2005)). My research is not entirely CA either, as I have not, for instance, timed pauses in making the transcripts; nevertheless this research does incorporate close analysis of talk into inquiries about workplaces (Heritage 1984). 
Claims that there is more to do are common, and we often say we wish we had more time for our research - an act that attempts many enlistings. While we may wish that we could do what Mol (2002) has so successfully done in her long-running research (Frankenberg 2005 links "prolonged work" to "quality"), it is not necessary to totally abandon an observation-based approach. I suggest it is possible, even in shorter research endeavours, to take up Mol's research sensibility. There are other ways to look carefully at practice and how people and things make the world than by undertaking ethnographies spanning many years. This is what I have done here by following (as ANT and CA advocate) something small like a single phrase (Wilkinson and Kitzinger 2000) and attending a few events. Observing practices of making worlds does not necessarily require prolonged fieldwork. I have valued witnessing in this research but suggest that witnessing can be achieved during fieldwork and also using recorded talk.

\subsection{Conclusions from watching meeting members' practices}

Finally I can no longer hold off the provision of a list. Maybe readers have started here rather than wade through my attempt to demonstrate the interconnectedness of the meeting members' activities at the centre of this research. If you have started here at the end you will have to go from the beginning to see the resources I have used to back up my claims. I hope also that readers will see things other than the ones I have provided on this partial list. What do I claim to know now in answer to the question, "what can we see when we look at these meetings?"

\subsubsection{Knowing}

First-hand experience seemed to be a valuable resource when it came to suggesting and defending what BANA should do next. However, the knowing produced from having been out in the field and the "seeing" that it entails was perhaps being put alongside seeing and knowing the information held by technical systems. How to share seemed a pressing issue for members as BANA increased in numbers of staff.

\subsubsection{Avoiding saying "no"}

Members interacted with each other carefully in the meetings. For instance, they rarely used the word "no" as a total rejection. The moveable whiteboard did the work 
of avoiding saying " $n o$ ". This whiteboard was also involved in acting as if the answer had been "yes".

\subsubsection{Avoiding confrontation and taking care}

In the meetings there were few obvious displays of power, yet control and hierarchy were achieved nevertheless. Members did not confront each other directly, yet they did disagree. One way they achieved disagreement was by using misunderstanding. Paradoxically, some turns of talk which used misunderstanding included "no".

The care taken in responses varied but what this depended on was not clear. For instance Sally seemed to misjudge her use of certain things (like time in the meetings and the phrase "out there") which perhaps meant that Prue had the right and responsibility to cut her off bluntly. Having rights to certain resources perhaps affected the degree of care required in responses by other speakers.

Confronting one another and being too direct was perhaps not useful for the purposes of meeting members, like staying in the room together and achieving appearances of co-operation with regard to working on what to do next.

\subsubsection{Rights and responsibilities}

Members appeared to be acting according to agreed-upon responsibilities and rights. There seemed to be certain expected contributions. The phrase "out there" was a resource useful for doing things in the meetings, but not all members seemed to have a right to use it in suggesting what should happen next. Pat and Prue's rights and responsibilities seemed to be different as the episode regarding how to order information showed. Prue was responsible for the whole organisation and she argued for the ready availability of information to all staff (so, open access). Pat, speaking as the most senior fieldworker showed her concerns regarding information about contact with the field (so, delivery and control).

\subsubsection{Opportunities}

Members provided each other with opportunities to speak, which sometimes seemed to be in the form of providing platforms from which to be convincing. The work of creating platforms did not seem to be distributed according to organisational authority or seniority in that Sally and Simone, but also Pat, did this creating. 
However, some kind of authority seemed involved in who the platforms were created for - Pat, Prue and Susan. This seems tied to the member who at that time was considered to have information or was taken to know.

\subsection{Conclusions from my researcher practices}

\subsubsection{Knowing from witnessing the details}

With regard to my own claims to know, I have been aware throughout this project of the high esteem in which ethnographies are held, as if being able to say I was there, and have been "out there" for quite some time is one way academic researchers support their claims to know how it is. My concern is that, like Sally, I may be placed as not having the right to know from witnessing the details of turns of talk. Practices of seeing are involved in both, yet my close examination may not be allowed to stand alone, as if mine has been some "other" kind of witnessing which can then be labelled as just another "micro" look at a few details. I use Strathern's concept of scale to defend my concern with the details, as Sally aligned herself with her high profile fieldworker (1991). However, I have worked hard to be clear about where the witnessing occurred, and I am prepared to dispute suggestions that my use of the details to create descriptions has been some kind of misunderstanding on my part.

\subsubsection{Using ANT and $C A$}

In suggesting that following is the practice of both ANT and CA, I have attempted to show that witnessing the small was to be at the same time to be witnessing the big. Broad questions about what is involved in attempts to hold worlds together can be considered by looking at the details of conversations. For instance, I have shown how members create for themselves, and provide for each other, opportunities to be convincing. In this I am emphasising how association is achieved by many actors. Clarifying Latour's statement by making it more plural, we need to treat power as "the consequence of ... intense activit[ies] of enrolling, convincing and enlisting" (1986 p. 273). These activities depend on what someone or some thing does next as it is with my project where "success is up to the reader" (Latour 2005 p. 13). 


\subsubsection{We make our worlds}

When I suggest that acting produces power effects I am not suggesting that we are always attempting to be more powerful than others but that acting may produce effects anyway. With regard to our associational research activity, I have tried in this thesis to say "hey look at this" if it is of any interest to you, if it is useful for your purposes. This reflects the ethnomethodological rejection of engaging in criticism. When we quickly or superficially scoop up the work of others for purposes of our own, like producing many publications, we show and perform "couldn't care less".

\subsection{So what then from this?}

Asking what it is that members use in attempts to defend what should happen next, place responsibility, and show membership, may be a useful way to inquire into what is seen as valuable in workplaces.

Asking how members use material things, like whiteboards, to avoid obviously attempting certain actions (like saying no), yet still achieving them, may be a useful way to consider what kinds of conduct are expected and also frowned upon in workplaces (like being democratic).

The concepts of "obligatory passage" and "positioning attempts" as used by Latour and Munro may be useful ways to explore workplace control and hierarchical effects. Being an "obligatory passage" is perhaps a way to avoid demanding control directly and avoiding saying "no" whilst also achieving control and saying no. Observing members' attempts to become or remain in positions of control and how these are achieved may be a fruitful research approach.

Moreover, do workers avoid positions of obligatory passage? For instance, is the phrase "just let me know" a way responsibility for acting next is placed with others in the mode of ready availability? Does the phrase attempt and achieve "I am readily available but you will have to seek me out"? Following this phrase may provide a way to reveal hierarchy. How and where is "availability" a prominent form of organisational ordering?

These kinds of questions, which seek some level of understanding of members' world-building activities, may be best asked by avoiding making assumptions early in 
research about how ordering and organisation are achieved. This includes paying careful attention to the timing of research moves, and waiting during analysis.

Moving beyond the emphasis on description in this thesis, it may be valuable to ask whether opportunity is a prominent form of ordering in some workplaces. Where and why are appearances of collaboration important? Is providing opportunity a way that some workplaces achieve dividing labour? For instance, is information made available (the web and in databases) for workers to seek out? In interaction do we provide each other with, and seek, opportunities to be convincing? Are workers expected to step forward into tasks and responsibilities and does this involve them also being responsible for finding out for themselves what these are? Comparing opportunity (new technologies) to delivery (old bureaucracies) may be a way to ask about "enterprise" in workplaces. Is there implicit effort being put into resisting the "hailing effects" of opportunities (Munro 2001b p. 476)? 


\subsection{Epilogue}

The appreciation of worlds as made, the view that we are engaged in associational activities, of togetherness and connectedness, is perhaps something I was shown long ago. Here is a story from growing up in a workplace.

On the nights Dad was slaughtering he would call in at the house at dusk to ask if I was coming along. We'd walk up to the woolshed where one or two sheep would be standing, after being shut away for the day so their stomachs would be empty. I remember going willingly up the paddock to be involved in the slaughtering. I do not remember being forced, or hearing anyone say I should, though I no longer eat the separated parts of sheep. I did not have any obvious work to do, but seemed to be needed nevertheless. One of Dad's techniques I remember being involved in is one I have used in this research. I remember being aware of the skills involved in turning sheep into (body) parts we could use. Seeing many dissected sheep in the shed may be where I was shown the value of doing "hey look at this":

My father is saying let's have a look, standing in the woolshed, bending down with his forearms resting above his knees holding the sheep's liver down between us, at my eye level and close to his, running his thumbs across its silky surface looking for parasites.

Asking, how clean is this, how clean are the paddocks?

I was part of a lopsided triangle fleetingly formed in association with the liver. To be part of that association was to be part of that world, part of getting together for the practical and shared purposes of that place. The next day when we ate those separated livers for breakfast, Dad and I and the liver formed a different association. No longer slaughterman and butcher but cook, calling liver by a different name - serving "lamb's fry" with bacon. With the same parts but in a different time and place we made different associations for just those purposes.

With many associations we make our worlds. 


\section{Page 225}

\section{References}

Allen, J. (2003). Lost Geographies of Power. Malden, Blackwell.

Alvehas, J. (1999). Managing meetings: Techniques for the control of interaction. Paper presented at the Critical Management Studies Conference (CMS), UMIST, Manchester, UK.

Atkinson, J. M. (1982). Understanding formality: The categorization and production of 'formal' interaction. The British Journal of Sociology 33(1): 86-117.

Atkinson, M. A., E. C. Cuff and J. R. E. Lee (1978). The recommencement of a meeting as a member's accomplishment. Studies in the Organization of Conversational Interaction. In J. Schenkein, Ed. New York, Academic Press: 133-155.

Atkinson, P. (1995). Medical Talk and Medical Work. London, Sage.

Austrin, T. and J. Farnsworth (2002). Reworking Sociology: Bruno Latour's Feeling for Genre. New Zealand Sociology 17(1): 1-18.

Austrin, T. and J. Farnsworth (2005). Hybrid genres: Fieldwork, detection and the method of Bruno Latour. Qualitative Research 5(2): 147-165.

Bate, S. P. (1997). Whatever happened to organizational anthropology? A review of the field of organizational ethnography and anthropological studies. Human Relations 50(9): 1147-1175.

Becker, H. S. (1960). Notes on the Concept of Commitment. American Journal of Sociology 66(1): 32-40.

Becker, H. S. (1982). Art Worlds. Berkeley, University of California Press.

Becker, H. S. (1986a). Doing Things Together: Selected Papers. Evanston, Illinois, Northwestern University Press.

Becker, H. S. (1986b). Writing for Social Scientists: How to Start and Finish your Thesis, Book, or Article. Chicago, University of Chicago Press.

Becker, H. S. (1998). Tricks of the Trade: How to Think About Your Research While You're Doing It. Chicago, University of Chicago Press.

Belfiore, M. E. (2004). Literacies, compliance and certification. Reading Work: Literacies in the New Workplace. In M. E. Belfiore, T. A. Defoe, S. Folinsbee, J. Hunter and N. S. Jackson, Eds. New Jersey, Lawrence Erlbaum Associates.

Blackler, F. and Y. Engestrom (2002). The rise of objects in the study of organizations. Organization 9(2): 357-358.

Boden, D. (1994). The Business of Talk: Organisations in Action. Cambridge, Polity Press.

Boden, D. (2000). Worlds in action: Information, instantaneity and global futures trading. The Risk Society and Beyond. In B. Adam, B. U. Beck and J. van Loon, Eds. London, Sage.

Brown, C. (1992). Organization studies and scientific authority. Rethinking Organization: New Directions in Organization Theory and Analysis. In M. Reed and M. Hughes, Eds. London, Sage. 
Callon, M. (1986). Some elements of a sociology of translation: Domestication of the scallops and the fishermen of St Brieuc Bay. Power, Action and Belief A New Sociology of Knowledge. In J. Law, Ed. London, Routledge and Kegan Paul. 32: 196-233.

Callon, M. (2001). Actor Network Theory. International Encyclopaedia of the Social and Behavioral Sciences. In N. J. Smelser and P. B. Baltes, Eds. Amsterdam, Elsevier. 1: 62-66.

Callon, M. and B. Latour (1981). Unscrewing the big Leviathan: How actors macrostructure reality and how sociologists help them to do so. Advances in Social Theory and Methodology: Toward Integration of Micro- and Macro-sociologies. In K. Knorr-Cetina and A. V. Cicourel, Eds. Boston, Routledge and Kegan Paul.

Callon, M. and B. Latour (1992). Don't throw the baby out with the Bath school! A reply to Collins and Yearley. Science as Practice and Culture. In A. Pickering, Ed. Chicago, University of Chicago Press: 343-368.

Callon, M., J. Law and A. Rip, Eds. (1986). Mapping the Dynamics of Science and Technology: Sociology of Science in the Real World. Houndmills, Macmillan Press.

Casey, C. (2002). Critical Analysis of Organizations: Theory, Practice, Revitalization. London, Sage.

Chia, R. (1998a). Exploring the expanded realm of technology, organization and modernity. Organized Worlds: Explorations in Technology and Organization with Robert Cooper. In R. Chia, Ed. London, Routledge.

Chia, R. C. H., Ed. (1998b). In the Realm of Organization: Essays for Robert Cooper. London, Routledge.

Clegg, S., M. Kornberger and C. Rhodes (2005). Learning/becoming/organizing. Organization 12(2): 147-167.

Cooper, R. and J. Law (1995). Organization: Distal and proximal views. Studies of Organizations in the European Tradition. In S. B. Bacharach, P. Gagliardi and B. Mundell, Eds. Greenwich, Conn, JAI Press. 13: 237-274.

Cooren, F. (2004a). The communicative achievement of collective minding: Analysis of board meeting excerpts. Management Communication Quarterly 17(4): 517-552.

Cooren, F. (2004b). Textual agency: How texts do things in organizational settings. Organization 11(3): 373-393.

Courpasson, D. and M. Reed (2004). Introduction: Bureaucracy in the age of enterprise. Organization 11(1): 5-12.

Cuff, E. C. and W. Sharrock (1985). Meetings. Handbook of Discourse Analysis. In T. van Dijk, A., Ed. London, Academic Press. 3: 149-.

Czarniawska, B. (1997). Narrating the Organization: Dramas of Institutional Identity. Chicago, The University of Chicago Press.

Deetz, S. (2003). Reclaiming the legacy of the linguistic turn. Organization 10(3): 421429.

Denzin, N. K. (2002). The interpretive process. The Qualitative Researcher's Companion. In M. A. Huberman and M. B. Miles, Eds. London, Sage: 349-366. 
Doolin, B. (2003). Narratives of change: Discourse, technology and organization. Organization 10(4): 751-770.

Drew, P. and J. Heritage (1992). Analyzing talk at work: An introduction. Talk at Work: Interaction in Institutional Settings. In P. Drew and J. Heritage, Eds. Cambridge, Cambridge University Press.

du Gay, P. (2004). Against 'enterprise' (but not against 'enterprise', for that would make no sense). Organization 11(1): 37-57.

Dugdale, A. (1999). Materiality: Juggling sameness and difference. Actor Network Theory and After. In J. Law and J. Hassard, Eds. Oxford, Sociological Review Monograph: Blackwell: 113-135.

Engestrom, Y. and F. Blackler (2005). On the life of the object. Organization 12(3): 307330.

Farnsworth, J. and T. Austrin (2004). Ceaseless conferring: The corporate university and the construction of opaque transparency. Paper presented at the 18th Annual Conference of the Australian and New Zealand Academy of Management (ANZAM), University of Otago, Dunedin, New Zealand.

Fox, S., J. Hughes, M. Iszatt White, S. Kelly, D. Randall and M. Rouncefield (2005). Talking leadership. 4th International Critical Management Studies Conference (CMS), University of Cambridge, Cambridge, UK.

Frankenberg, R. (2005). Book review. Sociology of Health and Illness 27(1): 149-150.

Garfinkel, H. (2002). Ethnomethodology's Program: Working Out Durkheim's Aphorism. Maryland, Rowman and Littlefield.

Gellner, D. N. and E. Hirsch, Eds. (2001). Inside Organizations: Anthropologists at Work. Oxford, Berg.

Gervais, R. and S. Merchant (2002). The Office. England, BBC Worldwide Limited.

Gherardi, S. (2000a). Practice-based theorizing on learning and knowing in organizations. Organization 7: 211-223.

Gherardi, S. (2000b). Where learning is: Metaphors and situated learning in a planning group. Human Relations 53(8): 1057-1080.

Gherardi, S. and D. Nicolini (2000). To transfer is to transform: The circulation of safety knowledge. Organization 7: 329-348.

Gordon, D. (1988). Clinical science and clinical expertise: Changing boundaries between art and science and medicine. Biomedicine Examined. In M. Lock and D. Gordon, Eds. Dordrecht, Kluwer.

Grant, D., T. Keenoy and C. Oswick (1998). Organizational discourse: Of diversity, dichotomy and multi-disciplinarity. Discourse and organization. In D. Grant, T. Keenoy and C. Oswick, Eds. London, Sage.

Greatbatch, D. and T. Clark (2005). Management Speak: Why We Listen to What Management Gurus Tell Us. Abingdon, Routledge.

Grint, K. (1998). The Sociology of Work: An Introduction. Cambridge, Polity Press. 
Gumperz, J. L. (1982). The linguistic bases of communicative competence. Analyzing Discourse: Text and Talk. In D. Tannen, Ed. Washington D C, Georgetown University Press.

Hardy, C., N. Phillips and S. Clegg (2001). Reflexivity in organization and management theory: A study of the production of the research 'subject'. Human Relations 54(5): 531-560.

Heath, C. (1981). The opening sequence in doctor-patient interaction. Medical Work: Realities and Routines. In P. Atkinson and C. Heath, Eds. Farnborough, Hants, Gower.

Heath, C. and G. Button (2002). Editorial introduction. Sociology 53(2 Special issue: Workplace studies): 157-161.

Heritage, J. (1984). Garfinkel and Ethnomethodology. Cambridge, Blackwell.

Heritage, J. (2004). Conversation analysis and institutional talk: Analyzing data. Qualitative Research: Theory, Method and Practice. In D. Silverman, Ed. London, Sage.

Hester, S. and P. Eglin (1997). Membership categorization analysis: An introduction. Culture in Action: Studies in Membership Categorization Analysis. In S. Hester and P. Eglin, Eds. Washington, D. C., International Institute for Ethnomethodology and Conversation Analysis \& University Press of America.

Hodgson, D. E. (2004). Project work: The legacy of bureaucratic control in postbureaucratic organization. Organization 11(1): 81-100.

Hughes, J., M. Rouncefield and P. Tolmie (2002). Representing knowledge: Instances of management information. Sociology 53(2 Special issue: Workplace studies): 221 238.

Hugill, D. (2004). Commercial negotiation: Reaching for disagreement within an overall project of reaching for agreement. Culture and Organization 10(2): 163-187.

Jeppesen, K., K. (2001). Tribulations of standardisation: Analysing standard setting from an Actor-Network perspective. unpublished conference paper.

Jones, C. and R. Munro (2005). Organization theory, 1985-2005. Contemporary Organization Theory. In C. Jones and R. Munro, Eds. London, Sociological Review Monograph: Blackwell: 1-15.

Jones, D. (2005). Undertaking qualitative research. Victoria University Post Graduate Workshops, Wellington.

Judge, M. (1998). Office Space. United States of America, Twentieth Century Fox.

Latimer, J. (2000). The Conduct of Care: Understanding Nursing Practice. Oxford, Blackwell Science.

Latimer, J. (2004). Commanding materials: (Re)legitimating authority in the context of multi-disciplinary work. Sociology 38(4): 757-775.

Latour, B. (1986). The powers of association. Power, action and belief: A new sociology of knowledge? In J. Law, Ed. London, Routledge and Kegan Paul. 32.

Latour, B. (1987). Science in Action. Milton Keynes, Open University Press. 
Latour, B, (1996). Aramis or the Love of Technology. Cambridge, Massachusetts, Harvard University Press.

Latour, B. (1999a). On recalling ANT. Actor Network Theory and After. In J. Law and J. Hassard, Eds. Oxford, Sociological Review Monograph: Blackwell.

Latour, B. (1999b). Pandora's Hope: Essays on the Reality of Science Studies. Cambridge, Massachusetts, Harvard University Press.

Latour, B. (2002). Gabriel Tarde and the end of the social. The Social in Question: New Bearings in History and the Social Sciences. In P. Joyce, Ed. London, Routledge.

Latour, B. (2003). Is Re-modernatization occurring - And if so, how to prove it? A commentary on Ulrich Beck. Theory, Culture \& Society 20(2): 35-48.

Latour, B. (2004). Why has critique run out of steam? From matters of fact to matters of concern. Critical Inquiry 30(Winter): 225-248.

Latour, B. (2005). Reassembling the Social: An Introduction to Actor-Network-Theory, Oxford University Press.

Latour, B. and S. Woolgar (1979). Laboratory Life. The Construction of Scientific Facts. Princeton, Princeton University Press.

Law, J. (1992). Notes on the theory of the Actor-Network: Ordering, strategy, and heterogeneity. Systems Practice 5(4): 379-393.

Law, J. (1994). Organizing Modernity. Oxford, Blackwell.

Law, J. (1996). Traduction/trahison - notes on ANT. Actor Network Resource: An Annotated Bibliography Retrieved 9 July, 2002, available at http://www.lancs.ac.uk/fss/sociology/css/antres/antres.htm.

Law, J. (1999). Actor Network Theory and After. Actor Network Theory and After. In J. Law and J. Hassard, Eds. Oxford, Sociological Review Monograph: Blackwell.

Law, J. (2000). Networks, relations, cyborgs: On the social study of technology.

Retrieved 21 February, 2003, available at

http://www.lancs.ac.uk/fss/sociology/css/antres/antres.htm.

Law, J. (2004a, 26 February 2004). Actor Network Resource: An Annotated Bibliography [On line]. available at http://www.lancs.ac.uk/fss/sociology/css/antres/antres.htm.

Law, J. (2004b). After Method: Mess in Social Science Research. London, Routledge.

Law, J. and J. Hassard, Eds. (1999). Actor Network Theory and After. Oxford, Sociological Review Monograph: Blackwell.

Law, J. and A. Mol (1998). On metrics and fluids: Notes on otherness. Organized Worlds: Explorations in Technology and Organization with Robert Cooper. In R. Chia, Ed. London, Routledge.

Law, J. and A. Mol, Eds. (2002a). Complexities: Social Studies of Knowledge Practices. Durham, North Carolina, Duke University Press.

Law, J. and A. Mol (2002b). Local entanglements or utopian moves: An inquiry into train accidents. Utopia and Organization. The Sociological Review: 83-105.

Law, J. and J. Urry (2004). Enacting the social. Economy and Society 33(3): 390-410. 
Lee, J. R. E. (1987). Prologue: Talking organisation. Talk and Social Organisation. In G. Button and J. R. E. Lee, Eds. Clevedon, Multilingual Matters.

Lee, N. and J. Hassard (1999). Organization unbound: Actor-Network Theory, research strategy and institutional flexibility. Organization 6(3): 391-404.

Linstead, S. (1994). Objectivity, reflexivity, and fiction: Humanity, inhumanity, and the science of the social. Human Relations 47(11): 1321-1346.

Lloyd, M. (2002a). Introduction. Occupational Health and Safety in New Zealand: Contemporary Social Research. In M. Lloyd, Ed. Palmerston North, Dunmore Press.

Lloyd, M. (2002b). Special issue Actor Network Theory. New Zealand Sociology 17(1).

Marra, M. (2003). Leadership and decision making style. Unpublished PhD thesis, Linguistics. Wellington, Victoria University of Wellington.

Mauthner, M., M. Birch, J. Jessop and T. Miller (2002). Ethics and Feminist Research. London, Sage.

May, T. (1997). Social Research Issues, Methods and Process. Buckingham, Open University Press.

Maynard, D. W. (1991). The perspective-display series and the delivery and receipt of diagnostic news. Talk and Social Structure: Studies in Ethnomethodology and Conversation Analysis. In D. Boden and D. H. Zimmerman, Eds. Cambridge, Polity Press in association with Blackwell Publishers.

Maynard, D. W. and S. Clayman, E. (1991). The diversity of ethnomethodology. Annual Review of Sociology 17: 385-418.

Mehan, H., A. Hertweck and M. Lee, J. (1986). Handicapping the Handicapped: Decision Making in Students' Educational Careers. Stanford, Stanford University Press.

Middleton, D. (1998). Talking work: Argument, common knowledge, and improvisation in teamwork. Cognition and Communication at Work. In Y. Engestrom and D. Middleton, Eds. Cambridge, Cambridge University Press.

Miller, G. and K. Fox (2004). Building bridges: The possibility of analytic dialogue between ethnography, conversation analysis and Foucault. Qualitative Research: Theory, Method and Practice. In D. Silverman, Ed. London, Sage.

Moerman, M. (1988). Talking Culture: Ethnography and Conversation Analysis. Philadelphia, University of Pennsylvania Press.

Mol, A. (2002). The Body Multiple: Ontology in Medical Practice. Durham, Duke University Press.

Mumby, D. K. (2004). Discourse, power and ideology. The Sage Handbook of Organizational Discourse. In D. Grant, C. Hardy, C. Oswick and L. L. Putnam, Eds. London, Sage.

Munro, R. (1995). Governing the new province of quality: Autonomy, accounting and the dissemination of accountability. Making Quality Critical: New Perspectives on Organizational Change. In A. Wilkinson and H. Willmott, Eds. London, Routledge. 
Munro, R. (1996a). Alignment and identity work: The study of accounts and accountability. Accountability: Power, Ethos, and the Technologies of Managing. In R. Munro and J. Mouritsen, Eds. London, Thomson International Business Press.

Munro, R. (1996b). The consumption view of self: Extension, exchange and identity. The Sociological Review: 248-273.

Munro, R. (1997). Connection/disconnection: Theory and practice in organization control. British Journal of Management 8(Special Issue): S43-S63.

Munro, R. (1998). Belonging on the move: market rhetoric and the future as obligatory passage. The Sociological Review: 208-243.

Munro, R. (1999a). The cultural performance of control. Organization Studies 20(4): 619640.

Munro, R. (1999b). Power and discretion: Membership work in the time of technology. Organization 6(3): 429-450.

Munro, R. (2001a). After knowledge: The language of information. The Language of Organization. In R. Westwood and S. Linstead, Eds. London, Sage.

Munro, R. (2001b). Calling for accounts: Numbers, monsters and membership. The Sociological Review 4: 473-493.

Munro, R. (2004). Punctualizing identity: Time and the demanding relation. Sociology 38(2): 293-311.

Oswick, C. and D. Richards (2004). Talk in organizations: Local conversations, wider perspectives. Culture and Organization 10(2): 107-123.

Patriotta, G. (2003). Organizational Knowledge in the Making: How Firms Create, Use and Institutionalize Knowledge. Oxford, Oxford University Press.

Pels, D., K. Hetherington and F. Vandenberghe (2002). The status of the object: Performances, mediations, and techniques. Theory, Culture \& Society 19(5/6): 121.

Polanyi, M. (1958). Personal Knowledge. London, Routledge \& Kegan Paul.

Pollner, M. (1987). Mundane Reason: Reality in Everyday and Sociological Discourse. Cambridge, Cambridge University Press.

Pomerantz, A., M. (1984). Giving a source or basis: The practice in conversation of telling 'how I know'. Journal of Pragmatics 5-6(8): 607-625.

Pomerantz, A., M. (1986). Extreme case formulations: A way of legitimizing claims. Human Studies 9(Interaction and language use): 219-29.

Powers, R. (2000). Plowing the Dark. London, William Heinemann.

Preda, A. (2000). Order with things? Humans, artifacts, and the sociological problem of rule-following. Journal for the Theory of Social Behaviour 30(4): p269, 30p.

Rouncefield, M. (2003). 'Business as Usual': An Ethnography of Everyday (Bank) Work. Unpublished PhD dissertation in Sociology. Lancaster, Lancaster University.

Sacks, H. (1987). On the preferences for agreement and contiguity in sequences in conversation. Talk and Social Organisation. In G. Button and J. R. E. Lee, Eds. Clevedon, Multilingual Matters. 
Sacks, H. (1992a). Lectures on Conversation Volume 1. Oxford, Blackwell.

Sacks, H. (1992b). Second stories; "Mm hm;" Story prefaces; 'Local news;' Tellability. Lectures on Conversation Volume 2. In G. Jefferson, Ed. Oxford, Blackwell. 2: 316 (Fall 1968 Lecture 1).

Sacks, H. (1992c). Storyteller as 'witness;' Entitlement to experience. Lectures on Conversation Volume 1. In G. Jefferson, Ed. Oxford, Blackwell. 1: 242-248 (Spring 1970 Lecture 4).

Sacks, H., E. A. Schegloff and G. Jefferson (1978). A simplest systematics for the organization of turn taking for conversation. Studies in the Organization of Conversational Interaction. In J. Schenkein, Ed. New York, Academic Press: 755 .

Salmond, A. (1975). Mana makes the man: A look at Maori oratory politics. Political Language and Oratory in Traditional Society. In M. Bloch, Ed. London, Academic Press: 45-63.

Schegloff, E. A. (1982). Discourse as an interactional achievement: Some uses of 'uh huh' and other things that come between sentences. Analyzing Discourse: Text and Talk. In D. Tannen, Ed. Washington D C, Georgetown University Press.

Schegloff, E. A. (1987). Recycled turn beginnings: A precise repair mechanism in conversation's turn-taking organisation. Talk and Social Organisation. In G. Button and J. R. E. Lee, Eds. Clevedon, Multilingual Matters.

Schegloff, E. A. (1992a). Introduction. Lectures on Conversation Volume 1. In G. Jefferson, Ed. Oxford, Blackwell. 1.

Schegloff, E. A. (1992b). Repair after next turn: The last structurally provided defense of intersubjectivity in conversation. The American Journal of Sociology 97(5): 1295345.

Schegloff, E. A. (1996). Confirming allusions: Towards an empirical account of action. The American Journal of Sociology 104: 161-216.

Schegloff, E. A. (2000). On granularity. Annual Review of Sociology 26: 715-720.

Schwartzman, H. B. (1989). The Meeting: Gatherings in Organizations and Communities. New York, Plenum Press.

Schwartzman, H. B. (1993). Ethnography in Organizations. London, Sage.

Sharrock, W. and B. Anderson (1986). The Ethnomethodologists. Chichester, Ellis Horwood.

Shields, J. (2000). The Fig Eater. London, Black Swan.

Silverman, D. (1973). Getting in: The managed accomplishment of 'correct' selection outcomes. Man and Organization. In J. Child, Ed. London, George Allen \& Unwin Ltd.

Silverman, D. (1993). Interpreting Qualitative Data: Methods for Analysing Talk, Text and Interaction. London, Sage.

Silverman, D. (1997). Discourses of Counselling: HIV Counselling as Social Interaction. London, Sage. 
Silverman, D. (1998). Harvey Sacks: Social Science and Conversation Analysis. New York, Oxford University Press.

Silverman, D. (1999). Warriors or Collaborators: Reworking Methodological Controversies in the Study of Institutional Interaction. Talk, work and the institutional order: Discourse in medical, mediation and management settings. In S. Sarangi and C. Roberts, Eds. Berlin, Mouton de Gruyter.

Silverman, D. (2001). Interpreting qualitative data: Methods for analysing talk, text and interaction. London, Sage.

Simpson, T. (2002). Bodies on the Floor: Representation, Existence, and Involvement in the Tranz Rail Ministerial Inquiry. Occupational Health and Safety in New Zealand: Contemporary Social Research. In M. Lloyd, Ed. Palmerston North, Dunmore Press.

Simpson, T. (2003). Bringing "out there" in: Contact stories in a workplace meeting. Paper presented at the Sociology Association of Aotearoa New Zealand (SAANZ) Conference 2003, AUT, Auckland.

Star, S. L. (1992). The trojan door: Organizations, work, and the 'open black box'. Systems Practice 5: 395-410.

Strathern, M. (1991). Partial Connections. Maryland, Rowman and Little.

Strathern, M. (1996). Cutting the network. Journal of the Royal Anthropological Institute 2(3): $517(19)$.

Suchman, L. (1987). Plans and Situated Actions: the Problem of Human-Machine Communication. Cambridge, Cambridge University Press.

Suchman, L. (2000). Organizing alignment: A case of bridge-building. Organization 7: 311-327.

ten Have, P. (1999). Doing Conversation Analysis: A Practical Guide. London, Sage Publications.

ten Have, P. (2001). Applied conversation analysis. How to Analyse Talk in Institutional Settings. In A. McHoul and M. Rapley, Eds. London, Continuum.

ten Have, P. (2002). The notion of the member is the heart of the matter: On the role of membership knowledge in ethnomethodological inquiry. Forum: Qualitative Social Research 3(3).

Timmermans, S. and M. Berg (2003). The practice of medical technology. Sociology of Health and Illness 25(Silver Anniversary Issue): 97-114.

Urry, J. (2003). Social networks, travel and talk. Sociology 54(2): 155-175.

Van Maanen, J., Ed. (1998). Different strokes: Qualitative research in the Administrative Science Quarterly from 1956 to 1996. Qualitative Studies of Organizations. Thousand Oaks, Sage.

Van Maanen, J. (2001). Afterword: Natives 'R' us: Some notes on the ethnography of organizations. Inside Organizations: Anthropologists at Work. In D. N. Gellner and E. Hirsch, Eds. Oxford, Berg.

Warfield Rawls, A. (2002). Editor's Introduction. Ethnomethodology's Program: Working Out Durkheim's Aphorism. In H. Garfinkel, Ed. Maryland, Rowman and Littlefield. 
Weick, K., E. (2002). Real-time reflexivity: Prods to reflection. Organization Studies 23(6): 893-898.

Whyte, W. F. and w. K. K. Whyte (1984). Learning From the Field: A Guide From Experience Beverly Hills, Sage

Wilkinson, S. and C. Kitzinger (2000). Thinking differently about thinking positive: A discursive approach to cancer patients' talk. Social Science and Medicine 50: 797811.

Woodilla, J. (1998). Workplace conversations: The text of organizing. Discourse and Organization. In D. Grant, T. Keenoy and C. Oswick, Eds. London, Sage.

Wooffitt, R. (2001). Analysing factual accounts. Researching Social Life. In N. Gilbert, Ed. London, Sage.

Woolgar (2002). After word? - On some dynamics of duality interrogation: Or: Why bonfires are not enough. Theory, Culture \& Society 19(5/6): 261-270.

Wynn, E. (1979). Office Conversation as an Information Medium. Unpublished PhD dissertation in Anthropology. Berkeley, University of California: 201.

Zimmerman, D. H. and D. Boden (1991). Structure-in-action: An introduction. Talk and Social Structure. In D. H. Zimmerman and D. Boden, Eds. Cambridge, Polity Press. 


\section{Appendix one: Lists of actions from meeting 5 for chapter two}

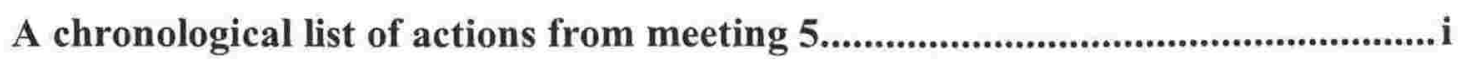

A separated, chronological, labelled, doubly numbered list .................................v

\section{A chronological list of actions from meeting 5}

One thing she's commenting on is that the meeting is a full house this time [1 who's here and so, who's staff]. May laughs, saying it's sold out.

Prue asks if anyone has anything specific for the agenda [2 agendas; using objects] [3 people settling in].

Jo and Kim are discussing the document, saying a graph, a table, sorry [4 discussing documents].

Simone says she'll take her seat so she can see out into the reception area [5 where to sit]. The door is always left open.

Prue says hi to everybody [ 6 greetings and starting the meeting] and that she has just a few bits and piecey sorts of things as pages rustle around the table.

There's no pause, Prue is telling us that she now does monthly reporting [7 accountability 1) to others and 2) to this group (showing what their jobs involve)] through the management team as part of our performance agreement.

Prue reads a list, and says that's what we've got [8 BANA products in no specific place, but moving].

Pat, with May saying a few things also, says some more service delivery is needed and there needs to be some "gutsy discussion", and that she knows Prue disagrees with something she's saying about developing some other areas. [9 clarifying understandings].

So that it won't hold other things up [10 work timing], Prue says it would be a separate project, with a project team.

Pat says they can't advertise until some work is done so it's quite urgent that they discuss this [11 getting face to face].

May says they've ended up using [12 compromise] the generic ones. Prue says she'll make a note [13 keeping track, being reminded; personal things to write on] and there's a pause while she is writing. 
Off again when Prue says there's something related - a new one of what they've been discussing [14 organising this meeting by linking].

Prue relays what she's done and will do - getting a group together to do this work, layers of consultation, focus group, email group [15 groups - how Prue finds people for a group to do this work] and if people are interested, to let us know [16 intentions by talking in communication].

After a few sentences Pat asks who this is for [17 target market?].

Pat says Ok and right as Prue goes on with her talk about the higher level qual being between "us and OBD" [18 OBD/other organisations], that's how it will be because the research and work has been done.

So, Prue says, the job will really be to match and get the balance right [19 defining the next task; example of doing consultation].

We can also tell she's finishing off because she tells us that's what we've got on the boil at the moment, and laughing, says Kim is relieved because she's finished with everything on her desk in this area [20 comments on other people].

Jo and Susan respond likewise - we laugh [Wittgenstein 21 trick irony/showing we know].

Prue says she favours doing it at the same time as OBD but is not bothered when that is [22 what's not in the written report].

Awaiting a decision from above [ 23 waiting on the hierarchy], but in the meantime they have short-listed two office spaces, which Prue describes in some detail [24 describing].

Next topic from Prue - position descriptions [25 their employment].

Prue talks about competency levels and what she's been doing as part of this work. She's talking about everyone being able to see how they fit [26 working together and sharing information/communication] and says she knows the admin team wants to work together on making sure there's a good alignment between the roles [27 alignment (between the documents or the people?)].

Prue asks us to look at the QTs, which others appear to understand because they're writing. She tells them to remember they've been written for a policy shop and that people won't be, like a 2, but will be 1 sometimes, 3 which she says is absolutely fine [28 comparison with other organisations (us and them)].

And here's the change in topic, signaled with "kind of in line with that" and she's emphasizing the word "team" as she uses it a number of times- admin team...fieldwork team [29 this organisation]. 
She says it might be useful to have "a reporting back" because "that might be another way of just keeping things going" [30 working together and sharing information/communication].

She's speaking slowly, laughing a bit and changing her voice when she tells us to use judgement here about what is significant communication, otherwise we'd be "filling the damn thing in all day". The idea is that after this effort, we will all know what's happening [31 sharing information/communication2].

Prue says she has had feedback from two different directions about subsidies [32 money; information]. There seems to be a problem, which Prue says could be crossed lines (so she's not blaming anyone then), but she wants to make sure everyone's clear.

Prue says there is an erroneous perception out there and we should correct it when we get a chance [ 33 what's happening "out there" (in the field)]. Prue says it reminds her to have a clear statement on their website [34 communicating outside BANA].

As usual, I don't follow all of this, as some others seem to, when Prue says, "so a bit of I told you so there" [35 irony/showing we know2].

Prue, looking at her book, says Irene is flying out [36 people going away].

Prue asks May to remind us about the preparation needed and people laugh [37 other meetings (arranging)].

There's a sound of flicking pages so presumably she has a diary of some sort in front of her [38 what's coming up].

Right she says, that's me, and we're into the usual round-the-table update from each person. I know this because Prue says "Simone" [39 organising this meeting].

Simone starts talking about waiting on subsidies [ 40 money2] and the special invoice ORG $A$ are insisting on. Pat says that's incredible, and there is discussion of it being embarrassing for public relations [41 other organisations2].

Prue asks if she can add something, [42 asking permission to speak] and the many voices stop.

She starts to hesitate and Pat says this could work out quite well and talks about the growth stuff [43 the future; target market?2] they looked at yesterday.

Prues says sorry, that was an aside and returns the talk to Simone and the topic of Org A and subsidies and letters [44 apologising for speaking out of turn].

Simone says that was the only important thing and asks about the forums she knows are coming up [45 other meetings (arranging)2]. 
Pat talks about having more structure and seeing how it goes [ 46 working together and sharing information/communication3].

Kim starts by saying Prue has already said her "desk is clearing". Does this mean that she agrees with Prue's assessment then? Kim says the most outstanding work is forensic mapping, and that they've had a wonderful conversation with Bill. Who they are, and who Bill is, are unclear to me [47 people doing work for BANA (about 5?)].

She turns to a discussion about boundaries and work areas, which came up in the admin team meeting last week and she suggests that she takes the requests for evidence guides rather than Simone and Pat [48 this organisation3]. Pat is enthusiastic and Kim says, "I'm the only one that really knows".

Prue goes to the whiteboard, boinging the metal legs of the chairs on her way, and explains what Robert has been doing [49 giving an example; other organisations3]. As Prue speaks, Pat says yeah, oh Ok. Someone is coughing. Prue says, "which is good assessor practice" and May starts adding yep yep.

May asks how far away the website is [50 the website] and there's laughter. Simone says she's sent a message and is hoping end of the month.

Pat is concerned that she's getting missed out on the loop, [51 working together and sharing information/communication4], discussion is needed.

Prue says Phillipa is here to talk to people about travel so she'd like to go around the table fairly quickly and those who travel will stay on [52 organising this meeting time].

Prue says some has been trickling in and Susan agrees. They discuss this briefly, finishing off: yeah, Ok so, and Prue says "goody, Sally ". [53 organising this meeting time]

Prue says tripping around the countryside and Simone asks when her next trip is [54 being "out there" (in the field)].

Pat is talking about when people leave positions and the issue she's finding with high turnover [55 \{issue of individuals leaving other organisations].

There are multiple voices now. Prue is announcing the people needed to meet with Phillipa [56 visitor and ending the meeting]. 


\section{A separated, chronological, labelled, doubly numbered list}

1. Who is here, and so, who is "staff". [This meeting and This organisation]

2. Agenda-making. [This meeting; using objects]

3. People settling in (cannot be separated from agenda-making). [This meeting]

4. Discussing documents. [This meeting and This organisation]

5. Where to sit. [This meeting]

6. Greetings and starting this meeting. [This meeting]

7. Accountability 1) to others and 2) to this group. [This organisation]

8. BANA products are in no specific place, but moving. [This organisation]

9. Clarifying understandings. [This meeting and This organisation]

10. Work timing. [This organisation]

11. Getting face-to-face. [This organisation]

12. Compromise. [This organisation]

13. Keeping track, being reminded (using personal things to write on). [This organisation]

14. Organising this meeting (1) (by producing a link). [This meeting]

15. Groups (how Prue finds people for a group to do this work). [This organisation]

16. Talking as if writing - people are to let us know if they're interested). [This organisation]

17. Target market/intended recipients of BANA products. [This organisation]

18. OBD/other organisations. [This organisation]

19. Defining the next task; example of doing consultation. [This organisation]

20. Comments on other people. [This meeting]

21. Irony/showing we know. [This organisation]

22. What's not in the written report. [This organisation]

23. Waiting on the hierarchy. [This organisation]

24. Describing - the description is tailored. [This meeting]

25. Their employment. [This organisation]

26. Working together and sharing information/communication (1). [This organisation]

27. Seeking alignment (between the documents or the people)? [This organisation]

28. Comparison with other organisations (us and them). [This organisation]

29. This organisation (us). [This organisation]

30. Working together and sharing information/communication (2). [This organisation] 
31. Sharing information/communication (3). [This organisation]

32. Money (1); information. [This organisation]

33. What's happening "out there" (in the field). [This organisation]

34. Communicating outside BANA. [This organisation]

35. Irony/showing we know. [This organisation]

36. People going away. [This organisation]

37. Other meetings (arranging) (1). [This organisation]

38. What's coming up. [This organisation]

39. Organising this meeting (2) (roundtable). [This meeting]

40. Money (2). [This organisation]

41. Other organisations (2). [This organisation]

42. Asking permission to speak. [This meeting]

43. The future; target market/intended recipients of BANA products (2). [This organisation]

44. Apologising for speaking out of turn. [This meeting]

45. Other meetings (arranging) (2). [This organisation]

46. Working together and sharing information/communication (3). [This organisation]

47. People doing work for BANA. [This organisation]

48. This organisation (3). [This organisation]

49. Giving an example; other organisations (3); comparison/good practice. [This organisation]

50. The website. [This organisation]

51. Working together and sharing information/communication (4). [This organisation]

52. Organising this meeting (3) (roundtable). [This meeting]

53. Organising this meeting (4) (roundtable). [This meeting]

54. Being "out there" (in the field). [This organisation]

55. Problem - individuals leaving other organisations. [This organisation]

56. Visitor, and ending this meeting. [This meeting] 


\section{Appendix two: Transcription symbols and meeting talk conventions}

Transcription symbols

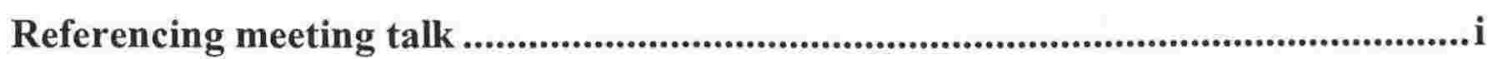

Meeting talk quoting and concept conventions........................................................ii

\section{Transcription symbols}

This turns of talk presented in the thesis have been amended as the talk was listened to repeatedly. Conversation analysis transcription marks were added following Paul Atkinson (1995 p. 152) and David Silverman (2001 p. 303). The transcription symbols used in the thesis are:

$\begin{array}{ll}\text { (word) } & \text { brackets around a word indicates a possible hearing } \\ \text { ( ) } & \text { indicates failure to transcribe } \\ \text { (unclear) } & \text { indicates failure to transcribe } \\ = & \text { no gaps, pauses, silences between lines of talk } \\ \text { [ ] } & \text { overlapping or simultaneous talk } \\ \text { (pause) } & \text { silence } \\ \text { wor- } & \text { word not completed } \\ \text { CAPITALS } & \text { increased loudness } \\ \text { word } & \text { italics indicate emphasis } \\ >\text { words }< & \text { noticeable increase in speed of speaking } \\ <\text { words }> & \text { noticeable slowing in speed of speaking } \\ ? & \text { speech rises } \\ \text { ? } & \text { omission of part of transcript }\end{array}$

\section{Referencing meeting talk}

For referencing empirical materials I follow Wilkinson and Kitzinger (2000). For example, in this use of the phrase "out there" (Pat, OT11, M6), "Pat" is the 
pseudonym, "OT11" the eleventh use of the phrase in this series of meetings, and "M6" the sixth meeting I attended as researcher.

\section{Meeting talk quoting and concept conventions}

Where excerpts of talk from the meetings are used within my text they are indicated by double quote marks and italics (see this convention in Middleton $1998 \mathrm{p}$. 250). For example: Though Prue has the last word, it is not a concrete action, it is less emphatic than her initial suggestion that they "go back to the individual departments and projects" (150).

Where I have developed concepts, these are italicized. For example: One focus of the research has become attempts at telling how I know in these meetings. 


\section{Appendix three: Turns of talk analyses for chapter six (OT29)}

Use of the phrase (OT29) ...................................................................................................

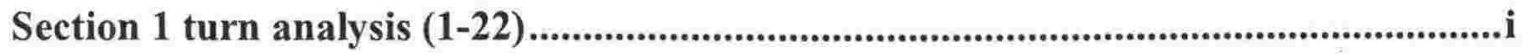

Section 2 turn analysis $(23-31)$............................................................................................i

Section 3 turn analysis $(32-60)$............................................................................................ii

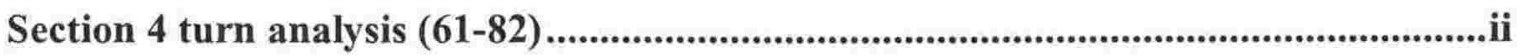

Final section turn analysis (83-92) ........................................................................................ii

\section{Use of the phrase (OT29)}

Ok what should be the priority here let's do this because we know that there's lots of those out there already but we need to get this right and in getting this right it helps develop that (Sally, OT29, M14, Turn of talk 80)

\section{Section 1 turn analysis (1-22)}

1. Prue: Introduction to the new topic, which shows previous joint action (uses we) of meeting); Query about the review

2. A

3. attempts turn

4. attempts turn

5. Q framed as what "no" means for the organisation (for benefit of audience)?

6. A; explains action taken (related to "progress"); tells what I saw

7. Supports by showing disappointment - produces a continuer? (28 seconds)

8. Judgement of action needed (1) to complete the review (what)

9. unclear who or what saying

10. Takes turn by doing being reminded; uses previous statements to support a way to complete the review (how (who)) (28 seconds)

11. Takes turn by doing accepting but qualifies acceptance by referring to the review (what (who))

12. Takes turn by repeating; tells what I saw; judgement of action needed (2) to complete the review (what)

13. Sally produces continuer - agreeing by repeating

14. Attempts a question possibly

15. Pat shows joint action (uses we); Tells of a problem; seeks confirmation of time spent (from other witness and/or questioner?) (43 seconds)

16. Continuer perhaps

17. Pat tells of how long spent on problem; shows joint decision to stop action (uses we); justifies decision with reference to organisational time

18. Prue confirms decision; Supports decision by suggesting action; lets turn continue

19. Sally sums up situation; Justifies action with reference to organisational priorities (ie, goes beyond this piece of work)

20. Agrees

21. Agrees

22. Sally : Further justifies decision with reference to (time?) (53 seconds) 


\section{Section 2 turn analysis (23-31)}

23. Prue: starts to ask Q; states problem, which again makes it a query

24. agrees

25. provides solution

26. Attempts to speak

27. Supports proposed solution

28. Attempts to speak

29. proposes timeframe or order of tasks connected to the review

30. Accepts

31. Pat: Asks question by repeating (1.04 minutes)

\section{Section 3 turn analysis (32-60)}

32. Prue: Answers by repeating; confirms decision by summing up (uses we); Q; guess

33. continuer

34. Takes turn by doing being surprised at guess ie, disputing

35. Q

36. A - it depends!

37. information?

38. Q (designed to get to an answer for the group?)

39. A based on what I saw

40. A based on what I've been told

41. Wins turn from a few speakers - A based on what I know

42. A?

43. Q using "so" ie, summing up?; guess (1.47 minutes)

44. A

45. A based on what I saw

46. A based on what I saw

47. Takes turn by expressing judgement ("Ok so")

48. Continuer (supports judgement with mixed repeat)

49. Continuer

50. Continuer

51. Continues turn with instructing; supports instruction by further instruction; supports instruction with judgement of timeframe of the review based on information from the update

52. Continuer

53. Continues turn by supporting judgement of timeframe with what I know; action needed (3) to complete the review (what)

54. Continuer

55. Continues turn with reason ("ah because") and what I know

56. Continuer

57. Continues turn with what I know

58. Continuer

59. Continues turn with what I know

60. Pat: Continuer

\section{Section 4 turn analysis (61-82)}

61. Prue: Overlapping talk

62. Overlapping talk

63. Pat achieves turn; judgement of amount of time needed with action taken and what they saw

64. continuer 
65. Continues turn by relaying consequences of what they saw (witnessed?)

66. Sally attempts to take turn

67. Pat makes judgement of when to do task

68. Sally takes turn with joint action needed; telling of what I know and intended action

69. Susan provides continuer or attempts to take turn?

70. Sally continues her turn

71. Pat supports Sally 's talk with queries

72. Susan asks question (2.40 minutes)

73. Sally continues her turn despite overlapping talk

74. Prue starts to answer Susan

75. Pat provides continuer or attempt to take turn?

76. Sally continues her turn (with a statement (shouldn't have used "the problem" or "Ok" - it's a summing up, which only Prue does?)

77. Prue tries to take turn with "Ok"

78. Sally continues her turn

79. someone attempts something (unclear)

80. Sally continues (with raised voice; supports the review with what "we know" about "out there"; attempts to sum up with statement of importance for the organisation?)

81. Prue provides continuer

82. Sally finishes her turn

\section{Final section turn analysis (83-92)}

83. Prue takes turn using "and", but challenges, disputes or moderates, rather than agrees with Sally

84. Sally agrees with Prue ie, retracts previous should statement (does it as a misunderstanding?) (2.50 minutes)

85. Continues turn

86. Continuer

87. Continuer

88. Continues turn

89. Continuer

90. Ends turn with what we should not do

91. Accepts Prue's point; but qualifies with what she was saying [trying to say not enough time in these meetings - see eg of Simone]

92. Prue holds pause 


\section{Appendix four: Turns of talk analyses for chapters seven and eight (OT11 and OT12)}

Uses of the phrase (OT11 and OT12) ................................................................................

Preceding turns of talk analysis $(1-146)$.............................................................................

Section 1 turn analysis $(147-178)$........................................................................................

Section 2 turn analysis (179-212) ....................................................................................vi

Section 3 turn analysis (213-257) ...................................................................................vii

Section 4 turn analysis $(262-288)$...................................................................................viii

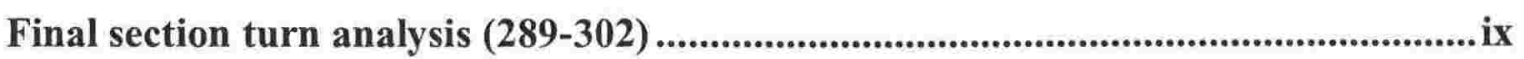

\section{Uses of the phrase (OT11 and OT12)}

but but there is a point where about the overview and about us being able to source stuff in a different way because the reason why I wanted to get back into that loop is that like when it comes to Jo and I looking for assessors for people out there we had taken a step and Paula a step back by not knowing who was registering it meant that we didn't know well look there's this group of people from this organisation in um City A that we could use as private contractors for assessors so so (Pat, OT11, M6, Turn of talk 156)

and I've got a manager who just wants to bypass those people cause nothing's happening and them just continuing to talk but reality is out there is more people it's a co-ordinator of a project as opposed to a co-ordinator of an organisation it's a bit like May with the diploma you know (Pat, OT12, M6, Turn of talk 270)

\section{Preceding turns of talk analysis (1-146)}

1. Introduction (Pat introduces the new topic, and shows previous joint action (uses we) from a different meeting by explaining the work the earlier group had done on key contacts [very similar to OT29 though not a query?])

2. Q (Prue asks where the material is on the whiteboard)

3. A (Pat says she doesn't know)

4. Statement of action (Prue says what she'll do next in the meeting)

5. Agrees (Pat)

6. Agrees (Susan)

7. Acts (Pat adds something for Prue to write)

8. Q; Acts (Prue continues to work on the task (of producing a list of key BANA contacts) by starting to ask a question and then saying it is her normally)

9. Acts (Pat also works on the task, saying field advisors)

10. Hesitates (Prue)

11. Acts (Pat says "us too")

12. Hesitates; Q (Prue still hesitating, asks a question) 
13. A (Pat confirms)

14. A (Susan confirms)

15. Hesitates (Prue)

16. Acts/responds/answers (Pat states "Simone")

17. Agrees/confirms (Prue)

18. Acts (Pat states "Jo")

19. Acts (Susan states "Simone" and gives Prue instruction)

20. Q (Prue asks a question)

21. Acts (Sally says "subsidies")

22. Acts (someone confirms May's "subsidies" and adds "Simone")

23. Apologises and hesitates (Prue)

24. Acts (Susan explains and laughs)

25. Hesitates (Prue)

26. Acts (Pat lists names)

27. Acts (Prue states or repeats list)

28. Acts (Simone states also herself)

29. Acts (Susan states also Irene)

30. Agrees/confirms (Pat confirms Susan's addition)

31. Disputes (Prue questions the addition of Irene as having "contact externally")

32. Reply ((Susan) says yes she does)

33. Acts (Jo, perhaps joking, adds Paula and himself and people laugh)

34. Acts (Pat adds Kim (the only one not on the list?) for a specific area)

35. Qualifies (Kim qualifies - it depends)

36. Continues reply/Acts (Susan explains what she (Kim or Irene?) does)

37. Agrees/confirms (Prue confirms, as if reminded)

38. Continues reply/Acts (Susan continues to explain)

39. (Prue) unclear

40. Queries (Sally asks questions, clarifying (says it (what?) goes elsewhere (where)?)

41. Attempts to speak (Jo overlaps repeating Paula and his name)

42. Takes turn by reminding/stating (Prue overlaps and takes the turn be stating that "we" want key contacts (the task))

43. Produces continuer by agreeing (Sally agrees)

44. Someone can't be heard

45. Continues turn (Prue repeats what the task is (looking at the key contacts))

46. Takes turn with but and makes point (Pat says it's good to see the contact workplace assessors have; using this to say that is shows how confusion happens (what confusion - from the stakeholder survey?))

47. Takes turn with why, then qualifies (Prue takes turn quickly saying that's the reason for saying key contacts (task) but then qualifies, saying the contact she has is with files (distancing herself from the field?))

48. Produces continuer? (someone agrees)

49. Continues turn (Prue says she has contact if there is something wrong with the file and people laugh)

50. Produces continuer (Jo says this is quite frequent and people laugh)

51. Prue continues turn and gives example (Prue picks this up but says "at least" and talks about a particular org (an org or multiple? Where else is Org C mentioned as more than single))

52. Takes turn with but and makes point (Pat stops this "yeah but" and repeats (using "my thing") her point about showing the number of contacts workplace assessors have)

53. Repairs (Susan says "no of course" (repairs?) Pat is the key)

54. Produces continuer/overlaps (Prue repeats what this is (task, object)) 
55. Continues turn (Susan continues using "secondary")

56. Continuer (someone continues Susan's turn)

57. Continues turn (Susan continues that Pat is key (using "probably" again))

58. Agrees (Prue)

59. Unclear (Jo says something about the contact list)

60. Attempts turn (Prue agrees and starts to say what would happen "otherwise")

61. Simone takes turn or provides turn for Prue (Simone says (anticipating Prue's point?) Prue's name)

62. Produces continuer? (Susan agrees)

63. Takes turn (Prue says her name would be everywhere)

64. Attempts turn or produces continuer (Pat)

65. Produces continuer (Susan overlaps, agreeing)

66. Continues turn (Prue continues her point and repeats what the task is)

67. Produces continuer (Susan overlaps and repeats "key contact" (what))

68. Continues turn (Prue continues, explaining or suggesting what they need to do with the other names (perhaps how they'll be discarded, as other, resulting in the remainder "key contacts"))

69. Agrees (Sally)

70. Agrees and sums up (Susan uses "ok" (end of 68 to beginning of 70 (rationalized=fit in=yeah) is a very quick sequence - Susan doing facilitator?))

71. Queries (Prue queries using "well" (who is key contact for workplace assessors))

72. Reply (Pat repeats "well" and raises an issue using "interesting point")

73. Repair or continuer? (Prue agrees, repeats "well" and repairs (?) using "me")

74. Continues turn (Pat says things have changed (was me, isn't now) (the situation) uses "certainly")

75. Produces continuer by accepting, doing understands now (Susan)

76. Continues turn (Pat repeats "well")

77. Unclear (Susan unclear - produces a continuer?)

78. Continues turn (Pat continues with what's happened recently (the situation))

79. Unclear (Jo unclear)

80. Q (Prue asks a question)

81. A (Simone replies)

82. Q (Prue asks another question)

83. A (Pat replies no)

84. A (Susan clarifies)

85. A (Pat explains)

86. Takes turn (Prue accepts and starts to explain her question)

87. Takes turn (Sally says she's never know)

88. Produces continuer or repairs? (Simone doing understands now)

89. Continues turn (Sally repeats that she's never know)

90. unsure Simone says something

91. Takes turn (or continues? (Pat explains what she has had to do, and so raises it as a problem, uses get in (where) and "loop"))

92. Produces continuer (Sally)

93. Continues turn (Pat explains what "being in that (specific) loop" means)

94. Produces continuer (Susan, things becoming clear/doing understands now?)

95. Continues turn (Pat continues to explain - "it allows me to know")

96. Produces continuer (someone agrees)

97. Continues turn (Pat continues uses "out here" (where is unclear to me))

98. Query (May makes a statement or queries? (queries are continuers - see OT29))

99. A (someone confirms) 
100. Attempts to take turn (Prue attempts to clarify?)

101. Attempts to take turn (Simone attempts to clarify (yes, these actions are attempts!))

102. Takes turn (Susan explains, by picking up Pat's point about getting in the loop?)

103. Produces continuer (Pat? repeats word, though diff tense)

104. Continues turn (Susan continues explaining)

105. unclear

106. Produces continuer (Pat murmurs)

107. Attempts to take turn (Prue)

108. Takes turn by repeating Prue's failed attempt, Produces continuer? (Sally overlaps, explaining)

109. Takes turn with overlap? (Prue says what she isn't)

110. Produces continuer (Sally agrees using "no"?)

111. Continues turn (Prue states what she is, using "chain" (loop, chain, link - the material world?))

112. Produces continuer (Sally agrees)

113. Produces continuer? (Susan)

114. Produces continuer? (Pat agrees - listen to this])

115. Continues turn (Sally explaining, asking for confirmation)

116. unclear (Prue)

117. Produces continuer (Pat agrees)

118. Continues turn (Sally asks again for confirmation and start to go on using "so")

119. Takes turn (Prue explains, gives an example (situation))

120. Takes turn (Pat explains (situation))

121. Produces continuer (Prue agrees)

122. Continues turn (Pat continues to explain (situation))

123. Produces continuer (Sally does understanding)

124. Does not take turn, Produces continuer? (Pat)

125. Takes turn (Prue attempts stop using "but"? or continues to explain?)

126. Produces continuer (Sally agrees)

127. Takes turn (Kim repeats "but" and attempts to clarify, stumbles over assessment manstill working on the task?)

128. Produces continuer (Pat)

129. Continues turn (Kim)

130. Produces continuer (Pat)

131. Continues turn (Kim)

132. Attempts to take turn (Sally overlaps, attempts to clarify "so")

133. Attempts to retain turn (Kim overlaps)

134. Achieves turn (Sally outlining what they haven't got (no one person responsible))

135. Takes turn (Pat, quickly saying things have changed (was then, isn't now) (the situation)) - or Produces continuer?

136. Continues turn? (Sally overlaps, repeats what they haven't got (no one person responsible))

137. Takes turn (Prue quickly takes turn, explaining what happens now)

138. Produces continuer (Sally)

139. unclear (Prue)

140. [.wav file from here] Takes turn (Sally with "but" repeats what they haven't got (no one person with an overview, a query?))

141. A (Pat confirms)

142. Takes turn (Prue? hesitates and asks question to clarify)

143. Takes turn (Pat overlaps, saying "supposed to")

144. Takes turn (Sally says no, repeats what they haven't got (no one overall)) 
145. Takes turn (Susan queries? Is there alignment being attempted - Prue and Susan; Pat and Sally?)

146. Takes turn (Sally repeats what they haven't got (no one person responsible or knowing))

\section{Section 1 turn analysis (147-178)}

147. Prue takes turn (with "and", questions whether what they haven't got (Sally's query) is possible and queries with how many, 350)

148. A (someone gives a lower number than Prue's)

149. A (Sally gives a higher number than Prue's)

150. Prue continues turn (queries with "is it not", which seems unusual phrase)

151. Produces continuer (someone murmurs?)

152. Prue continues turn (using "in here" (where))

153. unclear (someone unclear)

154. [27secs] Prue Continues turn (suggests being "realistic" because there's too many (using her number 350))

155. Jo Produces continuer (agrees and gives an example and people laugh (as if they know; [look at laughter responses]))

156. Pat Takes turn (stops this with "but but" and repeats wanting "to get back into that (specific) loop" and gives an example using "out there" [53 secs] and also Jo (who supported Prue?) and Paula. Not knowing (having information?) is the reason/means/caused them to go backwards (missed opportunity, which has meant BANA (or, and Jo, Paula, Pat) has gone backwards))

157. Prue Takes turn (the web will fix that example)

158. Produces continuer (murmurs?)

159. Pat Continues turn (Prue repeating the web will fix it and starts to make another point "but")

160. Susan says something about important

161. Pat Produces continuer

162. Susan continues (expresses a concern? - overlapping talk CA says is unusual?)

163. Prue Takes turn

164. Sally Produces continuer

165. Prue Continues turn

166. Pat Produces continuer

167. Prue Continues turn (says she cannot do it)

168. Pat Produces continuer

169. Sally Produces continuer (agrees)

170. Prue Continues turn (says there's too many and makes a point about separation)

171. Sally Produces continuer?

172. Prue Continues turn (continues her point, too much)

173. Pat Takes turn (attempts to stop, she disagrees, repeats Prue's word "independent") [1.57 secs]

174. Prue Attempts turn (attempts to take turn with "but")

175. Pat Continues extended turn (continues with "because I to me", or how she sees it and gives an example (missed opportunity?))

176. [2.46mins] Prue Takes extended turn with overlap (gains turn by doing Pat misunderstands and repeats her point about too much; I've considered this kind of talk of holding before eg, spaces analysis?)

177. Pat Produces continuer

178. Prue Continues turn (continues her point and needing other ways (not a single person?)) 


\section{Section 2 turn analysis (179-212)}

179. Takes turn (Pat takes turn with "yeah" and talks about the database - agreeing now? Is she doing misunderstanding, but less obviously? With this turn has Pat done the danger has passed, and Susan can come back in with how good the database will be?)

180. Produces continuer (Prue? Agrees)

181. Continues turn? (Pat unclear)

182. Takes turn (Prue takes turn with a "theoretical" example, what a person might do)

183. unclear May unclear

184. Continues turn (Prue continues with how that person might use the database - check with it)

185. Takes turn (Susan (supports Prue?) with how the database could be even better used (it send to them))

186. Prue attempts turn

187. Takes turn (Pat continues Susan's suggestion - so not against Prue and Susan? Though is Pat's 'us' different from Susan's "them" - fieldworkers?)

188. Prue Attempts turn

189. Takes turn (Susan continues with how the database could help)

190. Takes turn (Prue overlaps and gains turn with a specific example (using what we know))

191. Produces continuer (Pat)

192. Continues turn (Prue continues with her example of the report produced)

193. Produces continuer (May)

194. Query (Prue)

195. Produces continuer (Pat)

196. Produces continuer (May agrees)

197. Continues turn (Prue says what could be done like that report)

198. Produces continuer ((Sally) repeats words)

199. Produces continuer (Pat)

200. Takes turn (Susan adds more about potential report [is what is valued what's being worked on here - technical systems (database; website) vs. fieldworker contact/sight of paperwork?])

201. Produces continuer (Prue)

202. Continues turn (Susan continues her turn about potential report)

203. Takes turn (Prue adds more about potential report)

204. Takes turn (Susan continues)

205. Takes turn (Simone reminds? Asks question about workplace assessors?)

206. [3.50mins] A (Prue repeats her point with what will be better (attempting to resolve problem))

207. unclear

208. A (Susan gives example, laughing)

209. Continues turn (Prue repeats her point about better way; uses "holding" again)

210. Takes turn (Susan supports, using "reports")

211. Produces continuer (Pat)

212. Continues turn (Susan continues with judgement that concise information is better, supporting Prue's point that the database and website will fix it (title?); not rushed, this discussion trailing off?) 
Section 3 turn analysis (213-257)

213. [4.07mins] Q (Sally)

214. A (Susan answers not at the moment)

215. Takes turn (Pat takes turn quickly to say that's the problem with the existing database (mess))

216. Susan Produces continuer

217. Extended turn (Pat does extended turn, which is signaled with "this is the point" outlining the problem (if asked by members, BANA ("from here") wouldn't know and BANA expects they will know))

218. Produces continuer (Prue agrees)

219. Continues turn (Pat says because of size of organisation and BANA "has to be realistic" (word Prue used already))

220. Unclear (is Prue disputing or asking a question of someone other than Pat?)

221. Attempts turn (Pat overlaps repeating point about size)

222. Attempts turn (Prue overlaps apologizing and correcting what she had said)

223. Takes turn (Susan overlaps, saying it takes a long time)

224. Unclear ((May) agrees, produces continuer?)

225. Susan finishes overlapped turn "pull them out" (who, where)

226. Produces continuer (Pat)

227. Q (Simone)

228. A (Susan overlaps)

229. Continues turn (Simone continues question)

230. A (Prue rejects)

231. Takes turn (Susan overlaps saying don't and can't)

232. A (Prue agrees with "no")

233. Takes turn (Pat agrees "no" and starts turn)

234. unclear (Susan) overlaps unclear

235. Pat overlaps takes turn (explaining what she has to do because the database doesn't)

236. Produces continuer (someone agrees)

237. Continues turn (Pat continues turn saying why)

238. Q (Simone asks a question about the new)

239. A (Prue answers "yep" but qualifies "ah")

240. Susan takes turn (overlaps with her hopes and explains it's why she's keen to get it moving)

241. Produces continuer (Simone)

242. unclear (Pat unclear)

243. [5.10 minutes] Takes turn (Sally)

244. Attempts turn (Pat overlaps unclear)

245. Continues turn (Sally continues with what the information can do (where))

246. Produces continuer (Pat agrees)

247. Continues turn (Sally)

248. Produces continuer (Jo agrees "it's basic" [is this a query?])

249. unclear (Susan)

250. Takes turn (Pat continues Jo's turn, repeating "basic" AND WE'RE back with what the field advisors/Pat need - with Sally's support - at 213 did Sally provide a platform?

See OT29 aligning with Pat)

251. Produces continuer (Susan agrees)

252. Produces continuer (someone else agrees, this point is not disputed by the group?)

253. Produces continuer? (Pat) 
254. Takes turn (Jo gives an abstract example of the current problem, one of his few turns)

255. Produces continuer (Pat)

256. Produces continuer (Sally)

257. Unclear someone agrees? ("ok")

258. Extended turn (Susan gives an update on what she is waiting for on the new database and what she is doing ("pushing them quite hard") - have Sally, Pat and Jo called for this account?)

259. Produces continuer (someone)

260. Continues turn (Susan continues briefly)

261. Takes turn (Prue hesitating)

\section{Section 4 turn analysis (262-288)}

262. [5.49mins] Takes turn (Pat confirms currently "paper is the only way" [is this a statement for an overhearing audience - see CA; is this a summary?] Look at following speakers - does Pat often follow Prue's turns?)

263. Prue Takes turn (agrees pauses agrees (see OT29 J holds the meeting with the whiteboard, while she interacts with it, they wait))

264. Produces continuer (May? produces continuer)

265. Continues extended turn (Prue talks about what BANA can do [the future - compare my use of "situation, the new" with categories in the phrase chapter]. Is Prue suggesting the fieldworkers can do more?)

266. Produces continuer (Pat)

267. Continues turn (Prue continues with why - "a single point")

268. Takes turn (Pat overlaps saying in reply "lots of different situations" and gives actual example)

269. Produces continuer (Prue)

270. [7.17mins] Continues extended turn OT12 [are OTs within extended turns - varies in M6, but also depends how you define a turn]? Pat continues extended turn using example and saying Prue's point isn't easy "great idea but reality is out there"

271. Takes turn Prue agrees initially then hesitates

272. unclear (someone unclear)

273. Produces continuer (Pat)

274. unclear (someone unclear)

275. [7.40mins] Extended turn (Prue disagrees?, repeats BANA's need for a "single point" and gives an example)

276. Produces continuer (Pat)

277. Continues turn (Prue continues agrees things will vary and uses specific example to say keep those paying "in the loop")

278. Produces continuer (Pat)

279. Continues turn (Prue continues saying something is a warning and gives an example of something (a shared experience?) that might not have happened the way it did if they'd done this)

280. unclear (someone unclear)

281. Continues turn (Prue seems to pick up the point, laughs, says again things will vary)

282. Produces continuer (Pat)

283. Continues turn (Prue says shouldn't stop trying)

284. Produces continuer (Susan agrees)

285. Produces continuer (Pat [if I counted these, would it be a surprise that Pat also produces continuers?])

286. Produces continuer (Susan continues with what they can do) 
287. Continues turn (Prue gives an actual example)

288. Produces continuer (Susan adds to this example, though by saying 2 , she disputes Prue's point?)

Final section turn analysis (289-302)

289. Q; Continues turn (Prue starts but then pauses and asks if they've gone as far as can (where, future, path))

290. A (Pat agrees)

291. A (May) agrees?

292. Takes turn (Pat stops)

293. unclear (Prue)

294. [.wav file ends here $\mathbf{9 . 0 0 m i n s ] ~ C o n t i n u e s ~ t u r n ~ ( P a t ~ s t a t e s ~ w h a t ~ " w e " ~ w a n t ~ f r o m ~ t o d a y . ~}$ But what is it she uses "this" and "that" - assurance of change? A request? That people with contact will tell fieldworkers?)

295. Prue agrees Reply or continuer?

296. Reply (Pat says ok quickly)

297. Takes turn (Prue makes suggestion of what to do next)

298. Produces continuer (Pat)

299. unsure (Prue hesitates, working to get the whiteboard pages in the right place)

300. Takes turn (Pat takes turn with how many)

301. Produces continuer (May?)

302. Takes turn (Prue does link and move to next topic)

End of final section 